\title{
ANÁLISE TEÓRICA E EXPERIMENTAL DE PILARES DE CONCRETO ARMADO SOB AÇÃO DE FORÇA CENTRADA COM RESISTÊNCIA MÉDIA À COMPRESSÃO DO CONCRETO DE 40MPa
}

Walter Luiz Andrade de Oliveira

\begin{abstract}
Dissertação apresentada à Escola de Engenharia de São Carlos, da Universidade de São Paulo, como parte integrante dos requisitos para obtenção do título de Mestre em Engenharia de Estruturas.
\end{abstract}

Orientador: José Samuel Giongo 
Ficha catalográfica preparada pela Seção de Tratamento da Informação do Serviço de Biblioteca - EESC/USP

48a Aliveira, Waltélise teórica e experimental de pilares de concreto armado sob ação de força centrada com resistência média à compressão do concreto de $40 \mathrm{MPa} /$ Walter Luiz Andrade de Oliveira. -- São Carlos, 2004.

Dissertação (Mestrado) -- Escola de Engenharia de São Carlos-Universidade de São Paulo, 2004.

Área: Engenharia de Estruturas.

Orientador: Prof. Dr. José Samuel Giongo.

1. Pilares - análise experimental. 2. Concreto armado. 3. Ductilidade. I. Título. 
FOLHA DE JULGAMENTO

Candidato: Engenheiro WALTER LUIZ ANDRADE DE OLIVEIRA

Dissertação defendida e julgada em 28-04-2004 perante a Comissão Julgadora:

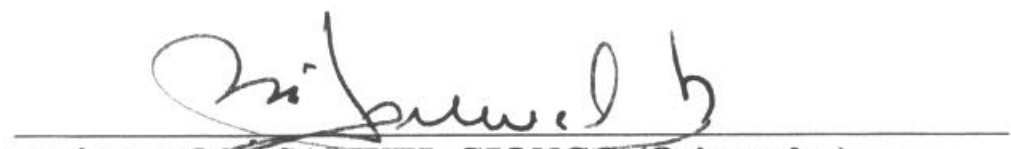

Prof. Dr. JOSE SAMUEL GIONGO (Orientador)

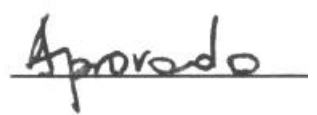

(Escola de Engenharia de São Carlos/USP)

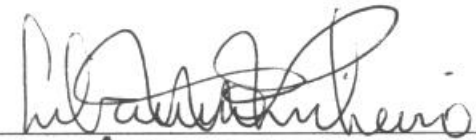

\section{Prof. Dr. LIBÂNIO MIRANDA PINHEIRO}

APROVAPO

(Escola de Engenharia de São Carlos/USP)

\section{Prof. Dr. NEWTON DE OLIVEIRA PINTO JUNIOR}

APROVADC

(Universidade Estadual de Campinas/UNICAMP)
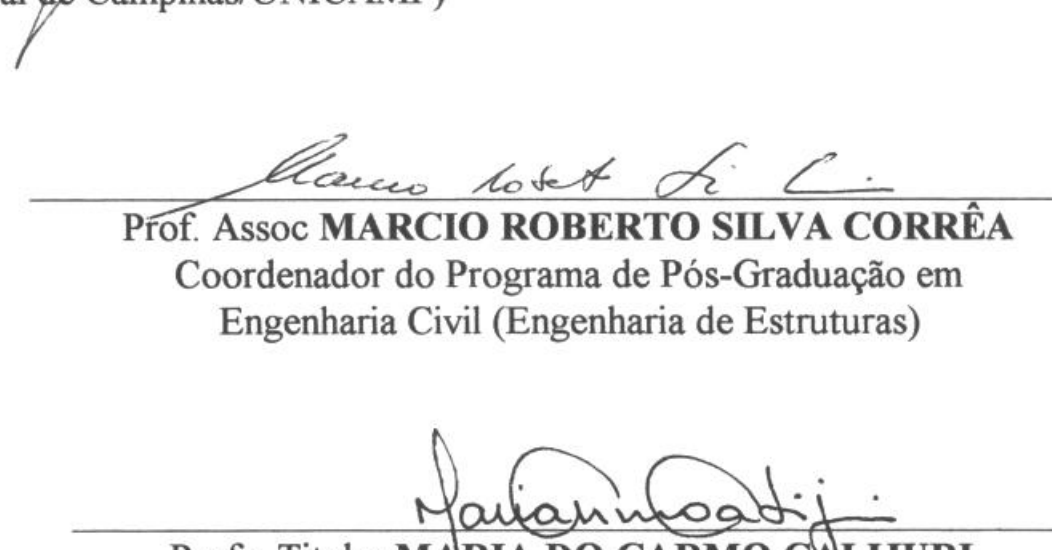

Profa. Titular MARIA DO CARMO CALIJURI

Presidente da Comissão de Pós-Graduação 
Dedico este trabalho aos meus pais, Maria José da Silva Oliveira e Luiz Andrade de Oliveira e aos meus irmãos, Maria Aparecida, José Almir, Quitéria Maria e Sílvia Rejane pelo apoio durante toda minha caminhada.

Agradeço especialmente à Suzana por ter estado ao meu lado nesses dois últimos anos. 


\section{AGRADECIMENTOS}

Ao final de mais uma etapa em minha vida, agradeço em primeiro lugar a Deus pela vida e por ter conseguido, apesar de todas as dificuldades, terminar este trabalho.

A CAPES que financiou este trabalho.

Ao professor Dr. José Samuel Giongo pela orientação, amizade e dedicação durante esses dois anos.

Aos meus cunhados, minha madrinha e demais familiares desta família a qual faço parte e me orgulho muito.

Ao amigo e conterrâneo Humberto que muito me ajudou e aconselhou sobre o trabalho desenvolvido e que disponibilizou o programa computacional que foi utilizado neste trabalho.

Ao professor Flávio Barboza de Lima e ao engenheiro Marcos Vinícius Queiroga por terem cedido as planilhas com os dados experimentais de suas pesquisas.

Aos demais conterrâneos do departamento de Estruturas, Fábio Lopes, Patrick, Romel, Luciano Barbosa, Márcio Félix, Jerônymo, Edson e Geilson.

Ao Valber pela amizade e convivência durantes esses dois anos.

Aos novos e grandes amigos Rodrigo Neves, Raïssa, Yuri e Patrícia pelos momentos divertidos e pelos conselhos a mim dados.

Aos demais amigos, Claudius, Murilo, Luciano, Larissa, Wesley, Oscar, Valério, Joel, Josafá, Rodrigo Delalibera, Fernando, Gustavo Tristão, Alex, Silvana, e tantos outros que não citei, pela amizade durante esses anos.

Aos funcionários e amigos do Laboratório de Estruturas, Amauri, Mauri, Luiz, Fabiano, Mário, Valdir, Valdemir e Vagner que foram essenciais na realização dos ensaios experimentais deste trabalho.

À todos os funcionários do Departamento de Estruturas, em especial a Maria Nadir e Rosi Jordão.

Aos professores do Departamento de Estruturas, pelo conhecimento compartilhado.

Aos professores do Curso de Engenharia Civil da Universidade Federal de Alagoas, pelos conhecimentos compartilhados e que me incentivaram a cursar uma pós-graduação, em especial ao professor Roberaldo Carvalho de Sousa, tutor do grupo PET de Engenharia Civil, ao qual fiz parte durante quatro anos, e do qual me orgulho muito. Obrigado amigos componentes do PET.

A empresa Holcim S.A., através do Engenheiro Sílvio P. Diniz Filho, pela doação do cimento utilizado na moldagem dos modelos ensaiados.

Aos funcionários da Marcenaria e da oficina mecânica da Escola de Engenharia de São Carlos pelas fôrmas e peças utilizadas nos ensaios experimentais. 


\section{SUMÁRIO}

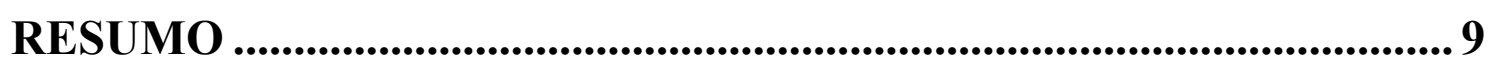

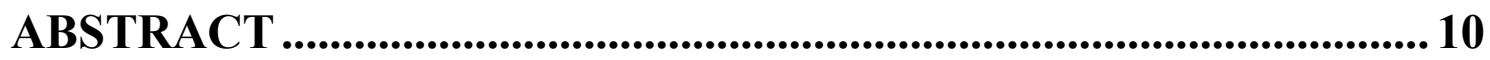

1. INTRODUÇÃ

1.1 CONSIDERAÇÕES INICIAIS..............................................................11

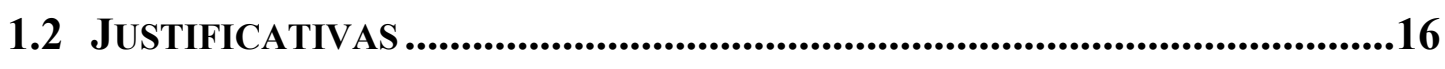

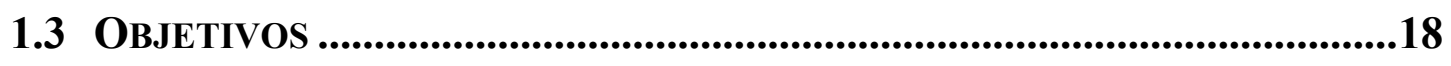

1.4 METODOLOGIA .....................................................................................19

1.4.1 Experimental .......................................................................................19

1.4.2 Numérica .....................................................................................20

1.5 CONTEÚDO DA DISSERTAÇÃ̃o .............................................................21

2. PILARES DE CONCRETO DE RESISTÊNCIA USUAL ................ 23

2.1 MATERIAIS CONSTITUINTES ........................................................................23

2.1.1 Cimento ..................................................................................................................223

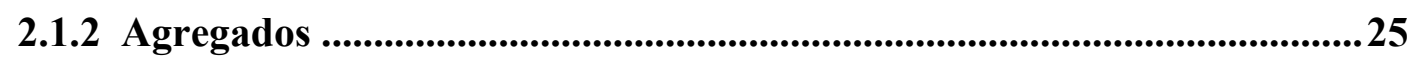

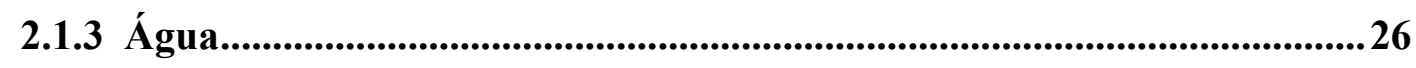

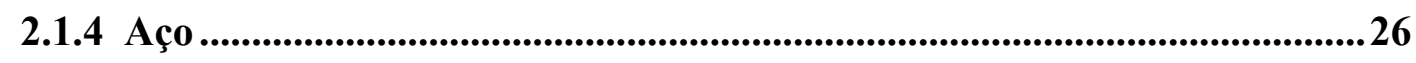

2.2 DOSAGEM .....................................................................................27

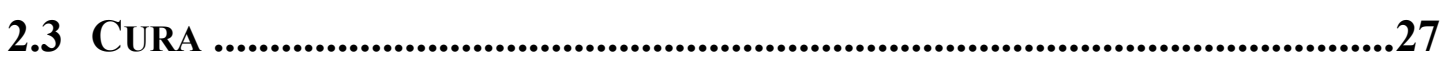

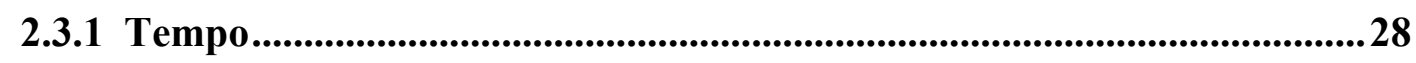

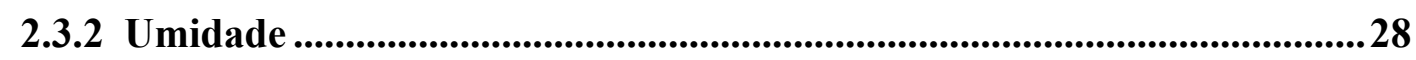

2.4 ClaSSIFICAÇÃ̃o .....................................................................................29

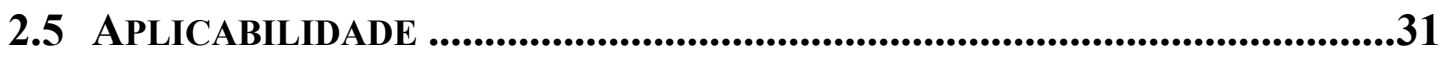

2.6 VANTAGENS E DESVANTAGENS ..........................................................32

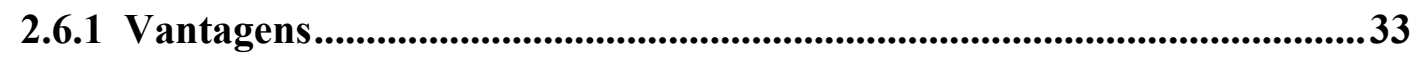

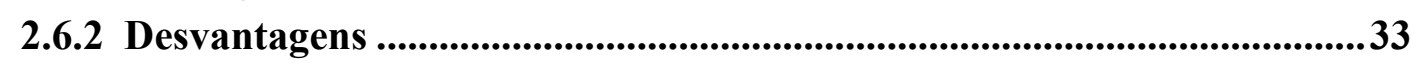

2.7 PROPRIEDADES MECÂNICAS.......................................................34

2.7.1 Resistência à compressão...........................................................................34

2.7.2 Resistência à tração ...............................................................................37

2.7.3 Módulo de elasticidade ..........................................................................37

2.7.4 Coeficiente de Poisson e módulo de elasticidade transversal...................39

2.7.5 Diagrama tensão vs. deformação ...........................................................39 
2.8 PilaRES DE CONCRETO ...................................................................41

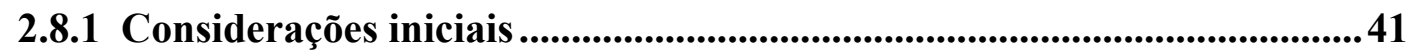

2.8.2 Tipos de seções transversais e localização dos pilares na estrutura ........43

2.8.3 Cálculo da capacidade resistente e recomendações da NBR 6118:2003 44

2.8.4 Análise experimental de pilares ............................................................48

2.8.5 Avaliação da ductilidade ...................................................................55

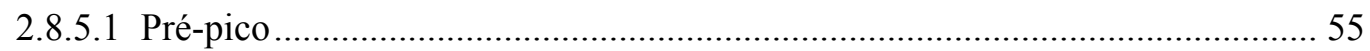

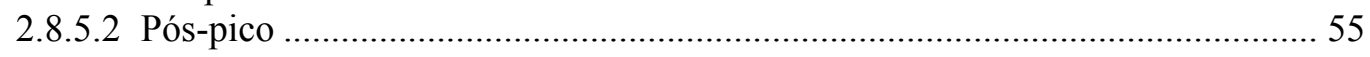

3. MODELOS PARA O CONCRETO CONFINADO..........................57

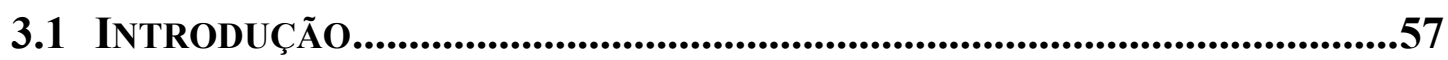

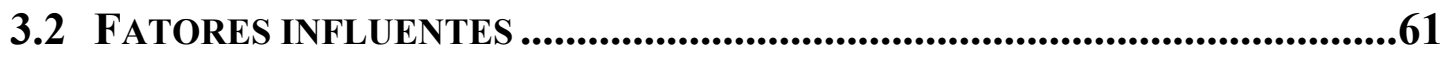

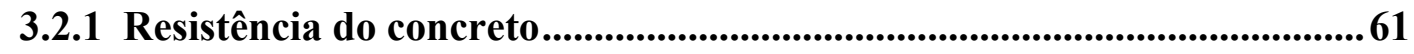

3.2.2 Cobrimento do concreto ...................................................................62

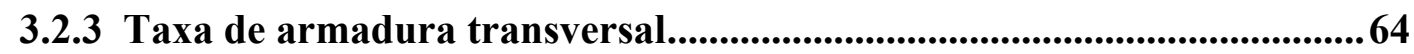

3.2.4 Taxa de armadura longitudinal .....................................................65

3.3 MODELOS TEÓRICOS ...............................................................65

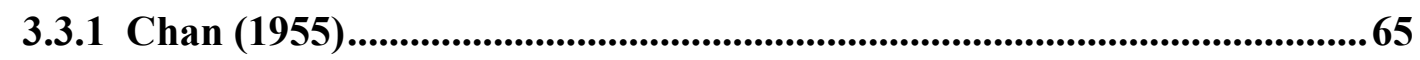

3.3.2 Roy e Sozen (1964) .................................................................................................66

3.3.3 Sargin et alli (1971) ..................................................................................66

3.3.4 Kent e Park (1971) .............................................................................67

3.3.5 Park et alli (1982) ...................................................................................68

3.3.6 Sheikh e Uzumeri (1982)...................................................................69

3.3.7 Mander et alli (1988a) .....................................................................70

3.3.8 Saatcioglu e Razvi (1992).................................................................. 71

3.3.9 Cusson e Paultre (1995) .....................................................................72

3.4 ModificaÇão do Modelo de CuSson e Paultre (1995) POR LiMA JÚNIOR (2003)...................................................................................................75

3.5 PROGRAMA COMPUTACIONAL ......................................................78

3.5.1 Considerações iniciais ......................................................................................78

3.5.2 Procedimentos adotados para utilização do programa nos modelos de pilares ............................................................................................................................ 78

4. PROGRAMA EXPERIMENTAL ...................................................... 80

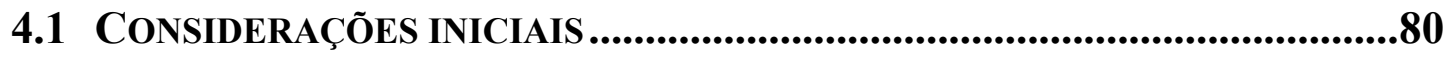

4.2 CARACTERIZAÇÃ̃ DOS MATERIAIS.................................................81

4.2.1 Agregado miúdo ........................................................................................81

4.2.2 Agregado graúdo .........................................................................82

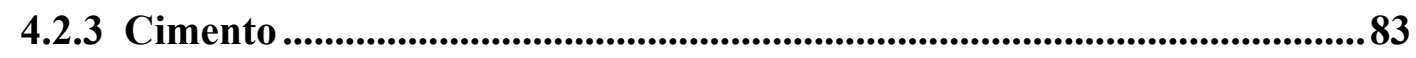




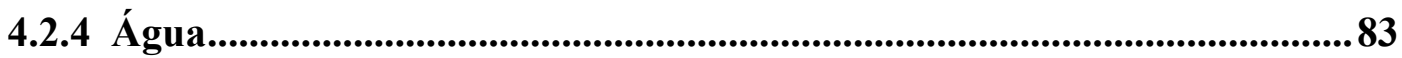

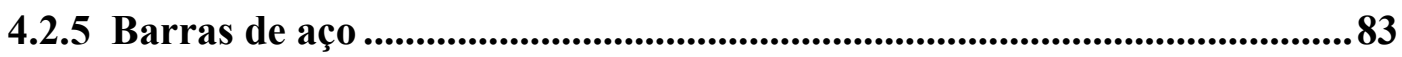

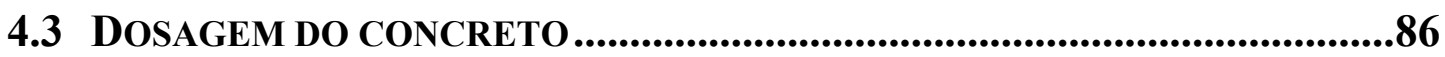

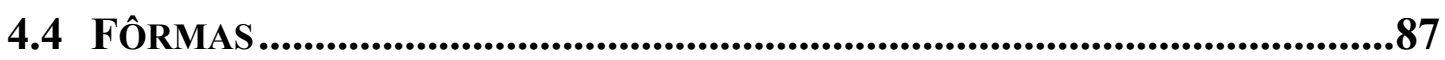

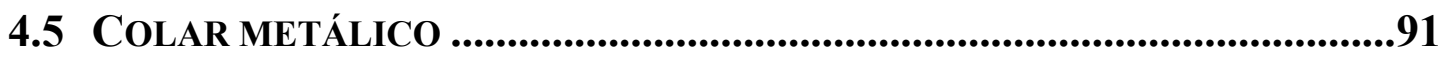

4.6 DEFINIÇÃO DOS MODELOS DE PILARES ...............................................94

4.6.1 Resistência à compressão do concreto.........................................................99

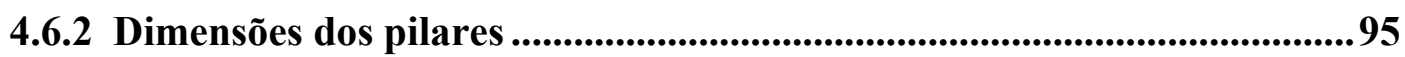

4.6.3 Diâmetros nominais das armaduras utilizadas ..........................................95

4.6.4 Detalhamento das armaduras .................................................................96

4.7 INSTRUMENTAÇÃO.................................................................................106

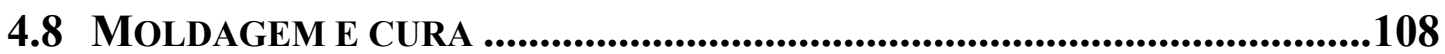

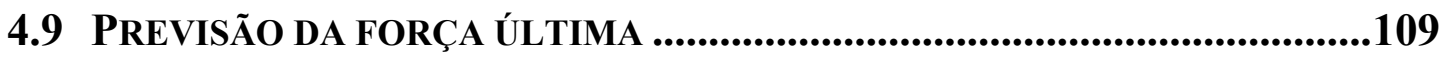

4.10EQUIPAMENTOS DE ENSAIO...........................................................................110

5. RESULTADOS EXPERIMENTAIS .........................................112

5.1 PROPRIEDADES DO CONCRETO .............................................................112

5.1.1 Comportamento geral...............................................................................112

5.1.2 Diagrama tensão vs. deformação do concreto ………………………….....116

5.2 COMPORTAMENTO DOS PILARES .............................................................120

5.3 AVALIAÇÃO DA PREVISÃo DAS FORÇAS ÚlTIMAS ....................................123

5.4 DESCRIÇÃO INDIVIDUAL DOS RESULTADOS EXPERIMENTAIS DOS PILARES DE CONCRETO ARMADO ...................................................................127

5.4.1 Série P1 .................................................................................................129

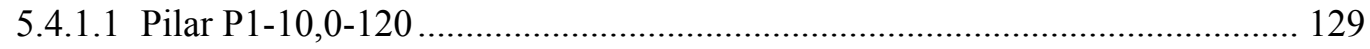

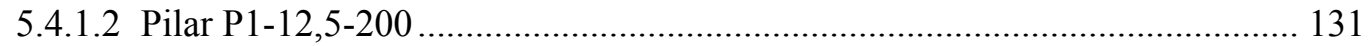

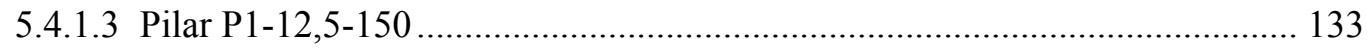

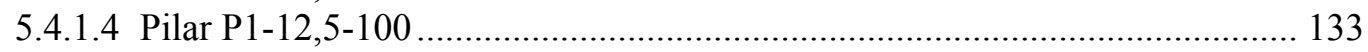

5.4.2 Série P2

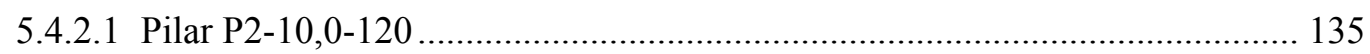

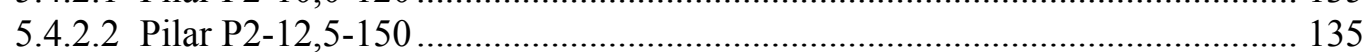

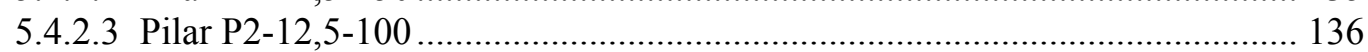

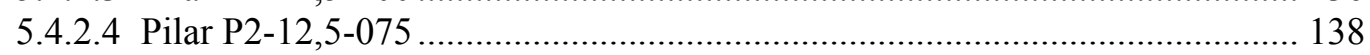

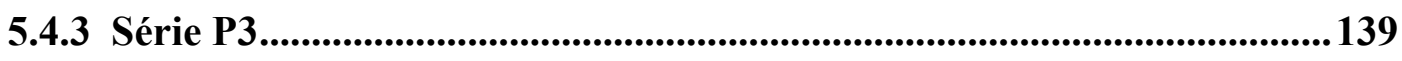

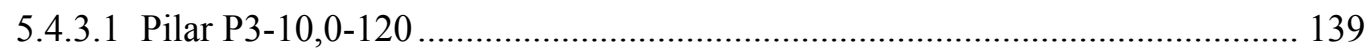

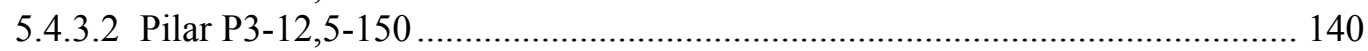

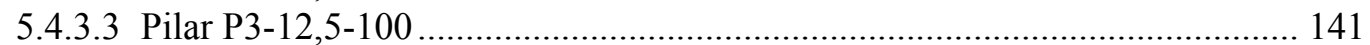

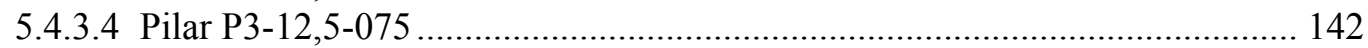




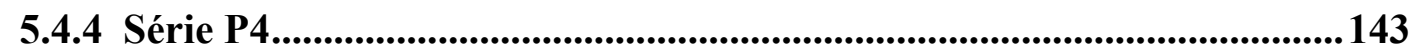

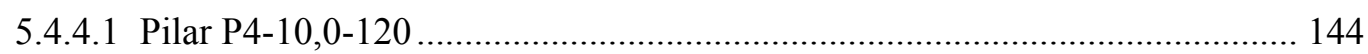

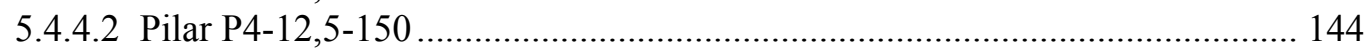

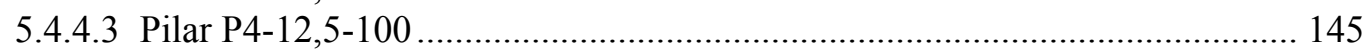

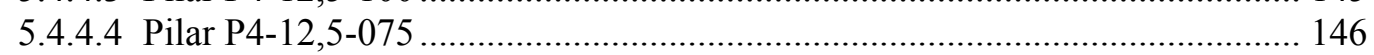

6. ANÁLISE DOS RESULTADOS ..................................................... 148

6.1 AVALIAÇÃO DA DUCTILIDADE...........................................................148

6.2 ANÁLISE DOS PILARES CONSIDERANDO O CORFICIENTE $K_{2}$.................157

6.3 ANÁLISE CONSIDERANDO O MODELO NUMÉRICO.................................162

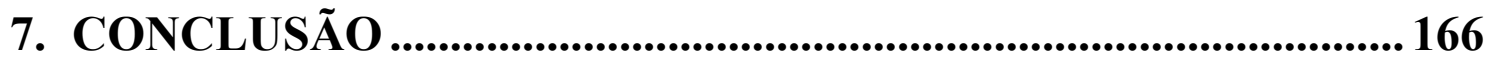

7.1 CONSIDERAÇÕES INICIAIS ...........................................................166

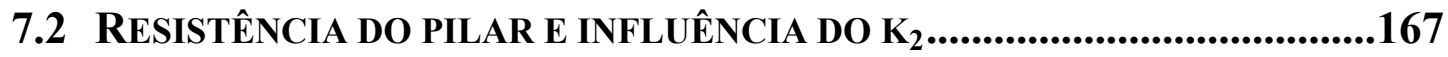

7.3 DUCTILIDADE ............................................................................170

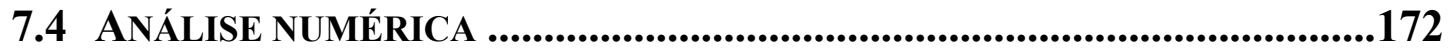

7.5 SUGESTÕES PARA PROJETO ..........................................................172

7.6 SUGESTÕES PARA CONTINUIDADE DA PESQUISA ...............................173

REFERÊNCIAS BIBLIOGRÁFICAS......................................................174

BIBLIOGRAFIA COMPLEMENTAR ................................................. 184

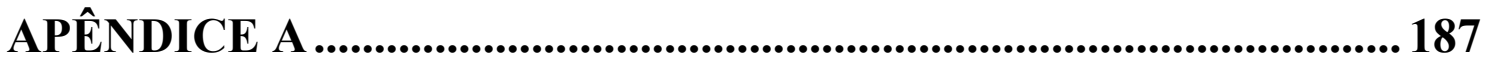

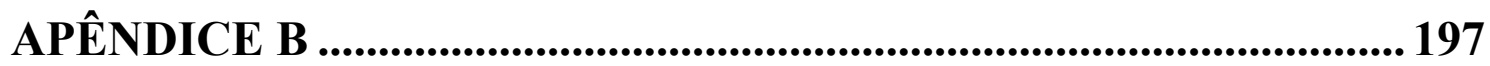




\section{RESUMO}

OLIVEIRA, W.L.A. (2004). Análise teórica e experimental de pilares de concreto armado sob ação de força centrada com resistência média à compressão do concreto de 40MPa. Dissertação (Mestrado) - Escola de Engenharia de São Carlos, Universidade de São Paulo, São Carlos.

O objetivo primordial da pesquisa foi obter informações sobre o comportamento dúctil de pilares submetidos à compressão centrada moldados com concreto de resistência média à compressão de 40MPa. Os resultados obtidos experimentalmente foram confrontados com da análise numérica e se mostraram satisfatórios. O modelo adotado para análise teórica considerou as equações de equilíbrio que regem a segurança da seção transversal, e, o comportamento do pilar confinado. Para o desenvolvimento da parte experimental foram ensaiados 16 modelos de concreto armado: quatro com dimensões da seção transversal de $200 \mathrm{~mm} \times 200 \mathrm{~mm}$ e altura de $1200 \mathrm{~mm}$ e doze com dimensões da seção transversal de $150 \mathrm{~mm} \times 300 \mathrm{~mm}$ e altura de $900 \mathrm{~mm}$, que apresentaram melhora no comportamento dúctil diretamente influenciada pelo aumento da taxa de armadura transversal. Foi verificado, também, o comportamento dúctil de pilares variando-se a resistência à compressão do concreto, a partir de dados experimentais de outros autores e deste trabalho. O comportamento de pilares se torna frágil com o aumento da resistência à compressão, assim foi gerada uma superfície que mostra o comportamento dúctil de pilares em função da taxa de armadura transversal e da resistência à compressão do concreto. Moldaram-se também, oito modelos não armados, para determinação do coeficiente $\mathrm{k}_{2}$, que leva em consideração a estimativa da resistência do concreto na estrutura, quando avaliada por meio de corposde-prova cilíndricos, e verificou-se que o valor desta variável diminui com o aumento da resistência à compressão do concreto, como sugere a norma Norueguesa. A utilização da variável $\mathrm{k}_{2}$ em função da resistência do concreto torna possível o dimensionamento de pilares de concreto de alta resistência considerando-se a seção íntegra ao invés da seção do núcleo.

Palavras-chave: Pilares, Concreto armado, Ductilidade, Análise experimental. 


\begin{abstract}
OLIVEIRA, W.L.A. (2004). Theoretical and experimental analysis of reinforced concrete columns under concentric compression with concrete strength of 40MPa. Master's degree dissertation - Engineering School at São Carlos, São Paulo University, São Carlos.
\end{abstract}

The main purpose of this research is to obtain information about the ductile behavior of concrete columns under concentric compression with concrete's compressive strength of $40 \mathrm{MPa}$. The experimental results were compared with those from a numerical analysis. The theoretical analysis was made using the equations that govern the safety of the cross section and the columns confinement behavior. For the development of the experimental program 16 specimens of reinforced concrete were tested: four with a $200 \mathrm{~mm} \times 200 \mathrm{~mm}$ cross section and $1200 \mathrm{~mm}$ height, and twelve with a $150 \mathrm{~mm} \times 300 \mathrm{~mm}$ cross section and $900 \mathrm{~mm}$ height, which presented improvement directly in the ductile behavior influenced by the increase in the rate of transverse reinforcement. It was also verified that the ductile behavior of columns with variations of the compressive strength of concrete, starting from third-party experimental data and from experimental results from this work, becomes fragile with the increase in concrete's compressive strength. Thus, a surface was drawn showing the ductile behavior of concrete columns in function of the rate of traverse reinforcement and the concrete's compressive strength. Eight specimens of plain concrete were also tested to determine the $\mathrm{k}_{2}$ coefficient that takes into account the estimate of the resistance for the concrete used in the column when appraised through cylindrical specimens. It was verified that the value for this variable decreases with the increase of the concrete's compressive strength, as the Norwegian norm suggests. The use of the $\mathrm{k}_{2}$ coefficient in function of the concrete's compressive strength turns possible calculate high-strength concrete columns being considered the complete section instead the core section.

Keywords: Columns, Reinforced concrete, Ductile behavior, Experimental analysis 


\section{Capítulo 1}

\section{INTRODUÇÃO}

\subsection{CONSIDERAÇÕES INICIAIS}

Ao longo dos anos em que o concreto tem sido utilizado como material estrutural, em poucas oportunidades, visto a quantidade de estruturas construídas com concreto no mundo, sua resistência à compressão superou os $30 \mathrm{MPa}$. A qualidade das estruturas depende de inovações tecnológicas que procuram garantir maior durabilidade e resistência ao concreto. É o caso do concreto de alta resistência, o CAR, utilizado em alguns países no mundo, com resistências que podem ultrapassar $100 \mathrm{MPa}$, como o concreto utilizado na construção do edifício E-Tower no Brasil, apresentado na figura 1.1, que atingiu a resistência de 149MPa aos 28 dias de idade.

No Brasil, concretos com resistências acima de 50MPa são considerados de alta resistência, segundo a NBR 8953:1992. 


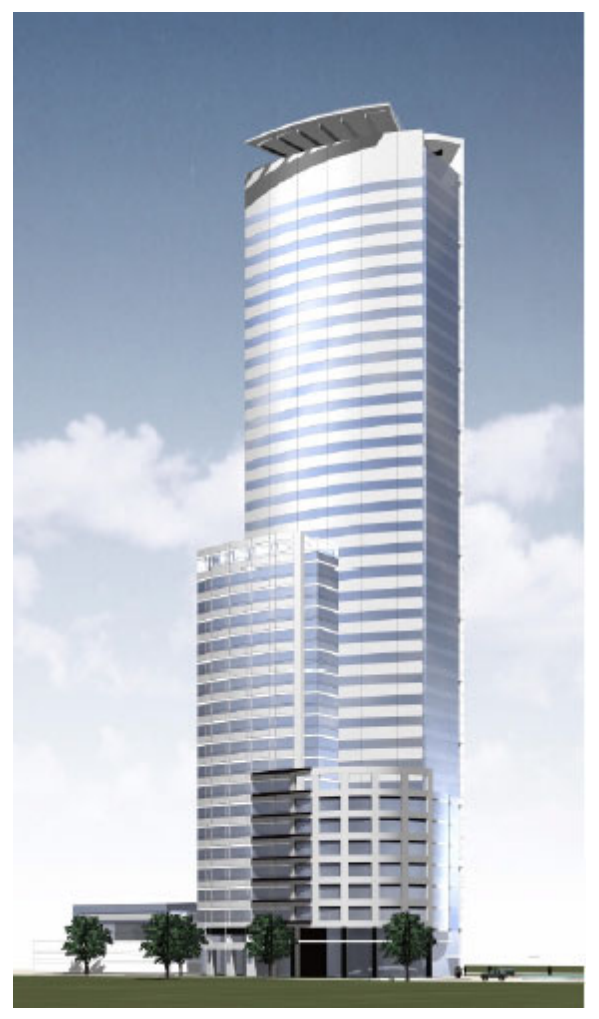

Figura 1.1 - Edifício E-Tower construído com concreto de resistência média de 149MPa aos 28 dias de idade (DEGUSSA, 2004)

Tem-se observado nos últimos anos que a grande maioria das estruturas brasileiras em concreto armado foi projetada e construída com concretos com resistências características que variavam entre $10 \mathrm{MPa}$ e $20 \mathrm{MPa}$. Contudo observa-se que, atualmente, há maior preocupação com a durabilidade das estruturas de concreto armado e existe a necessidade de que os edifícios tenham áreas livres maiores, portanto com pilares mais afastados e com ações de intensidade maiores e, com isso, a necessidade de adotar concretos com resistência de $30 \mathrm{MPa}$ a $50 \mathrm{MPa}$ se intensificou. Nesta linha de raciocínio a NBR 6118:2003 indica 20MPa como limite mínimo da resistência característica do concreto, para utilização em estruturas de concreto armado com armaduras passivas. Por essa norma, é permitida a utilização de concreto com resistência à compressão de $15 \mathrm{MPa}$ para ser utilizado em fundações, seguindo as recomendações da NBR 6122:1996.

Por trabalharem submetidos preponderantemente a tensões de compressão, os pilares de edifícios têm seus comportamentos definidos pelas 
propriedades mecânicas do concreto, quais sejam resistência e deformação. Esse fato torna a ductilidade desses elementos estruturais sensível ao valor da resistência e ao comportamento do respectivo diagrama tensão-deformação. Observa-se que, quando concretos com maiores resistências são usados em pilares, a ductilidade desses elementos estruturais é reduzida e suas ruínas ficam caracterizadas por ruptura do concreto com pequenas deformações. Assim, a redistribuição de esforços solicitantes, capaz de evitar o colapso de uma edificação, quando da ruína do pilar, fica comprometida.

Ao contrário do concreto de resistência usual, o concreto de alta resistência apresenta um diagrama tensão vs. deformação bem mais linearizado. Observa-se que com o aumento da resistência do concreto a parte ascendente do diagrama tensão vs. deformação passa a ser mais linear até praticamente à deformação de ruptura do concreto. A parte descendente da curva é mais inclinada, ou seja, após o pico de tensão, a capacidade de resistência do concreto cai bruscamente, caracterizando material de comportamento frágil, como apresentado na figura 1.2 nos ensaios de corpos-de-prova cilíndricos.

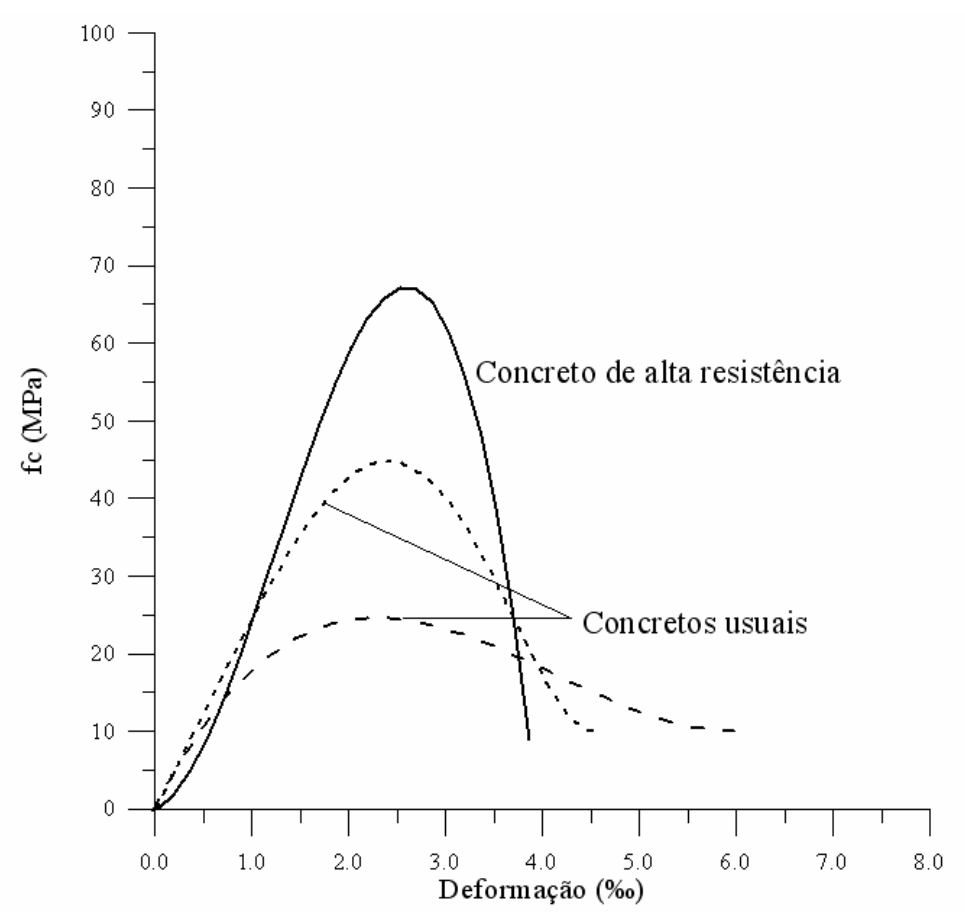

Figura 1.2 - Comportamento dos concretos usuais e de alta resistência. 
A fim de evitar a fragilidade pós-pico dos elementos, alguns pesquisadores têm estudado modos de melhorar a ductilidade dos mesmos com a utilização de armaduras que proporcionem o confinamento do concreto (SAATCIOGLU \& RAZVI, 1992; CUSSON \& PAULTRE, 1995; DINIZ \& FRANGOPOL, 1997). Em pilares, o uso desta técnica implica em utilizar altas taxas de estribos.

Por meio do encamisamento por elementos de concreto de alto desempenho, segundo Takeuti (2003), observa-se o efeito do confinamento que resulta em aumento da capacidade resistente, mas principalmente ganho de ductilidade. O estudo do confinamento é importante para o conhecimento do comportamento estrutural do elemento, bem como de todos os mecanismos resistentes que interagem conjuntamente.

O encamisamento por perfis metálicos, segundo De Nardin (2003), proporciona o confinamento do concreto e promove ganho de ductilidade aos pilares. Essa técnica surgiu da necessidade de minimizar a "fragilidade" do concreto de alto desempenho utilizando perfis tubulares, tomando por base três aspectos:

$\checkmark$ a armadura contínua tubular propicia taxa de armadura transversal superior à obtida com estribos convencionais e oferece maior grau de confinamento;

$\checkmark$ toda a seção de concreto encontra-se confinada, o que não ocorre no caso de pilares em concreto armado; e

$\checkmark$ o perfil tubular atua como fôrma e elemento resistente durante a concretagem e, posteriormente, até o concreto contribuir para a capacidade resistente da seção formando um elemento misto.

Fibras metálicas podem ser utilizadas na massa de concreto para permitir ductilidade aos pilares, geralmente em concreto de alta resistência que tem comportamento frágil (GUIMARÃES, 1999; LIMA JÚNIOR, 2003). A adoção de fibras no concreto aumenta o custo final da obra.

$\mathrm{O}$ aumento da taxa de armadura transversal nos pilares não implica em ganho direto de resistência do elemento estrutural. A força de compressão axial 
atuante no pilar conduz à deformação transversal do elemento que, por sua vez, solicita a armadura transversal criando, como reação, pressão lateral sobre o núcleo de concreto, apresentado na figura 1.3, ductilizando o pilar.

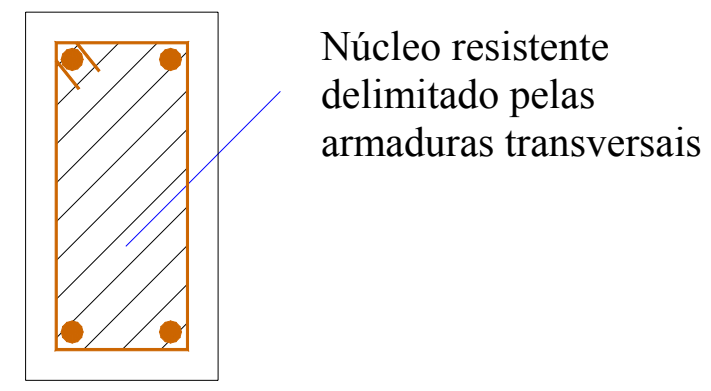

Figura 1.3 - Núcleo resistente de concreto.

Deste modo, a maior quantidade de armadura transversal e o maior limite de escoamento desta fazem com que a pressão lateral exercida sobre o núcleo de concreto aumente e, com isso, a resistência do pilar na direção axial cresça. $\mathrm{O}$ modo como a armadura transversal é solicitada, em pilares cintados, cria forças internas que resultam no descolamento do cobrimento de concreto das armaduras (MÖRSCH, 1952).

A busca pelo confinamento do concreto de resistência usual foi um dos principais objetivos das pesquisas realizadas ao longo dos anos com pilares de concreto armado submetidos à compressão centrada. Assim, o aumento da taxa volumétrica de armadura transversal resultou em acréscimo na resistência à compressão axial dos modelos, diminuição da inclinação da parte descendente da curva tensão vs. deformação e aumento da deformação longitudinal no instante da ruptura dos estribos (MANDER et alli, 1988b).

Por meio de observação experimental, foi verificado que as deformações médias na fase elástica dos pilares de concreto armado são superiores às deformações médias dos pilares sem armadura, com qualquer resistência do concreto.

Lima (1997) e Queiroga (1999) verificaram nos resultados dos ensaios de seus modelos que considerar a seção total do pilar como contribuinte para a resistência do mesmo, não é a melhor solução, pois foi verificado que ao ser 
considerada esta área para o cálculo da capacidade resistente dos pilares os mesmos romperam com forças inferiores às avaliadas teoricamente. $\mathrm{O}$ valor da força experimental de ruína foi aproximadamente igual ao valor da força teórica calculada com a área equivalente a do núcleo de concreto, ou seja, ocorreu a formação do núcleo de concreto confinado. Ressalta-se que esses autores trabalharam com resistências à compressão de $80 \mathrm{MPa}$ e $60 \mathrm{MPa}$, respectivamente.

$\mathrm{Na}$ análise teórica experimental de pilares feita por Ramos (2001), que trabalhou com a resistência à compressão do concreto de $25 \mathrm{MPa}$, não se caracterizou a formação do núcleo de concreto confinado, pois os valores das forças experimentais de ruína dos modelos foram aproximadamente iguais aos valores calculados para as capacidades resistentes considerando-se as seções totais, e o valor da força última foi, em média, 29\% maior que o valor teórico calculado com a contribuição apenas do núcleo.

Esses valores teóricos calculados pelos autores citados levaram em consideração o valor da variável $\mathrm{k}_{2}$, coeficiente que pondera a resistência média à compressão do concreto medida por meio de corpos-de-prova cilíndricos, quando se calcula o valor da força teórica máxima em pilares de concreto armado utilizando a Teoria da Resistência dos Materiais, como sendo constante e igual a 0,95 para todos os seus pilares, como sugere Fusco (1989). A análise dos resultados deste trabalho avaliará se esta foi a alternativa correta para adoção do valor dessa variável.

\subsection{JUSTIFICATIVAS}

Nas análises feitas por Lima (1997) e Queiroga (1999), que estudaram pilares moldados com concreto de alta resistência submetidos à compressão simples, com resistências de $80 \mathrm{MPa}$ e $60 \mathrm{MPa}$ respectivamente, percebeu-se que quando se compararam os valores das forças últimas experimentais com as teóricas obtidas considerando apenas a área do núcleo confinado, definido como sendo a área delimitada pelos eixos dos estribos, esta relação foi sempre maior que 1 , e quando se compararam estas às últimas experimentais com os valores 
teóricos levando em conta a seção total, obtiveram valores menores que 1. Com isso, para ambas as resistências as seções resistentes dos pilares são as seções dos núcleos dos pilares.

No estudo feito por Ramos (2001), em que se trabalhou com concreto de resistência à compressão de $25 \mathrm{MPa}$, a relação entre a força última experimental e a força última teórica considerando a seção total ficou em torno de 1, enquanto que a relação entre essa força experimental e a capacidade resistente do núcleo girou em torno de 1,29, ou seja, pode-se afirmar que para pilares com resistência do concreto de $25 \mathrm{MPa}$ não há a formação do núcleo resistente, isto é a seção total trabalha para absorver os esforços solicitantes.

A justificativa desta pesquisa é verificar a formação, ou não, do núcleo resistente em pilares de concreto com resistência média à compressão de $40 \mathrm{MPa}$, e se a determinação do comportamento da variável $\mathrm{k}_{2}$ influenciará nesses resultados.

A pesquisa bibliográfica mostra que pilares com resistência do concreto de 50MPa têm sido adotados em projetos no Brasil, com os demais elementos estruturais fletidos com resistência do concreto de $25 \mathrm{MPa}$. Por outro lado as análises teóricas e experimentais são escassas e quando encontradas analisaram exclusivamente o problema do confinamento do elemento estrutural, sem considerar outras variáveis como já comentado.

Foi utilizado programa que apresenta o comportamento do diagrama tensão vs. deformação dos pilares submetidos à compressão centrada, considerando o efeito do confinamento do concreto utilizando um modelo desenvolvido por Cusson e Paultre (1995) e modificado por Lima Júnior (2003). A implementação do modelo teórico de confinamento, no programa citado, foi feita pelo mesmo autor. 


\subsection{OBJETIVOS}

O objetivo primordial da pesquisa é obter informações sobre o comportamento de pilares submetidos à compressão centrada moldados com concreto de resistência média à compressão de $40 \mathrm{MPa}$. Os resultados obtidos experimentalmente foram confrontados com os obtidos por meio da análise numérica.

Os objetivos complementares são listados a seguir.

Determinar, por análise experimental, a existência, ou não, de núcleo resistente em pilares moldados com concretos de resistência 40MPa. A verificação foi feita por análise numérica utilizando-se as equações de equilíbrio que regem a segurança da seção transversal.

Verificar, caso seja comprovado, o confinamento do núcleo, adotando as taxas mínimas de armaduras longitudinal e transversal indicadas na NBR 6118:2003, sendo que um modelo foi detalhado com taxa de armadura transversal $25 \%$ menor que a mínima exigida por norma.

Fornecer subsídios para o desenho de uma superfície que retrate o comportamento dúctil de pilares de concreto armado em função das resistências médias à compressão e das taxas de armaduras transversal.

Obter informações sobre o valor da variável $\mathrm{k}_{2}$, coeficiente que pondera a resistência média à compressão do concreto medida por meio de corpos-de-prova cilíndricos, quando se calcula o valor da força teórica máxima em pilares de concreto armado utilizando a Teoria da Resistência dos Materiais, verificando se essa variável é influenciada pela resistência do concreto como sugere a NS 3473 E (1992), ou se não é dependente dessa característica, como sugerem o ACI (1989) e Fusco (1989). 


\subsection{Metodologia}

\subsubsection{Experimental}

Para o desenvolvimento da parte experimental foi tomado como base inicial os trabalhos desenvolvidos por Lima (1997), Queiroga (1999) e Ramos (2001).

Foram ensaiados 16 modelos: quatro com dimensões da seção transversal de $200 \mathrm{~mm} \times 200 \mathrm{~mm}$ e altura de $1200 \mathrm{~mm}$ (série P1) e doze com dimensões da seção transversal de $150 \mathrm{~mm} \times 300 \mathrm{~mm}$ e altura de 900mm (séries P2, P3 e P4).

Para os modelos, foram adotados diferentes tipos e taxas de armaduras transversais para a avaliação da ductilidade. Junto às extremidades dos pilares foram dispostas armaduras de fretagem compostas por seis estribos com diâmetro de $6,3 \mathrm{~mm}$, espaçados de $2,5 \mathrm{~cm}$, e com configuração idêntica aos estribos do trecho central do pilar.

Alem desses modelos armados, foram ensaiados oito outros modelos não armados, quatro de seção quadrada e quatro de seção retangular, para verificar o valor da variável $\mathrm{k}_{2}$, que leva em consideração a estimativa da resistência do concreto nas estruturas, quando avaliadas por meio dos corpos-de-prova cilíndricos, e se o valor se aproxima de 0,95, como sugerem Fusco (1989) e o ACI (1989).

Os modelos foram ensaiados com força estática controlada por deslocamento imposto. A taxa de deformação em todos os casos foi de $0,005 \mathrm{~mm} / \mathrm{m} \cdot \mathrm{s}$ no trecho ascendente do diagrama força vs. deformação, conforme especificação do RILEM TC 148-CCS (2000), e de $0,01 \mathrm{~mm} / \mathrm{m} \cdot \mathrm{s}$ no trecho descendente. O tempo aproximado de duração de cada ensaio foi de $25 \mathrm{~min}$. 
Dois colares metálicos foram dispostos nas extremidades dos modelos, com objetivo de suporte para a instrumentação e prevenção da ruína prematura dessa região. Foram dispostos $4 \mathrm{LVDT}^{1}$ junto ao colar, com $50 \mathrm{~mm}$ de curso cada e centésimos de milímetro de sensibilidade, para medir as deformações longitudinais dos modelos.

\subsubsection{Numérica}

Para representar o comportamento do confinamento em pilares, para a resistência média à compressão do concreto de $40 \mathrm{MPa}$, foi utilizado o modelo teórico desenvolvido por Cusson e Paultre (1995), que foi modificado por Lima Júnior (2003). Será realizada também uma análise computacional na qual utilizase programa desenvolvido pelos professores Ney Augusto Dumont e Giuseppe Barbosa Guimarães, da Pontifícia Universidade Católica do Rio de Janeiro, e que foi composto por dissertações de Mestrado (KRÜGER, $1989^{2}$ apud Lima Júnior, 2003), baseado no método dos elementos finitos que leva em consideração a não linearidade física do material, a não linearidade geométrica da estrutura e o efeito exercido pelo confinamento. A implementação do modelo teórico de confinamento, no programa citado, foi feita por Lima Júnior (2003).

O programa utiliza um elemento finito de viga inicialmente em um sistema natural de coordenadas (Figura 1.4a). Em seguida, este é transformado para um sistema auxiliar de coordenadas, cujas coordenadas de deslocamentos são dispostas segundo as coordenadas globais do pórtico e permitem a descrição de deslocamentos de corpo rígido (Figura 1.4b). Logo após ocorre a

\footnotetext{
${ }^{1}$ O transformador diferencial variável linear, conhecido como LVDT (Linear Variable Displacement Transducer), é um transdutor de deslocamento, que produz uma tensão de saída proporcional ao deslocamento de um núcleo móvel. O LVDT possui uma bobina primária, a qual é excitada com uma tensão alternada, e duas bobinas secundárias idênticas ligadas em série e com os condutores enrolados em sentidos opostos. Este transdutor caracteriza-se por uma relativa linearidade entre a diferença de potencial medida na saída e o deslocamento operado sobre o núcleo magnético. Esta classe de transdutores, com algumas variantes, é utilizada quer na medição do deslocamento, da velocidade e da aceleração de objetos, quer na medição da força exercida.
}

${ }^{2}$ KRÜGER, S.D. (1989). Uma metodologia para a análise de pórticos planos de concreto armado sujeitos a grandes deslocamentos. Dissertação (Mestrado). Departamento de Engenharia de Civil Pontifícia Universidade Católica do Rio de Janeiro, Rio de Janeiro. 
transformação para o sistema global de coordenadas e a partir daí se segue o método da rigidez direta (LIMA JÚNIOR, 1997).
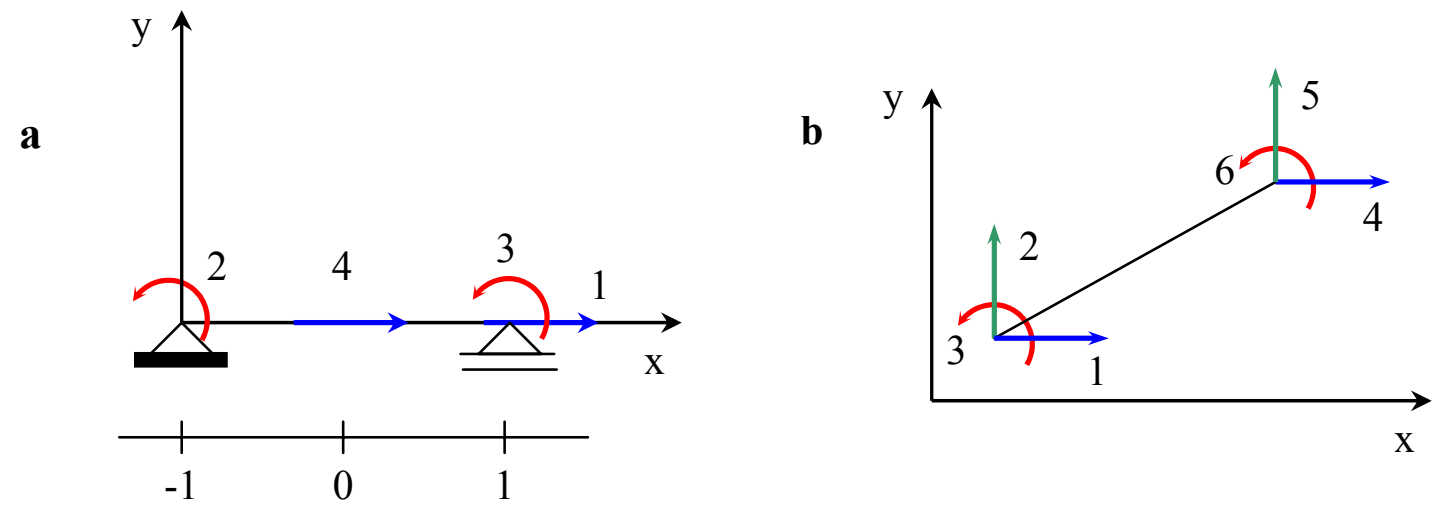

Figura 1.4 - Sistema de coordenadas natural e auxiliar respectivamente (LIMA JÚNIOR, 1997).

A partir da determinação, por análise experimental, das características mecânicas do aço e do concreto, e de uma discretização do elemento estrutural, fez-se análise numérica utilizando o programa citado, onde são calculadas as deformações longitudinais do modelo e compararam-se essas deformações as obtidas por meio dos ensaios experimentais.

\subsection{CONTEÚDO DA DISSERTAÇÃO}

Esta dissertação foi dividida em sete capítulos e dois apêndices. No primeiro capítulo são apresentadas as considerações iniciais relativas ao tema proposto, as justificativas do trabalho, os objetivos e a metodologia empregada nos ensaios experimentais e na análise numérica.

No capítulo dois são apresentadas as características do concreto de resistência usual, os materiais que o constituem, sua aplicabilidade e propriedades mecânicas e apresenta, também, uma descrição das características dos pilares de concreto de resistência usual, como o cálculo da capacidade resistente e o comportamento no tocante a ductilidade. 
O capítulo três apresenta os modelos teóricos para o concreto confinado e os fatores que influenciam esse parâmetro. Neste capítulo há uma descrição detalhada do modelo de Cusson e Paultre (1995) modificado por Lima Júnior (2003). São apresentados também, os procedimentos adotados para utilização do programa computacional neste trabalho.

No capítulo quatro são apresentados os procedimentos empregados na análise experimental, como caracterização dos materiais, a construção de fôrmas e modelos para ensaio, a instrumentação utilizada, a previsão da força última e os equipamentos utilizados nos ensaios.

$\mathrm{O}$ quinto capítulo apresenta os resultados experimentais e o comportamento global dos pilares ensaiados.

No capítulo seis constam a avaliação da ductilidade dos pilares de acordo com os critérios adotados, a avaliação da variável $\mathrm{k}_{2}$ com base nos ensaios experimentais de outros autores e deste trabalho e a comparação dos resultados experimentais com o programa computacional utilizado.

O capítulo sete apresenta as conclusões do trabalho de acordo com os objetivos propostos.

Por fim são apresentadas as referências bibliográficas, a bibliografia complementar e dois apêndices com os procedimentos de implantação do programa computacional (apêndice A) e os diagramas força aplicada vs. deformação das barras de aço das armaduras dos pilares ensaiados (apêndice B). 


\section{Capítulo 2}

\section{PILARES DE CONCRETO DE RESISTÊNCIA USUAL}

\subsection{MATERIAIS CONSTITUINTES}

\subsubsection{Cimento}

Os aglomerantes hidráulicos ou resistentes à água consistem essencialmente de cimento portland e suas diversas modificações. Para entender as propriedades do cimento portland, é proveitoso adquirir alguma familiaridade com o seu processo de fabricação, sua composição química e mineralógica, sua estrutura cristalina e a reatividade dos seus compostos constituintes como os silicatos de cálcio e os aluminatos de cálcio. Além disso, as propriedades do concreto contendo cimento portland desenvolvem-se como resultado de reações químicas entre os compostos do cimento portland e a água, uma vez que estas reações de hidratação são acompanhadas por trocas de matéria e energia. (MEHTA \& MONTEIRO, 1994).

O cimento utilizado neste trabalho foi o cimento portland de alta resistência inicial (CP V - ARI), este cimento não difere essencialmente do 
cimento Portland comum, sob o ponto de vista químico. De forma simplificada, pode-se passar progressivamente do cimento portland comum ao de alta resistência inicial com uma melhor homogeneização da mistura crua, melhor cozimento, moagem mais intensa e mesmo, às vezes, com uma relação cal/sílica um pouco mais elevada.

A resistência atingida pelo cimento de alta resistência inicial aos 3 dias é da mesma ordem de grandeza da atingida por um cimento portland comum a 7 dias com igual relação água/cimento. Sua resistência mínima à compressão aos 7 dias de idade deve ser de 34MPa.

O cimento de alta resistência inicial, fabricado no Brasil, é aconselhável nas aplicações em que o concreto deve suportar ações elevadas em curto prazo, ou quando se pretende um melhor aproveitamento das fôrmas, reutilizando-as o mais rápido possível.

Para os concretos de resistência usual não há necessidade do emprego de um determinado cimento, no entanto, o uso de um ou outro dependerá das características que envolvem o projeto e a obra.

A NBR 6118:2003 procura estabelecer valores mínimos e máximos quanto à relação água/cimento para a produção de concretos estruturais a depender da classe de agressividade do ambiente em que a estrutura será construída. Para estruturas de concreto armado, esses valores variam de 0,65 para uma ambiente de agressividade fraca a 0,45 para agressividade muito forte. Quanto a classe de agressividade do ambiente, a NBR 6118:2003 faz exigência quanto a resistência do concreto empregado nesses ambientes, para ambiente de agressividade fraca, a resistência do concreto deve ser maior ou igual a 20MPa e em ambiente de agressividade muito forte, a resistência do concreto deve ser maior ou igual a $40 \mathrm{MPa}$, com valores intermediários para as classes intermediárias. 


\subsubsection{Agregados}

Os agregados são materiais granulares, sem forma e volume definidos. Ocupam pelo menos 3/4 do volume total do concreto, portanto sua qualidade é de grande importância para a qualidade final do mesmo. Os agregados são materiais inertes, isto é, que não reagem com o aglomerante, mas que conferem resistência ao produto final.

De acordo com Mehta e Monteiro (1994), o agregado é um material granular, tal como a areia, o pedregulho, a pedra britada ou a escória de alto forno, usado com um meio cimentante, para formar um concreto ou argamassa de cimento hidráulico.

As características dos agregados que são importantes para a tecnologia do concreto incluem porosidade, composição granulométrica, absorção de água, forma e textura superficial das partículas, resistência à compressão, módulo de elasticidade e os tipos de substâncias deletérias presentes.

A classificação dos agregados conforme a dimensão das partículas, massa específica, ou origem têm gerado uma terminologia especial que deve ser claramente entendida. Por exemplo, o termo agregado graúdo é usado para descrever partículas maiores que $4,8 \mathrm{~mm}$ (retidas na peneira $\mathrm{N}^{\circ} 4$ ), e o termo agregado miúdo é usado para partículas menores do que 4,8mm; tipicamente, os agregados miúdos contêm partículas que variam, em dimensão, de $75 \mu \mathrm{m}$ (peneira $\mathrm{N}^{\mathrm{o}} 200$ ) a $4,8 \mathrm{~mm}$, e os agregados graúdos de $4,8 \mathrm{~mm}$ até cerca de $50 \mathrm{~mm}$, exceto para concreto massa, que pode conter agregado graúdo de até $150 \mathrm{~mm}$. (MEHTA \& MONTEIRO, 1994).

A maioria dos agregados naturais, tais como areia, pedregulho e pedra britada têm massa unitária que varia entre $1520 \mathrm{~kg} / \mathrm{m}^{3}$ e $1680 \mathrm{~kg} / \mathrm{m}^{3}$ e produzem concretos normais com aproximadamente $2400 \mathrm{~kg} / \mathrm{m}^{3}$ de massa específica. 


\subsection{3 Água}

A água para obtenção de um concreto de boa qualidade deve estar livre de impurezas. Essas impurezas na água de amassamento, quando em excesso, podem afetar a resistência e o tempo de pega, provocar a ocorrência de eflorescência (depósitos de sais sobre a superfície do concreto) e a corrosão da armadura passiva e ativa. Em geral, a água de amassamento raramente é um fator que prejudica a resistência final do concreto, porque nas especificações para execução das misturas de concreto a qualidade da água é garantida pela potabilidade. A água distribuída por uma Companhia de Abastecimento Municipal raramente contém sólidos dissolvidos excedendo a 1000ppm (partes por milhão). Além dessas características, seu pH deve estar compreendido entre 6 e 8 .

\subsubsection{Aço}

De acordo com a NBR 6118:2003, nos projetos de estruturas de concreto armado devem ser utilizados aços classificados pela NBR 7480:1986 com os valores característicos da resistência de escoamento classificados nas seguintes categorias: CA-25, CA-50 e CA-60. Os diâmetros e seções transversais nominais devem ser estabelecidos na NBR 7480:1986.

Os fios e barras podem ser lisos ou providos de saliências ou mossas. Para cada categoria de aço, o coeficiente de conformação superficial mínimo, $\eta_{\mathrm{b}}$, determinado por meio de ensaios de acordo com a NBR 7477:1982, deve atender ao indicado na NBR 7480:1986.

Para o valor da massa específica do aço de armadura passiva pode-se adotar o valor de $7850 \mathrm{~kg} / \mathrm{m}^{3}$. Para temperaturas compreendidas entre $-20^{\circ} \mathrm{C}$ e $150^{\circ} \mathrm{C}$ pode ser usado o valor de $10^{-5} /{ }^{\circ} \mathrm{C}$ para o coeficiente de dilatação térmica do aço, e na falta de ensaios experimentais ou valores fornecidos pelos fabricantes, o módulo de elasticidade do aço pode ser admitido igual a 210GPa. 


\subsection{DOSAGEM}

Segundo Mehta e Monteiro (1994) a seleção dos materiais componentes dos concretos é o primeiro passo na busca da obtenção de concretos com certas e desejadas características de desempenho; o passo seguinte é um processo denominado dosagem do concreto pela qual é obtida a proporção ideal entre esses componentes.

Considerando que a proporção dos materiais componentes tem grande influência no custo e nas propriedades dos concretos, e que os engenheiros são freqüentemente chamados para opinar durante o desenvolvimento ou na aprovação das proporções da mistura, é importante que estes estejam familiarizados com os princípios básicos e com os procedimentos usuais de dosagem dos concretos.

A tarefa de dosagem é complexa pelo fato de certas propriedades desejadas do concreto serem afetadas no sentido desfavorável por uma mudança numa certa variável específica. Por exemplo, a adição de água a um concreto fresco, mantendo-se o consumo de cimento por unidade de volume, poderá aumentar a fluidez desse concreto tornando-o mais trabalhável, porém irá reduzir sua resistência. De fato, a trabalhabilidade é uma propriedade composta intrinsecamente por dois componentes principais, e ambas, tendem a ser afetadas em sentidos opostos quando a água é adicionada a um certo concreto. O processo de dosagem resume-se, então, na arte de contrabalançar efeitos conflitantes, tais como os descritos anteriormente.

\subsection{CURA}

O termo cura do concreto trata dos procedimentos destinados a promover a hidratação do cimento, consistindo do controle do tempo, temperatura e condições de umidade, imediatamente após a colocação do concreto nas fôrmas. 
Para um dado fator água/cimento, a porosidade da pasta endurecida de cimento hidratada é determinada pelo grau de hidratação do cimento. Em condições normais de temperatura, alguns dos constituintes do cimento portland começam a se hidratar à medida que é adicionada água, mas as reações de hidratação cobrem os grãos de cimento anidro. Esta é a razão porque a hidratação somente pode proceder satisfatoriamente em condições de saturação; ela quase pára quando a pressão de vapor de água nos capilares cai para menos de $80 \%$ da umidade de saturação. Tempo e umidade são, portanto, fatores importantes nos processos de hidratação controlados pela difusão da água. Além do mais, como em todas as reações químicas, a temperatura tem um efeito acelerador sobre as reações químicas.

\subsubsection{Tempo}

Deve ser lembrado que as relações tempo-resistência em Tecnologia do Concreto geralmente supõem condições de cura úmida e temperatura normal. Para um dado fator água/cimento, quanto maior o período de cura úmida maior a resistência, admitindo-se que a hidratação das partículas de cimento anidro continua ocorrendo. Nas peças de concreto esbeltas, se a água for perdida por evaporação pelos capilares as condições de cura ao ar prevalecem, e a resistência não aumentará com o tempo. A idade de cura não tem efeito benéfico sobre a resistência do concreto a menos que a cura seja realizada na presença de umidade.

\subsubsection{Umidade}

A influência da umidade de cura sobre a resistência do concreto é evidente a partir dos dados da figura 2.1, que mostram que, depois de 180 dias, para um dado fator água/cimento, a resistência do concreto curado sob condições continuamente úmidas foi quase três vezes maior do que a resistência do concreto curado continuamente ao ar. Além disso, provavelmente como resultado da microfissuração na zona de transição causada pela retração de secagem, um 
pequeno retrocesso da resistência ocorre em peças esbeltas de concreto curadas sob condições úmidas quando estas são submetidas à secagem ao ar. A velocidade de perda de água do concreto, logo depois do seu lançamento não depende unicamente do fator superfície/volume do elemento de concreto, mas também da temperatura, umidade e velocidade do ar circundante.

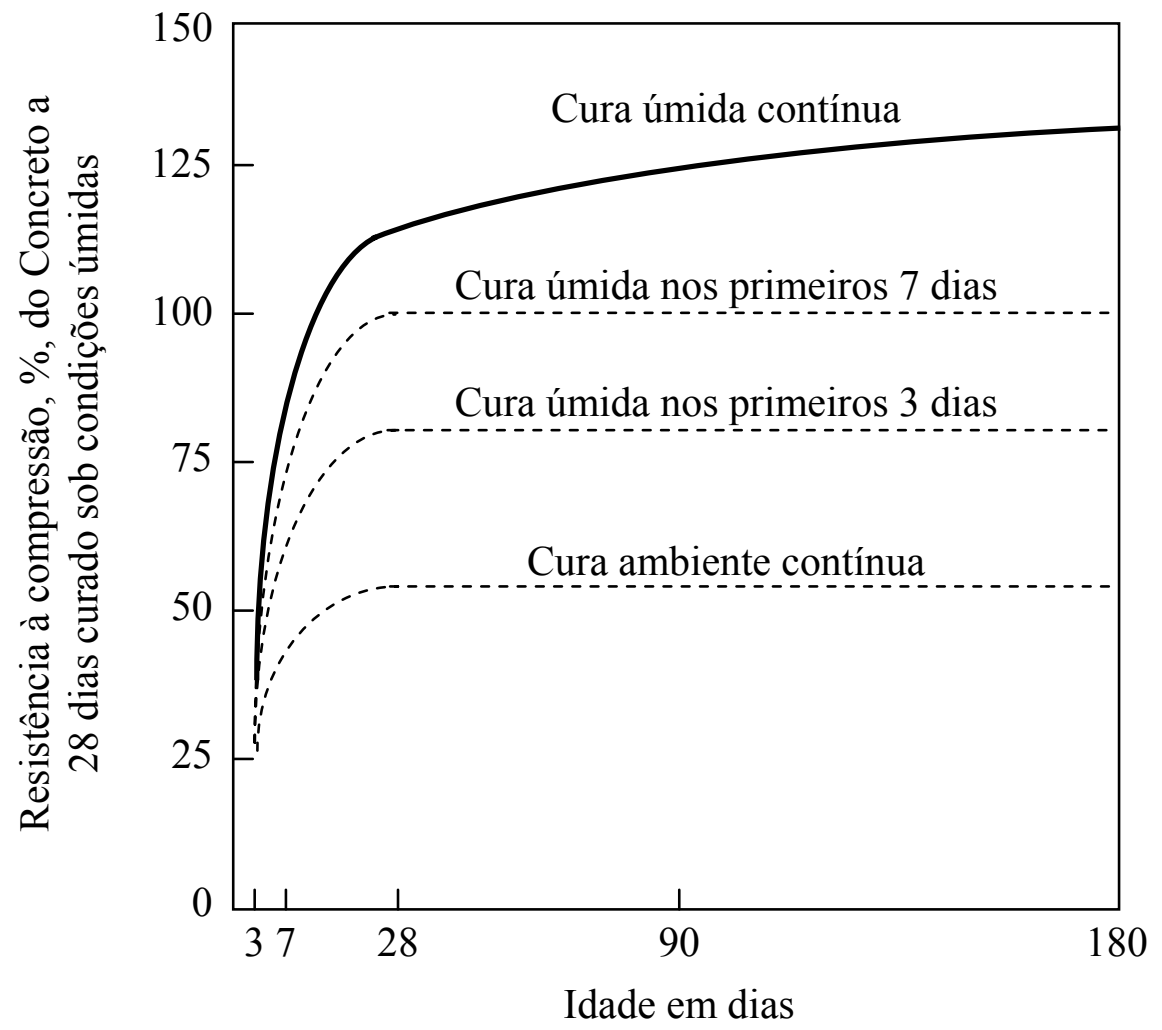

Figura 2.1 - Influência das condições de cura sobre a resistência. (MEHTA \& MONTEIRO, 1994)

\subsection{ClassificaÇão}

Segundo a NBR 8953:1992, os concretos são classificados em grupos de resistência, grupo I e grupo II, conforme a resistência característica à compressão $\left(f_{\mathrm{ck}}\right)$, determinada a partir do ensaio de corpos-de-prova preparados de acordo com a NBR 5738:1994 e ensaiados conforme a NBR 5739:1994. 
Dentro dos grupos, os concretos normais com massa específica seca, de acordo com a NBR 9778:1987, compreendida entre $2000 \mathrm{~kg} / \mathrm{m}^{3}$ e $2800 \mathrm{~kg} / \mathrm{m}^{3}$, são designados pela letra $\mathrm{C}$ seguida do valor da resistência característica à compressão $\left(f_{\mathrm{ck}}\right)$, expressa em MPa, conforme a tabela 2.1 .

Tabela 2.1 - Classes de resistência

\begin{tabular}{|c|c|c|c|}
\hline \multicolumn{3}{|c|}{ Grupos de resistência } & \multirow{2}{*}{$\begin{array}{c}\begin{array}{c}\text { Resistência } \\
\text { característica à } \\
\text { compressão }(\mathrm{MPa})\end{array} \\
10 \\
15\end{array}$} \\
\hline & $\begin{array}{c}\text { Concreto não } \\
\text { estrutural }\end{array}$ & $\begin{array}{l}\mathrm{C} 10 \\
\mathrm{C} 15\end{array}$ & \\
\hline I & $\begin{array}{l}\text { Concreto } \\
\text { estrutural }\end{array}$ & $\begin{array}{l}\text { C20 } \\
\text { C25 } \\
\text { C30 } \\
\text { C35 } \\
\text { C40 } \\
\text { C45 } \\
\text { C50 }\end{array}$ & $\begin{array}{l}20 \\
25 \\
30 \\
35 \\
40 \\
45 \\
50\end{array}$ \\
\hline & II & $\begin{array}{l}\text { C55 } \\
\text { C60 } \\
\text { C70 } \\
\text { C80 }\end{array}$ & $\begin{array}{l}55 \\
60 \\
70 \\
80\end{array}$ \\
\hline
\end{tabular}

Fonte: NBR 8953:1992

A NBR 6118:2003 aplica-se às estruturas de concretos normais, com as características, quanto a massa específica, exigidas pela NBR 9778:1987 e do grupo de resistência I (C10 a C50).

Nesta linha de raciocínio a NBR 6118:2003 indica 20MPa como limite mínimo da resistência característica do concreto, para utilização em estruturas de concreto armado com armaduras passivas.

Mehta e Monteiro (1994) classificam os concretos em três classes de resistência mostradas na tabela 2.2 . 
Tabela 2.2 - Classificação dos concretos

\begin{tabular}{|c|c|}
\hline \hline $\begin{array}{c}\text { Resistência à compressão } \\
(\mathrm{MPa})\end{array}$ & Classificação \\
\hline \hline$<20$ & Baixa \\
\hline $20-40$ & Moderada \\
\hline$>40$ & Alta \\
\hline \hline
\end{tabular}

Fonte: Mehta e Monteiro (1994)

\subsection{APLICABILIDADE}

Ainda que haja uma grande tendência de utilização do CAR (concreto de alta resistência), o CRU (concreto de resistência usual) possui aplicação garantida em edificações de pequena altura e construções fora dos grandes centros urbanos. Além disso, outra forma de aplicação do CRU, visando aproveitar ao máximo as potencialidades da estrutura, está na possibilidade do edifício ser executado com concreto de resistência variável ao longo das partes que o compõe.

Mehta e Monteiro (1994) apresentam um exemplo de edifício executado com concretos de diferentes resistências ao longo dos pavimentos. O Water Tower Place, em Chicago, apresentado na figura 2.2, com 262,5m de altura possui os pilares do térreo com resistência de $63 \mathrm{MPa}$, acima do $25^{\circ}$ pavimento a resistência do concreto dos pilares foi sendo progressivamente reduzida de $53 \mathrm{MPa}$ a $28 \mathrm{MPa}$. 


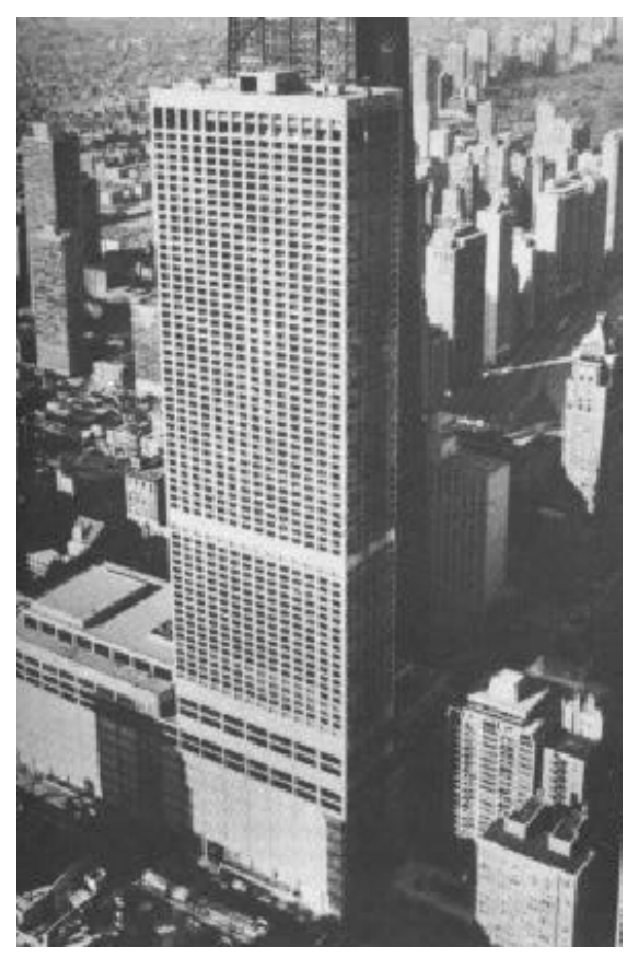

Figura 2.2 - Water Tower Place em Chicago, Illinois, 1976. (MEHTA E MONTEIRO, 1994)

\subsection{VANTAGENS E DESVANTAGENS}

Como qualquer outro material, o concreto armado possui qualidades e defeitos. Além disso, uma determinada vantagem tem sempre caráter relativo, dependendo do padrão de referência. Quando dizemos, por exemplo, que o concreto armado é econômico, tal afirmação pode ser falsa em relação à madeira e verdadeira em comparação com o aço, neste último caso, entre outros fatores, conforme o estágio de desenvolvimento da siderurgia no país onde é feito o cotejo.

Santos (1983) relaciona algumas vantagens e desvantagens do uso do concreto armado em relação a outros materiais, a saber: 


\subsubsection{Vantagens}

3. Economia de construção. Muitas vezes, os agregados são obtidos no local da obra ou perto desta, com custos mínimos e sem altas despesas com transporte;

B Economia de conservação. Esta é uma vantagem praticamente absoluta, desde que convenientemente dimensionada e executada, a estrutura de concreto armado não necessita de manutenção por vários anos. O cobrimento do concreto protege as barras de armadura da deterioração causada pela oxidação;

3 Possibilidade de realizar todas as formas criadas pela arquitetura, adaptando-se a uma grande variedade de tipos estruturais;

B Durabilidade. A resistência do concreto aumenta com o endurecimento ao longo do tempo;

3 Impermeabilidade. Em boas condições de consistência plástica e adensamento, o concreto é pouco permeável à água;

B Monolitismo. A disposição das armaduras e a concretagem são de modo a fazer com que a estrutura forme um monólito, isto é, todo o conjunto trabalha quando uma das peças é solicitada isoladamente;

3 Eventual aproveitamento do material como elemento estético ou decorativo, em fachadas e interiores, com economia de revestimento e pintura;

B Resistência a choques e vibrações. Os problemas de fadiga são menores nas estruturas de concreto armado.

\subsubsection{Desvantagens}

Peso próprio elevado, relativamente à resistência. O concreto é cerca de três vezes mais leve que o aço, mas sua resistência pode ser mais de dez vezes inferior, assim as estruturas metálicas são consideravelmente mais leves; 
Q Dificuldade de adaptações, no caso de se desejar qualquer modificação depois da concretagem. As reformas são tecnicamente difíceis e caras. Este é um defeito sério, uma desvantagem praticamente absoluta;

8 Facilidade de fissuração aparente. Embora não haja, em geral, danos do ponto de vista estático ou de resistência, o lado estético fica prejudicado, e, eventualmente, agravam-se os problemas de permeabilidade;

$\vartheta \quad$ Transmissão de calor;

๑ Transmissão de sons.

\subsection{PropriedAdes MECÂNICAS}

\subsubsection{Resistência à compressão}

Para a medida da resistência à compressão uniaxial do concreto, está padronizado na NBR 5739:1980 o ensaio de compressão de corpos-de-prova cilíndricos de concreto. A NBR 5738:1994 prescreve a moldagem e cura dos corpos-de-prova cilíndricos e, no caso de se utilizarem concretos de resistência usual, costuma-se definir os corpos-de-prova com 150mm de diâmetro e $300 \mathrm{~mm}$ de altura. Contudo, é importante conhecer a relação entre a resistência à compressão do concreto nas condições reais de carregamento da estrutura e nas condições do ensaio em laboratório.

Segundo Fusco (1989), para representar a diferença entre a resistência do concreto da estrutura e a dos corpos-de-prova de controle, proveniente da influência das placas da prensa sobre os corpos-de-prova, utiliza-se um coeficiente de redução no valor de 0,95. Admitindo-se que as ações nas estruturas permanecem por longos períodos de tempo, a resistência de longa duração do seu concreto pode ficar reduzida para 0,75 da resistência potencial que poderia ser atingida com longos períodos de maturação. Este fenômeno é conhecido como “efeito Rüsch” por ter sido estudado pelo alemão Hubert Rüsch. Por fim, quando 
se utilizam cimentos de endurecimento normal, tem-se um acréscimo de resistência, obtido depois dos 28 dias até se atingir alguns anos de idade, da ordem de $20 \%$.

Em resumo, pode-se agrupar estas três influências para definir um único coeficiente de modificação $\mathrm{k}_{\bmod }$, o qual irá representar a relação entre a resistência à compressão do concreto nas condições reais de carregamento da estrutura e nas condições do ensaio em laboratório. Assim, tem-se:

$$
\mathrm{f}_{\mathrm{c}, \text { estrutura }}=\mathrm{k}_{\text {mod }} \cdot \mathrm{f}_{\mathrm{c}, 28}
$$

onde:

$\mathrm{f}_{\mathrm{c}, \text { estrutura }}$ é a resistência à compressão do concreto da estrutura;

$\mathrm{f}_{\mathrm{c}, 28}$ é a resistência média à compressão do concreto dos corpos-de-prova de controle aos 28 dias de idade;

$\mathrm{k}_{\text {mod }}$ é calculado pela equação 2.2 .

$$
\mathrm{k}_{\mathrm{mod}}=\mathrm{k}_{1} \cdot \mathrm{k}_{2} \cdot \mathrm{k}_{3}
$$

na qual $\mathrm{k}_{1}$ leva em conta o acréscimo de resistência do concreto após 28 dias, $\mathrm{k}_{2}$ considera a estimativa da resistência do concreto na estrutura, quando avaliadas por meio dos corpos-de-prova cilíndricos, e $\mathrm{k}_{3}$ considera a diminuição da resistência do concreto para ações de longa duração. $\mathrm{Na}$ falta de dados experimentais, pode-se adotar $\mathrm{k}_{1}=1,2, \mathrm{k}_{2}=0,95$ e $\mathrm{k}_{3}=0,75$, resultando, portanto, $\mathrm{k}_{\text {mod }}=0,85$ (FUSCO, 1989).

A norma Norueguesa - NS 3473 E (1992) - não considera o valor de $k_{2}$ constante, ela apresenta a tabela 2.3 que compara os valores de resistência do concreto na estrutura com os valores obtidos por meio de ensaio de corpos-deprova cilíndricos. 
Tabela 2.3 - Resistência a compressão do concreto em MPa

\begin{tabular}{|l|c|c|c|c|c|c|c|c|c|c|}
\cline { 2 - 11 } \multicolumn{1}{c|}{} & \multicolumn{7}{|c|}{ Concretos } \\
\cline { 2 - 11 } & $\mathrm{C} 15$ & $\mathrm{C} 25$ & $\mathrm{C} 35$ & $\mathrm{C} 45$ & $\mathrm{C} 55$ & $\mathrm{C} 65$ & $\mathrm{C} 75$ & $\mathrm{C} 85$ & $\mathrm{C} 95$ & $\mathrm{C} 105$ \\
\hline $\begin{array}{l}\text { Resistência do corpo- } \\
\text { de-prova cilíndrico }- \\
\mathrm{f}_{\mathrm{c}, \mathrm{cp}}\end{array}$ & 12 & 20 & 28 & 36 & 44 & 54 & 64 & 74 & 84 & 94 \\
\hline $\begin{array}{l}\text { Resistência do concreto } \\
\text { na estrutura }-\mathrm{f}_{\mathrm{cn}}\end{array}$ & 11,2 & 16,8 & 22,4 & 28,0 & 33,6 & 39,2 & 44,8 & 50,4 & 56,0 & 61,6 \\
\hline $\mathrm{k}_{2}=\frac{\mathrm{f}_{\mathrm{cn}}}{\mathrm{f}_{\mathrm{c}, \mathrm{cp}}}$ & $\mathbf{0 , 9 3}$ & $\mathbf{0 , 8 4}$ & $\mathbf{0 , 8 0}$ & $\mathbf{0 , 7 8}$ & $\mathbf{0 , 7 6}$ & $\mathbf{0 , 7 3}$ & $\mathbf{0 , 7 0}$ & $\mathbf{0 , 6 8}$ & $\mathbf{0 , 6 7}$ & $\mathbf{0 , 6 6}$ \\
\hline
\end{tabular}

Fonte: NS 3473 E (1992)

Com esses dados, fez-se análise de regressão logarítmica e obteve-se a equação 2.3, que correlaciona o coeficiente $\mathrm{k}_{2}$ com a resistência do concreto:

$$
\mathrm{k}_{2}=-0,1358 \cdot \ell \mathrm{n}\left(\mathrm{f}_{\mathrm{cj}}\right)+1,2908
$$

Para a pesquisa em questão, algumas particularidades tiveram de ser consideradas na determinação do $\mathrm{k}_{\text {mod, }}$ ou seja, como os pilares e os corpos-deprova foram ensaiados no mesmo dia e sob ação de curta duração, os coeficientes $\mathrm{k}_{1}$ e $\mathrm{k}_{3}$ receberam o valor igual a 1,00. Além disso, a data dos ensaios foi aos 14 dias e, portanto, teve-se $\mathrm{f}_{c, 14}$ ao invés de $\mathrm{f}_{\mathrm{c}, 28}$. Deste modo, a relação passou a ser:

$$
\mathrm{f}_{\mathrm{c}, \text { pilar }}=\mathrm{k}_{2} \cdot \mathrm{f}_{\mathrm{c}, 14}
$$

onde:

$\mathrm{f}_{\mathrm{c}, 14}$ é a resistência média à compressão do concreto dos corpos-de-prova de controle aos 14 dias de idade.

Para este trabalho os valores de $\mathrm{k}_{2}$ foram determinados pela relação entre a resistência dos prismas de concreto não armados e a resistência medida por meio dos corpos-de-prova cilíndricos. 


\subsubsection{Resistência à tração}

A NBR 7222:1994 prescreve a determinação da resistência à tração do concreto por compressão diametral de corpos-de-prova cilíndricos. Esta propriedade mecânica ainda pode ser obtida com ensaios de tração direta ou tração por flexão com carregamento nos terços do vão de um prisma com dimensões padronizadas segundo prescrições da NBR 12142:1991.

Os diferentes métodos de ensaio costumam fornecer diferentes valores de resistências. Segundo Mehta e Monteiro (1994), o ensaio de compressão diametral superestima a resistência à tração do concreto com valores entre $10 \% \mathrm{e}$ $15 \%$, enquanto que, o ensaio de flexão pode superestimar a resistência de $50 \%$ a 100\%. A NBR 6118:2003 especifica a resistência à tração direta sendo 90\% e $70 \%$ daquelas obtidas por ensaios de compressão diametral e flexão, respectivamente.

$\mathrm{Na}$ falta de determinação experimental, a NBR 6118:2003 permite a utilização das relações entre as resistências à tração e à compressão do concreto apresentadas nas equações 2.5 a 2.7 .

$$
\begin{aligned}
& f_{c t, m}=0,3 \cdot f_{c k}^{2 / 3} \\
& f_{c t k, \text { inf }}=0,7 \cdot f_{c t, m} \\
& f_{c t k, \text { sup }}=1,3 \cdot f_{c t, m}
\end{aligned}
$$

onde $f_{c k}$ e $f_{c t, m}$ são expressos em MPa.

\subsubsection{Módulo de elasticidade}

O módulo de elasticidade ou módulo de deformação longitudinal tangente, deve ser obtido segundo ensaio descrito na NBR 8522:1984, sendo considerado o módulo de deformação longitudinal tangente a $30 \% \cdot f_{c}$ (Figura 2.3 ), ou a outra tensão especificada em projeto. 


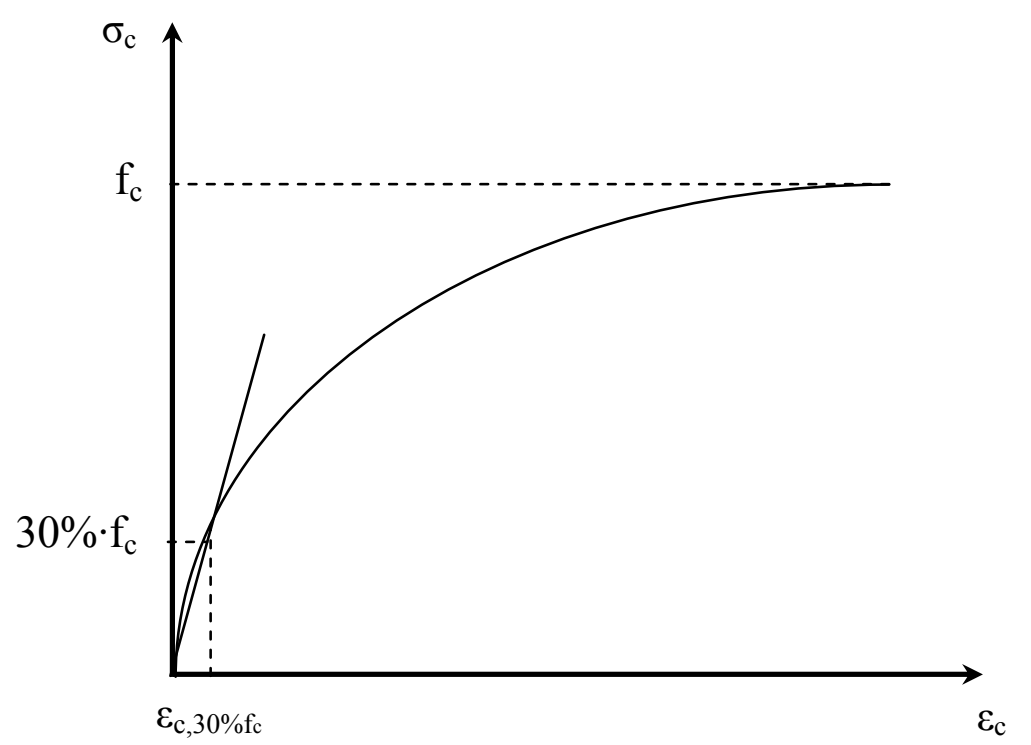

Figura 2.3 - Diagrama tensão vs. deformação do concreto

Quando não forem feitos ensaios e não existirem dados mais precisos sobre o concreto usado na idade de 28 dias, pode-se estimar o valor do módulo de elasticidade usando a expressão 2.8 (NBR 6118:2003).

$$
\mathrm{E}_{\mathrm{ci}}=5600 \cdot \sqrt{\mathrm{f}_{\mathrm{ck}}}
$$

onde, $\mathrm{E}_{\mathrm{ci}}$ e $\mathrm{f}_{\mathrm{ck}}$ são dados em MPa

$\mathrm{O}$ módulo de elasticidade numa idade $\mathrm{j} \geq 7$ dias pode também ser avaliado pela expressão 2.8, substituindo-se $\mathrm{f}_{\text {ck }}$ por $\mathrm{f}_{\text {ckjj }}$, onde, $\mathrm{f}_{\text {ckj }}$ é a resistência característica à compressão do concreto no j-ésimo dia de idade.

Quando for o caso, é esse o módulo de elasticidade a ser especificado em projeto e controlado na obra.

O módulo de elasticidade secante a ser utilizado nas análises elásticas de projeto, especialmente para determinação de esforços solicitantes e verificação de estados limites de serviço, deve ser calculado pela equação 2.9.

$$
\mathrm{E}_{\mathrm{cs}}=0,85 \cdot \mathrm{E}_{\mathrm{ci}}
$$


$\mathrm{Na}$ avaliação do comportamento de um elemento estrutural ou seção transversal pode ser adotado um módulo de elasticidade único, à tração e à compressão, igual ao módulo de elasticidade secante $\left(\mathrm{E}_{\mathrm{cs}}\right)$.

$\mathrm{Na}$ avaliação do comportamento global da estrutura e para o cálculo das perdas de protensão, pode ser utilizado em projeto o módulo de deformação tangente inicial $\left(\mathrm{E}_{\mathrm{ci}}\right)$.

\subsubsection{Coeficiente de Poisson e módulo de elasticidade transversal}

O coeficiente de Poisson é a relação entre a deformação transversal e a deformação axial resultantes de um carregamento uniaxial dentro de um intervalo elástico. De acordo com Mehta e Monteiro (1994), apesar desta relação poder estar entre 0,11 e 0,21, em geral, ela se apresenta entre 0,15 e 0,20.

A NBR 6118:2003 indica que, para tensões de compressão menores que $0,5 \cdot f_{c}$ e tensões de tração menores que $f_{c t}$, o coeficiente de Poisson $v$ pode ser tomado igual a 0,2 e o módulo de elasticidade transversal $G_{c}$ igual a $0,4 \cdot E_{c s}$.

\subsubsection{Diagrama tensão vs. deformação}

O diagrama tensão vs. deformação do concreto mostra, de início, que o material não obedece a Lei de Hooke: o diagrama é curvo praticamente desde a origem. Segundo Santos (1983), a forma desta curva é influenciada por uma série de parâmetros, dos quais os principais são: resistência do concreto; idade do concreto quando do carregamento; modo de colocação da carga; duração do carregamento; forma da seção transversal e posição da linha neutra (compressão centrada ou excêntrica).

Segundo Mehta e Monteiro (1994), a relação tensão-deformação, do ponto de vista da intensidade de tensão e da microfissuração no concreto, apresenta quatro estágios no comportamento do concreto sob compressão simples, apresentados na figura 2.4. 


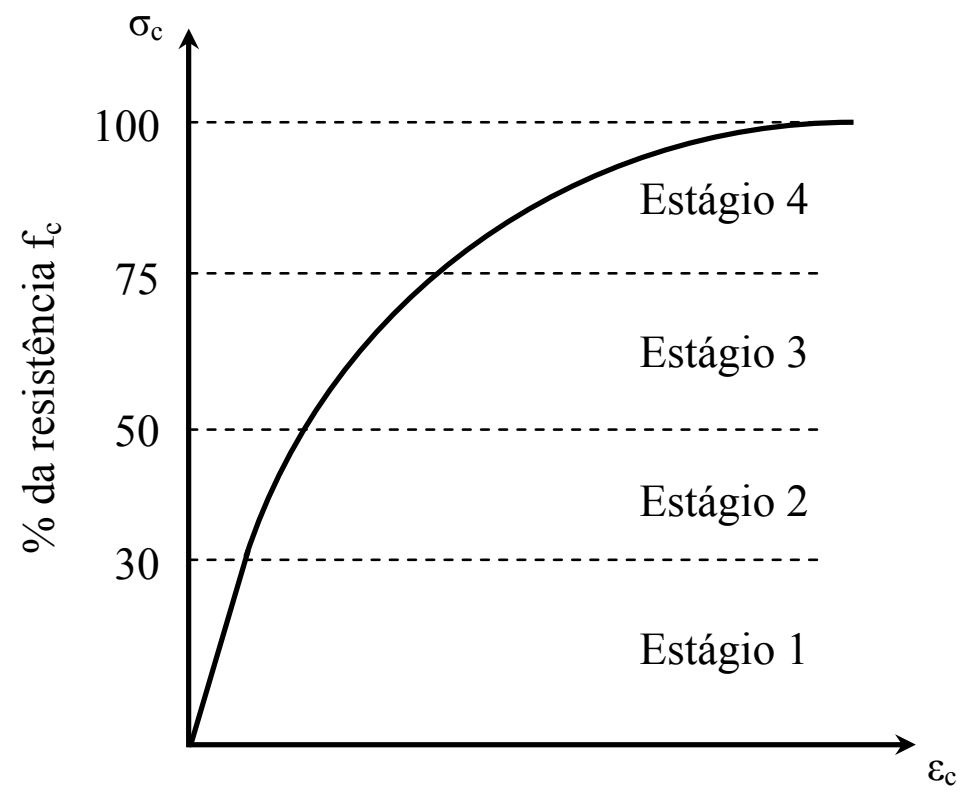

Figura 2.4 - Representação dos estágios na relação tensão vs. deformação do concreto sob carregamento uniaxial. (MEHTA \& MONTEIRO, 1994)

Para se compreender o primeiro estágio, deve-se partir do pressuposto que existem microfissuras na zona de transição entre a matriz e o agregado graúdo do concreto, antes da aplicação do carregamento. Deste modo, estas fissuras irão permanecer estáveis até que se alcance a tensão igual a $30 \%$ da resistência, resultando em uma relação tensão-deformação linear até este ponto. O segundo estágio está compreendido entre $30 \%$ e $50 \%$ da resistência de ruptura do concreto. Nesta fase, na medida em que as tensões aumentam, as microfissuras da zona de transição começam a aumentar em comprimento, largura e quantidade. Porém, o sistema de microfissuras ainda é considerado estável e a relação tensão-deformação começa a se desviar sensivelmente de uma reta. De $50 \%$ a $75 \%$ da resistência de ruptura do concreto, se desenvolvem as fissuras na matriz, antes desprezíveis no segundo estágio, e o sistema de fissuras na zona de transição torna-se instável. Com isso, a curva tensão-deformação inclina-se mais ainda na direção horizontal, caracterizando o terceiro estágio. $\mathrm{O}$ quarto estágio dá-se com intensidades de tensão entre $75 \%$ e $80 \%$ da resistência de ruptura do concreto. A partir de então, a taxa de liberação de energia de deformação atinge intensidade crítica necessária para o crescimento espontâneo 
das fissuras sob tensão constante. Desta forma, desenvolvem-se grandes deformações até a ruptura do material.

A NBR 6118:2003 indica que para tensões de compressão menores que $0,5 \mathrm{f}_{\mathrm{c}}$, pode-se admitir uma relação linear entre tensões e deformações, adotandose para módulo de elasticidade o valor secante dado pela expressão 2.9.

Para análises considerando o estado limite último, pode ser empregado o diagrama tensão-deformação idealizado mostrado na figura 2.5.

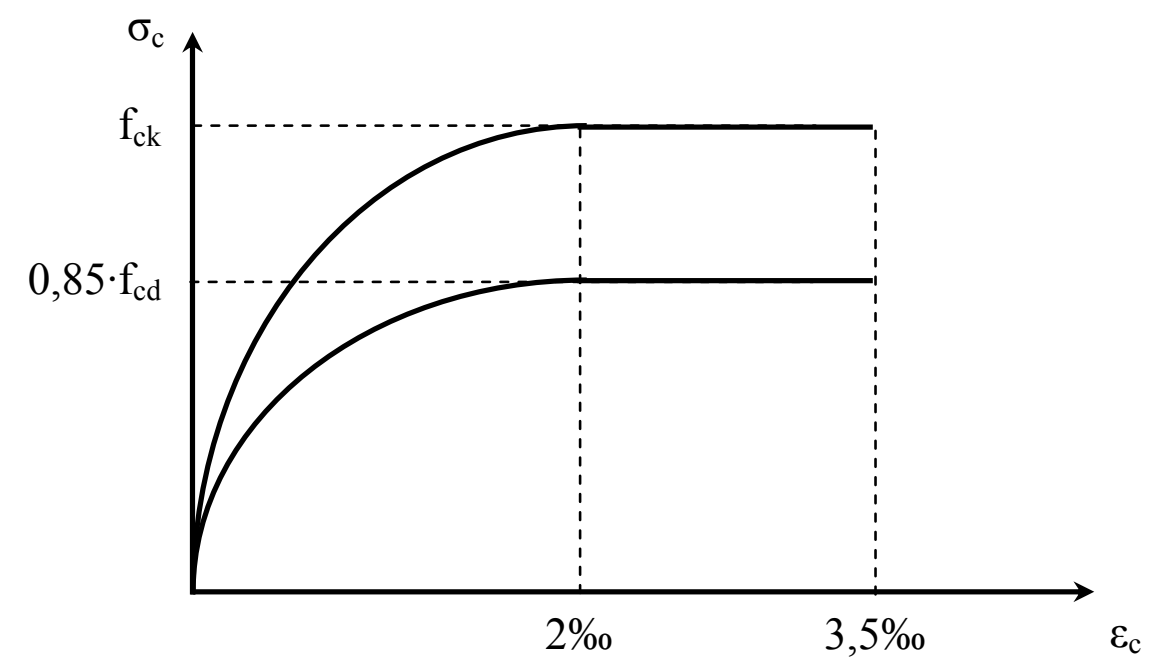

Figura 2.5 - Diagrama tensão vs. deformação idealizado (NBR 6118:2003)

A curva inferior do diagrama apresentado é dada pela equação 2.10.

$$
\sigma_{\mathrm{c}}=0,85 \cdot \mathrm{f}_{\mathrm{cd}} \cdot\left[1-\left(1-\frac{\varepsilon_{\mathrm{c}}}{2 \% \mathrm{o}}\right)^{2}\right]
$$

\subsection{Pilares de CONCRETO}

\subsubsection{Considerações iniciais}

Os pilares são peças alongadas em que predominam força normal de compressão, a maior parte da força é absorvida pelo concreto, servindo as 
armaduras para auxiliar na resistência e atender a inevitáveis excentricidades de força axial. As armaduras longitudinais, utilizadas na prática, têm suas taxas geométricas (área de armadura dividida pela área de concreto) limitadas por valores inferiores (armadura mínima) e superiores (armadura máxima). As barras longitudinais são colocadas nos cantos e nas faces da seção, onde elas são mais eficientes para absorver tensões provocadas por excentricidade das forças. As peças comprimidas, quando muito alongadas, estão, ainda, sujeitas a efeitos de segunda ordem, que é a instabilidade decorrente de deslocamento transversal do eixo do elemento.

Segundo Pfeil (1988b), as forças axiais (tração ou compressão) constituem, na verdade, idealizações de cálculo. Na prática, existem sempre excentricidades nas solicitações, decorrentes de imprecisões construtivas, excentricidade das forças nos extremos e de momentos por causa das ligações. Para cobrir essas eventualidades, são adotadas, nos projetos, excentricidades mínimas de cálculo, determinadas em função de uma dimensão transversal ou do comprimento de haste.

A armadura longitudinal dos pilares tem sempre função resistente, enquanto que, a transversal, quando espaçada convenientemente, servirá apenas para evitar a flambagem das barras longitudinais e mantê-las na distância prevista pelo projeto durante a execução. Todavia, se a armadura transversal apresentar-se pouco espaçada, ela terá função resistente, pois irá impedir a deformação transversal do concreto e, com isso, confinar o concreto do núcleo do pilar. Esta última constatação foi feita por Mörsch (1952) depois das análises de uma série de ensaios de pilares de concreto armado conduzidos por instituições européias, no início do século XX.

Pilares sujeitos a forças axiais são raros na prática. Geralmente existe momento em virtude da rigidez da ligação ou excentricidade de força. A maioria das normas reconhece isso e, quando necessário, o momento é considerado no projeto. Porém, examinando as diferenças em desempenho de pilares de concreto, é válido tratar de ações axiais primeiro. 


\subsubsection{Tipos de seções transversais e localização dos pilares na estrutura}

A forma da seção transversal dos pilares deixou de ser um fator de grande relevância durante a fase de concepção e cálculo estrutural. Com isso, as seções circulares e octogonais perderam sua "popularidade", pois a dificuldade na execução e montagem de suas fôrmas fez com que somente alguns projetistas e arquitetos optassem por estas seções por questões estéticas ou em casos especiais, como por exemplo, em pilares de pontes sobre rios. Na figura 2.6, apresentam-se seções transversais quadradas e retangulares com as configurações de armaduras mais empregadas nos dias de hoje.

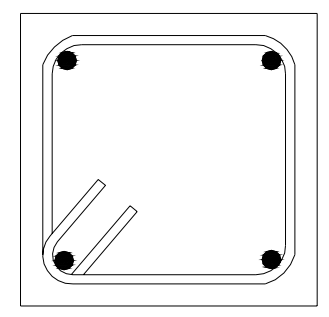

Pilar de seção quadrada e estribo simples

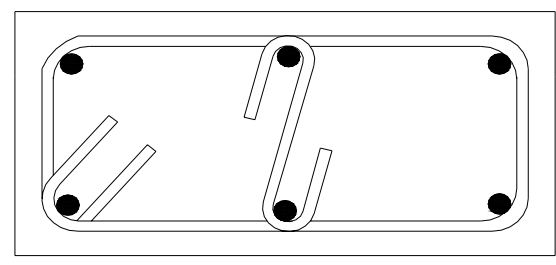

Pilar de seção retangular com estribo adicional

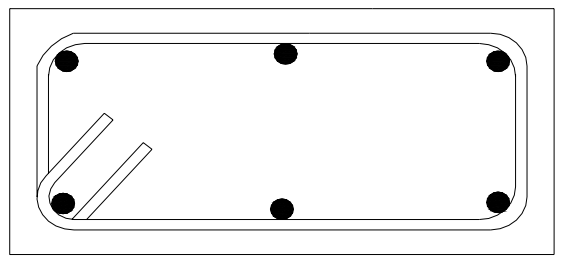

Pilar de seção retangular e estribo simples

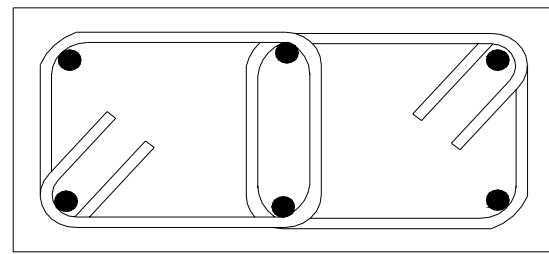

Pilar de seção retangular com estribos duplos

Figura 2.6 - Seções e configurações de armaduras mais empregadas atualmente em pilares de concreto armado

Os pilares em uma edificação, como consideração de projeto, podem ser classificados quanto a sua posição na estrutura, eles podem ser intermediários (situação mais próxima da compressão centrada), de extremidade (caracteriza flexo-compressão reta) ou de canto (caracteriza flexo-compressão oblíqua). A 
depender da posição dos pilares na edificação e da excentricidade, outras configurações de seção transversal podem vir a ser utilizadas, é o caso de seções em L e T. A figura 2.7 apresenta a classificação de pilares quanto seu posicionamento na estrutura.

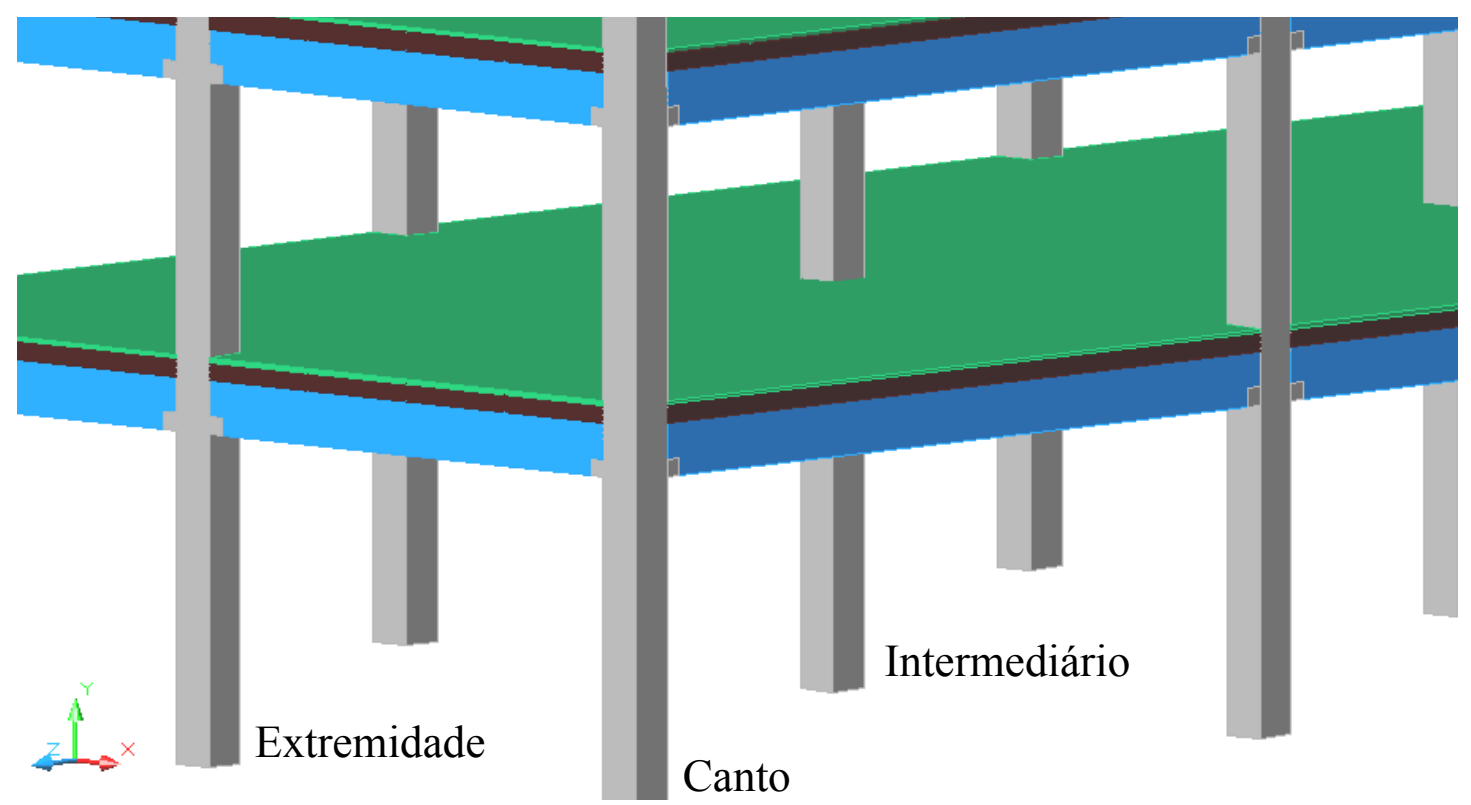

Figura 2.7 - Considerações de projeto quanto ao posicionamento dos pilares na estrutura

\subsubsection{Cálculo da capacidade resistente e recomendações da NBR 6118:2003}

Para o cálculo da capacidade resistente dos pilares, são adotadas algumas simplificações, a saber:

\footnotetext{
$\checkmark$ a dimensão do pilar o caracteriza como pilar curto (são desprezados os efeitos de segunda ordem);

$\checkmark$ admite-se a força de compressão centrada;
}

Na maioria dos projetos, é calculada a força nominal de um pilar usando a lei de adição direta, somando as contribuições de resistência individuais do concreto e do aço. A justificativa para isto é mostrada na figura 2.8, que sobrepõe as curvas de tensão vs. deformação típicas de três concretos (um concreto de alto 
desempenho e dois concretos usuais) e a curva de um aço com $414 \mathrm{MPa}$ de resistência de escoamento, obtidas por meio de ensaios de corpos-de-prova. A curva para o aço foi traçada numa escala diferente a dos concretos por questão de conveniência.

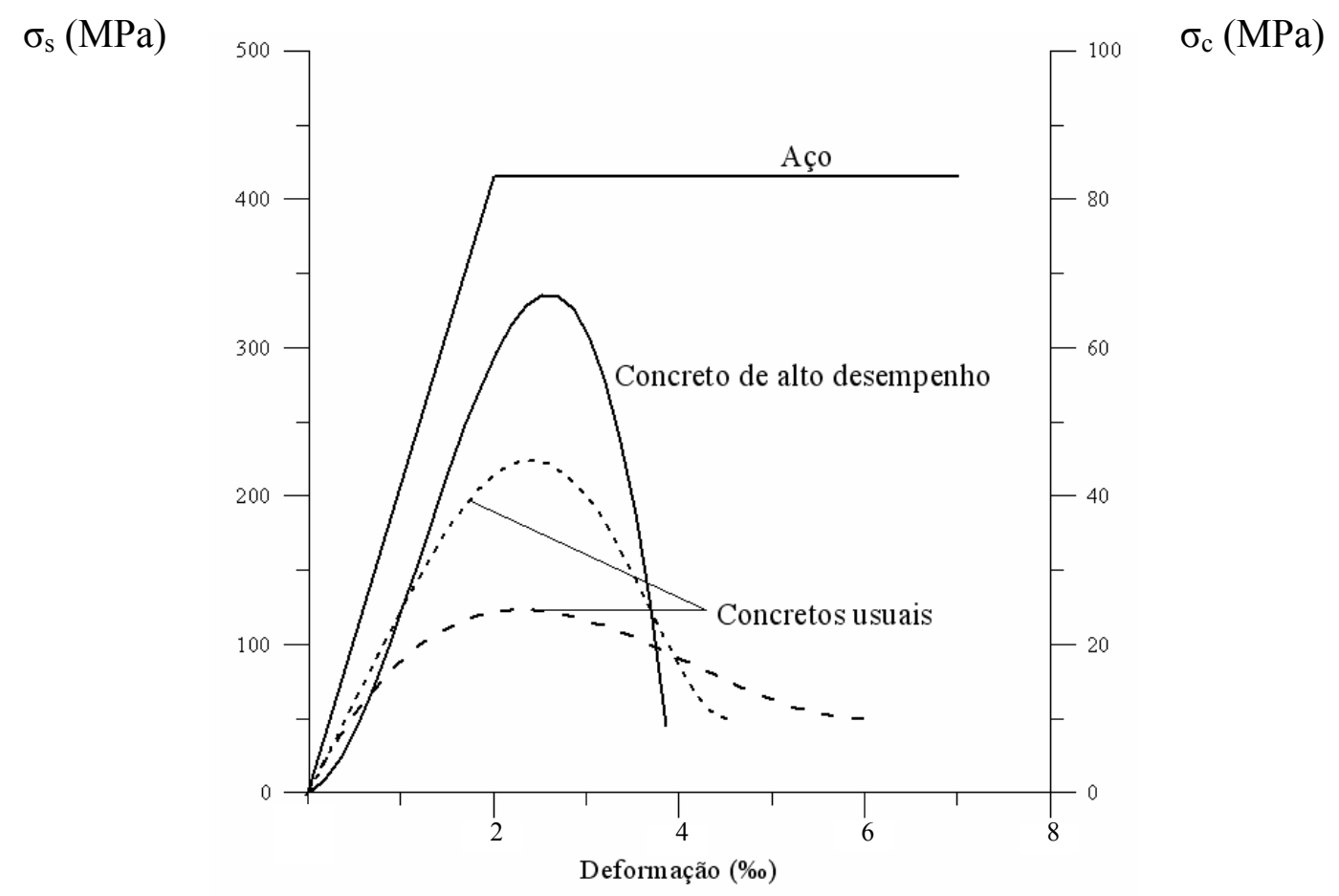

Figura 2.8 - Curvas típicas tensão vs. deformação dos concretos e do aço obtidas em corpos-de-prova (SHAH \& AHMAD, 1994)

Mehta e Monteiro (1993) explicam que até atingir 30\% da força última, o concreto apresenta comportamento elástico-linear, pois a microestrutura está intacta. Para forças a partir deste ponto as curvas mostram um aumento gradual na curvatura $\left(0,75 \cdot f_{c}^{\prime}\right.$ a $\left.0,9 \cdot f_{c}^{\prime}\right)$, logo após atinge o ponto de máximo e decresce rapidamente, caso o elemento não seja dúctil para se deformar sem romper bruscamente.

Shah e Ahmad (1994) afirmam que para os concretos de resistência usual, quando os mesmos atingem um ponto de não-linearidade significativo (aproximadamente na deformação 1\%o), o aço ainda está na fase elástica e, por conseguinte, começa a suportar uma parte maior da ação. Quando a deformação está perto de $2 \%$, o declive da curva do concreto é quase zero, e há pequena 
mudança na tensão. O aço alcança o ponto máximo de rendimento sob esta tensão. Ambos os materiais deformam plasticamente, e a força resistente do pilar pode ser calculada pela expressão 2.11:

$$
\mathrm{F}_{\text {teo }}=0,85 \cdot \mathrm{f}_{\mathrm{c}}^{\prime} \cdot \mathrm{A}_{\mathrm{c}}+\mathrm{f}_{\mathrm{y}} \cdot \mathrm{A}_{\mathrm{s}}
$$

na qual, $f_{c}^{\prime}$ é a resistência do concreto determinada em corpos-de-prova cilíndricos; $\mathrm{f}_{\mathrm{y}}$ é a resistência de escoamento do aço; $\mathrm{A}_{\mathrm{c}}$ é a área da seção de concreto; $\mathrm{A}_{\mathrm{s}}$ é a área total das barras de aço.

Esses autores indicam que o fator 0,85 é usado para considerar a diferença na força do concreto em um pilar comparada com concreto da mesma mistura em um corpo-de-prova cilíndrico.

O mesmo raciocínio foi empregado na década de 80 por Fusco (1981) e Pfeil (1989b). Esses autores determinam a força normal de cálculo em um pilar segundo a expressão 2.12 .

$$
\mathrm{N}_{\mathrm{d}} \leq 0,85 \cdot \mathrm{f}_{\mathrm{cd}} \cdot \mathrm{A}_{\mathrm{cc}}+\mathrm{f}_{\mathrm{sd}} \cdot \mathrm{A}_{\mathrm{s}}
$$

onde,

$$
\mathrm{A}_{\mathrm{cc}}=\mathrm{A}_{\mathrm{c}}-\mathrm{A}_{\mathrm{s}}
$$

$\mathrm{f}_{\mathrm{sd}}$ é a tensão na armadura para uma deformação de $2 \%$, pois na compressão centrada admite-se que o encurtamento da ruptura do concreto seja 2\%o. Para o aço CA-50 $\mathrm{f}_{\text {sd }}$ é igual a 420MPa.

$\mathrm{f}_{\mathrm{cd}}$ é a resistência de cálculo do concreto.

A NBR 6118:2003 faz algumas indicações quanto as dimensões dos pilares e das armaduras e quanto aos espaçamentos mínimos.

O diâmetro da barra de armadura longitudinal não deve ser inferior a $10 \mathrm{~mm}$, nem superior a $1 / 8$ da menor dimensão da seção transversal do pilar. A taxa geométrica deve respeitar o seguinte intervalo:

$$
8 \% \cdot A_{c} \geq A_{s \ell} \geq 0,4 \% \cdot A_{c} .
$$


As armaduras longitudinais devem ser dispostas na seção transversal de forma a garantir a adequada resistência do elemento estrutural. Em seções poligonais, deve existir pelo menos uma barra em cada vértice; em seções circulares, no mínimo seis barras distribuídas ao longo do perímetro.

O espaçamento livre entre as barras da armadura longitudinal, medido no plano da seção transversal, fora da região de emendas, deve ser igual ou superior ao maior dos seguintes valores:

$\checkmark 40 \mathrm{~mm} ;$

$\checkmark \quad$ o diâmetro da barra, do feixe ou da luva;

$\checkmark \quad$ 1,2 vez o diâmetro máximo do agregado.

Para feixes de barras, deve-se considerar o diâmetro do feixe como sendo: $\phi_{\mathrm{n}}=\phi_{\ell} \cdot \sqrt{\mathrm{n}}$, onde $\Phi_{\ell}$ é o diâmetro da barra de armadura longitudinal e n é o número de barras do feixe. Esses valores se aplicam também às regiões de emendas por traspasse das barras.

Quando for previsto no plano de concretagem o adensamento através de abertura lateral na face da forma, o espaçamento das armaduras deve ser suficiente para permitir a passagem do vibrador.

O espaçamento máximo entre eixos das barras, ou de centros de feixes de barras, deve ser menor ou igual a duas vezes a menor dimensão da seção no trecho considerado, sem exceder $400 \mathrm{~mm}$.

A armadura transversal de pilares, constituída por estribos e, quando for o caso, por grampos suplementares, deve ser colocada em toda a altura do pilar, sendo obrigatória sua colocação na região de cruzamento com vigas e lajes.

O diâmetro dos estribos em pilares não deve ser inferior a $5 \mathrm{~mm}$ nem a 1/4 do diâmetro da barra isolada ou do diâmetro equivalente do feixe que constitui a armadura longitudinal.

O espaçamento longitudinal entre estribos, medido na direção do eixo do pilar, para garantir o posicionamento, impedir a flambagem das barras longitudinais e garantir a costura das emendas de barras longitudinais nos pilares usuais deve ser igual ou inferior ao menor dos seguintes valores: 
$\checkmark 200 \mathrm{~mm}$;

$\checkmark$ menor dimensão da seção transversal do pilar;

$\checkmark \quad 24 \cdot \Phi_{\ell}$ para CA-25, $12 \cdot \Phi_{\ell}$ para CA-50.

Pode ser adotado o valor $\Phi_{\mathrm{t}}<\Phi_{\ell} / 4$ desde que as armaduras sejam constituídas do mesmo tipo de aço e o espaçamento respeite também a limitação da equação 2.13 .

$$
\mathrm{S}_{\text {máx }}=9000 \cdot\left(\frac{\phi_{\mathrm{t}}^{2}}{\phi_{\ell}}\right) \cdot \frac{1}{\mathrm{f}_{\mathrm{yk}}}
$$

com $\mathrm{f}_{\mathrm{yk}}$ (resistência característica de escoamento do aço) em MPa.

\subsubsection{Análise experimental de pilares}

Dentre os primeiros ensaios conhecidos com pilares de concreto armado, MÖRSCH (1952) apresenta e comenta alguns deles. Estes ensaios foram realizados no início do século XX por instituições européias como o Laboratório da Universidade Industrial de Stuttgart e o Laboratório Oficial de BerlimGrosslichterfelde.

Em meio aos principais objetivos destas pesquisas, destacou-se a observação do comportamento de pilares sob compressão centrada e a criação de subsídios à formulação de um modelo teórico de cálculo de pilares não cintados e cintados.

Antes de apresentar os ensaios, MÖRSCH (1952) faz questão de alertar para o fato de que mesmo um ensaio de pilar submetido à compressão simples está sujeito a influências perturbadoras, as quais podem tornar contraditórios e incompreensíveis os resultados obtidos. Deste modo, o referido autor descreve os seguintes cuidados que devem ser tomados com o objetivo de minimizar estas influências:

$\checkmark$ as superfícies de compressão dos modelos devem estar totalmente planas e o mais paralelas possíveis para que se permita uma transmissão 
uniforme das forças de compressão e, assim, se evite a ruptura prematura das extremidades do pilar;

$\checkmark$ as placas de aço acopladas a máquina de ensaio devem ficar apoiadas em rótulas, de tal modo que não ocorra solicitação de momento fletor;

$\checkmark$ o pilar deve estar posicionado de modo que a máquina de ensaio aplique uma ação completamente centrada sobre ele;

$\checkmark$ as barras da armadura longitudinal devem estar totalmente retas e seus eixos paralelos ao eixo axial do pilar. Esta medida irá contribuir para que a força solicitante esteja centrada na seção transversal;

$\checkmark$ devem ser evitadas as seções transversais demasiadamente pequenas e, em especial, com armadura longitudinal de diâmetros entre $4 \mathrm{~mm}$ e 10mm (como sugere, também, a NBR 6118:2003). A justificativa está no fato de que os golpes do pistão da máquina de ensaio produzem flexão lateral nas barras longitudinais delgadas que, por sua vez, apresentarão uma convexidade entre os estribos na direção exterior do pilar. Tendo isto ocorrido, desenvolve-se uma pressão lateral sobre o cobrimento de concreto das armaduras que levará ao descolamento deste cobrimento e, conseqüentemente, à ruptura prematura do pilar;

$\checkmark$ devem ser tomados cuidados nos processos de dosagem, cura, lançamento e adensamento do concreto e desforma dos pilares. Isto irá permitir que os modelos previamente especificados para uma mesma resistência do concreto apresentem ao menos valores próximos.

A obtenção do comportamento pós-pico dos pilares de concreto armado, principalmente os com concreto de alta resistência, apresenta algumas dificuldades (PAIVA, 1994; LIMA; GIONGO \& TAKEYA, 1997, QUEIROGA; GIONGO \& TAKEYA, 1999; GUIMARÃES, 1999; LIMA JÚNIOR, 2003). Essas dificuldades residem no controle das deformações do elemento estrutural quando a resistência de pico é atingida. Esse problema pode ser solucionado com a utilização de algumas técnicas diferenciadas de ensaio. 
Inicialmente, pode-se solucionar estes problemas, utilizando-se em vez do controle da força aplicada, o controle do deslocamento imposto. A técnica é bastante simples, e é análoga ao sistema de parafuso como mecanismo de aplicação de força. Esse sistema consiste basicamente em um parafuso como atuador de força, onde a cada giro que é aplicado ao mesmo, este se desloca e aplica uma força ao modelo ensaiado. Uma célula de carga acoplada ao sistema serve com sistema de leitura da força. Ao se atingir a força de colapso do modelo, observa-se que as leituras obtidas da célula de carga vão diminuindo à medida que se gira o parafuso e, ainda, que as deformações do modelo só são incrementadas se o parafuso for girado. O sistema de parafuso é comumente utilizado em máquinas de ensaio com capacidade até $50 \mathrm{kN}$.

Em máquina de ensaio com capacidade de força superior a $50 \mathrm{kN}$, o sistema utilizado é o hidráulico, com controle eletrônico. Um exemplo dessa máquina pode ser encontrado no LE - EESC - USP, marca INSTRON, conforme figura 2.9 .

1 - Máquina INSTRON, capacidade: $2500 \mathrm{kN}$; altura útil de ensaio: $4 \mathrm{~m}$;

2 - Pilar instrumentado;

3 - Sistema de aquisição de dados SYSTEM 5000;

4 e 5 - Controladores da máquina.

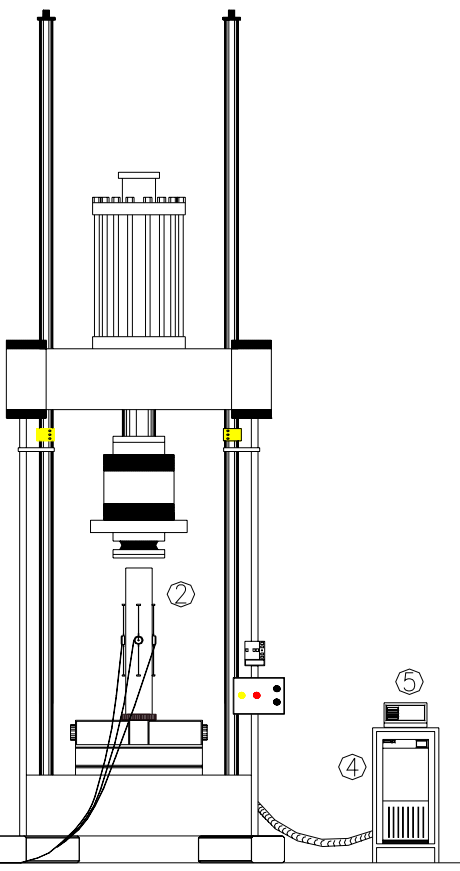

Figura 2.9 - Dispositivo de Ensaio.

Alguns cuidados devem ser tomados com relação à instrumentação nos ensaios de pilares. Inicialmente, observa-se que por ocorrer o desprendimento 
prematuro do cobrimento dos pilares, é comum a perda dos extensômetros elétricos dispostos na sua superfície. Ainda, por conta da flambagem localizada das barras da armadura longitudinal, as leituras dos extensômetros elétricos dispostos nesta armadura, também, ficam comprometidas, a partir de certos valores de deformações, que podem variar entre 5\% e 15\%, como constatado nos ensaios experimentais deste trabalho. Deste modo, alguns pesquisadores costumam utilizar sistemas de colares de aço presos nas duas extremidades dos pilares e nos quais são acoplados LVDTs para medir as deformações do conjunto durante o caminho pós-pico do ensaio (SHEIKH \& UZUMERI, 1980, CUSSON \& PAULTRE, 1993, LIU et alli, 2000). Outros utilizam o deslocamento dos pratos da máquina de ensaio com ou sem o deslocamento do atuador hidráulico (ESSAWY \& EL-HAWARY, 1998). A grande desvantagem desta última técnica é que nestas leituras de deslocamentos, estão inclusos deslocamentos relativos à acomodação do sistema, deformações da máquina de ensaios e deformações por conta do capeamento das extremidades dos pilares, sendo necessárias as correções destes valores, mais tarde, no instante da análise.

São essenciais a perfeita centralização dos modelos na máquina de ensaio e o capeamento de suas extremidades, de modo a evitar excentricidades acidentais e concentrações de tensões, que podem promover a ruína prematura de suas extremidades. Observa-se ainda, a preocupação dos autores com o efeito localizado da transferência da força para as extremidades dos pilares. Essa preocupação reside no fato dessa região estar sujeita a concentrações de tensões que podem vir a apresentar ruptura prematura (LEONHARDT \& MÖNNING, 1978). Algumas metodologias são utilizadas para contornar esse problema, dentre elas está o encamisamento das extremidades dos pilares por chapas metálicas, metodologia esta utilizada por Lloyd e Rangan (1996) e Lima Jr. (2003), como mostrado na figura 2.10. Essa metodologia é ainda eficaz por permitir a colocação da instrumentação (LVDTs) nela, e não colados no pilar como feito nos ensaios de Lima; Giongo e Takeya, (1997), Queiroga; Giongo e Takeya, (1999) e Ramos e Giongo (2002), que ao aparecerem as fissuras nas faces do concreto, estas faziam com que os transdutores colados se 
desprendessem das faces, resultando na perda de dados. Na figura 2.11 é mostrado um dos pilares de Lima Júnior (2003) rompido e os pilares sem as chapas, comprovando a eficiência das mesmas.

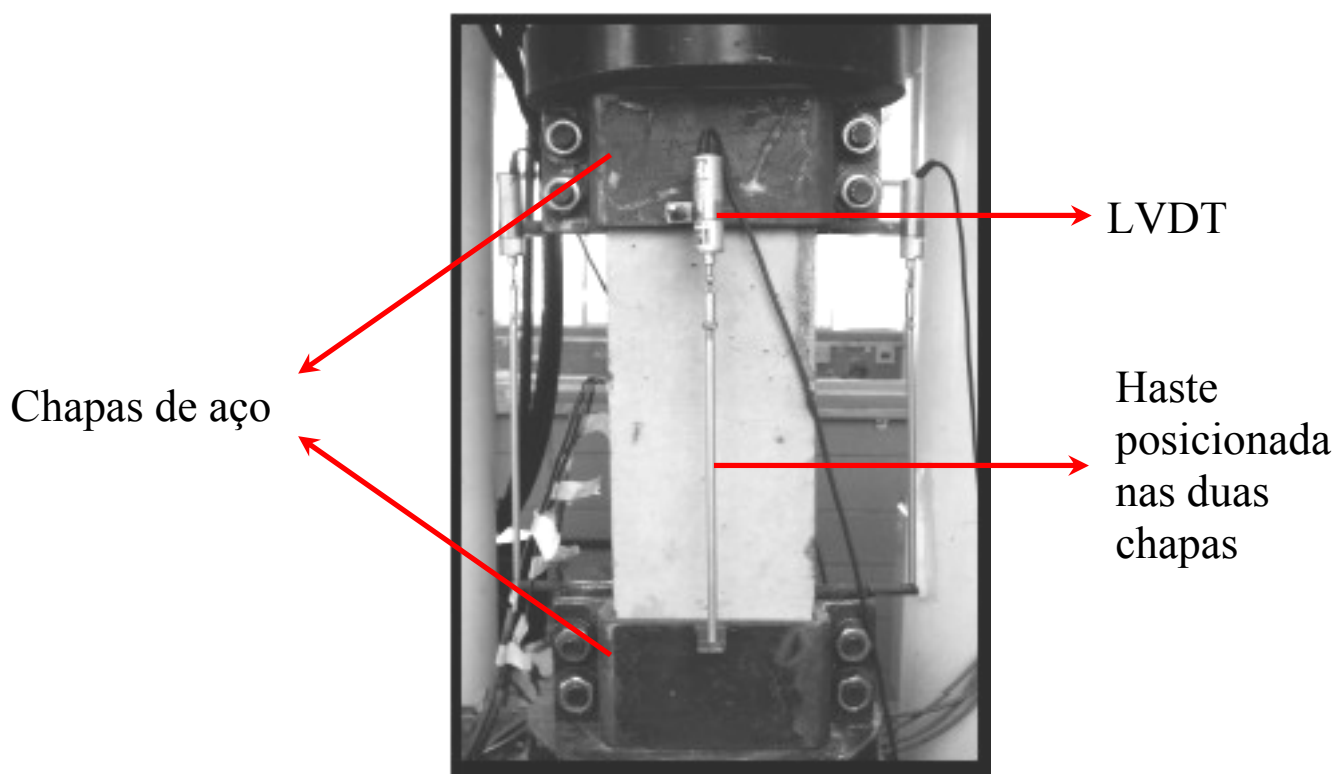

Figura 2.10 - Reforço metálico utilizado para os ensaios de Lima Júnior (2003)

$$
\begin{array}{r}
\text { Pilar durante o } \\
\text { ensaio, } \\
\text { apresenta os } \\
\text { LVDTs ainda } \\
\text { posicionados e } \\
\text { coletando os } \\
\text { dados de } \\
\text { deformação, e } \\
\text { as chapas } \\
\text { impedindo a } \\
\text { destruição das } \\
\text { extremidades. }
\end{array}
$$
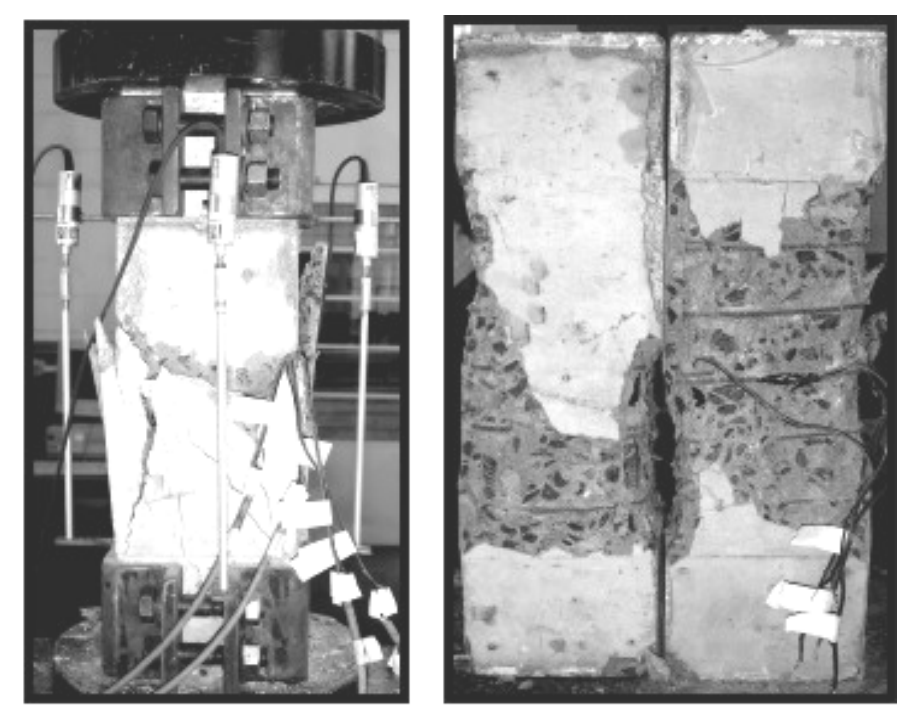

Pilares após serem ensaiados, apresentam suas extremidades intactas, apesar do modelo estar destruído.

Figura 2.11 - Detalhe das extremidades dos pilares durante e após o ensaio de Lima Júnior (2003) 
Outra técnica consiste no alargamento da seção transversal das extremidades dos pilares, como apresentado na figura 2.12. Essa técnica é bastante difundida na literatura por ser simples e de fácil execução (SHEIKH \& UZUMERI, 1980; CUSSON \& PAULTRE, 1992; CUSSON \& PAULTRE, 1994; LIU et alli, 2000).

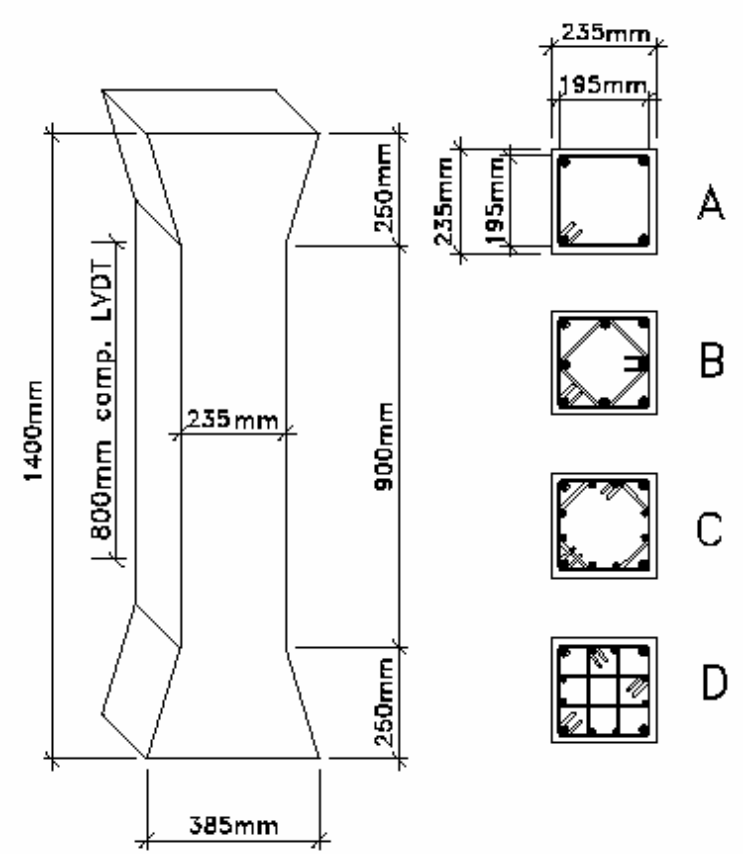

Figura 2.12 - Detalhes do alargamento da seção transversal e dos arranjos de armadura transversal no modelo de Cusson e Paultre (1994)

Finalmente, diversos autores utilizam a metodologia de dispor armadura de fretagem nas extremidades dos pilares (Figura 2.13). O grande problema dessa metodologia deve-se ao fato de que a elevada taxa de armadura transversal prejudica o adensamento do concreto, gerando vazios e conseqüentemente diminuindo a resistência do concreto nesta região. Apesar desse fato, diversos pesquisadores têm utilizado essa metodologia (BJERKELI et alli, 1990; LIMA, 1997; QUEIROGA, 1999; RAZVI \& SAATCIOGLU, 1999; RAMOS, 2001). 


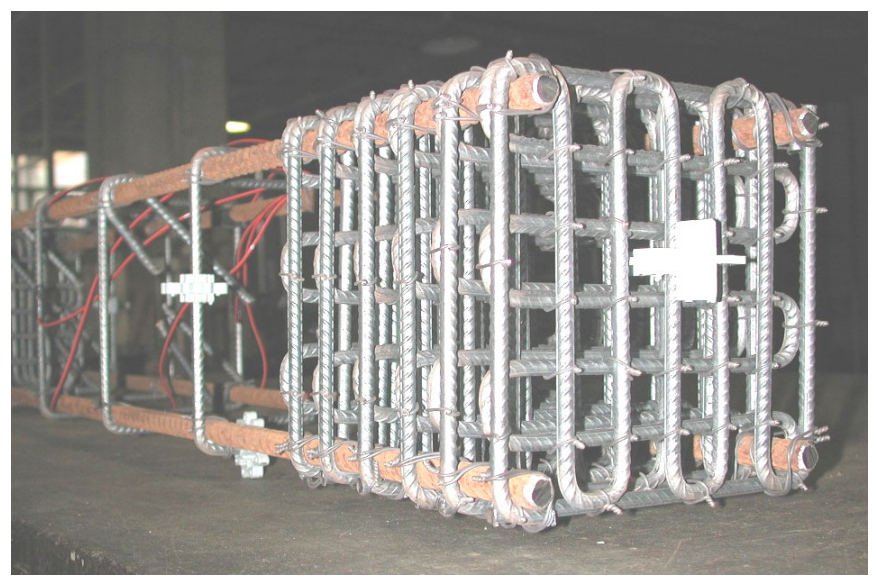

A grande concentração de armadura nessa região dificulta a passagem dos agregados graúdos da massa do concreto, prejudicando a resistência final dessa região.

Figura 2.13 - Armadura de fretagem nas extremidades do pilar.

\subsubsection{Avaliação da ductilidade}

No estudo da ductilidade é comum a utilização de três abordagens: a do material, a do elemento estrutural e a da estrutura. Aqui será enfocado apenas o estudo do material concreto. A ductilidade dos concretos é comumente avaliada por meio do diagrama tensão vs. deformação, obtidos em ensaios de corpos-deprova submetidos à compressão. Em uma comparação rápida e visual dos diagramas tensão vs. deformação dos concretos, quando da elevação da resistência à compressão, observa-se que a parte ascendente torna-se cada vez mais linear, a deformação correspondente a tensão de pico eleva-se e que a capacidade de carga, no trecho descendente, diminui drasticamente. Essas diferenças, nos diagramas, são explicadas pela mudança da estrutura interna do concreto que ocorre com o aumento da resistência à compressão e que modifica completamente o processo de microfissuração desse material.

Ductilidade é uma medida de deformação que indica a capacidade de um corpo deformar-se inelasticamente sem perder de forma brusca a sua capacidade resistente. Esta propriedade é normalmente avaliada por meio do diagrama tensão vs. deformação obtidos em ensaios de corpos-de-prova dos materiais ou modelos estruturais. 
Lima Júnior e Giongo (2001) sugerem que sejam calculados índices que relacionem as deformações elástica e plástica com a deformação de pico, em ambas as fases ascendente e descendente do diagrama tensão-deformação. Isto permitirá saber o quanto as deformações plásticas e elástica são maiores ou menores que a deformação registrada na força máxima e, assim, ter-se-á uma idéia da ductilidade apresentada pelo elemento estrutural. A avaliação foi dividida em pré-pico e pós-pico.

\subsubsection{Pré-pico}

$$
\mathrm{ID}_{\text {pré }}=\frac{\varepsilon_{\mathrm{p}-\mathrm{pré}}}{\varepsilon_{\text {máx }}}
$$

na qual,

$$
\varepsilon_{\mathrm{p}-\mathrm{pré}}=\frac{2 \cdot \int_{0}^{\varepsilon_{\max }} \mathrm{f}\left(\varepsilon_{\mathrm{c}}\right) \mathrm{d} \varepsilon_{\mathrm{c}}}{\mathrm{F}_{\text {máx }}}-\frac{\mathrm{F}_{\text {máx }}}{\mathrm{E}_{\mathrm{c}} \cdot \mathrm{A}_{\mathrm{c}}}
$$

onde, $\varepsilon_{\text {máx }}$ é a deformação correspondente a força última; $\varepsilon_{\text {p-pré é a deformação }}$ plástica de pré-pico; $\mathrm{f}\left(\varepsilon_{\mathrm{c}}\right)$ é o polinômio que representa a curva tensão vs. deformação dos dados experimentais, obtido por meio de uma regressão polinomial sobre esses dados; $\mathrm{F}_{\text {máx }}$ é a força última do elemento estrutural; $\mathrm{A}_{\mathrm{c}}$ é a área da seção transversal do pilar; $\mathrm{E}_{\mathrm{c}}$ é o módulo de elasticidade tangente na origem.

ID pré irá variar de 0 (comportamento elástico-linear) a 2 (comportamento plástico-perfeito).

\subsubsection{Pós-pico}

$\mathrm{O}$ índice de ductilidade correspondente ao ramo descendente do diagrama foi denominado de índice de ductilidade pós-pico e foi definido como sendo o comprimento da base de um retângulo de altura unitária e área igual à área abaixo do ramo descendente do diagrama parametrizado tensão vs. 
deformação do concreto (Figura 2.14). Assim, o índice de ductilidade pós-pico pode ser escrito pela equação 2.16 .

$$
\mathrm{ID}_{\text {pós }}=\frac{\int_{\varepsilon_{\text {max }}}^{\varepsilon_{\mathrm{c} 2}} \mathrm{f}\left(\varepsilon_{\mathrm{c}}\right) \mathrm{d} \varepsilon_{\mathrm{c}}}{\varepsilon_{\text {máx }} \cdot \mathrm{F}_{\text {máx }}}
$$

na qual $\varepsilon_{\mathrm{c} 2}$ é a deformação última de avaliação da ductilidade. Ensaios experimentais mostram que, mesmo com máquinas de ensaio de compressão, com mecanismo de controle de deslocamento, é difícil obter o comportamento do concreto simples e confinado após a deformação correspondente a quatro vezes a deformação correspondente à tensão máxima. Esse fato ocorre porque, a partir dessa deformação, tensões de flexão, fendilhamento e cisalhamento surgem na massa do material. Além disso, o grau de fissuração do concreto é tão elevado que já não se pode considerar o material um meio contínuo. Desse modo, considerou-se, no presente trabalho, a deformação última como sendo o valor relativo a três vezes a deformação correspondente a tensão máxima. A grande vantagem dessa metodologia é que ela leva em consideração todos os pontos do ramo ascendente e descendente do diagrama tensão vs. deformação dos diversos concretos. (LIMA JÚNIOR \& GIONGO, 2001).
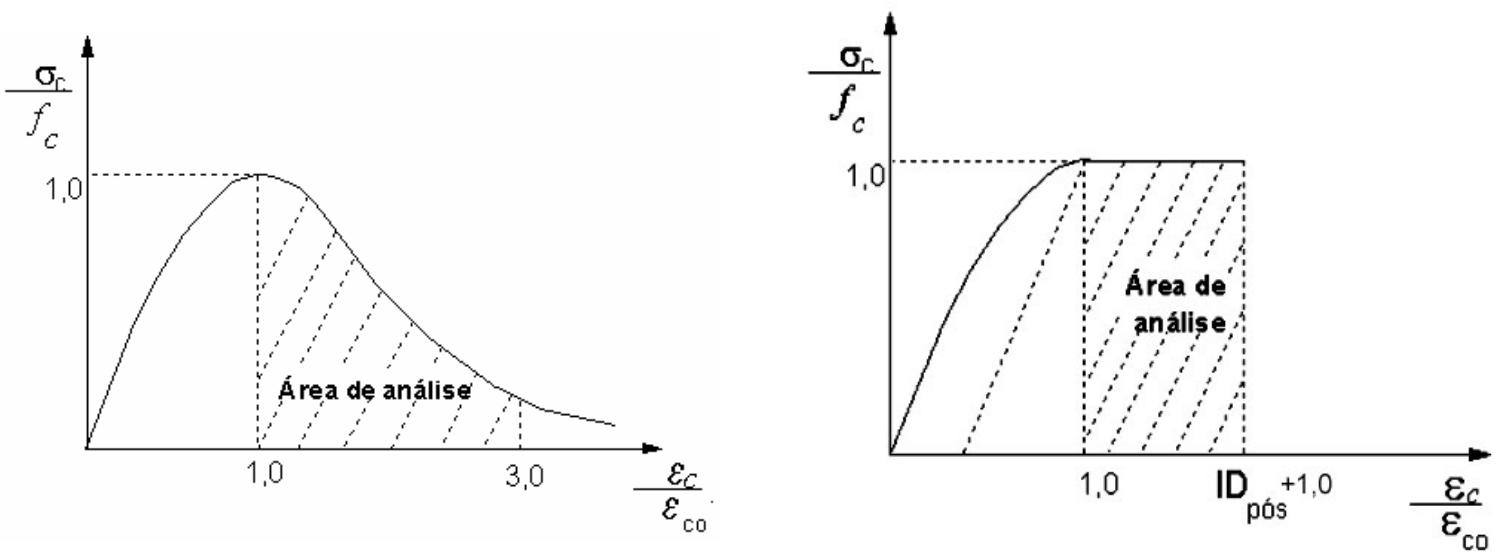

Figura 2.14 - Metodologia do índice de ductilidade pós-pico.

Lima Júnior e Giongo (2001)

IDPós irá variar de 0 (comportamento frágil-perfeito) a 2 (comportamento plástico-perfeito). 


\section{Capítulo 3}

\section{MODELOS PARA O CONCRETO CONFINADO}

\subsection{INTRODUÇÃO}

A busca pelo confinamento do concreto de resistência usual foi um dos principais objetivos das pesquisas realizadas ao longo dos anos com pilares de concreto armado submetidos à compressão centrada. As pesquisas mais recentes sobre o assunto foram realizadas por Mander et alli (1988a), Saatcioglu e Razvi (1992), Cusson e Paultre (1995) e no Brasil, as referências são Agostini (1992) e Paiva (1994).

Nos pilares, o concreto pode ser submetido a um estado tri-axial de tensões, por meio do confinamento por armaduras transversais. Essas armaduras podem ser formadas por estribos com pequeno espaçamento, por tubos metálicos, ou ainda por tubos de materiais compósitos. Em todos esses casos, as armaduras transversais geram um confinamento passivo. Assim, para baixas intensidades de forças, a expansão lateral do concreto é desprezível; conseqüentemente, a armadura transversal é praticamente não-solicitada e o comportamento do concreto é semelhante ao do não-confinado. Com a elevação da força para intensidades da resistência uniaxial do material, o processo de microfissuração se 
intensifica, a expansão lateral do material atinge o valor máximo e, então, a armadura transversal é solicitada intensamente, confinando, desse modo, o concreto.

A armadura de confinamento é muito utilizada em pilares de concreto armado, com o objetivo de aumentar a capacidade resistente e melhorar o seu comportamento no tocante à ductilidade. Cusson e Paultre (1992) explicam que isso acontece pelo fato de a distribuição das tensões de confinamento longitudinalmente, entre os estribos, ser em forma de arco. Desse modo, o espaçamento entre os estribos deixa um volume de concreto sem confinamento, que pode se desprender da peça durante o carregamento da estrutura por causa do gradiente interno de tensões, conforme mostrado na figura 3.1.

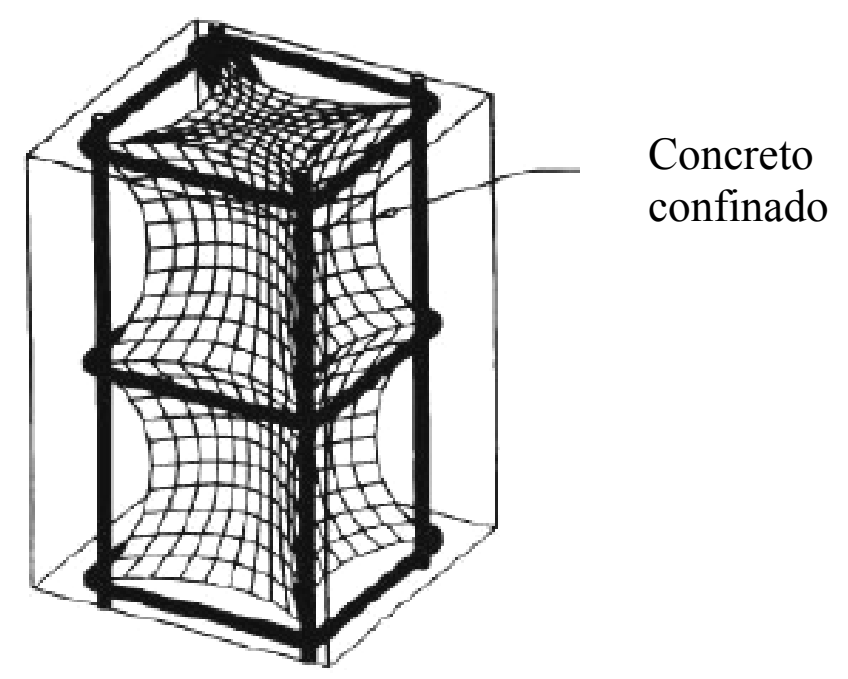

Figura 3.1 - Efeito do espaçamento dos estribos no confinamento do concreto. Cusson e Paultre (1992)

Pela figura anterior, pode-se notar que quando o espaçamento entre os estribos for grande, formar-se-á um volume de concreto sem o efeito do confinamento e mais susceptível à ruptura.

Claeson e Gyltoft (2000) observaram por meio de ensaios de pilares de seção quadrada, que quanto menor for o espaçamento entre os estribos mais eficiente será o efeito do confinamento, melhorando a ductilidade dos pilares. Dessa forma, pode-se diminuir o diâmetro da barra do estribo e o espaçamento 
entre os mesmos, mantendo uma mesma taxa de armadura transversal, obtendo no final um pilar com comportamento mais dúctil.

Mau (1990) estudou o efeito da relação entre o espaçamento dos estribos (s) e o diâmetro da barra da armadura longitudinal $\left(\Phi_{\ell}\right)$, e verificou para três valores de $\mathrm{s} / \Phi_{\ell}$ o comportamento da barra da armadura longitudinal (Figura 3.2).

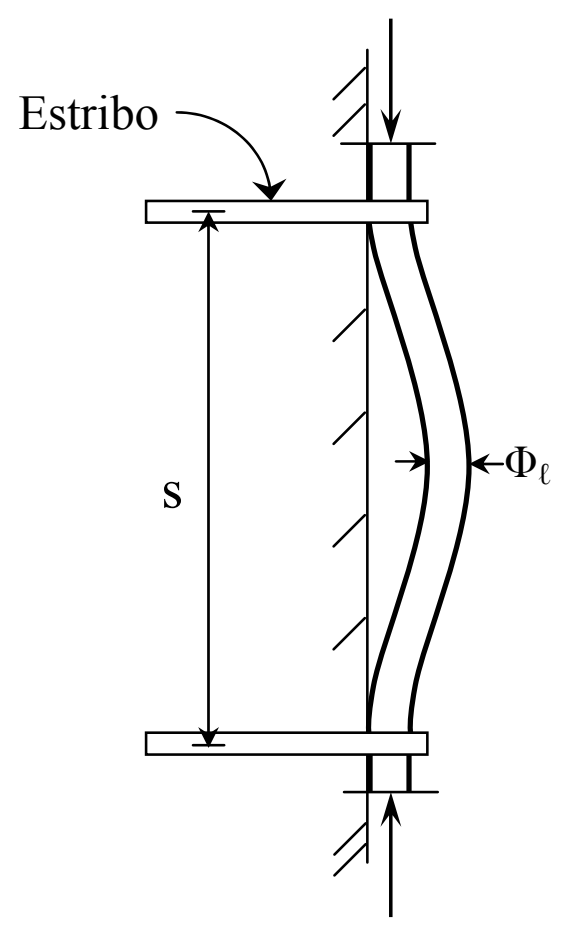

Figura 3.2 - Flambagem da armadura longitudinal entre estribos. (MAU, 1990)

Para $\mathrm{s} / \Phi_{\ell}=5$, a curva tensão vs. deformação da barra no modelo é similar a curva tensão vs. deformação do material isolado. Antes de a força última ser atingida, a capacidade resistente do material pode ser estimada de acordo com a curva tensão vs. deformação do material; para $\mathrm{s} / \Phi_{\ell}=10$, a amarração provocada pelo estribo promove ganho de resistência um pouco acima da força de pico; para $\mathrm{s} / \Phi_{\ell}=15$, após ser atingida a força de pico, o aço perde sua capacidade de carga rapidamente (MAU, 1990).

O ACI-441 (1997) apresenta um diagrama do comportamento de pilares de concreto de alta resistência submetidos à compressão centrada (Figura 3.3). Neste diagrama pode-se observar que o comportamento pós-pico dos pilares é diretamente influenciado pelo confinamento. 


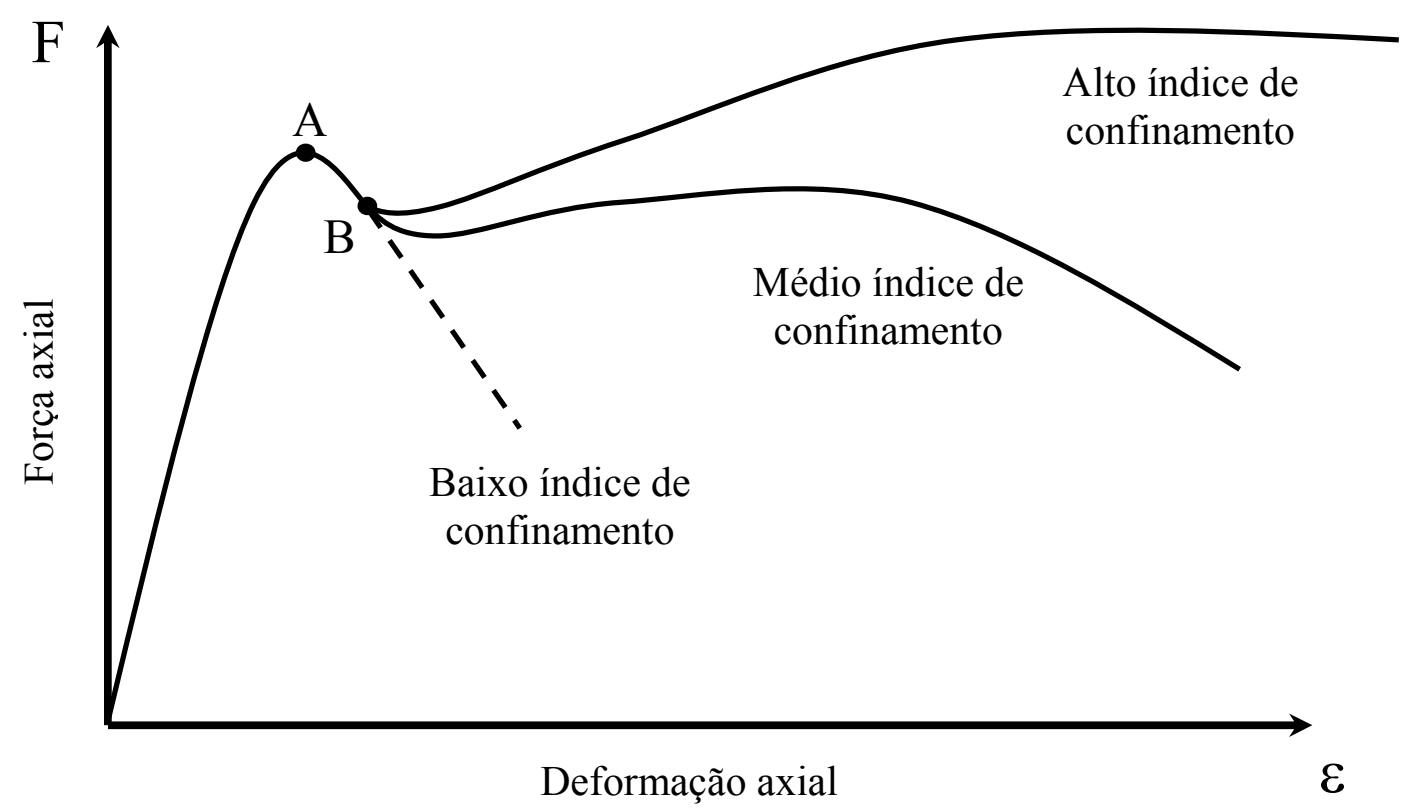

Figura 3.3 - Comportamento esquemático dos pilares de concreto de alta resistência sob compressão centrada. ACI-441 (1997)

O trecho ascendente do diagrama é praticamente linear até aproximadamente $90 \%$ da força máxima, correspondente ao ponto A. Segundo Cusson e Paultre (1994), nesse trecho a armadura de confinamento praticamente não colabora, sendo exigida com $50 \%$ de sua tensão de escoamento. O ponto A corresponde ao descolamento do cobrimento, que ocasiona uma perda de resistência, levando o diagrama ao ponto B. A diferença entre as forças correspondentes aos pontos A e B é influenciada diretamente pela espessura do cobrimento e pela quantidade de armadura transversal, e varia, aproximadamente, entre $10 \%$ e $15 \%$. Após o ponto B, a expansão do concreto atinge seu valor máximo e o comportamento do pilar torna-se função da quantidade de armadura de confinamento.

O descolamento do cobrimento tem sido uma preocupação quando se utiliza concreto de alta resistência em pilares submetidos a compressão centrada ou com pequena excentricidade. $\mathrm{O}$ descolamento do cobrimento ocorre com força inferior a máxima teórica e a capacidade resistente é limitada pela força que provoca o descolamento (FOSTER et alli, 1988; FOSTER, 2001). 
Bae e Bayrak (2003) concordam com a afirmação de Cusson e Paultre (1994) no tocante ao descolamento do cobrimento, e concluem que este fenômeno não afeta os concretos de resistência usual, e sim aos concretos com resistência superior a $60 \mathrm{MPa}$. Esses autores apresentam dois parâmetros de redução da resistência em virtude da ruptura prematura do cobrimento, $\gamma_{1}$ e $\gamma_{2}$, que são associados a força axial e momento, respectivamente. $O$ ponto de descolamento do cobrimento é adotado como sendo a deformação de 2,5\% e sua força correspondente, e o parâmetro relacionado a força axial é calculado com a equação 3.1 .

$$
\gamma_{1}=\frac{\mathrm{F}_{2,5}}{\mathrm{~F}}
$$

na qual, $\mathrm{F}_{2,5}$ é a força correspondente a deformação de 2,5\%; $\mathrm{F}$ é a máxima capacidade resistente do pilar sem considerar o descolamento prematuro do cobrimento.

Sheikh e Uzumeri (1980) dizem que fissuração na interface núcleocobrimento também ocorre nos pilares de concreto de resistência usual, porém, o destacamento não acontece de forma brusca, imediatamente após o início da fissuração. O cobrimento perde sua capacidade resistente de modo gradual durante a ativação do confinamento passivo, não sendo observado o segmento AB no diagrama força axial vs. deformação axial.

\subsection{FATORES INFLUENTES}

\subsubsection{Resistência do concreto}

Segundo Cusson e Paultre (1994), a influência da resistência do concreto está relacionada a dois fatores: ao coeficiente de Poisson e à ductilidade do concreto. Durante a fase elástica dos diagramas tensão de compressão vs. deformação, os coeficientes de Poisson, dos concretos de resistências usual e alta, são da mesma ordem de grandeza. Entretanto, próximo à ruptura, o CAR 
apresenta coeficiente de Poisson menor, isto é, menor expansão lateral, por causa da menor microfissuração interna. Desse modo, a armadura transversal só é solicitada para valores elevados de deformações, superiores aos do concreto de resistência usual, reduzindo, assim, a eficiência do confinamento.

\subsubsection{Cobrimento do concreto}

O ACI-441 (1997) indica que, ao contrário do que ocorre nos pilares de concreto de resistência usual, o cobrimento dos pilares de CAR se destacam antes que a capacidade resistente axial teórica do elemento seja atingida. Esse fato é refletido no diagrama força axial vs. deformação axial do pilar, pela perda de resistência correspondente ao trecho $\mathrm{AB}$ do diagrama (Figura 3.3). $\mathrm{O}$ desprendimento prematuro do cobrimento, segundo Foster et alli (1998) e Foster (2001), é provocado pelo alto volume de armadura transversal, que interrompe a continuidade entre o concreto do núcleo e do cobrimento, gerando, desse modo, uma linha preferencial de falha, que é agravada quando o espaçamento entre os estribos é pequeno.

Por outro lado, Sargin et alli (1971) sugerem que a presença de altas taxas de armadura transversal prejudica a compactação do concreto do cobrimento e, assim, uma maior concentração de ar e água localiza-se nesta região. Esses fatores fazem com que a resistência do concreto do cobrimento seja inferior ao do núcleo, colaborando para sua ruptura prematura.

Foster et alli (1998), por meio de análise com Elementos Finitos, mostraram que as deformações laterais do núcleo são inferiores às do cobrimento, uma vez que a armadura transversal impede a expansão lateral do núcleo (Figura 3.4). Esse gradiente de deformações gera tensões de tração entre o núcleo e o cobrimento, que, quando atinge a resistência à tração do concreto, ocasiona o surgimento de fissuras na interfase núcleo-cobrimento, as quais ocasionam a separação entre as duas partes. Para acontecer o destacamento do cobrimento é preciso não só o surgimento das fissuras, mas também outros 
mecanismos, como a flexão da armadura longitudinal, e a instabilidade lateral a que fica sujeito o cobrimento devido a sua baixa esbeltez.
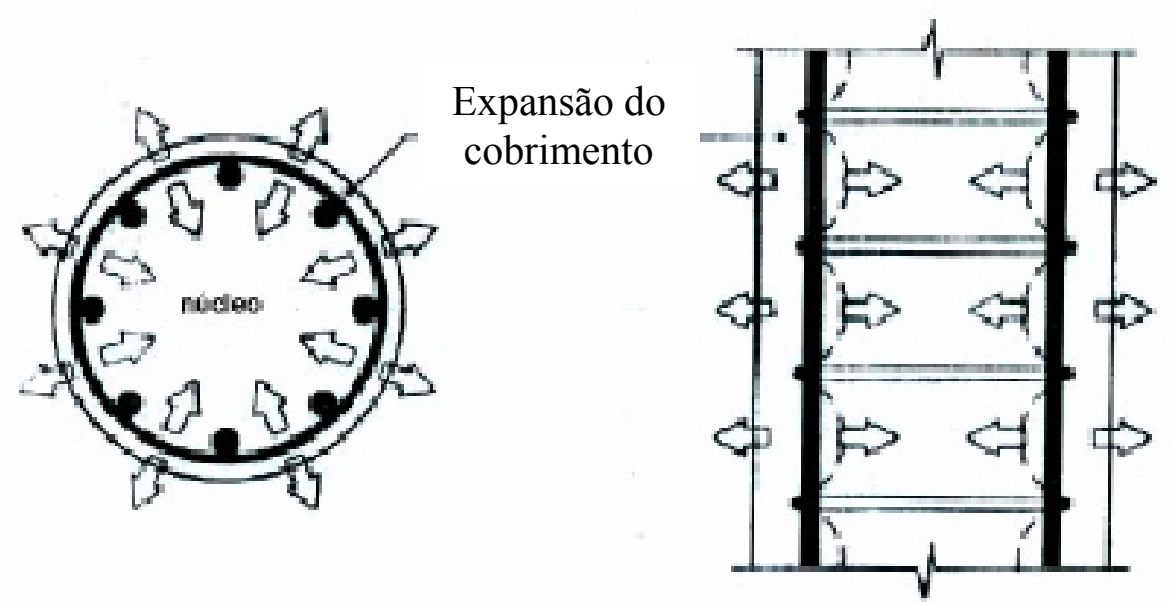

Figura 3.4 - Mecanismo de destacamento do cobrimento. Foster at alli (1998)

Segundo Sheikh e Uzumeri (1980) e Chung et alli (2002), em elementos de concreto com confinamento efetivo do núcleo, o núcleo e o cobrimento apresentam diferentes comportamentos. Antes da aplicação do carregamento, pode ser assumido que as deformações longitudinais, tanto no núcleo, quanto no cobrimento, são iguais. Nos estágios iniciais de carregamento, enquanto as deformações axiais e o efeito Poisson do concreto são pequenos, o confinamento lateral provocado pelas armaduras transversais pode ser desprezado, como resultado, o núcleo e o cobrimento se comportarão de maneira similar. Com o aumento da deformação longitudinal e do efeito Poisson do concreto, a deformação lateral do concreto tende a aumentar, e com isso, começam a aparecer fissuras paralelas as barras de armadura longitudinal do pilar. O núcleo fica confinado pela armadura transversal, havendo separação do cobrimento do concreto. A partir daí o núcleo e o cobrimento seguem diferentes caminhos de deformação. 


\subsubsection{Taxa de armadura transversal}

Diversos pesquisadores relatam que a tensão lateral de confinamento aplicada ao concreto está diretamente relacionada com a taxa de armadura transversal.

As barras da armadura transversal são usadas para promover ductilidade ao pilar de concreto de alta resistência, que tem menor expansão lateral do que o pilar de concreto de resistência usual, dessa forma, apresentam ruptura frágil após a força de pico, com altas deformações nas barras da armadura transversal, assim, é necessária a utilização de uma alta taxa de armadura transversal com aço de alta resistência. (Chung et alli, 2002)

Cusson e Paultre (1992) observaram melhora, tanto na ductilidade, como também na capacidade resistente dos pilares, quando o espaçamento dos estribos era reduzido. O fato é explicado, uma vez que a distribuição das tensões de confinamento longitudinalmente, entre estribos, se dá em forma de arco. Desse modo, quando o espaçamento é elevado, um grande volume de concreto permanece não-confinado e, durante o carregamento da estrutura, este pode se desprender da peça, em virtude do gradiente interno de tensões (Figura 3.5).
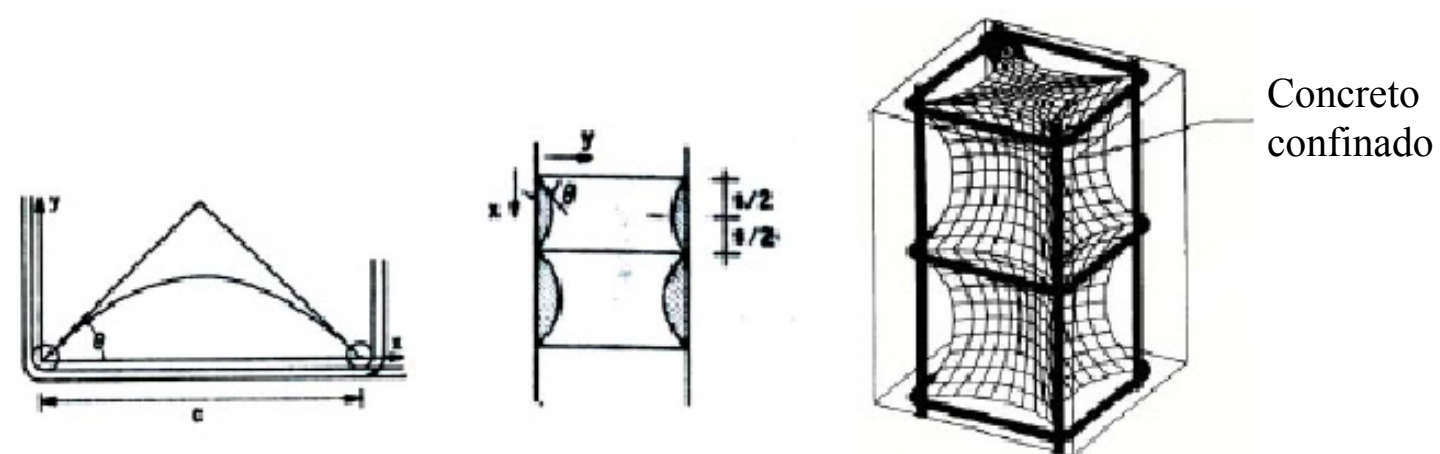

Figura 3.5 - Distribuição das tensões de confinamento nas seções transversais e ao longo do pilar. Sheikh e Uzumeri (1982) 


\subsubsection{Taxa de armadura longitudinal}

Verifica-se que elevadas taxas e diâmetros da armadura longitudinal melhoram a eficiência do confinamento, aumentando o ganho na capacidade resistente e ductilidade dos elementos (CUSSON \& PAULTRE, 1992).

Segundo Sheikh e Uzumeri (1982), a distribuição da armadura longitudinal ao longo do perímetro do núcleo deve ser uniforme e o espaçamento entre as barras pequeno. $\mathrm{O}$ contato entre as barras da armadura longitudinal e os estribos da armadura transversal deve ser garantido, de modo a impedir qualquer movimento de corpo rígido das barras longitudinais.

\subsection{MODELOS TEÓRICOS}

\subsubsection{Chan (1955)}

O estudo da modelagem do concreto confinado teve início em 1955, quando Chan $\left(1955^{3}\right.$ apud Sheikh, 1982) propôs equações para avaliar a resistência do concreto confinado e sua deformação. Ele sugeriu um diagrama tensão vs. deformação tri-linear em que o trecho ascendente do diagrama fosse modelado por trechos lineares, cujas inclinações diminuíam em função de um coeficiente $\lambda_{\mathrm{i}}$ que multiplicava o módulo de elasticidade tangente na origem, como mostrado na figura 3.6.

\footnotetext{
${ }^{3}$ CHAN, W.W.L. (1955). The ultimate strength and deformation of plastic hinges in reinforced concrete framework. Magazine of Concrete Research, v.7, n.21, p.121-132.
} 


\subsubsection{Roy e Sozen (1964)}

Em 1964, Roy e Sozen (1964 ${ }^{4}$ apud Sheikh, 1982) propuseram um modelo em que o concreto confinado era representado por um diagrama com dois trechos lineares (Figura 3.7), um ascendente e outro descendente. Eles estudaram modelos com até $25 \mathrm{MPa}$ de resistência à compressão e submetidos à compressão axial, e concluíram que o confinamento obtido por meio dos estribos não promovia um acréscimo na resistência do modelo. Eles sugeriram que a avaliação da ductilidade pós-pico fosse feita no ponto de deformação correspondente a $50 \%$ da tensão máxima suportada no trecho descendente.

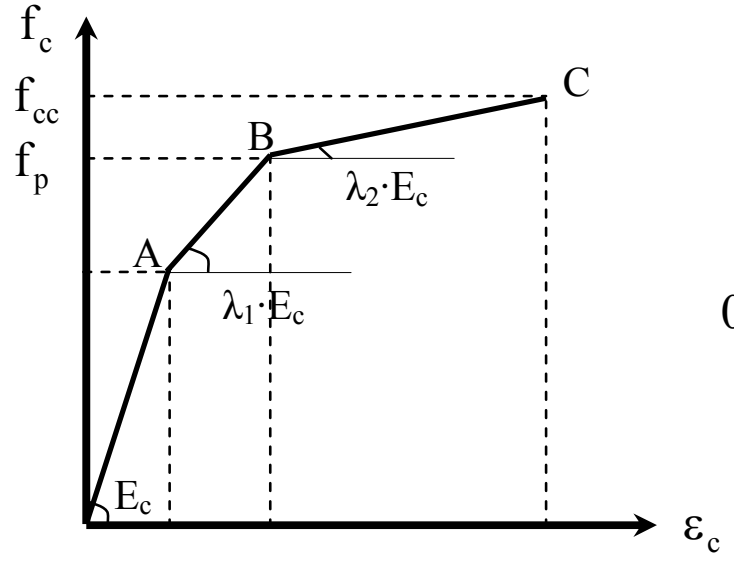

Figura 3.6 - Modelo proposto por Chan (1955)

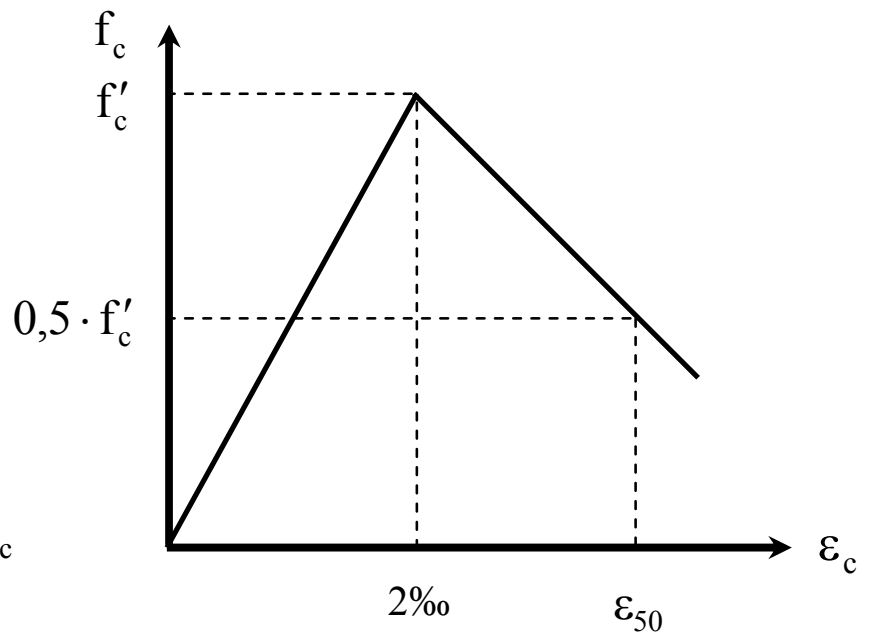

Figura 3.7 - Modelo proposto por Roy e Sozen (1964)

\subsubsection{Sargin et alli (1971)}

Em 1971, Sargin et alli (1971) apresentaram quatro equações para modelar o comportamento do concreto confinado. Três dessas equações eram utilizadas para calcular a tensão máxima do concreto confinado e a outra para a respectiva deformação. Essas equações foram obtidas por meio da análise de

\footnotetext{
${ }^{4}$ ROY H.E.H.; SOZEN, M.A. (1964). Ductility of concrete. American Concrete Institute SP-12. Detroit. p.213-224.
} 
regressão dos resultados experimentais de ensaios realizados em pilares com dimensões $127 \mathrm{~mm} \times 127 \mathrm{~mm} \times 635 \mathrm{~mm}$, submetidos à compressão centrada e excêntrica. As variáveis consideradas nas equações citadas foram: a taxa volumétrica de armadura transversal, a resistência de escoamento das barras de aço da armadura transversal, a resistência do concreto medida em corpos-deprova cilíndricos e a relação entre o espaçamento da armadura transversal e a largura do núcleo de concreto. Na Figura 3.8, é apresentado o diagrama tensão vs. deformação para o concreto confinado proposto pelos autores.

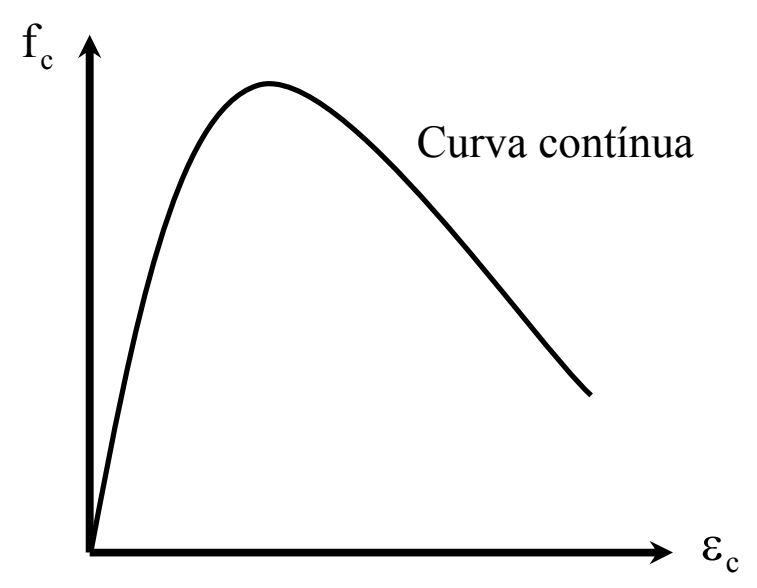

Figura 3.8 - Modelo proposto por Sargin et alli (1971)

\subsubsection{Kent e Park (1971)}

Kent e Park (1971) desenvolveram um modelo para o concreto confinado utilizando estribos circulares e retangulares. Esse modelo é conservativo no tocante a capacidade resistente do elemento estrutural, pois não leva em consideração o acréscimo de resistência por causa do confinamento, garantindo apenas a ductilidade da estrutura. A curva proposta é mostrada na figura 3.9. Essa curva é dividida em três partes, o trecho $\mathrm{AB}$ é uma parábola que compreende o trecho ascendente do diagrama até a deformação de $2 \%$. O trecho $\mathrm{BC}$, que caracteriza o efeito do confinamento, é caracterizado pelo ajuste da inclinação da reta no trecho, e vai da deformação $2 \%$ até $\varepsilon_{20 c}$ (deformação correspondente a 
$20 \%$ da tensão máxima suportada, anotada no trecho descendente). O último trecho corresponde as deformações superiores a $\varepsilon_{20 \mathrm{c}}$.

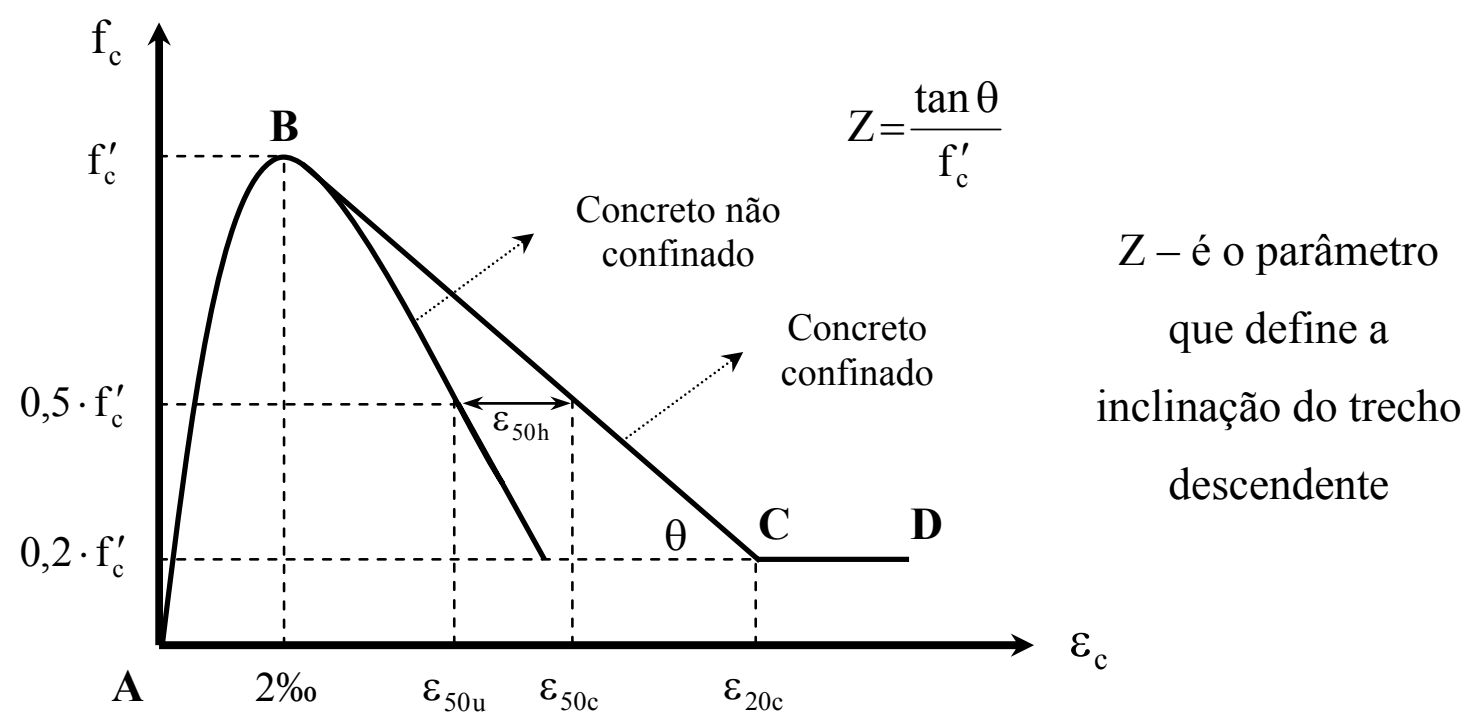

Figura 3.9 - Modelo proposto por Kent e Park (1971)

\subsubsection{Park et alli (1982)}

Esse modelo foi ajustado em 1982 por Park et alli (1982), que introduziram o acréscimo da resistência do concreto em virtude do confinamento. Contudo, esse novo modelo não leva em consideração a distribuição das armaduras longitudinais no comportamento do concreto confinado. A parte ascendente do diagrama é uma parábola que vai até a máxima tensão suportada pelo concreto confinado, que depende apenas da taxa volumétrica de armadura transversal e da resistência dos materiais (Figura 3.10). O trecho descendente é similar ao modelo anterior. 


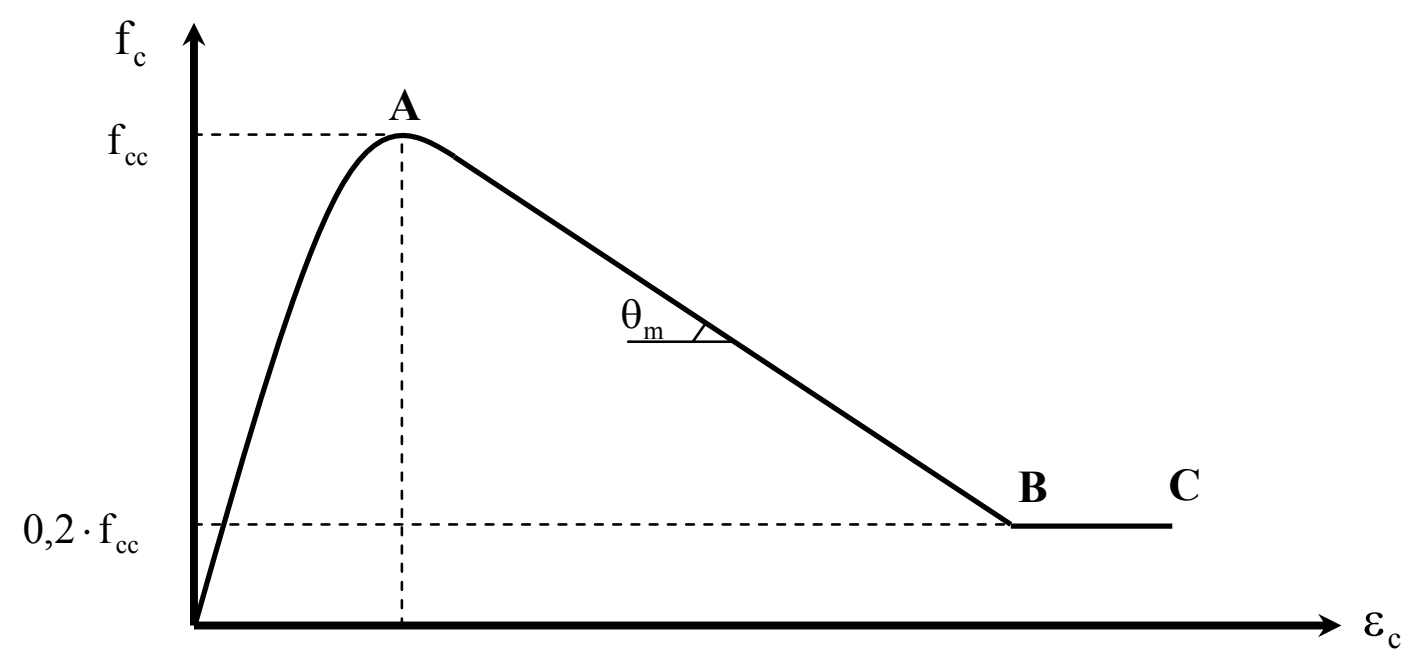

Figura 3.10 - Modelo proposto por Park et alli (1982)

\subsubsection{Sheikh e Uzumeri (1982)}

Ainda em 1982, Sheikh e Uzumeri (1982) apresentaram um modelo que se aplicava apenas a seções transversais confinadas por estribos quadrangulares ou retangulares, e, por meio do ajuste da tensão máxima por um coeficiente, o efeito do confinamento era incorporado ao diagrama tensão vs. deformação do concreto não confinado.

O diagrama tensão vs. deformação proposto (Figura 3.11) é composto por quatro trechos. $\mathrm{O}$ trecho $\mathrm{OA}$ é assumido como sendo uma parábola, com o ponto A limitado a tensão $\mathrm{f}_{\mathrm{cc}}\left(\mathrm{k}_{\mathrm{s}} \cdot \mathrm{f}_{\mathrm{cp}}\right)$ e a deformação $\varepsilon_{\mathrm{s} 1}$, com $\mathrm{f}_{\mathrm{cc}}$ sendo a resistência do concreto confinado, $\mathrm{k}_{\mathrm{s}} \mathrm{o}$ fator de aumento da resistência à compressão do concreto não confinado, $f_{c}$ é a resistência à compressão do concreto e $\varepsilon_{\mathrm{s} 1}$ é a deformação mínima correspondente à tensão máxima. $\mathrm{O}$ trecho $\mathrm{AB}$ é delimitado pela máxima deformação correspondente à tensão máxima. $\mathrm{O}$ ponto $\mathrm{C}$ é definido para uma tensão de $0,85 \cdot \mathrm{f}_{\mathrm{cc}}$ e o trecho $\mathrm{BD}$ limita-se à deformação correspondente a tensão de $0,3 \cdot f_{\mathrm{cc}}$. A partir do ponto $\mathrm{D}$ admite-se um comportamento com tensão constante. 


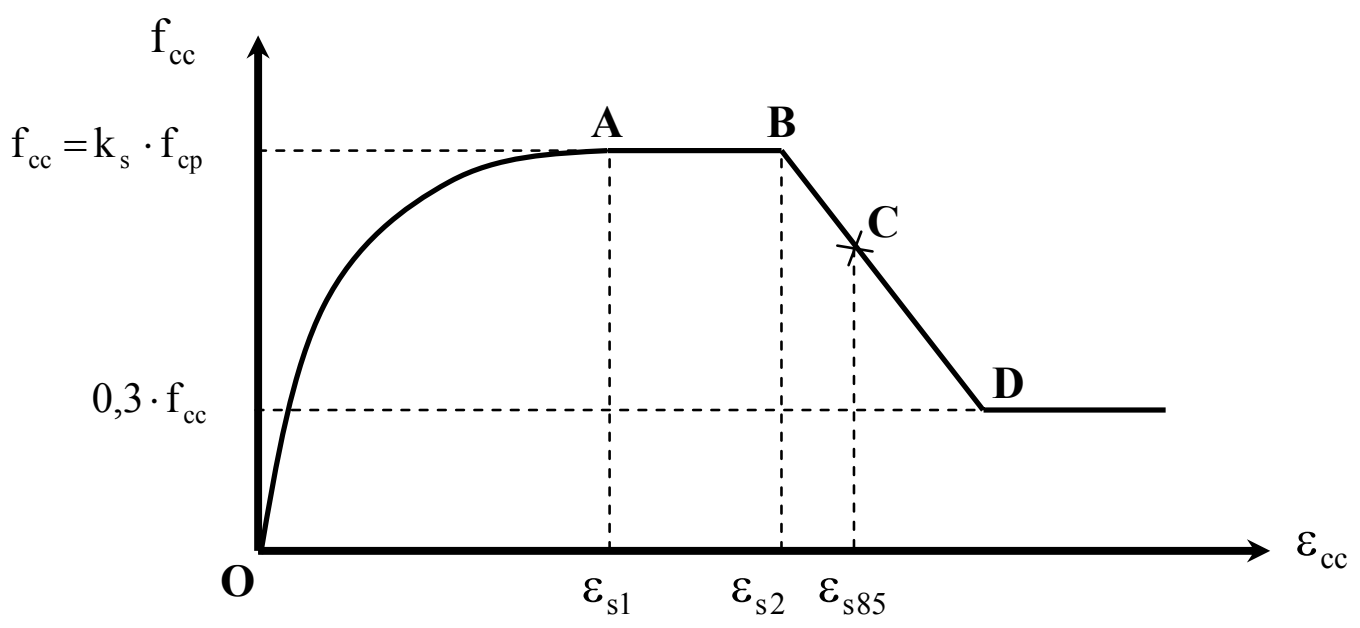

Figura 3.11 - Modelo proposto por Sheikh e Uzumeri (1982)

\subsubsection{Mander et alli (1988a)}

Mander et alli (1988a) utilizaram o conceito de área efetivamente confinada, introduzido por Sheikh e Uzumeri (1982), para calcular a pressão de confinamento efetiva na seção de concreto. Este conceito foi generalizado para seções circulares e retangulares com taxas iguais, ou não, de aço nas duas direções ortogonais.

A curva de tensão vs. deformação proposta (Figura 3.12) é representada por uma equação sugerida por Popovics (1973). A forma da curva é determinada pelo módulo de elasticidade secante à tensão de pico do concreto confinado e pela deformação de pico do concreto confinado $\left(\varepsilon_{\mathrm{cc}}\right)$. Dados de compressão axial, obtidos em vários pilares de concreto altamente confinado, foram usados no desenvolvimento do modelo. 


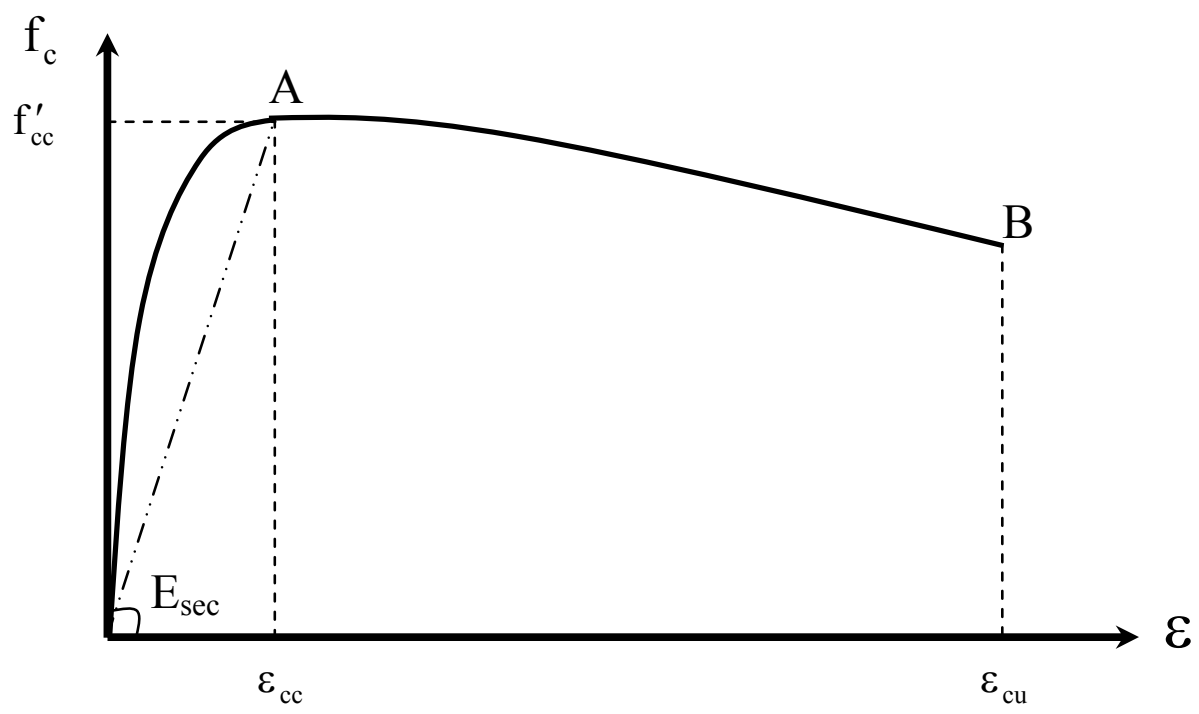

Figura 3.12 - Modelo proposto por Mander et alli (1988a)

\subsubsection{Saatcioglu e Razvi (1992)}

Na década de 90, Saatcioglu e Razvi (1992) desenvolveram um modelo para concreto de resistência usual que pode ser aplicado à seções quadradas, circulares e retangulares, sendo que para essa última a pressão equivalente de confinamento é calculada para a direção da maior e menor dimensão separadamente. Este modelo baseia-se em um longo programa experimental, assim como os outros modelos anteriormente citados.

Em 1999, Razvi e Saatcioglu (1999), aperfeiçoaram o modelo de 1992, incluindo os concretos de alta resistência e fazendo modificações no equacionamento, mas o diagrama proposto é o mesmo.

A curva tensão vs. deformação proposta é formada por uma parábola no trecho ascendente e um trecho linear descendente. A inclinação do trecho descendente é função do ponto correspondente a $85 \%$ da tensão de pico, como mostrado na figura 3.13 . 


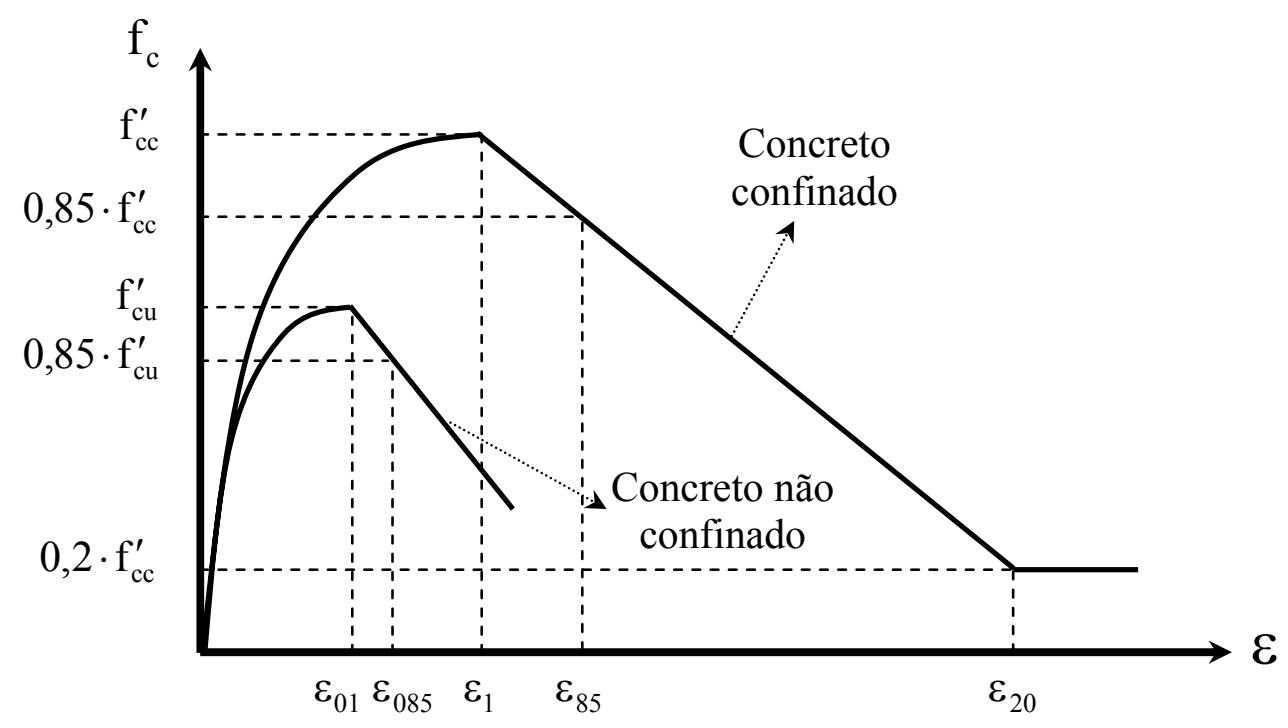

Figura 3.13 - Modelo proposto por Saatcioglu e Razvi (1992)

\subsubsection{Cusson e Paultre (1995)}

O programa computacional que é utilizado nesta dissertação baseia-se no modelo proposto por Cusson e Paultre (1995) e que foi modificado por Lima Júnior (2003). O modelo original foi fruto de um programa experimental onde foram ensaiados 50 pilares, sendo que 30 foram ensaiados por Cusson e Paultre (1994) e 20 por Nagashima et alli (1992). O modelo original é limitado a pilares de seção quadrada.

O trecho ascendente (OA) do diagrama tensão vs. deformação proposto (Figura 3.14), é descrito por uma equação proposta por Popovics (1973) equação 3.2 .

$$
\frac{\sigma_{\mathrm{c}}}{\mathrm{f}_{\mathrm{cc}}}=\frac{\beta \cdot\left(\frac{\varepsilon_{\mathrm{c}}}{\varepsilon_{\mathrm{cc}}}\right)}{(\beta-1)+\left(\frac{\varepsilon_{\mathrm{c}}}{\varepsilon_{\mathrm{cc}}}\right)^{\beta}}
$$


na qual, $\varepsilon_{\mathrm{c}}$ é a deformação em um ponto qualquer do diagrama, $\varepsilon_{\mathrm{cc}}$ é a deformação correspondente à tensão máxima e $\beta$ é um coeficiente expresso pela equação 3.3 .

$$
\beta=\frac{E_{c}}{E_{c}-\left(\frac{f_{c c}}{\varepsilon_{c c}}\right)}
$$

Para o trecho descendente $(\mathrm{ABC})$ utiliza-se uma equação proposta por Fafitis e Shah (1985) - equação 3.4.

$$
\frac{\sigma_{\mathrm{c}}}{\mathrm{f}_{\mathrm{cc}}}=\exp \left[\mathrm{k}_{11} \cdot\left(\varepsilon_{\mathrm{c}}-\varepsilon_{\mathrm{cc}}\right)^{\mathrm{k}_{22}}\right]
$$

na qual $\mathrm{k}_{11}$ é o coeficiente responsável pela inclinação da curva, tendo sido ajustado para passar pelo ponto $\left(\varepsilon_{\mathrm{c} 50 \mathrm{c}}, 0,5 \cdot \mathrm{f}_{\mathrm{cc}}\right)$ e $\mathrm{k}_{22}$ é um coeficiente que foi obtido por análise de regressão e é responsável pela curvatura. Esses coeficientes são calculados pelas equações 3.5 e 3.6 , a seguir.

$$
\begin{aligned}
& \mathrm{k}_{11}=\frac{\ell \mathrm{n}(0,5)}{\left(\varepsilon_{\mathrm{c} 50 \mathrm{c}}-\varepsilon_{\mathrm{cc}}\right)^{\mathrm{k}_{22}}} \\
& \mathrm{k}_{22}=0,58+16 \cdot\left(\frac{\mathrm{f}_{\ell \mathrm{e}}}{\mathrm{f}_{\mathrm{c}}}\right)^{1,4}
\end{aligned}
$$

na qual, $\mathrm{f}_{\ell_{\mathrm{e}}}$ é a pressão efetiva de confinamento. 


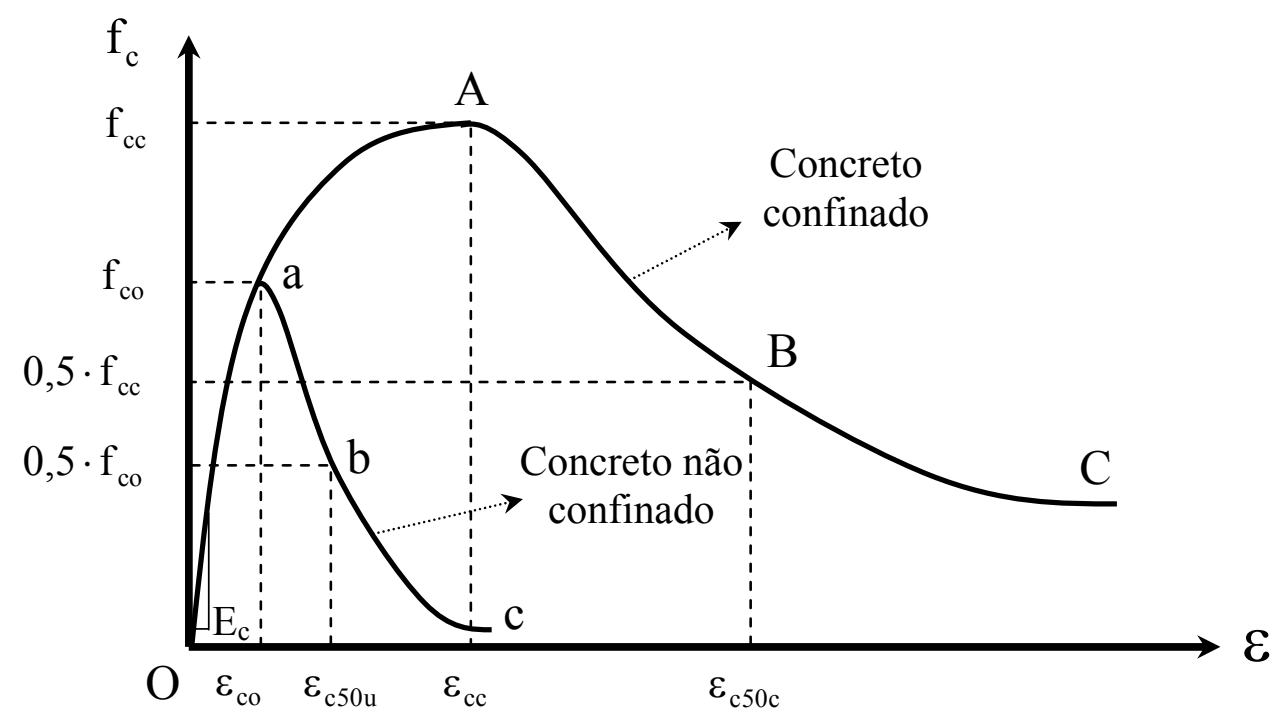

Figura 3.14 - Modelo proposto por Cusson e Paultre (1995)

Legeron e Paultre (2003) criaram um processo iterativo para determinar a deformação da armadura de confinamento no instante em que o modelo atinge a força de pico.

O novo modelo baseia-se em um longo programa experimental, no qual foram tomados dados experimentais de trabalhos publicados em décadas anteriores (SHEIKH \& UZUMERI, 1980; NAGASHIMA et alli, 1992; CUSSON \& PAULTRE, 1994), entre outros, totalizando 210 pilares com seções quadrada e circular, submetidos à compressão centrada.

A curva tensão vs. deformação sugerida por Legeron e Paultre (2003) é a mesma sugerida por Cusson e Paultre (1995), mas o modelo de Legeron e Paultre (op. cit.) é aplicável a pilares de seção quadrada ou circular, feitos com concreto de resistência usual ou de alta resistência, e com armadura de confinamento feita com aço de resistência normal ou de alta resistência. 


\subsection{ModificaÇão do Modelo de Cusson e Paultre (1995) POR LIMA JÚNIOR (2003)}

Lima Júnior (2003), modificou o modelo de Cusson e Paultre (1995). Os trechos, ascendente e descendente, continuam sendo regidos pelas equações de Popovics (1973) e Fafitis e Shah (1985), respectivamente.

Para o modelo, a resistência do concreto nas estruturas deve ser calculada a partir da equação 3.7 .

$$
\mathrm{f}_{\mathrm{c}}=\mathrm{k}_{\text {mod }} \cdot \mathrm{f}_{\mathrm{cj}}
$$

na qual $f_{c j}$ é a resistência medida por meio de ensaio em corpos-de-prova cilíndricos $15 \mathrm{~cm} \times 30 \mathrm{~cm}$ e $\mathrm{k}_{\bmod }$ é um coeficiente calculado de acordo com a equação 2.2 .

Para realizar as modificações no modelo de Cusson e Paultre (1995), foi utilizada a equação 2.3, que leva em conta a estimativa da resistência do concreto na estrutura, quando avaliadas por meio dos corpos-de-prova cilíndricos.

Para o modelo de Cusson e Paultre (1995), foram realizados ensaios de pilares com altas taxas de confinamento e com isso foi obtida a equação 3.6. Para os modelos ensaiados por Lima Júnior (2003) as taxas de armaduras transversais não ultrapassavam as utilizadas por Cusson e Paultre (op. cit.), e algumas taxas eram as mínimas permitidas pela NBR 6118:2003.

Assim, Lima Júnior (2003), verificou uma incoerência no modelo de Cusson e Paultre (1995). Cusson e Paultre (op. cit.) calculam o coeficiente $\mathrm{k}_{22}$ segundo a equação 3.6 e sugeriram o valor de 1,5 para o valor desse coeficiente quando o concreto não possuir confinamento, ou seja a relação $\frac{\mathrm{f}_{\ell \mathrm{e}}}{\mathrm{f}_{\mathrm{c}}}=0$. Ao substituir $\frac{\mathrm{f}_{\ell \mathrm{e}}}{\mathrm{f}_{\mathrm{c}}}=0$, encontra-se $\mathrm{k}_{22}=0,58$.

Dessa maneira, acrescentando alguns pontos com baixas taxas de confinamento aos de Cusson e Paultre (1995), e fazendo uma regressão 
polinomial de segundo grau, foi obtida a equação 3.8, com coeficiente de correlação, $\mathrm{r}^{2}$, de $92 \%$.

$$
\mathrm{k}_{22}=1,344-8,864 \cdot\left(\frac{\mathrm{f}_{\ell \mathrm{e}}}{\mathrm{f}_{\mathrm{c}}}\right)+41,455 \cdot\left(\frac{\mathrm{f}_{\ell \mathrm{e}}}{\mathrm{f}_{\mathrm{c}}}\right)^{2}+0,525 \cdot \mathrm{R}^{0,789}
$$

na qual, $\mathrm{R}$ é o índice de reforço relativo a adição de fibras de aço. Para esta dissertação, considera-se $\mathrm{R}=0$.

O diagrama tensão vs. deformação resultante das modificações feitas, é traçado seguindo os seguintes passos:

1. considera-se a seção transversal resistente do pilar como sendo a seção íntegra, ignorando-se o efeito do confinamento;

2. considera-se a seção transversal resistente do pilar como sendo apenas a seção do núcleo do pilar delimitada pelos ramos mais externos dos estribos, e a pressão lateral de confinamento deve ser calculada considerando a deformação da armadura transversal dada pela equação 3.9;

3. o diagrama resultante será formado pelas linhas externas dos dois diagramas obtidos nos procedimentos 1 e 2 .

$$
\varepsilon_{\mathrm{tcc}}=v \cdot \varepsilon_{\mathrm{cc}}-\left(\frac{\mathrm{f}_{\ell \mathrm{e}}-v \cdot \mathrm{f}_{\ell \mathrm{e}}}{\mathrm{E}_{\mathrm{secc}}}\right)
$$

na qual, $\varepsilon_{\text {tcc }}$ é a deformação na armadura transversal, $v$ é o coeficiente de Poisson do concreto confinado, no ponto correspondente à máxima tensão e que pode ser tomado como 0,$5 ; \mathrm{E}_{\mathrm{secc}}$ é o módulo de elasticidade secante no ponto de máxima tensão do concreto confinado; $\mathrm{f}_{\ell \mathrm{e}}$ é a pressão efetiva de confinamento, dada pela equação 3.10:

$$
\mathrm{f}_{\ell \mathrm{e}}=\mathrm{K}_{\mathrm{e}} \cdot \mathrm{f}_{\ell}
$$


onde,

$$
\mathrm{K}_{\mathrm{e}}=\frac{\left(1-\frac{\sum_{\mathrm{i}} \mathrm{w}_{\mathrm{i}}^{2}}{6 \cdot \mathrm{c}_{\mathrm{x}} \cdot \mathrm{c}_{\mathrm{y}}}\right) \cdot\left(1-\frac{\left(\mathrm{s}-\phi_{\mathrm{t}}\right)}{2 \cdot \mathrm{c}_{\mathrm{x}}}\right) \cdot\left(1-\frac{\left(\mathrm{s}-\phi_{\mathrm{t}}\right)}{2 \cdot \mathrm{c}_{\mathrm{y}}}\right)}{1-\rho_{\ell}}
$$

e,

$$
\mathrm{f}_{\ell}=\frac{\mathrm{f}_{\mathrm{tcc}}}{\mathrm{s}} \cdot\left(\frac{\mathrm{A}_{\mathrm{stx}}+\mathrm{A}_{\mathrm{sty}}}{\mathrm{c}_{\mathrm{x}}+\mathrm{c}_{\mathrm{y}}}\right)
$$

nas quais $\mathrm{f}_{\text {tcc }}$ é a tensão na armadura transversal de confinamento; s é a distância de centro a centro entre estribos; $\mathrm{A}_{\text {stx }}$ e $\mathrm{A}_{\text {sty }}$ são as áreas da seção transversal das armaduras de confinamento, perpendiculares aos eixos x e y, respectivamente; $c_{x}$ e $c_{y}$ são as larguras do núcleo do pilar, nas direções x e y, respectivamente; $w_{i}$ são os espaços entre as armaduras longitudinais; $\phi_{\mathrm{t}}$ é o diâmetro dos estribos; e $\rho_{\ell}$ é a taxa de armadura longitudinal, em relação ao núcleo do pilar.

O diagrama resultante é representado na figura 3.15.

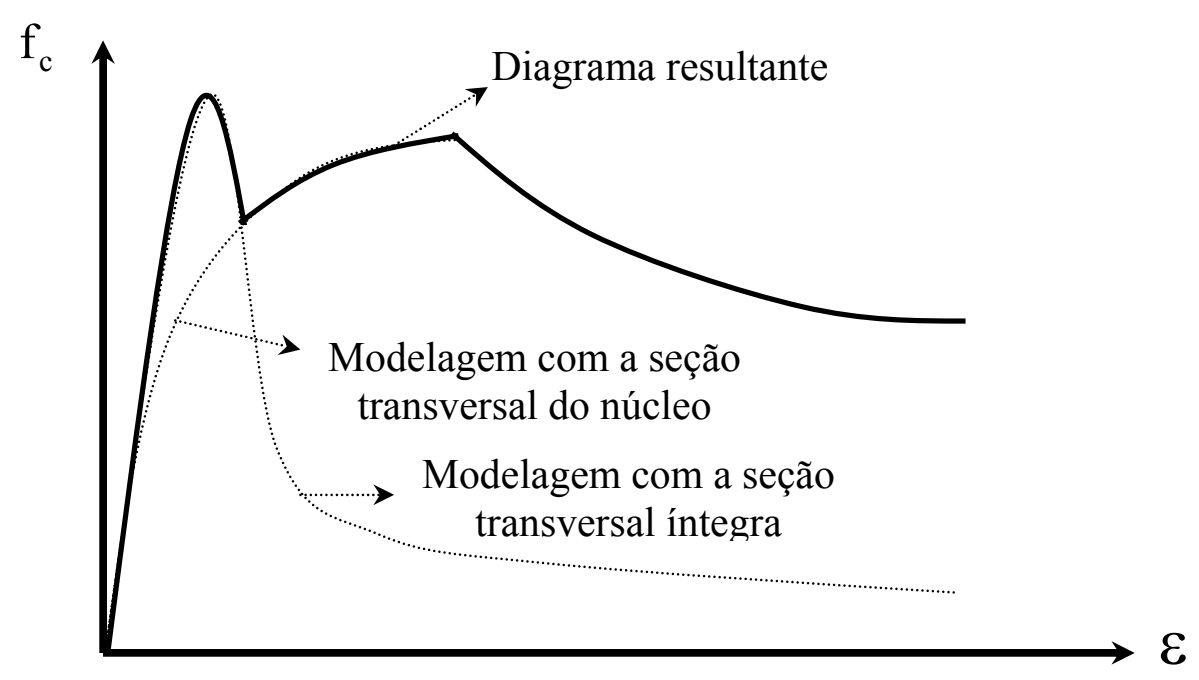

Figura 3.15 - Modificação do modelo de Cusson e Paultre (1995) por Lima Júnior (2003) 


\subsection{Programa COMPUTACIONAL}

\subsubsection{Considerações iniciais}

O programa utilizado neste trabalho foi o ANAPROT. Esse programa é fruto de uma linha de pesquisa desenvolvida pelos Professores Ney Augusto Dumont e Giuseppe Barbosa Guimarães, da Pontifícia Universidade Católica do Rio de Janeiro, e foi elaborado durante quatro dissertações de mestrado.

O modelo teórico para representar o comportamento do concreto confinado foi desenvolvido por Cusson e Paultre (1995) e modificado por Lima Júnior (2003).

O código fonte do programa foi cedido ao Professor Humberto Correia Lima Júnior, para que fosse possível a implementação do modelo teórico de confinamento, no programa citado. O programa foi desenvolvido para análise de pórticos planos de concreto armado e protendido; ele utiliza o método dos elementos finitos e leva em consideração as não-linearidades físicas do material e as geométricas da estrutura.

As leis constitutivas para o concreto confinado e não confinado, para a armadura e o procedimento empregado para resolução dos sistemas de equações não lineares são encontrados no apêndice A deste trabalho e em Lima Júnior (2003).

\subsubsection{Procedimentos adotados para utilização do programa nos modelos de pilares}

Foram feitas análises prévias com o programa computacional, com o valor da resistência do concreto, medida por meio dos corpos-de-prova cilíndricos de $15 \mathrm{~cm} \times 30 \mathrm{~cm}$, obtidos no dia do ensaio do modelo, e com as demais características dos pilares.

Uma primeira análise foi feita para determinar o número de elementos a serem utilizados para discretizar os modelos. Fizeram-se análises com 12, 10, 8 e 6 elementos e não foram notadas diferenças nos resultados no tocante a 
deformação longitudinal dos pilares. Conclui-se então que uma discretização muito mais refinada não acarretaria em maior precisão no resultado numérico. Dessa maneira, optou-se por fazer uma análise numérica utilizando-se uma malha com 6 elementos (Figura 3.16), porque dividindo-se a estrutura por esse número de elementos obtém-se valores inteiros para o arquivo de entrada de dados.

Para cada nó, são medidos os deslocamentos na vertical e horizontal e a rotação, no caso de haver excentricidade.

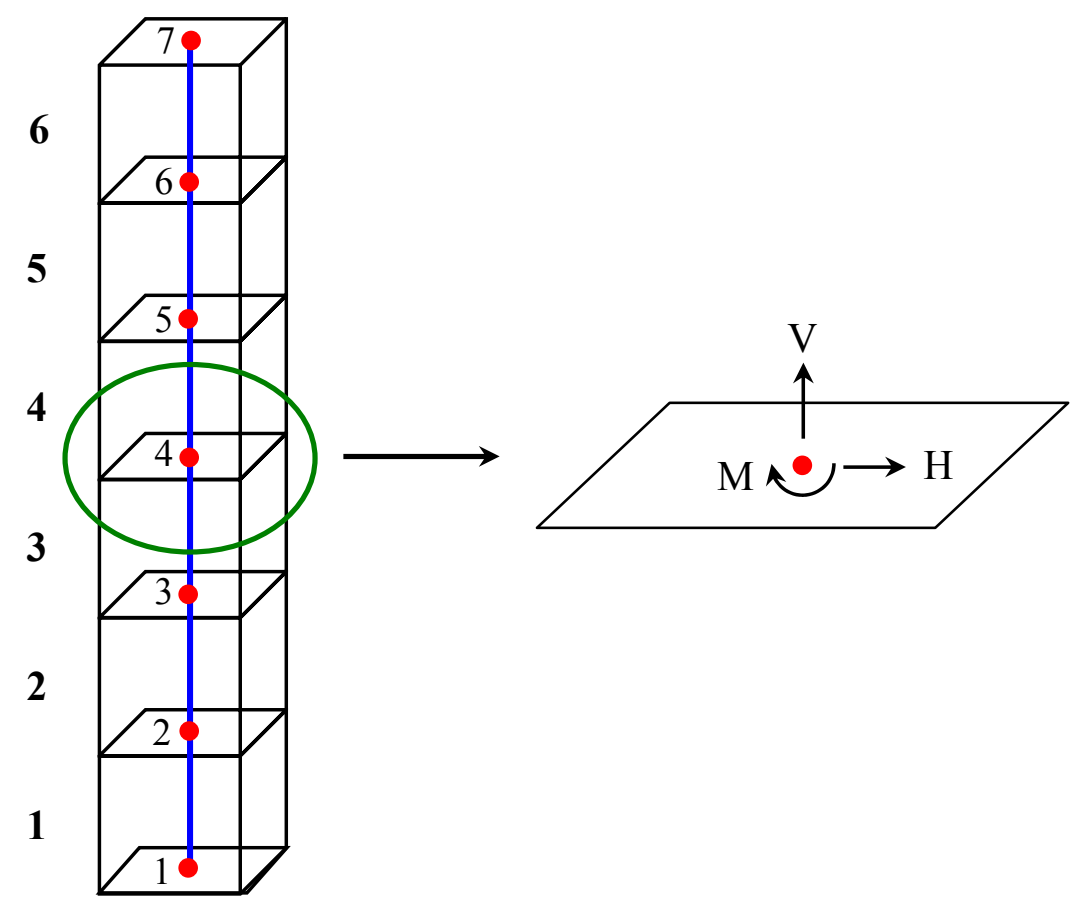

Figura 3.16 - Discretização empregada para o pilar

Para o traçado do diagrama tensão vs. deformação do modelo numérico, são tomados os dados de um dos arquivos de saída. Esse arquivo fornece os dados de deslocamento $(\mathrm{cm})$ e força $(\mathrm{kN})$ para cada incremento, e com isso os deslocamentos são transformados em deformação (\%). 


\section{Capítulo 4}

\section{PROGRAMA EXPERIMENTAL}

\subsection{CONSIDERAÇÕES INICIAIS}

Neste capítulo são apresentados os procedimentos no tocante a parte experimental da pesquisa. A análise dos materiais constituintes do concreto, as condições mecânicas das barras de aço da armadura, a definição dos modelos de pilares, a determinação da dosagem do concreto e a previsão da força última calculada com os resultados da resistência média à compressão do concreto determinada em ensaios dos corpos-de-prova cilíndricos.

Para o desenvolvimento da parte experimental foi tomado como base inicial os trabalhos desenvolvidos por Lima (1997), Queiroga (1999) e Ramos (2001). Os modelos de ensaio tiveram a mesma configuração, quanto a distribuição e taxas de armaduras, dos modelos de Ramos (op. cit.).

As dimensões dos modelos foram estabelecidas para que os mesmos pudessem ser calculados de modo simplificado, ou seja, sem a consideração dos efeitos de segunda ordem, com força suposta centrada. A NBR 6118:2003, considerando que não há escorregamento relativo entre as extremidades dos pilares e as prensas da máquina de ensaio, define que o comprimento de flambagem $\left(\ell_{\mathrm{e}}\right)$ dos modelos é igual a altura dos mesmos. 
Os índices de esbeltez dos pilares foram calculados pela equação 4.1.

$$
\lambda=\frac{\ell_{\mathrm{e}}}{\mathrm{i}}
$$

na qual, i é o raio de giração dos pilares, calculado pela equação 4.2.

$$
\mathrm{i}=\frac{\mathrm{h}}{\sqrt{12}}
$$

na qual, h é a menor dimensão da seção transversal do pilar.

Os índices de esbeltez dos pilares foram iguais a 20,8, tanto para o modelo de seção retangular, quanto para o de seção quadrada. Comparando-se esse valor de $\lambda$ com o limite $\lambda_{1}$, definido na NBR 6118:2003, com $\lambda_{1}$ igual ao limite inferior 35 , os efeitos de segunda ordem não precisam ser considerados. Na versão atual da Norma o limite inferior de $\lambda_{1}$ é igual a $35 / \alpha_{b}$ e, segundo informação do Professor Ricardo Leopoldo da Silva França, na próxima versão revisada da Norma o limite inferior será igual a 35 .

\subsection{CARACTERIZAÇÃO DOS MATERIAIS}

\subsubsection{Agregado miúdo}

O agregado miúdo empregado na pesquisa foi areia natural do tipo quartzosa, proveniente do rio Mogi-Guaçu. Os ensaio de caracterização foram realizados no Laboratório de Materiais Avançados à Base de Cimento - SET EESC - USP.

A granulometria foi determinada segundo a NBR 7217:1987, resultando dimensão máxima característica de 2,36 e módulo de finura de 2,26.

A massa específica de $2,63 \mathrm{~g} / \mathrm{cm}^{3}$ foi determinada de acordo com as recomendações da NBR 9776:1987. A massa unitária de $1,5 \mathrm{~kg} / \mathrm{dm}^{3}$ foi determinada de acordo com a NBR 7251:1982. 
A areia se enquadrou nos limites granulométricos de areia fina, máximo e mínimo, sugeridos pela NBR 7211:1983, conforme mostrado na figura 4.1.

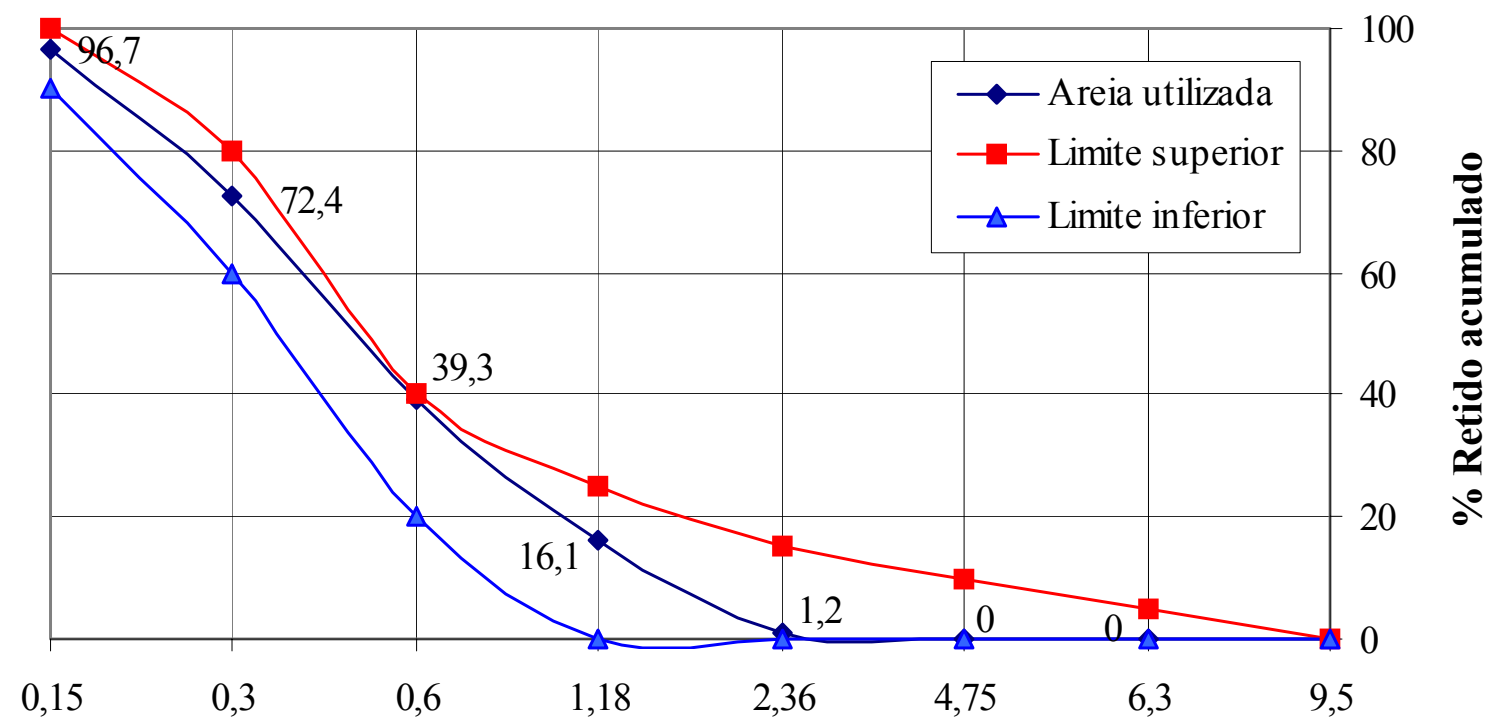

Peneiras mm

Figura 4.1 - Limites granulométricos para o agregado miúdo. NBR 7221:1983

\subsubsection{Agregado graúdo}

O agregado graúdo é de origem basáltica da Região de São Carlos. Os ensaios foram realizados no Laboratório de Materiais Avançados à Base de Cimento - SET - EESC - USP.

A granulometria foi determinada segundo a NBR 7217:1987. Ainda por essa norma a dimensão máxima característica foi de $19 \mathrm{~mm}$ e seu módulo de finura foi de 5,92 .

A massa específica de $2,86 \mathrm{~g} / \mathrm{cm}^{3}$ foi determinada de acordo com a recomendação da NBR 9776:1987. A massa unitária, determinada de acordo com a NBR 7251:1982, foi de $1,47 \mathrm{~kg} / \mathrm{dm}^{3}$. 


\subsubsection{Cimento}

O cimento utilizado foi o CP V - ARI - Plus, da marca Ciminas. Cimento de coloração clara e uniforme com valores aproximados de resistência à compressão com um dia de idade superiores a 26MPa, e aos 28 dias $53 \mathrm{MPa}$, permitindo desmoldagens antecipadas e propiciando bom desempenho aos concretos e argamassas.

\subsection{4 Água}

Para a água de amassamento do concreto, foi utilizada a água da rede pública de abastecimento da cidade de São Carlos.

\subsubsection{Barras de aço}

Antes dos ensaios à tração das barras e fios de aço, os corpos-de-prova tiveram sua massa medida em balança com precisão de $0,1 \mathrm{~g}$, medidos seus comprimentos com trena e, em seguida, foram calculadas as áreas e os diâmetros efetivos, considerando a massa específica do aço igual a $7850 \mathrm{~kg} / \mathrm{m}^{3}$.

As barras de aço de $5,0 \mathrm{~mm}$ e $6,3 \mathrm{~mm}$ de diâmetro foram ensaiadas no Laboratório de Madeiras e Estruturas de Madeira - LaMEN - EESC - USP, utilizando a máquina universal de ensaios, marca DARTEC; com capacidade para $100 \mathrm{kN}$, servocontrolada, conectada a um sistema de aquisição de dados que gerencia as operações do atuador e registra automaticamente os valores de força e deslocamento; utilizaram-se dois corpos-de-prova para cada diâmetro, com $30 \mathrm{~cm}$ de comprimento cada.

Os dados de deslocamento foram posteriormente transformados em deformação para o cálculo do módulo de elasticidade, então se verificou que os valores dos módulos de elasticidade ficaram muito aquém dos esperados, pelo fato de não ter sido usado clipe gage para medição dos deslocamentos, adotaramse os dados de deslocamento do pistão. Esses dados levam em consideração deformações e a acomodação das barras nas garras da máquina, que foram 
responsáveis pelo acréscimo no valor da deformação correspondente à resistência de escoamento. As figuras 4.2 e 4.3 apresentam os diagramas tensão vs. deformação para as barras de 5,0mm e 6,3mm, respectivamente.

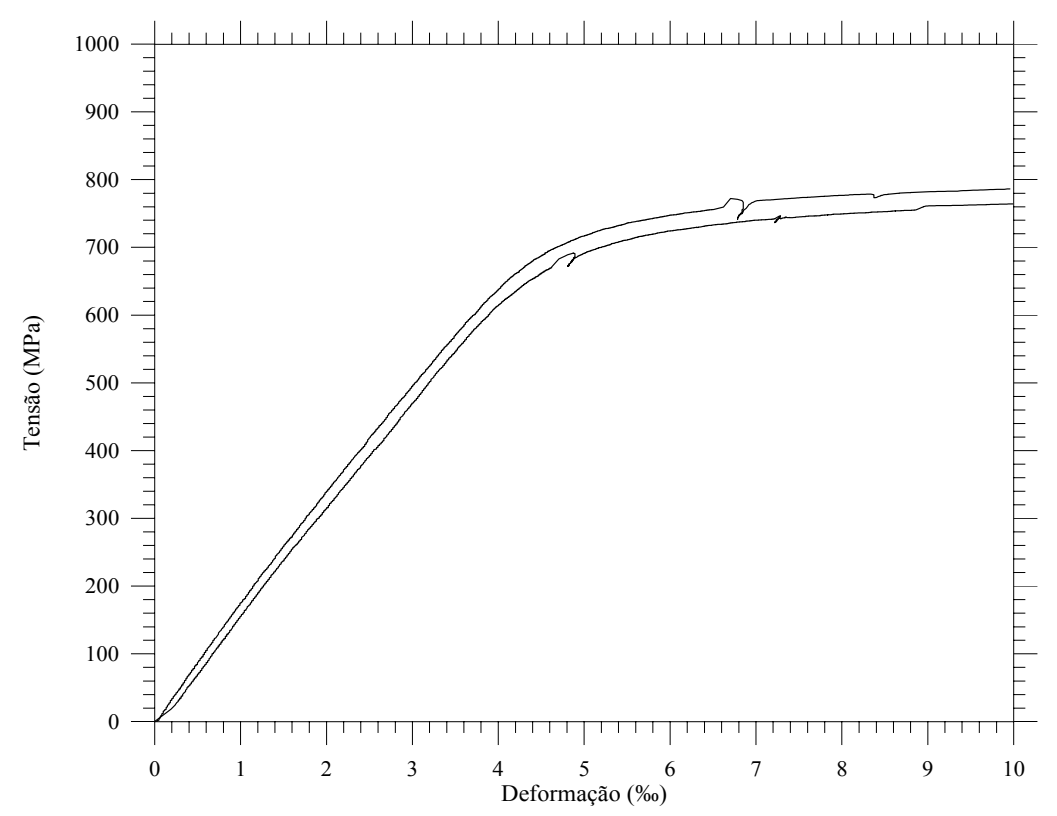

Figura 4.2 - Diagrama tensão vs. deformação do aço com diâmetro de 5,0mm

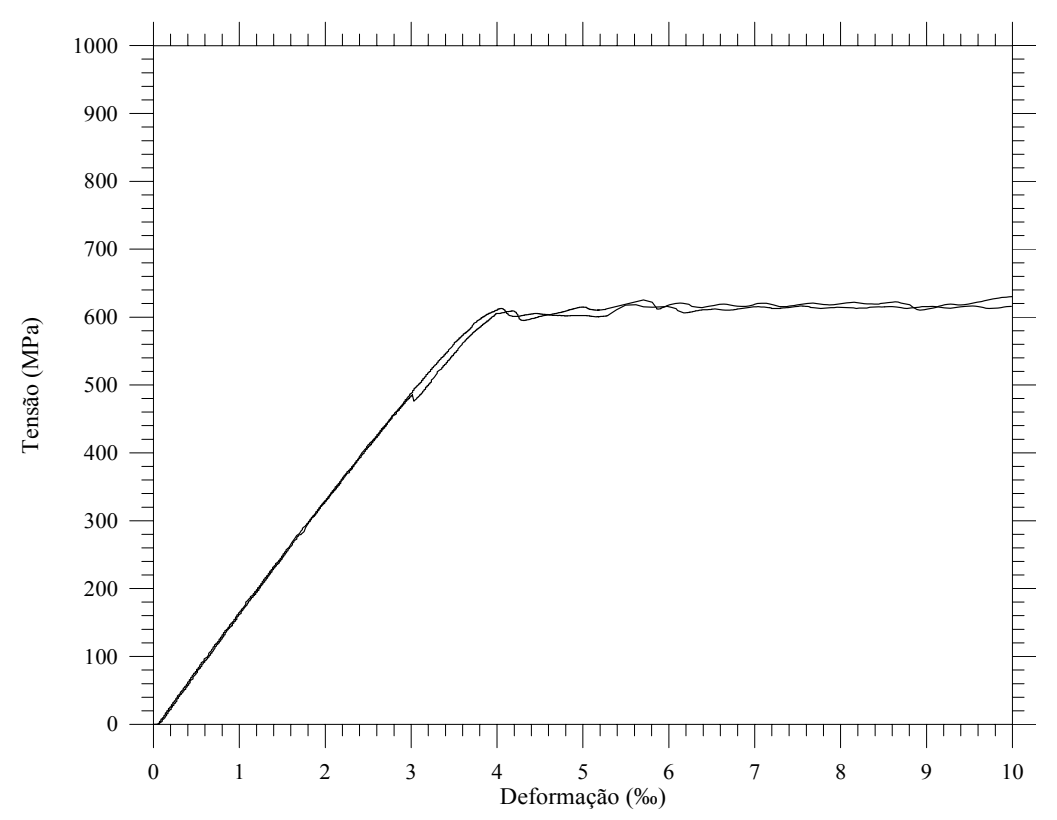

Figura 4.3 - Diagrama tensão vs. deformação do aço com diâmetro de 6,3mm

As barras de $10,0 \mathrm{~mm}$ e $12,5 \mathrm{~mm}$ de diâmetro foram ensaiadas no Laboratório de Estruturas - LE - EESC - USP, utilizando a máquina INSTRON, apresentada anteriormente na figura 2.8. Foram ensaiados dois corpos-de-prova 
para cada diâmetro, com $80 \mathrm{~cm}$ de comprimento cada, instalando-se clipe gage para medição dos deslocamentos e posterior cálculo das deformações. As figuras 4.4 e 4.5 apresentam os diagramas tensão vs. deformação para as barras de $10,0 \mathrm{~mm}$ e $12,5 \mathrm{~mm}$, respectivamente.

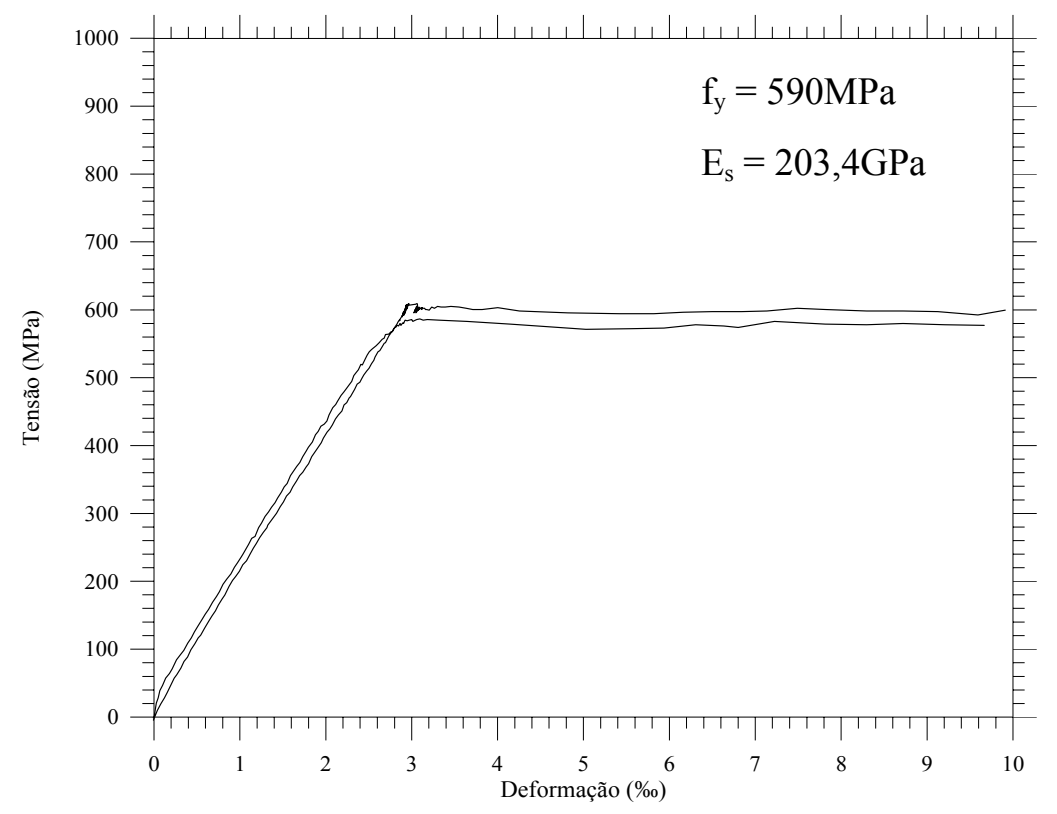

Figura 4.4 - Diagrama tensão vs. deformação do aço com diâmetro de 10,0mm

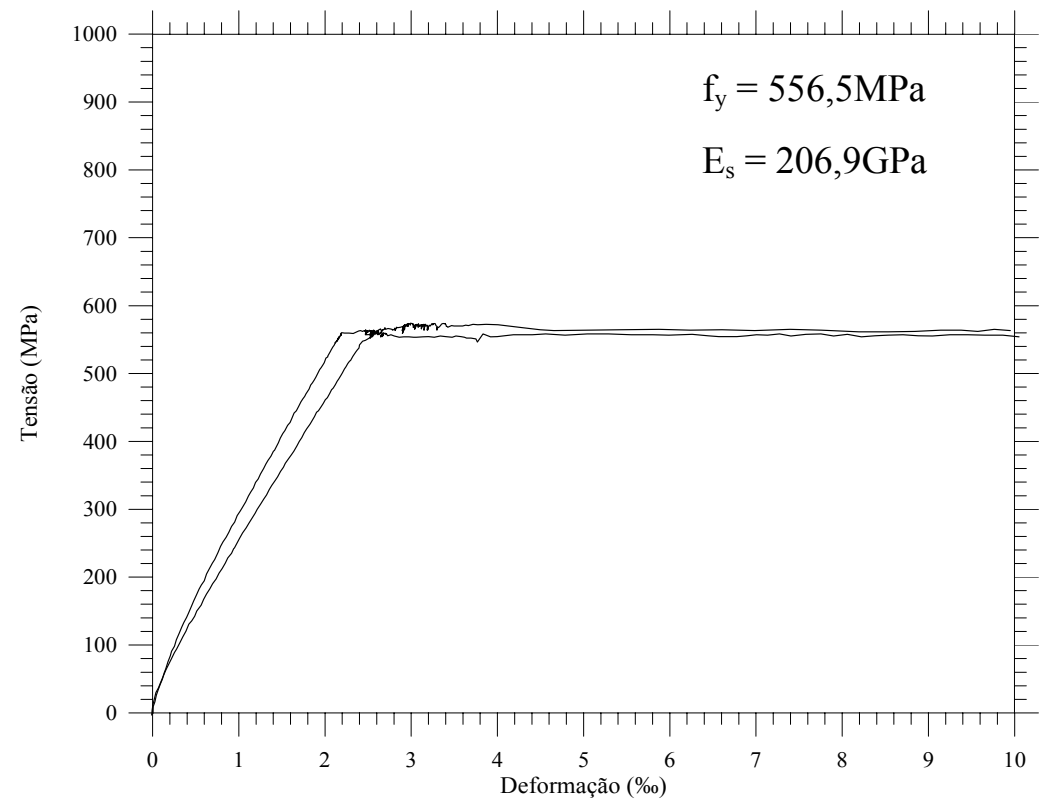

Figura 4.5 - Diagrama tensão vs. deformação do aço com diâmetro de 12,5mm

A tabela 4.1 apresenta as propriedades físicas e mecânicas das armaduras ensaiadas. 
Tabela 4.1 - Propriedades físicas e mecânicas das armaduras

\begin{tabular}{cccccc}
\hline \hline Aço & $\begin{array}{c}\text { Área }-\mathrm{s}_{\mathrm{d}} \\
\left(\mathrm{cm}^{2}\right)\end{array}$ & $\begin{array}{c}\phi_{\mathrm{s}}-\mathrm{s}_{\mathrm{d}} \\
(\mathrm{mm})\end{array}$ & $\begin{array}{c}\mathrm{f}_{\mathrm{y}}-\mathrm{s}_{\mathrm{d}} \\
(\mathrm{MPa})\end{array}$ & $\begin{array}{c}\mathrm{E}_{\mathrm{s}}-\mathrm{s}_{\mathrm{d}} \\
(\mathrm{GPa})\end{array}$ & $\begin{array}{c}\mathrm{f}_{\mathrm{u}} \\
(\mathrm{MPa})\end{array}$ \\
\hline \hline$\phi 5,0$ & $0,1992-0,0012$ & $5,036-0,015$ & $746,5-19,09$ & $205^{*}-0$ & 790,15 \\
\hline$\phi 6,3$ & $0,3083-0,0004$ & $6,265-0,004$ & $617,5-3,54$ & $205^{*}-0$ & 708,68 \\
\hline$\phi 10,0$ & $0,7995-0,0009$ & $10,089-0,006$ & $590-11,31$ & $203,4-1,06$ & 685,40 \\
\hline$\phi 12,5$ & $1,2264-0,0016$ & $12,496-0,008$ & $556,5-2,12$ & $206,9-4,05$ & 662,80 \\
\hline \hline
\end{tabular}

* Valores adotados

Nota: $\mathrm{s}_{\mathrm{d}}$ é o desvio padrão da amostra de dois corpos-de-prova; $\phi_{\mathrm{s}}$ é o diâmetro da barra de aço; $\mathrm{E}_{\mathrm{s}}$ é o módulo de elasticidade do aço; $\mathrm{f}_{\mathrm{y}}$ é a tensão de escoamento e $\mathrm{f}_{\mathrm{u}}$ é a tensão de ruptura.

\subsection{DOSAGEM DO CONCRETO}

Seguindo os procedimentos de Helene e Terzian (1995), foram feitos ensaios para determinação da dosagem do concreto de resistência 40MPa aos 14 dias.

O traço em massa encontrado foi de $1: 1,8: 2,82$ e a/c=0,58. Com esse traço, a tabela 4.2 indica a quantidade de materiais por metro cúbico de concreto.

Tabela 4.2 - Consumo de materiais $\left(\mathrm{kg} / \mathrm{m}^{3}\right)$

\begin{tabular}{lr}
\hline Cimento & 400 \\
\hline Areia & 720 \\
\hline Pedra Britada & 1128 \\
\hline Água & 232 \\
\hline \hline Total & 2480 \\
\hline
\end{tabular}

Apesar de ter sido usado o mesmo traço para todas as concretagens, as resistências finais dos corpos-de-prova tiveram variação no seu valor em virtude de variações climáticas. Este fato será mais bem explicado no item 5.1.1 deste trabalho. 


\subsection{FôRMAS}

As fôrmas dos modelos foram construídas na Marcenaria da Escola de Engenharia de São Carlos. Foram feitas fôrmas para dois modelos, sendo que eram duas fôrmas para os pilares com seção retangular e uma para os modelos com seção quadrada, pelo fato de serem 12 modelos com seção retangular e 4 com seção quadrada a serem ensaiados.

Nas figuras 4.6 a 4.9 são apresentados os desenhos das fôrmas dos modelos de seção quadrada. Todas as dimensões estão em milímetros.

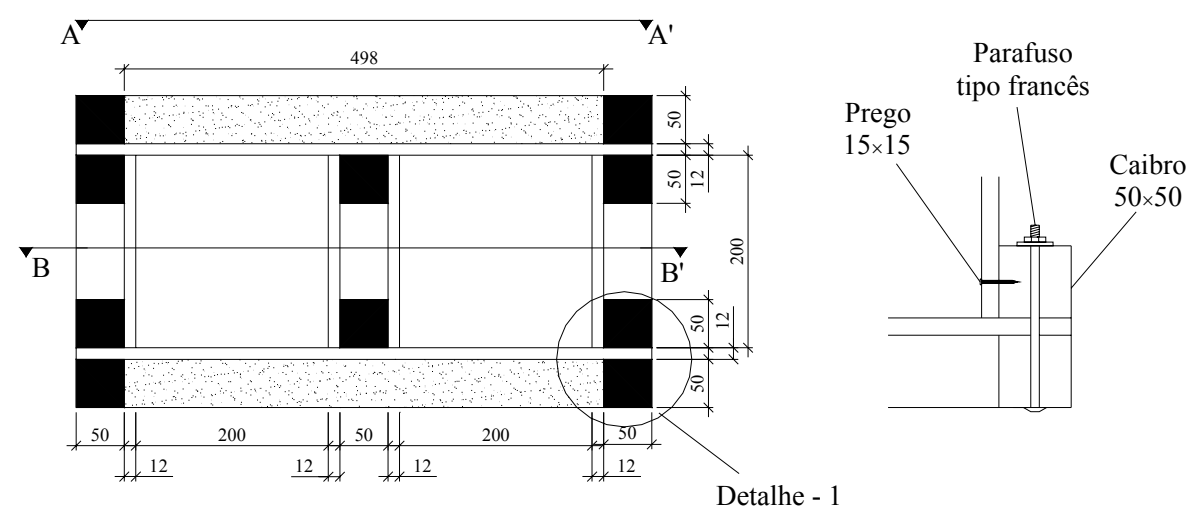

Figura 4.6 - Vista de cima

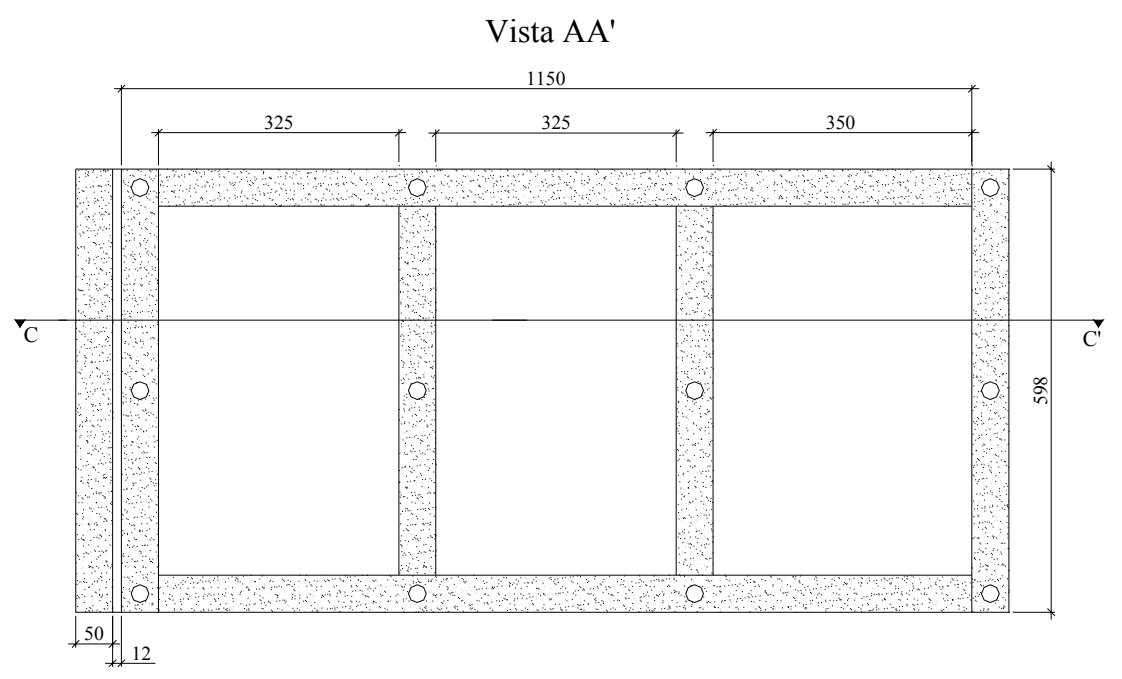

Figura 4.7 - Vista de frente com a tampa 


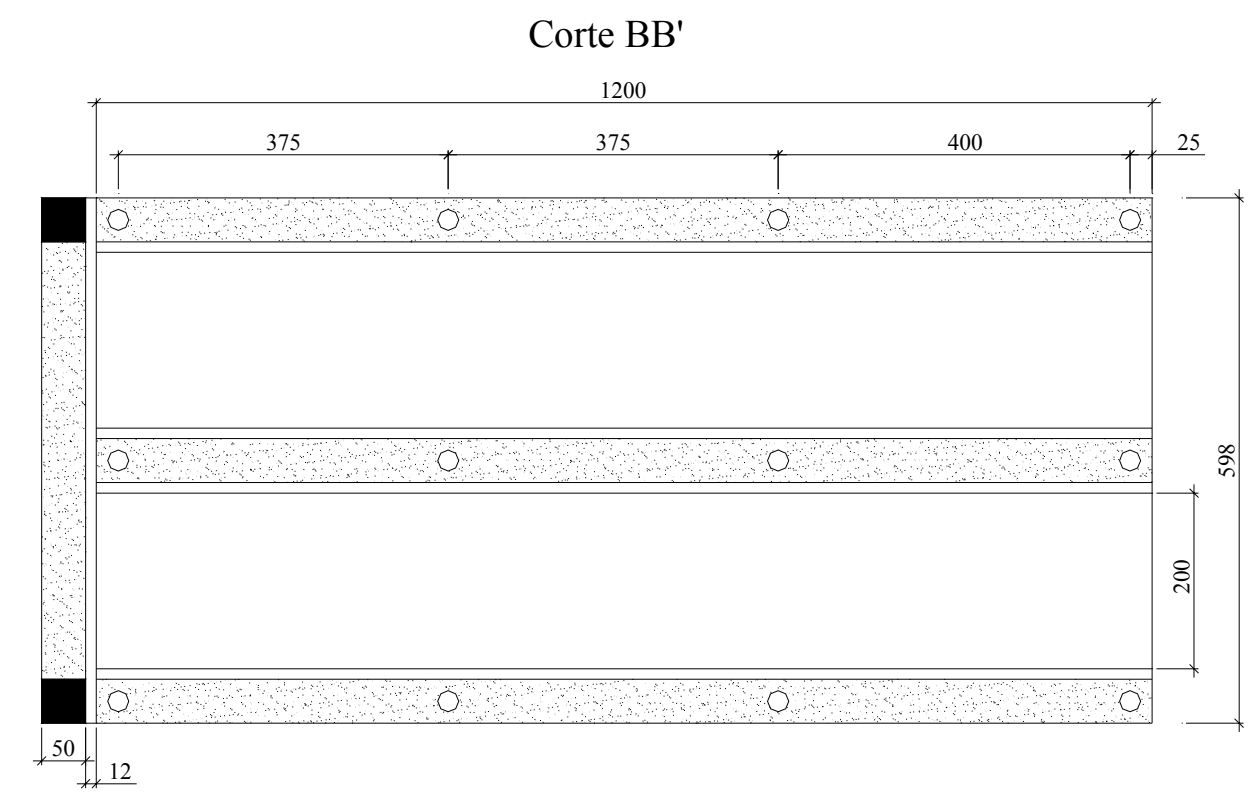

Figura 4.8 - Vista de frente sem a tampa

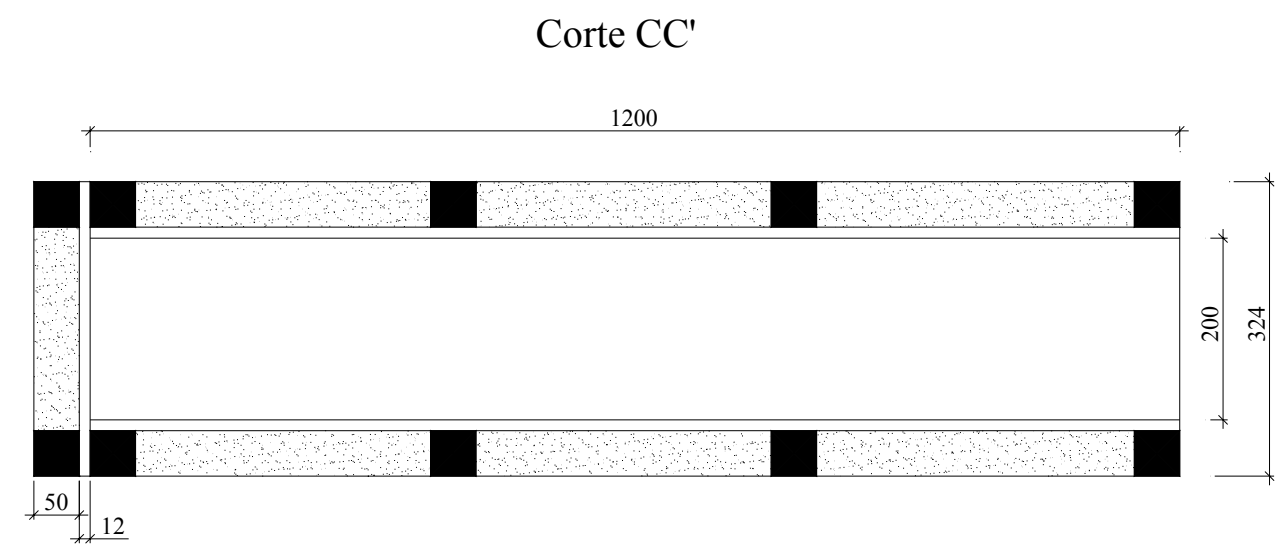

Figura 4.9 - Corte interno longitudinal

As figuras 4.10 a 4.13 apresentam os desenhos das fôrmas dos modelos de seção retangular. Todas as dimensões estão em milímetros. 
Fôrma para os pilares $150 \times 300$

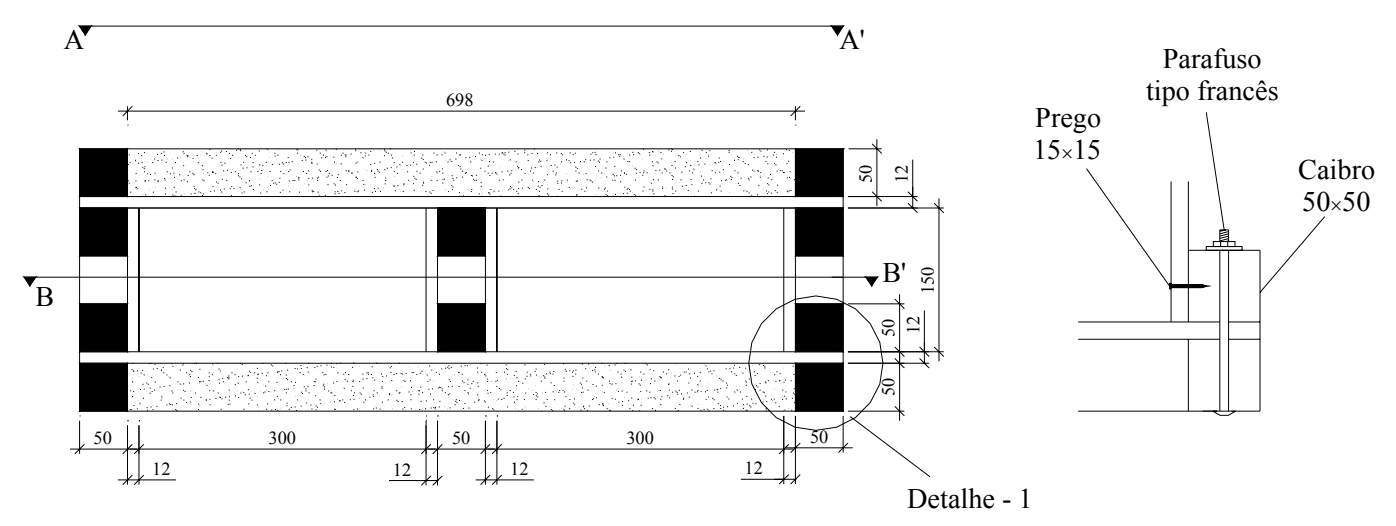

Figura 4.10 - Vista de cima

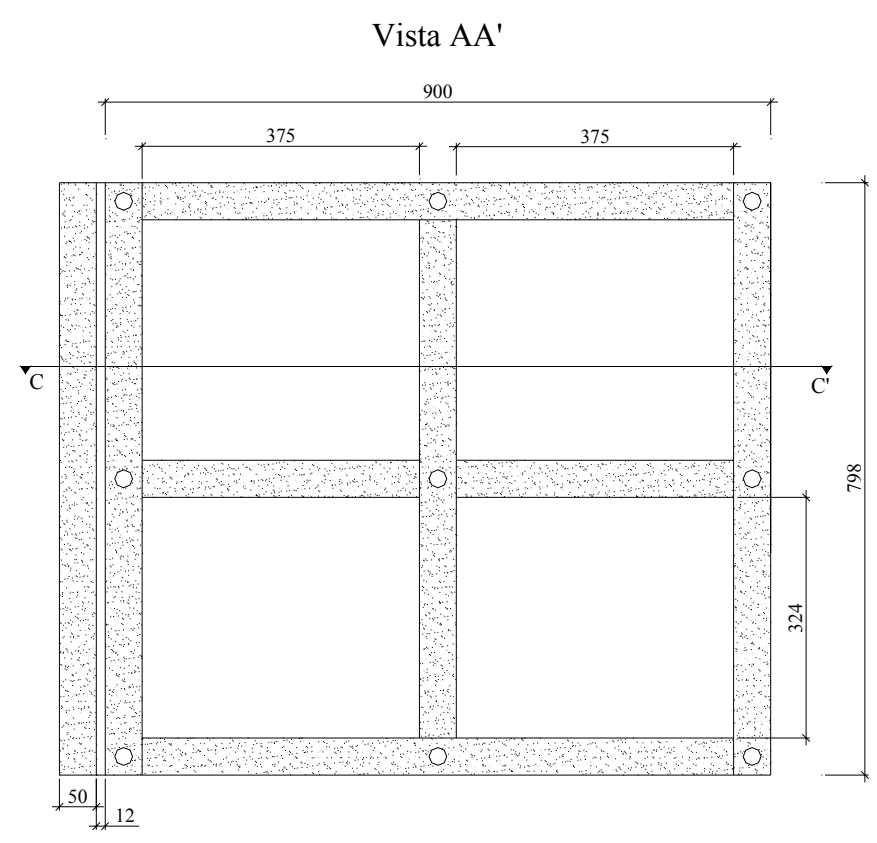

Figura 4.11 - Vista de frente com a tampa 
Corte BB'

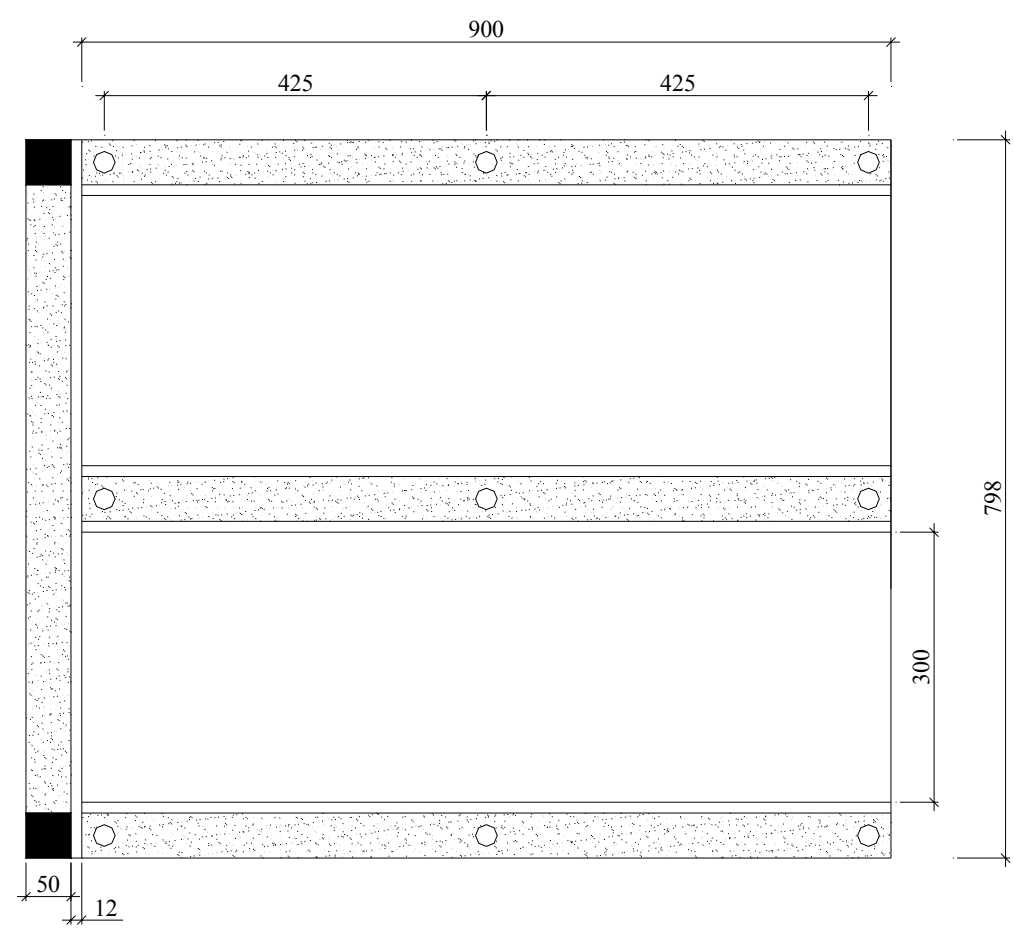

Figura 4.12 - Vista de frente sem a tampa

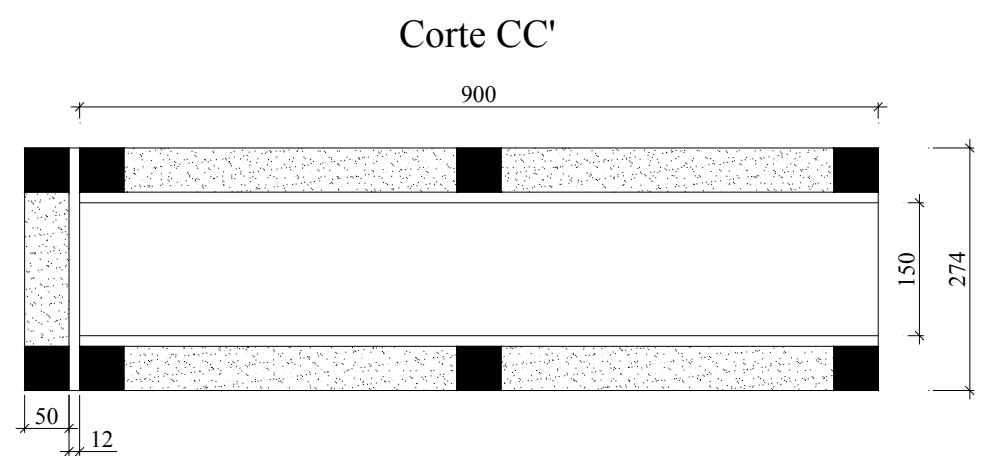

Figura 4.13 - Corte interno longitudinal

O desenho em 3D das fôrmas é apresentado na figura 4.14. 

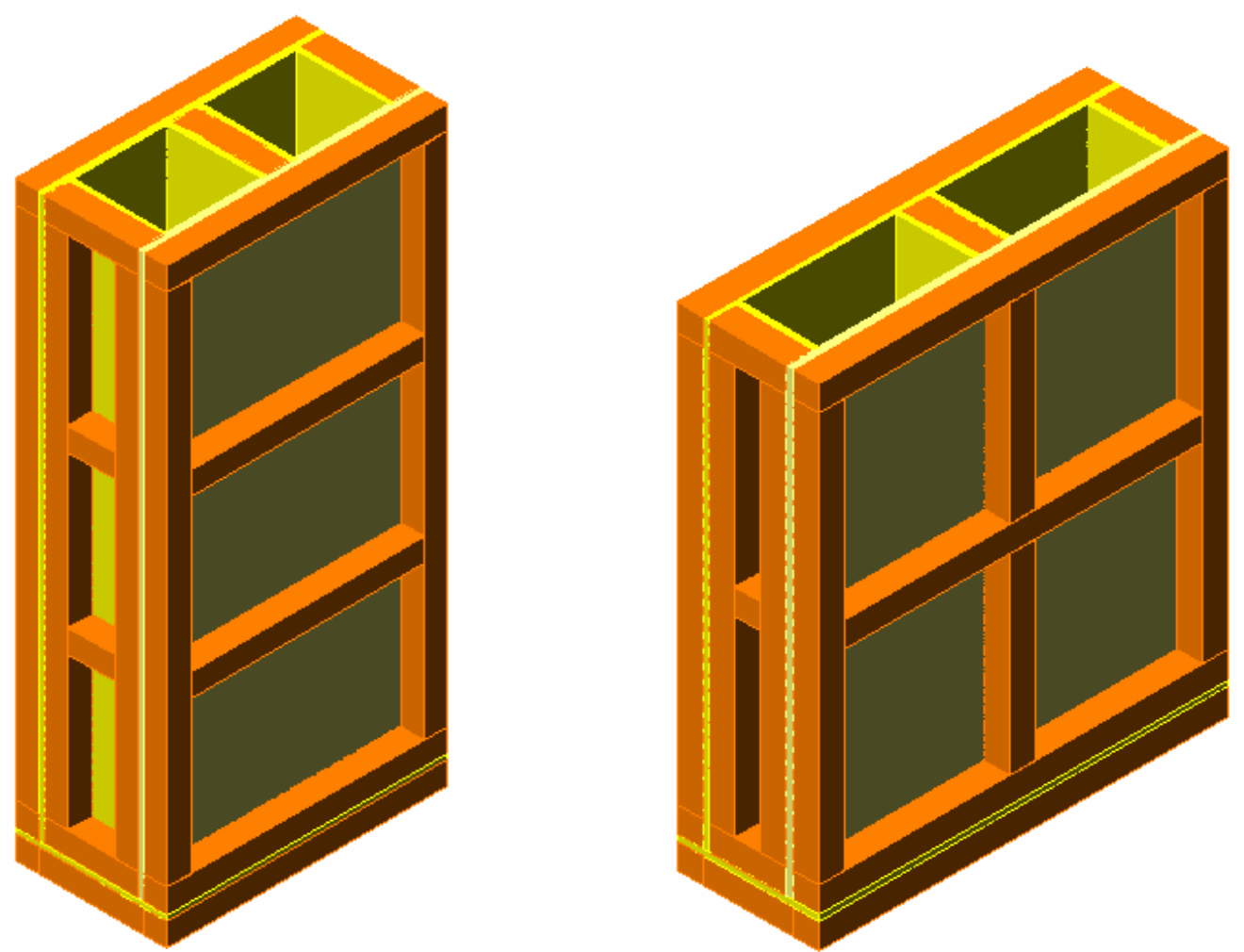

Figura 4.14 - Fôrmas para os modelos de seção quadrada e retangular, respectivamente

\subsection{COLAR METÁlico}

Para os colares metálicos foi usado Aço 1020, com largura de $20 \mathrm{~cm}$ e espessura de $15,8 \mathrm{~mm}$. Como já foi mencionado, os colares serviram para confinar as regiões extremas dos modelos, evitando que essas rompam no instante da aplicação da força.

A dimensão de $20 \mathrm{~cm}$ dos colares leva em conta o princípio de Saint Venant para o modelo de seção quadrada.

"Existe uma região definida por dimensões da mesma ordem de grandeza da seção transversal do elemento carregado, na qual se processa a regularização das tensões”

Saint Venant

In. Silva e Giongo (2000) 
A espessura e o tipo de solda utilizada garantiram a integridade dos colares ao ser aplicada a força máxima para cada modelo. Os colares foram construídos na oficina mecânica da Escola de Engenharia de São Carlos.

As figuras 4.15 e 4.16 mostram os desenhos, em planta, das chapas dos modelos de seção quadrada e retangular, respectivamente. Todas as medidas estão em milímetros.
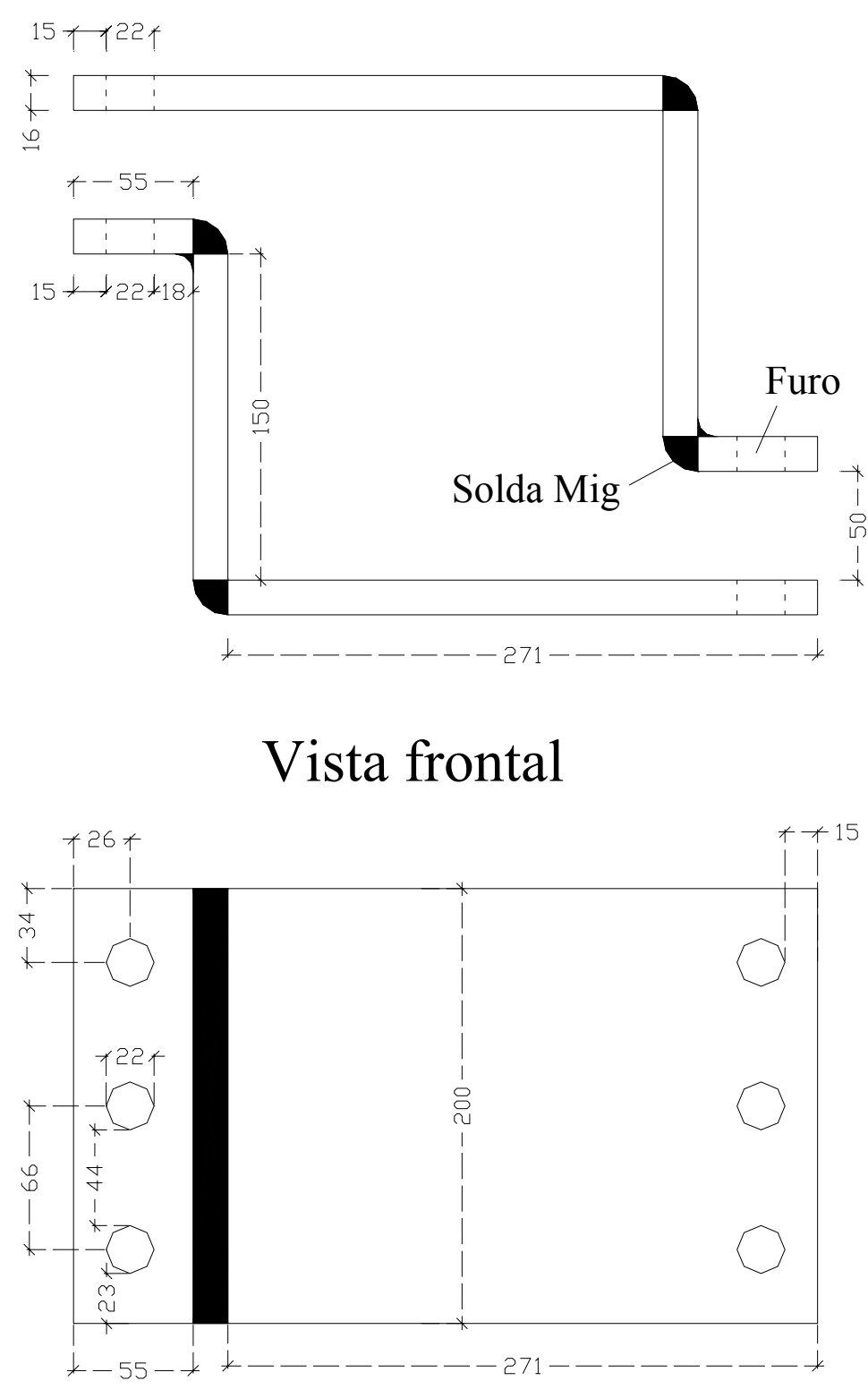

Figura 4.15 - Desenho, em planta, do colar metálico para os modelos de seção quadrada 


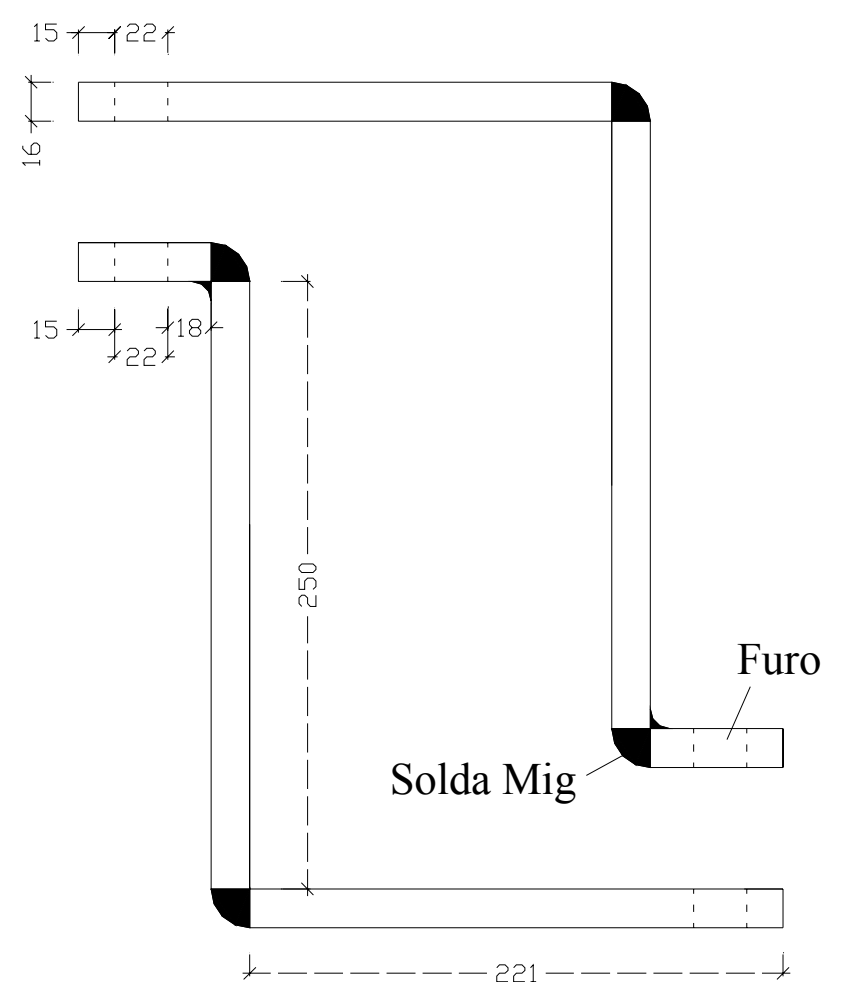

\section{Vista frontal}

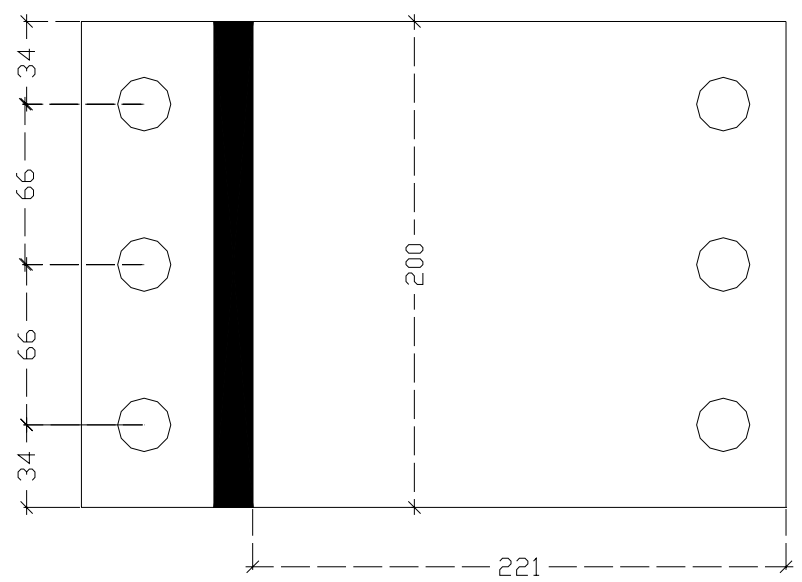

Figura 4.16 - Desenho, em planta, do colar metálico para os modelos de seção quadrada

O detalhe em 3D das chapas é apresentado na figura 4.17. 


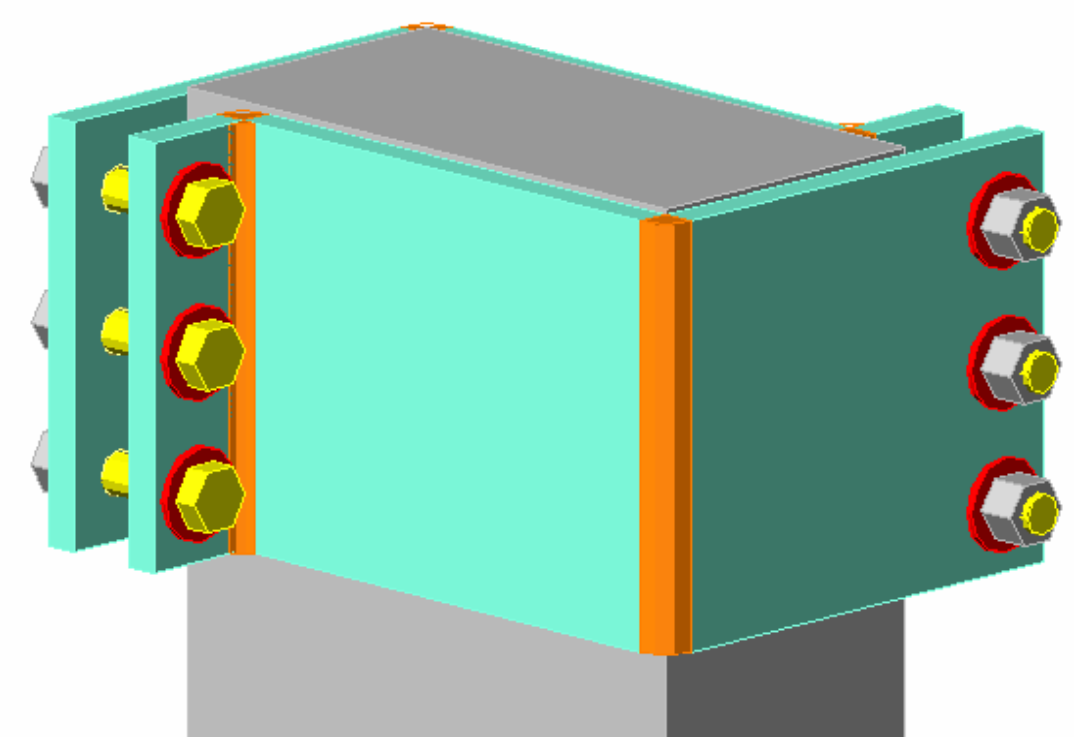

Figura 4.17 - Detalhe em 3D das chapas utilizadas nos modelos de seção retangular

Para assegurar que os parafusos não rompessem quando da aplicação da carga axial, foram utilizados parafusos e porcas feitos com aço de alta resistência.

\subsection{DEFINIÇÃO DOS MODELOS DE PILARES}

A definição dos modelos levou em consideração a resistência à compressão do concreto aos 14 dias de idade, as dimensões dos pilares e os diâmetros nominais das armaduras utilizadas e o detalhamento dessas armaduras. Os itens a seguir detalharão cada característica levada em consideração.

\subsubsection{Resistência à compressão do concreto}

Para complementar os dados de pesquisas anteriores, Lima (1997), Queiroga (1999) e Ramos (2001), que avaliaram o comportamento de pilares submetidos a compressão centrada com resistência característica do concreto de $80 \mathrm{MPa}, 60 \mathrm{MPa}$ e $25 \mathrm{MPa}$, respectivamente, foi escolhida a resistência de $40 \mathrm{MPa}$ para que fosse disposto à comunidade cientifica um estudo abrangente sobre 
pilares de concreto armado submetidos à força de compressão centrada com uma faixa considerável de resistência do concreto.

\subsubsection{Dimensões dos pilares}

As considerações iniciais foram feitas no item 5.1 deste trabalho.

Quanto às prescrições normativas a respeito das dimensões mínimas exigidas, a NBR 6118:2003 indica que os pilares maciços não devem ter dimensão menor que $19 \mathrm{~cm}$. Em casos especiais, permite-se a consideração de dimensões entre $19 \mathrm{~cm}$ e $12 \mathrm{~cm}$, desde que se multipliquem as ações a serem consideradas no dimensionamento por um coeficiente adicional $\gamma_{n}$, que varia com a dimensão do pilar. Para o pilar com uma dimensão de $15 \mathrm{~cm}$, o valor de $\gamma_{\mathrm{n}}$ é 1,2 (este coeficiente não foi usado neste trabalho pois se trata de um critério para projeto).

\subsubsection{Diâmetros nominais das armaduras utilizadas}

O diâmetro da barra de armadura longitudinal, segundo as recomendações da NBR 6118:2003, não deve ser inferior a 10mm nem superior a $1 / 8$ da menor dimensão do pilar, ou seja, para o pilar com dimensão de $15 \mathrm{~cm}$, o diâmetro da barra não deve ser superior a 18,75mm, assim, as barras com os diâmetros de $10 \mathrm{~mm}$ e $12,5 \mathrm{~mm}$ atendem as exigências normativas.

Pela mesma norma, o diâmetro dos estribos em pilares não deve ser inferior a $5 \mathrm{~mm}$ nem a $1 / 4$ do diâmetro da barra isolada ou do diâmetro equivalente do feixe que constitui a armadura longitudinal, dessa forma os diâmetros de $5 \mathrm{~mm}$ e $6,3 \mathrm{~mm}$ se enquadram aos limites prescritos pela norma.

O espaçamento longitudinal entre estribos, medido na direção do eixo do pilar, para garantir o posicionamento, impedir a flambagem das barras longitudinais e garantir a costura das emendas de barras longitudinais nos pilares usuais deve ser igual ou inferior ao menor dos seguintes valores: 


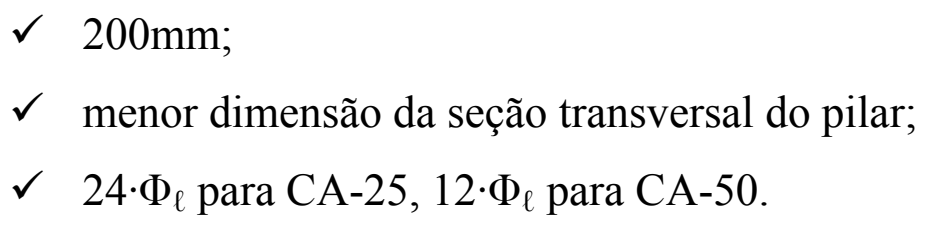

Um dos pilares não atende as exigências normativas quanto ao espaçamento dos estribos. O pilar possui armadura longitudinal composta por barras de diâmetro $12,5 \mathrm{~mm}$ e seção transversal de $20 \mathrm{~cm} \times 20 \mathrm{~cm}$. Segundo as recomendações da NBR 6118:2003, o espaçamento mínimo entre os estribos deveria ser de $15 \mathrm{~cm}$, atendendo à terceira exigência das apresentadas anteriormente, mas o pilar foi construído com estribos a cada $20 \mathrm{~cm}$ para verificar o comportamento do mesmo quanto à ductilidade.

\subsubsection{Detalhamento das armaduras}

Os detalhamentos das armaduras dos modelos de pilares são apresentados nas figuras 4.18 a 4.33 e na tabela 4.3. A identificação dos pilares foi feita com a letra $\mathrm{P}$ seguida de um número que está relacionado aos modelos com mesma configuração da armadura transversal. Além disso, foram utilizados dois números separados por hífen que correspondem, respectivamente, ao diâmetro nominal das barras longitudinais e ao espaçamento da armadura transversal, ambos em milímetros. Para os prismas de concreto simples a identificação foi feita com a letra $\mathrm{P}$ seguida do número 5 para os pilares de seção quadrada e do número 6 para os pilares de seção retangular. Além desses números foi colocado o número da respectiva concretagem $(1,2,3$, ou 4).

Para os pilares de seção quadrada, foram dispostas armaduras de fretagem compostas por sete estribos de diâmetro 6,3mm, com a mesma configuração dos estribos da região central, espaçados de $2,5 \mathrm{~cm}$, para dar maior segurança à região das extremidades, como disposto no item 4.5 deste trabalho. Nos pilares de seção retangular, a armadura de fretagem foi composta por seis estribos. 

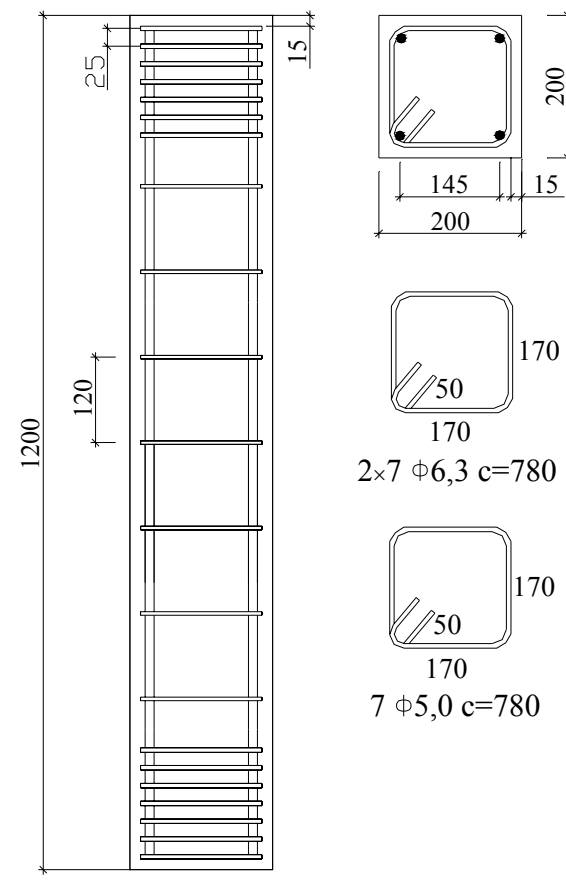

$4 \phi 10,0 \mathrm{c}=1170$

Figura 4.18 - Detalhamento da armadura do pilar P1-10,0-120
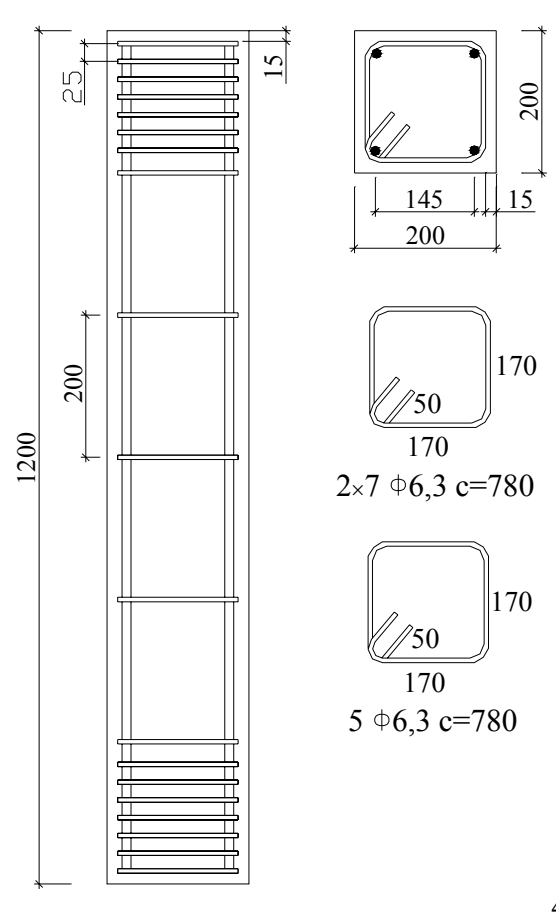

$4 \$ 12,5 \mathrm{c}=1170$

Figura 4.19 - Detalhamento da armadura do pilar P1-12,5-200 

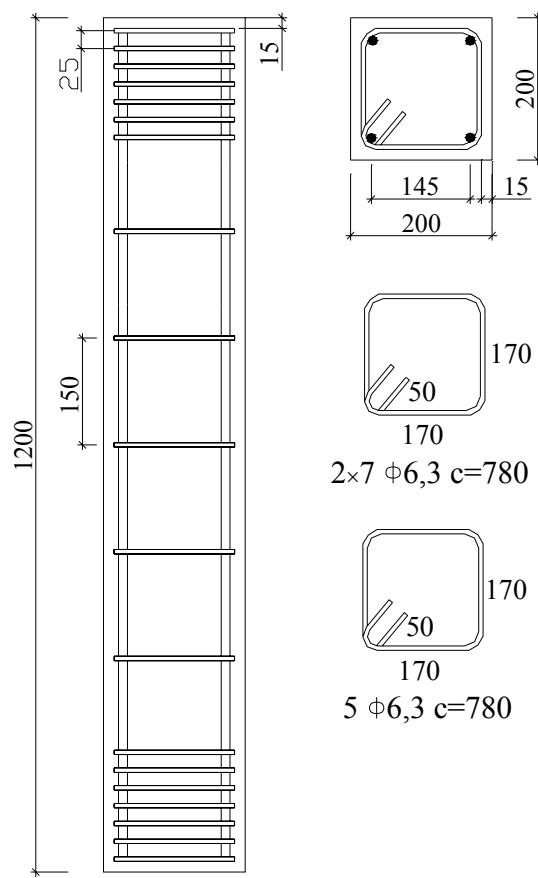

$$
5 \$ 6,3 \mathrm{c}=780
$$

$4 \phi 12,5 \mathrm{c}=1170$

Figura 4.20 - Detalhamento da armadura do pilar P1-12,5-150
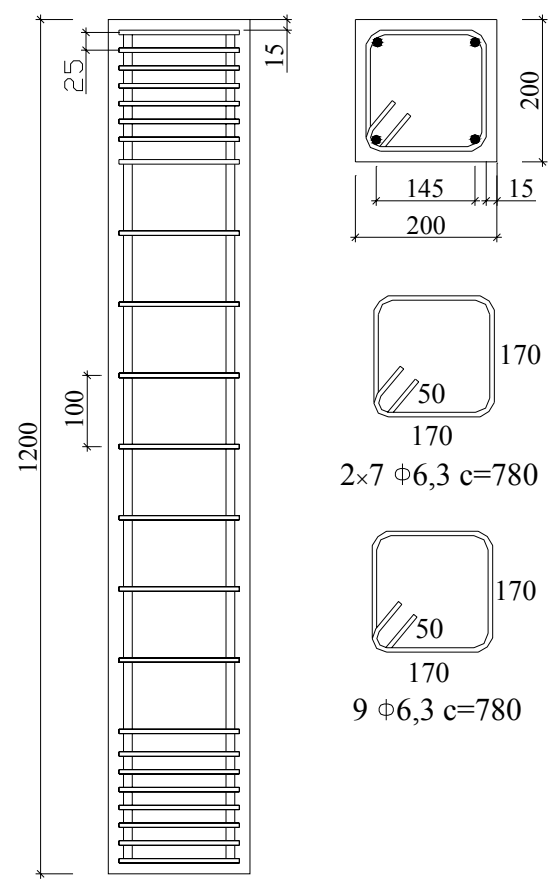

$$
4 \phi 12,5 \mathrm{c}=1170
$$

Figura 4.21 - Detalhamento da armadura do pilar P1-12,5-100 

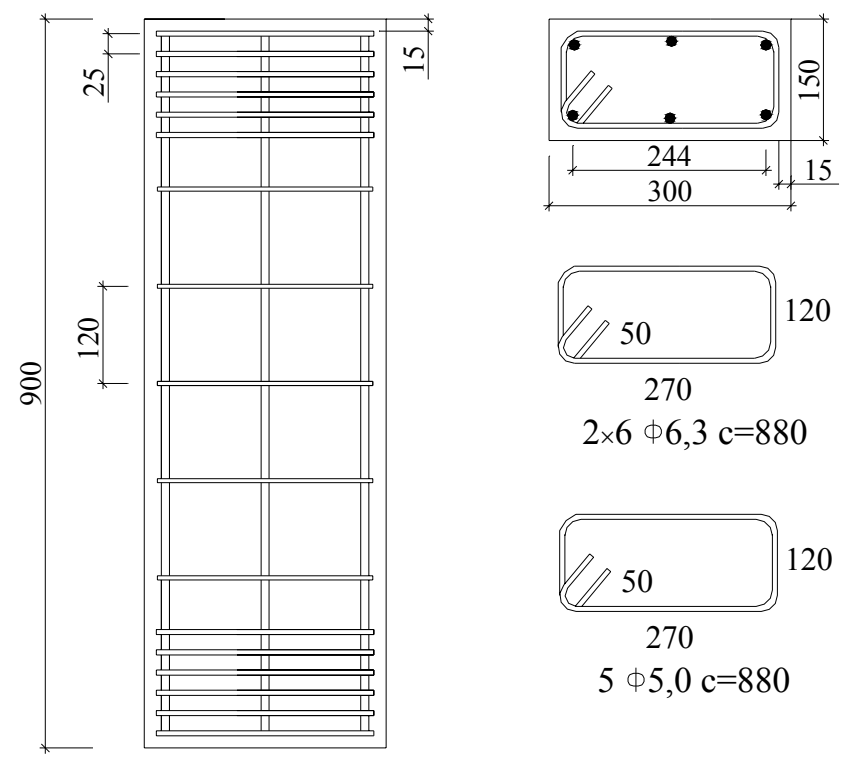

$2 \times 6 \uparrow 6,3 \mathrm{c}=880$

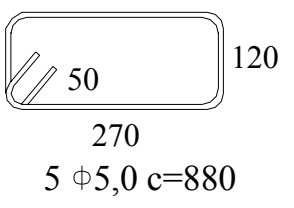

$6 \$ 10,0 c=870$

Figura 4.22 - Detalhamento da armadura do pilar P2-10,0-120
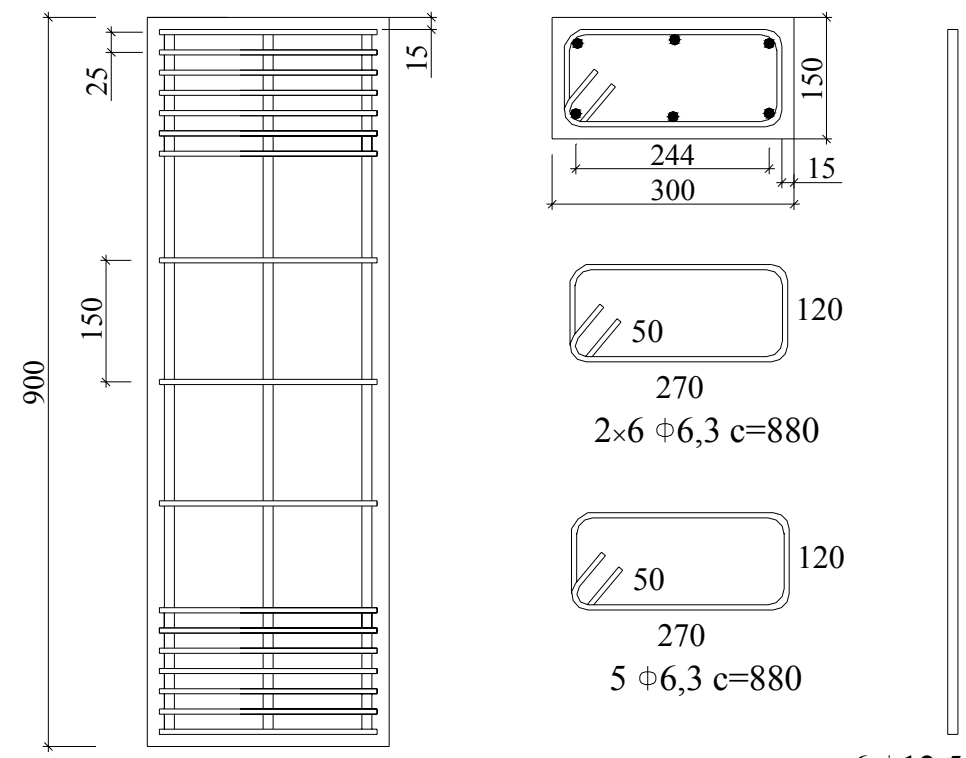

$6 \$ 12,5 c=870$

Figura 4.23 - Detalhamento da armadura do pilar P2-12,5-150 

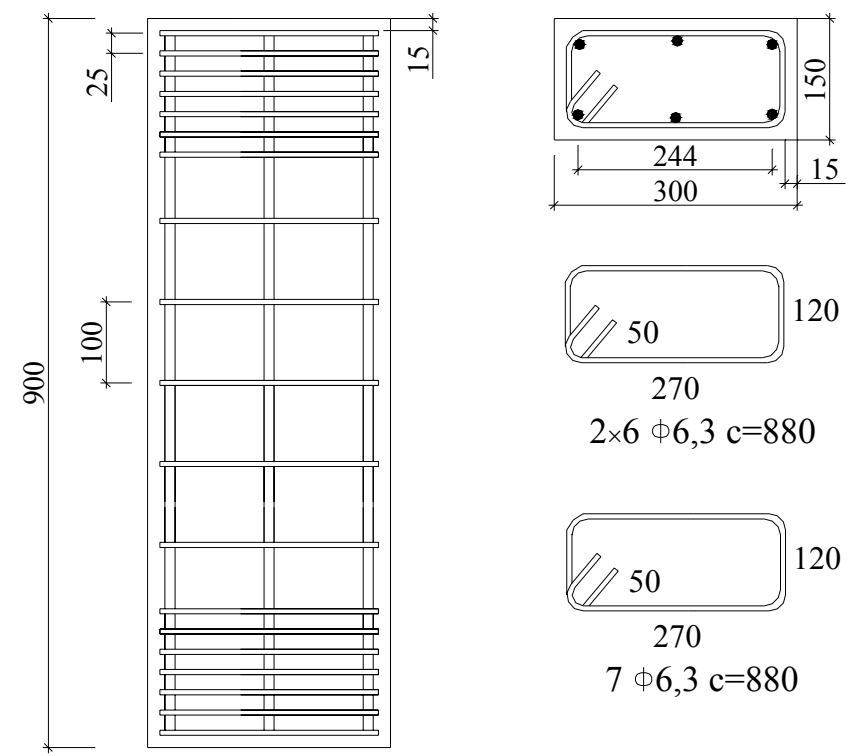

$6 \$ 12,5 \mathrm{c}=870$

Figura 4.24 - Detalhamento da armadura do pilar P2-12,5-100
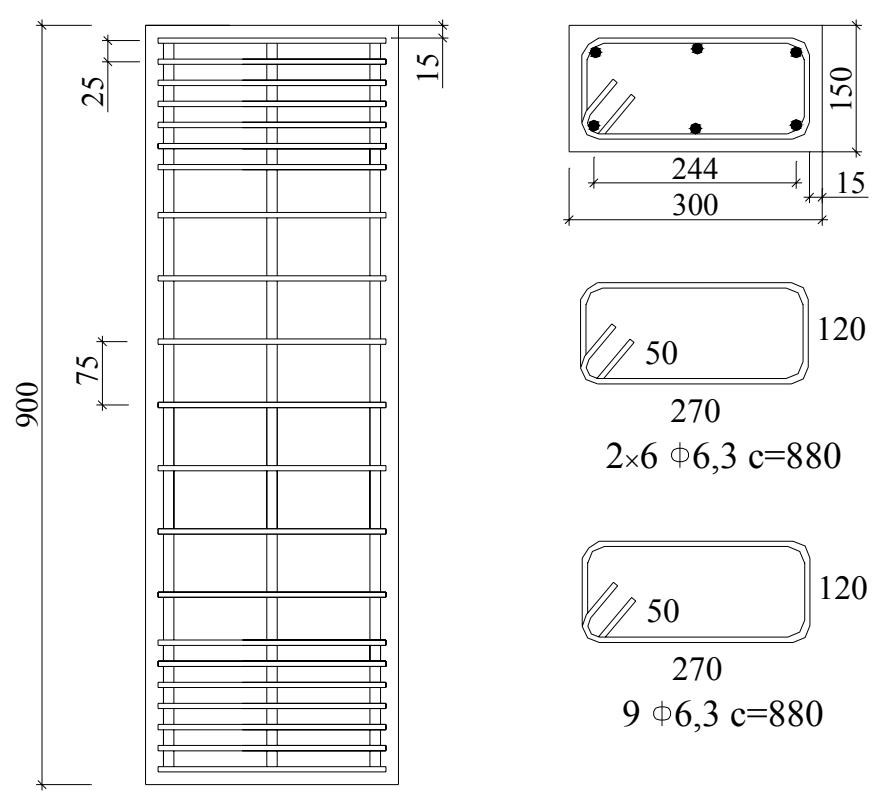

$6 \pitchfork 12,5 \mathrm{c}=870$

Figura 4.25 - Detalhamento da armadura do pilar P2-12,5-075 

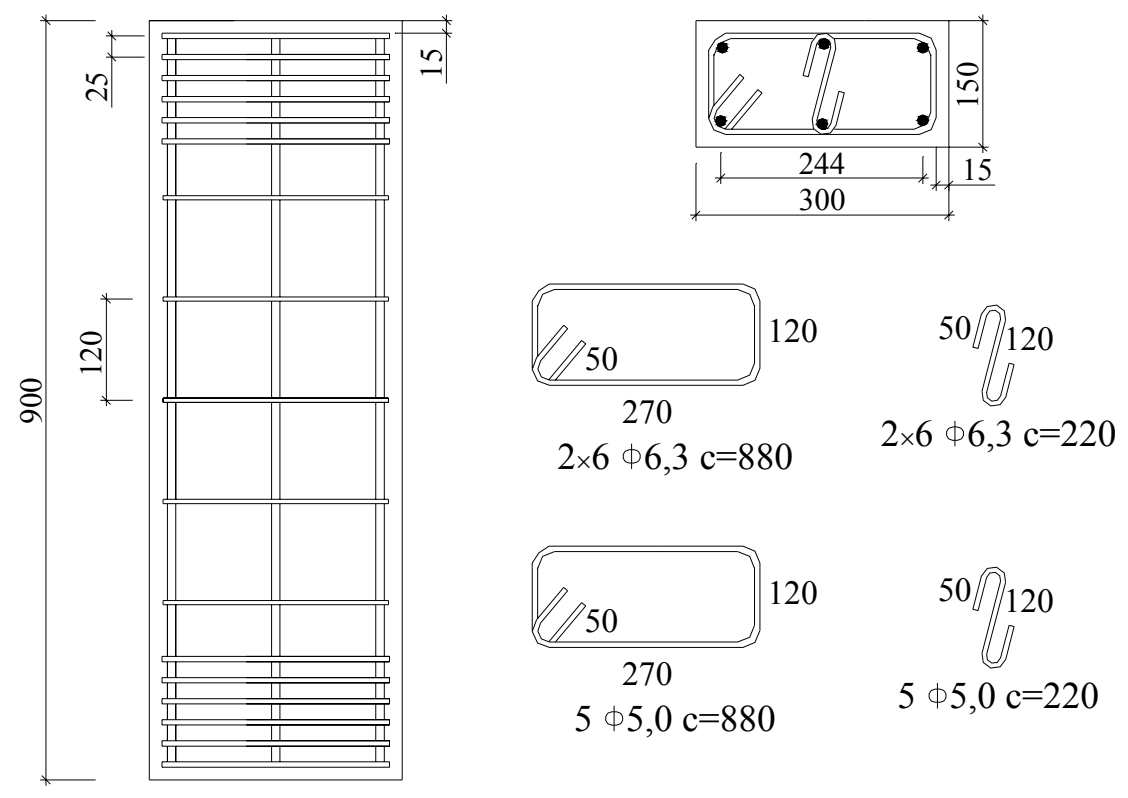

$6 \pitchfork 10,0 \mathrm{c}=870$

Figura 4.26 - Detalhamento da armadura do pilar P3-10,0-120
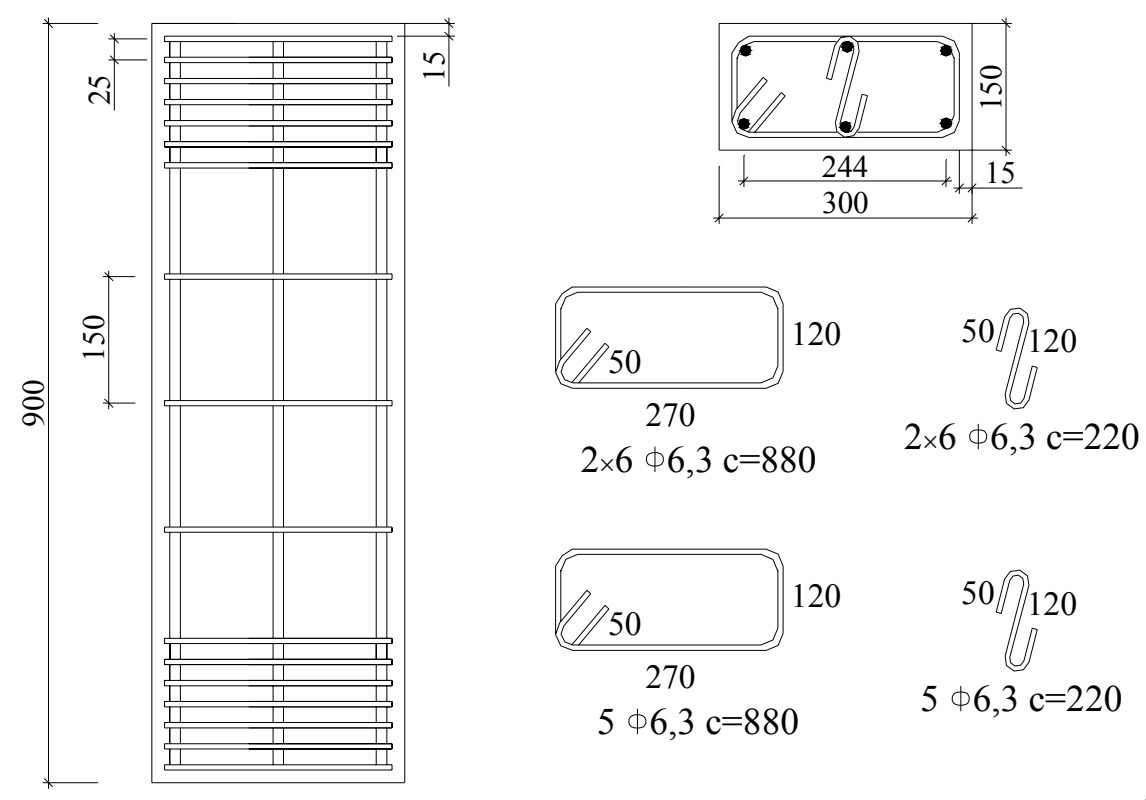

$6 \pitchfork 12,5 c=870$

Figura 4.27 - Detalhamento da armadura do pilar P3-12,5-150 

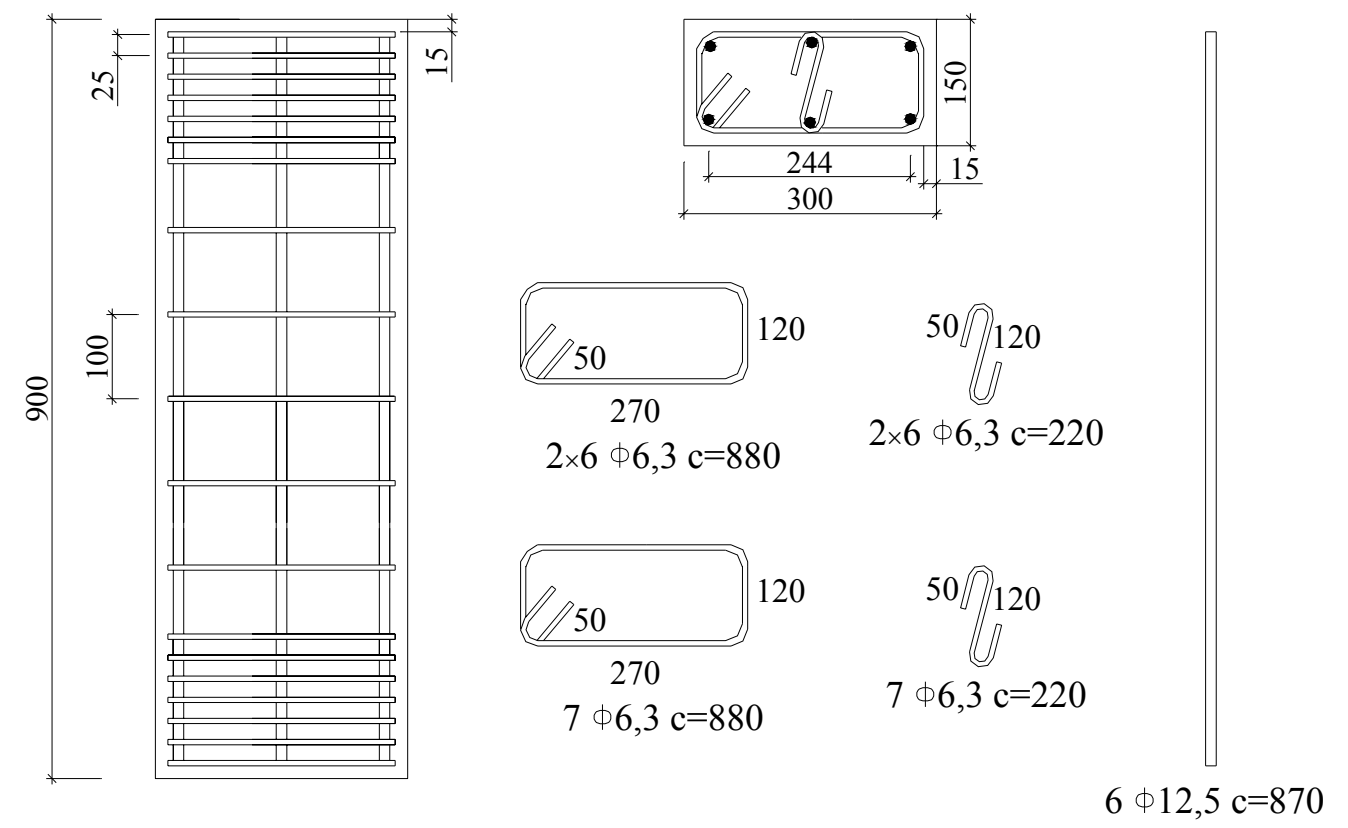

Figura 4.28 - Detalhamento da armadura do pilar P3-12,5-100
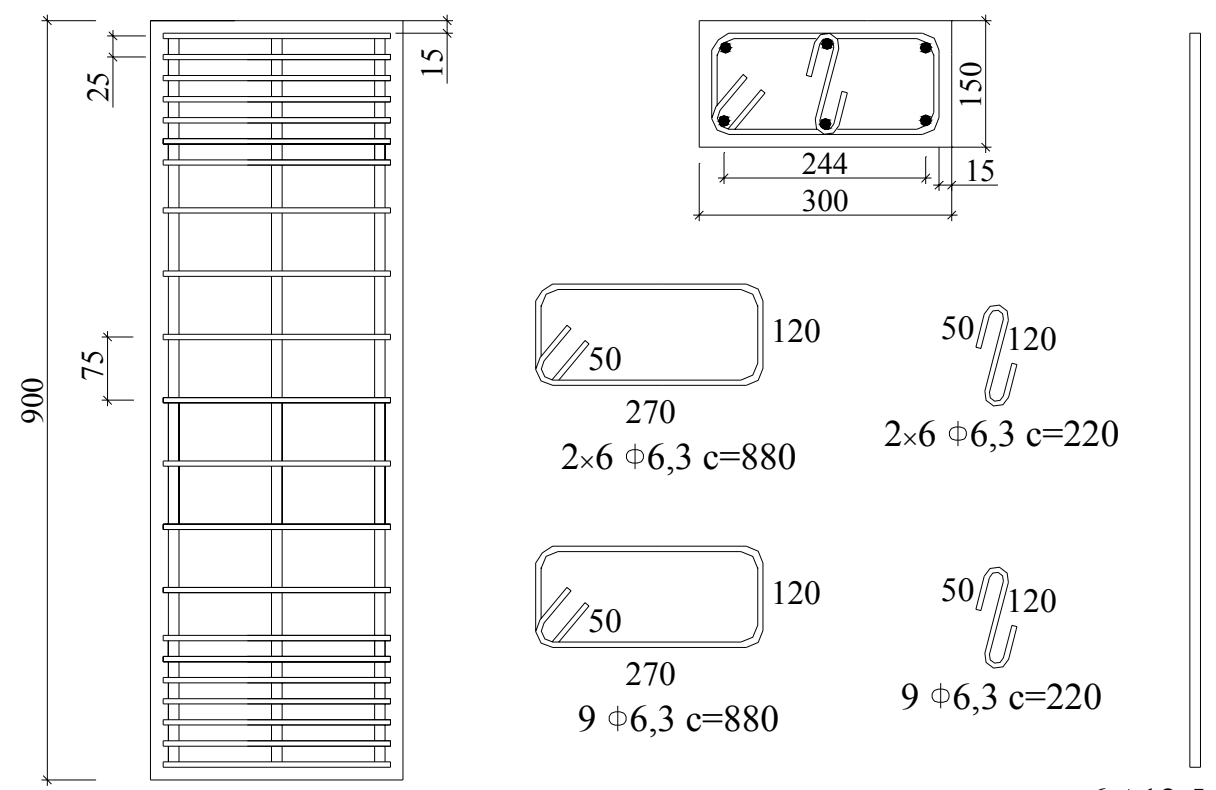

$6 \phi 12,5 \mathrm{c}=870$

Figura 4.29 - Detalhamento da armadura do pilar P3-12,5-075 

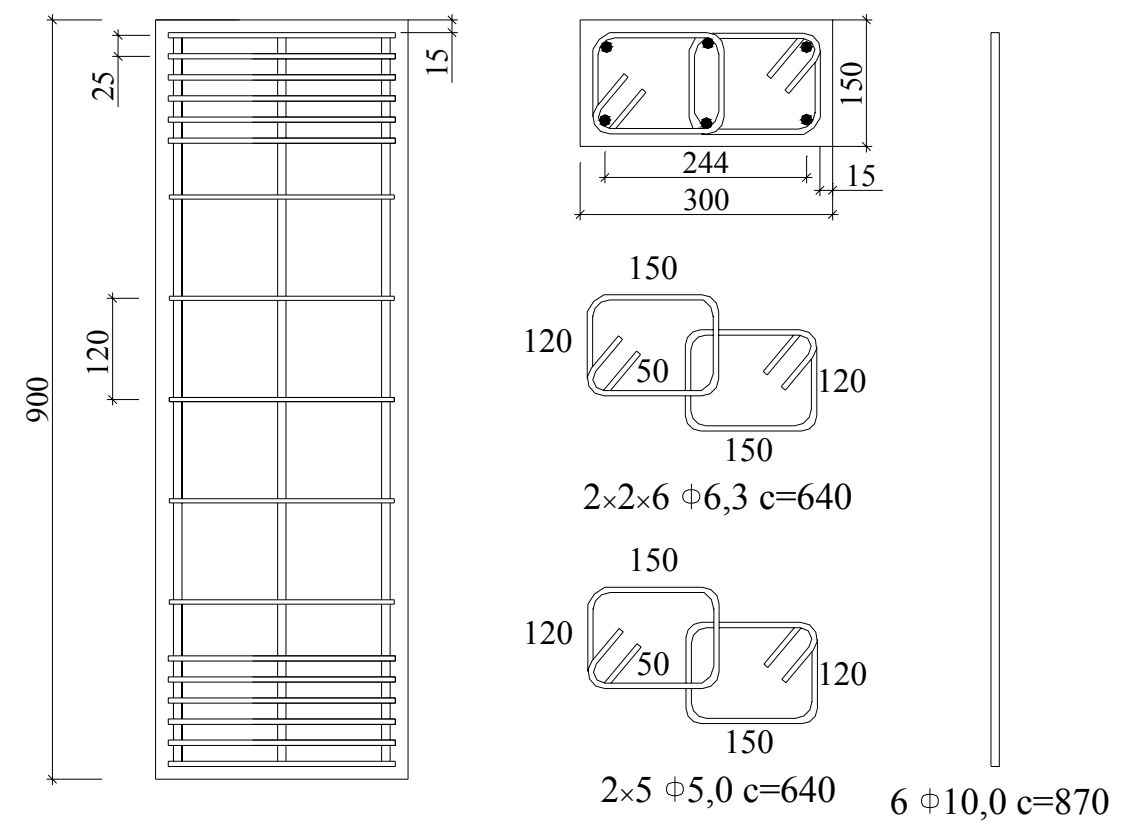

Figura 4.30 - Detalhamento da armadura do pilar P4-10,0-120
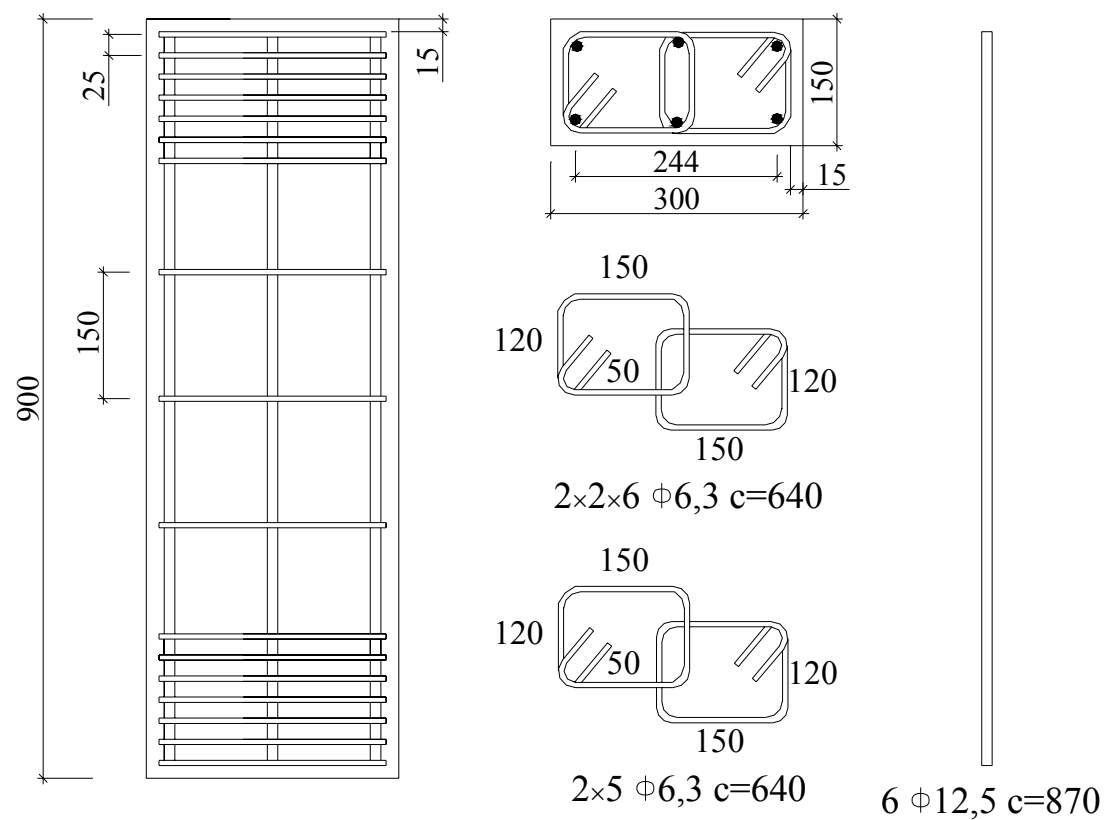

Figura 4.31 - Detalhamento da armadura do pilar P4-12,5-150 

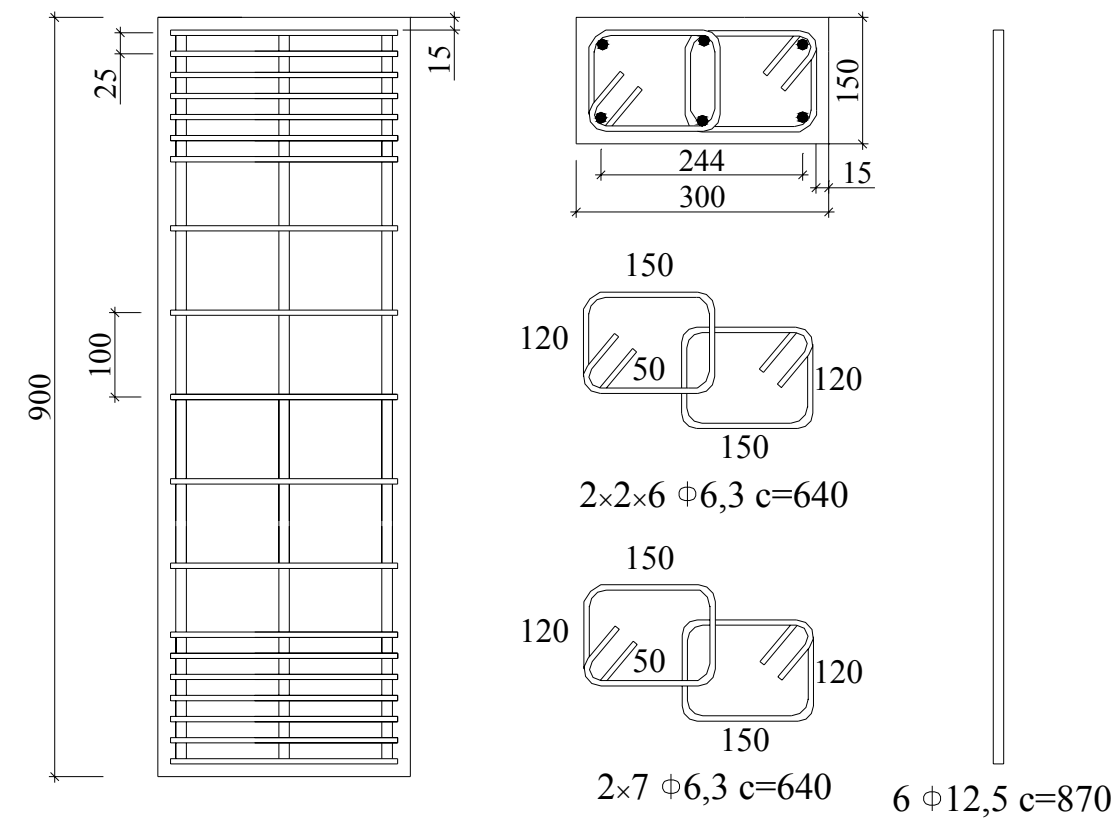

Figura 4.32 - Detalhamento da armadura do pilar P4-12,5-100
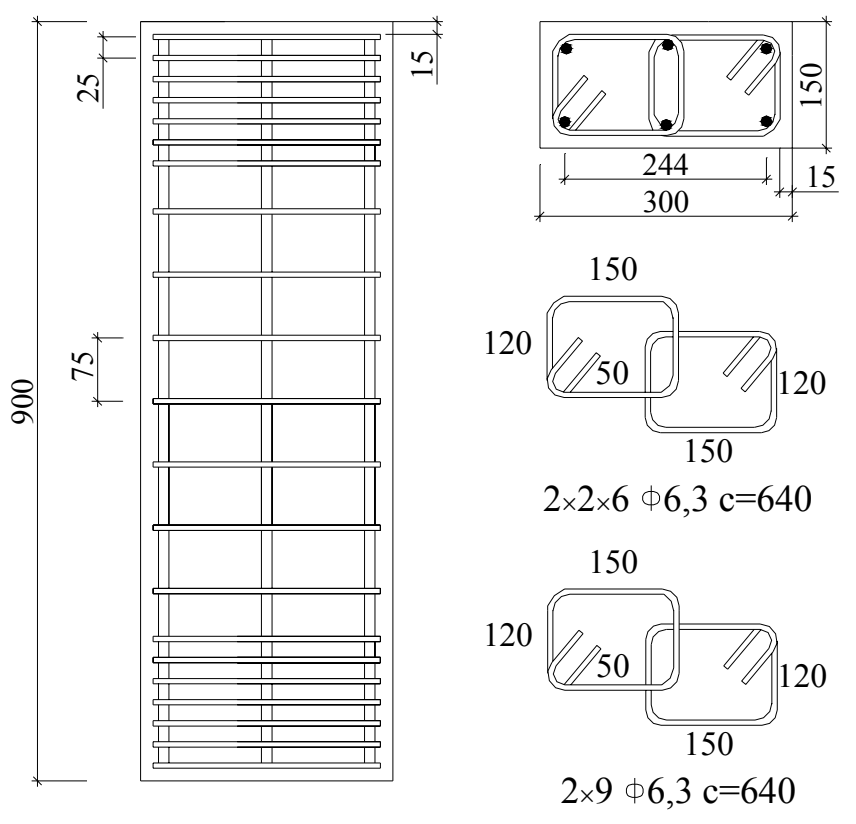

$6 \$ 12,5 c=870$

Figura 4.33 - Detalhamento da armadura do pilar P4-12,5-075 
A taxa de armadura transversal foi calculada de acordo com a equação 4.3, sugerida por Saatcioglu e Razvi (1992).

$$
\rho_{\mathrm{w}}=\frac{\sum \mathrm{A}_{\mathrm{st}}}{\mathrm{s} \cdot\left(\mathrm{c}_{\mathrm{x}}+\mathrm{c}_{\mathrm{y}}\right)}
$$

na qual, $\mathrm{A}_{\mathrm{st}}$ é a área da seção transversal do estribo; s é o espaçamento entre estribos; $c_{\mathrm{x}}$ e $\mathrm{c}_{\mathrm{y}}$ são as dimensões do núcleo do pilar, medidas de centro a centro dos estribos. A taxa de armadura longitudinal $\left(\rho_{\ell}\right)$ é igual a área de armadura longitudinal dividida pela área da seção transversal do pilar.

Tabela 4.3 - Propriedades geométricas dos modelos de pilares

\begin{tabular}{|c|c|c|c|c|c|c|c|}
\hline \multirow{2}{*}{$\begin{array}{l}\text { Modelo de } \\
\text { Pilar }\end{array}$} & \multirow{2}{*}{$\begin{array}{c}\text { Medidas da } \\
\text { seção } \\
(\mathbf{m m} \times \mathbf{m m})\end{array}$} & \multicolumn{3}{|c|}{ Armadura transversal } & \multicolumn{3}{|c|}{ Armadura longitudinal } \\
\hline & & $\begin{array}{c}\Phi_{\mathbf{t}} \\
(\mathbf{m m})\end{array}$ & $\begin{array}{c}\mathbf{s} \\
(\mathbf{m m})\end{array}$ & $\begin{array}{c}\rho_{w} \\
(\%)\end{array}$ & $\begin{array}{l}\text { Número } \\
\text { de barras }\end{array}$ & $\begin{array}{c}\Phi_{\ell} \\
(\mathbf{m m})\end{array}$ & $\begin{array}{c}\rho_{\ell} \\
(\%)\end{array}$ \\
\hline $\mathrm{P} 1-10,0-120$ & $200 \times 200$ & 5,0 & 120 & 0,198 & 4 & 10,0 & 0,79 \\
\hline$P 1-12,5-200$ & $200 \times 200$ & 6,3 & 200 & 0,189 & 4 & 12,5 & 1,23 \\
\hline $\mathrm{P} 1-12,5-150$ & $200 \times 200$ & 6,3 & 150 & 0,252 & 4 & 12,5 & 1,23 \\
\hline $\mathrm{P} 1-12,5-100$ & $200 \times 200$ & 6,3 & 100 & 0,378 & 4 & 12,5 & 1,23 \\
\hline $\mathrm{P} 2-10,0-120$ & $150 \times 300$ & 5,0 & 120 & 0,172 & 6 & 10,0 & 1,05 \\
\hline $\mathrm{P} 2-12,5-150$ & $150 \times 300$ & 6,3 & 150 & 0,219 & 6 & 12,5 & 1,64 \\
\hline $\mathrm{P} 2-12,5-100$ & $150 \times 300$ & 6,3 & 100 & 0,328 & 6 & 12,5 & 1,64 \\
\hline$P 2-12,5-075$ & $150 \times 300$ & 6,3 & 75 & 0,438 & 6 & 12,5 & 1,64 \\
\hline P3 - 10,0-120 & $150 \times 300$ & 5,0 & 120 & 0,215 & 6 & 10,0 & 1,05 \\
\hline P3 - 12,5-150 & $150 \times 300$ & 6,3 & 150 & 0,274 & 6 & 12,5 & 1,64 \\
\hline P3 - 12,5-100 & $150 \times 300$ & 6,3 & 100 & 0,412 & 6 & 12,5 & 1,64 \\
\hline P3 - 12,5-075 & $150 \times 300$ & 6,3 & 75 & 0,549 & 6 & 12,5 & 1,64 \\
\hline $\mathrm{P} 4-10,0-120$ & $150 \times 300$ & 5,0 & 120 & 0,259 & 6 & 10,0 & 1,05 \\
\hline $\mathrm{P} 4-12,5-150$ & $150 \times 300$ & 6,3 & 150 & 0,330 & 6 & 12,5 & 1,64 \\
\hline $\mathrm{P} 4-12,5-100$ & $150 \times 300$ & 6,3 & 100 & 0,495 & 6 & 12,5 & 1,64 \\
\hline $\mathrm{P} 4-12,5-075$ & $150 \times 300$ & 6,3 & 75 & 0,660 & 6 & 12,5 & 1,64 \\
\hline
\end{tabular}




\subsection{INSTRUMENTAÇÃO}

A medição das deformações nas armaduras dos modelos foi feita por meio de extensômetros elétricos de resistência fixados nas barras longitudinais e transversais, na seção média dos modelos. Para a medição das deformações nos modelos, foram utilizados LVDTs ao invés de ser usada a instrumentação do concreto, como disposto no item 2.3.4 deste trabalho. A figura 4.34 apresenta os desenhos das seções instrumentadas dos pilares de seção quadrada e retangular. A figura 4.35 apresenta a esquematização em 3D da instrumentação completa de um pilar da série P1 e a figura 4.36 a e de um pilar da série P4. A numeração não é seqüenciada, pois os LVDTs e as armaduras são ligadas em canais diferentes no sistema de aquisição de dados, assim tanto os transdutores quanto as armaduras possuem identificação a partir do número 1.
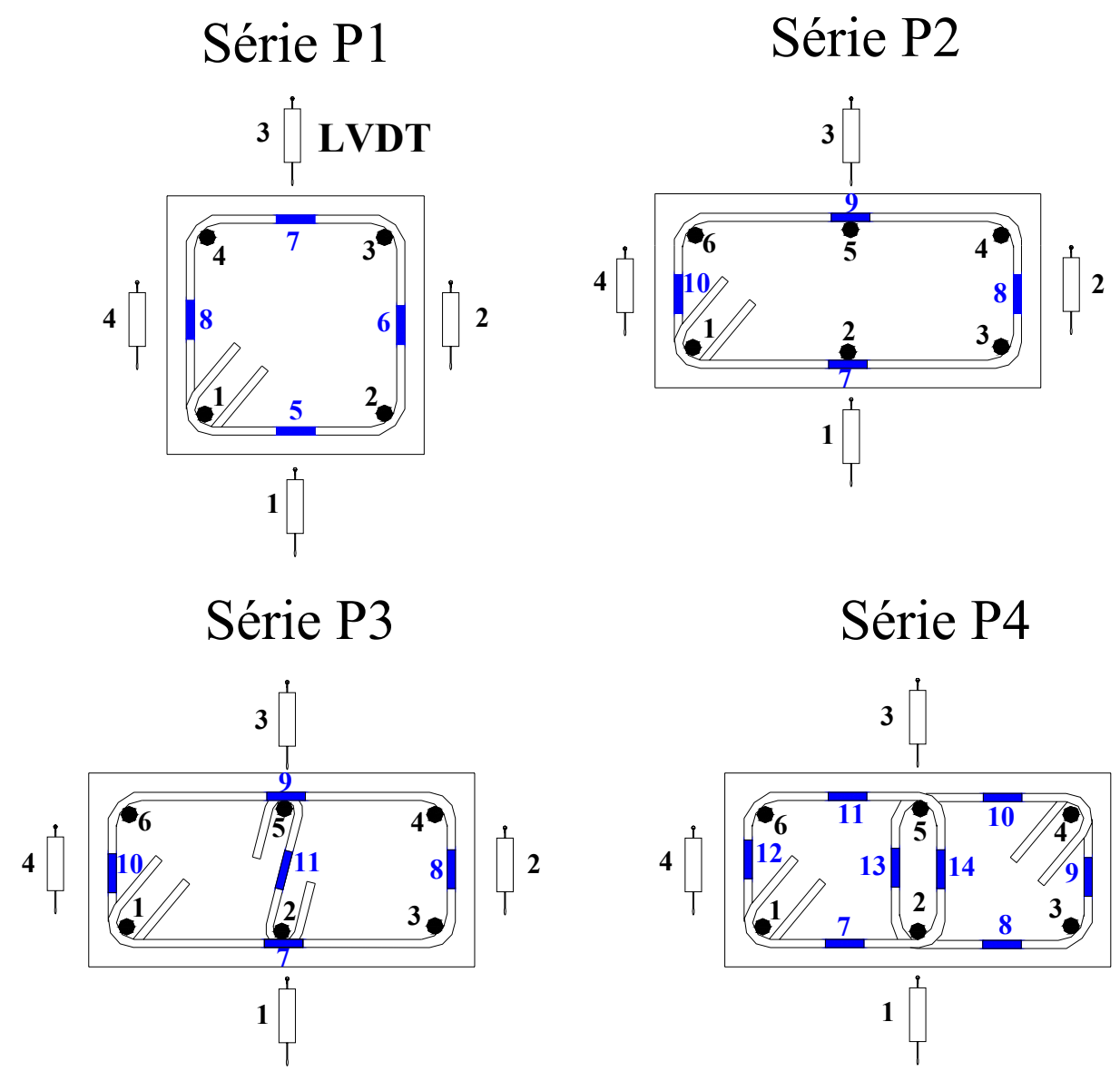

Figura 4.34 - Instrumentação empregada nas armaduras dos estribos 


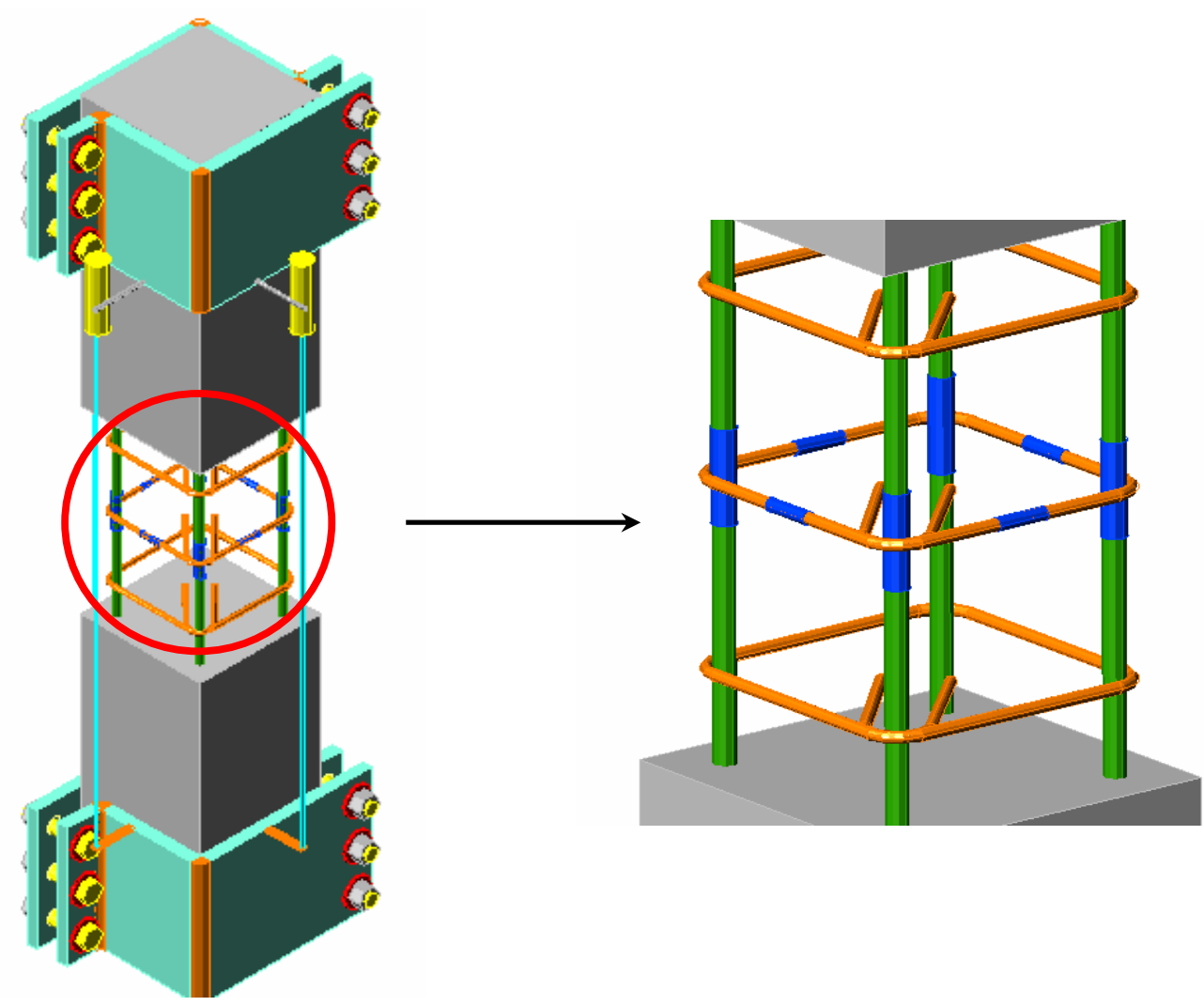

Figura 4.35 - Detalhe de um dos modelos da série P1

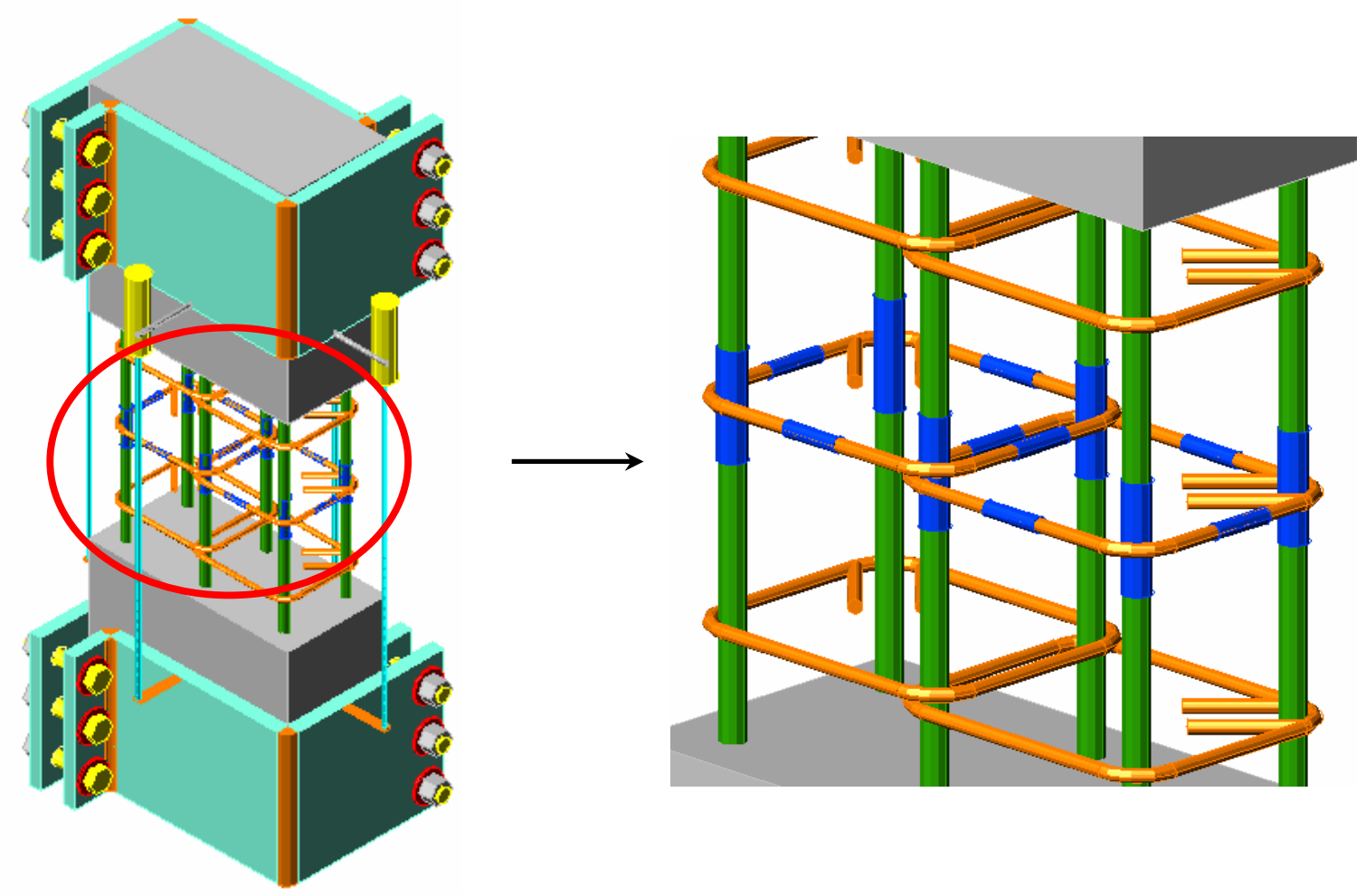

Figura 4.36 - Detalhe de um dos modelos da série P4 


\subsection{MOLDAGEM E CURA}

Todos os pilares foram moldados pela manhã. Na hora da moldagem foram anotados os dados de umidade e temperatura ambiente, pois influenciam na resistência final do concreto pelo aumento ou diminuição do abatimento da massa de concreto, como será exposto no item 5.1.1. As fotografias das figuras 4.37 e 4.38 apresentam a moldagem dos pilares e dos corpos-de-prova cilíndricos, respectivamente.

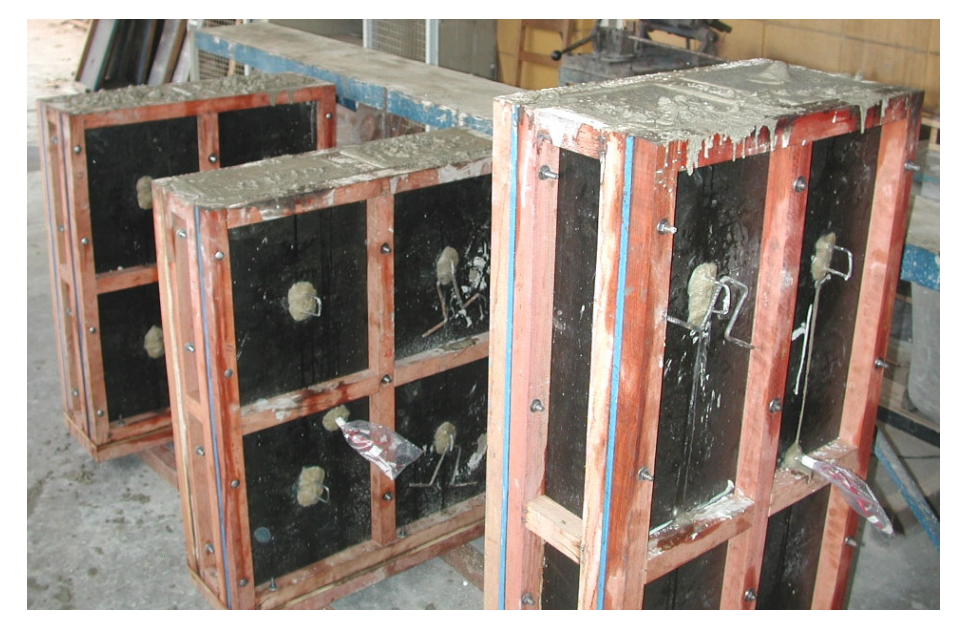

Figura 4.37 - Moldagem dos pilares

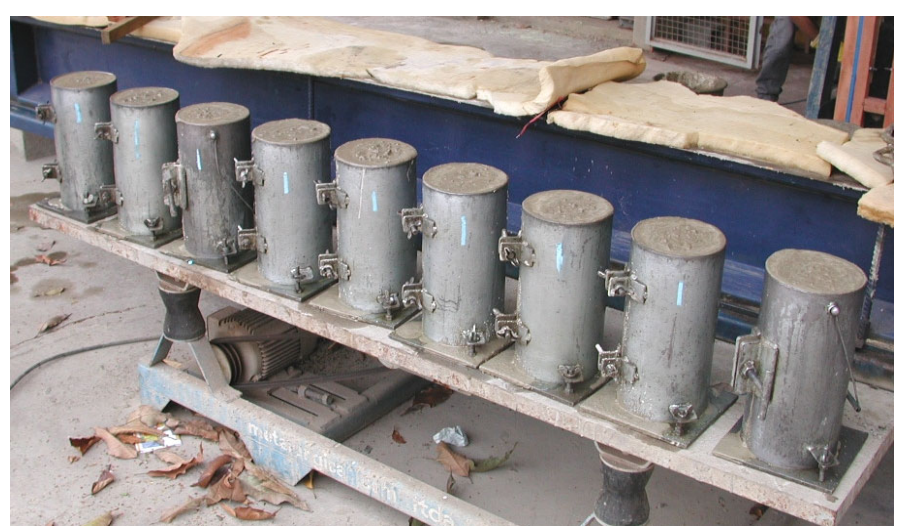

Figura 4.38 - Moldagem dos corpos-de-prova

Um ou dois dias após a moldagem, os pilares eram colocados em câmara úmida onde permaneciam por sete dias. Os corpos-de-prova eram desmoldados um dia após a moldagem e permaneciam também sete dias em câmara úmida. 


\subsection{PREVISÃo dA FORÇA Última}

Com base no exposto no item 2.3.3 deste trabalho e levando em consideração o valor da resistência do concreto no pilar, calculado pela equação 2.4, foram feitas as previsões das forças últimas dos modelos obedecendo a equação 4.4. $\mathrm{O}$ valor de $\mathrm{k}_{2}$ foi tomado como sendo a relação entre a resistência do concreto medida por meio dos prismas de concreto simples e as resistências medidas por meio dos corpos-de-prova cilíndricos, moldados com o mesmo traço, e é calculado pela equação 4.5. A tabela 4.4 apresenta a previsão da força última para os modelos.

$$
f_{\text {teo }}=f_{c, p i l a r} \cdot\left(A_{c}-A_{s}\right)+\sigma_{s} \cdot A_{s}
$$

Tabela 4.4 - Previsão da força última dos pilares

\begin{tabular}{|c|c|c|c|c|c|c|c|c|}
\hline \hline Modelo & $\begin{array}{c}\mathrm{f}_{\mathrm{c}, \mathrm{cp}} \\
(\mathrm{MPa})\end{array}$ & $\begin{array}{c}\mathrm{f}_{\mathrm{c}, \text { prisma }} \\
(\mathrm{MPa})\end{array}$ & $\begin{array}{c}\mathrm{h}_{\mathrm{y}} \\
(\mathrm{cm})\end{array}$ & $\begin{array}{c}\mathrm{h}_{\mathrm{x}} \\
(\mathrm{cm})\end{array}$ & $\begin{array}{c}\mathrm{A}_{\mathrm{s}} \\
\left(\mathrm{cm}^{2}\right)\end{array}$ & $\begin{array}{c}\sigma_{\mathrm{s}} \\
(\mathrm{MPa})\end{array}$ & $\mathrm{k}_{2}$ & $\begin{array}{c}\mathrm{F}_{\text {teo }} \\
(\mathrm{kN})\end{array}$ \\
\hline \hline P1-10,0-120 & 46,57 & 40,56 & 20 & 20 & 3,14 & 590,0 & 0,871 & 1794,89 \\
\hline P1-12,5-200 & 46,29 & 41,29 & 15 & 30 & 4,91 & 556,5 & 0,892 & 2110,73 \\
\hline P1-12,5-150 & 46,30 & 40,47 & 15 & 30 & 4,91 & 556,5 & 0,874 & 2074,46 \\
\hline P1-12,5-100 & 43,89 & 42,26 & 15 & 30 & 4,91 & 556,5 & 0,963 & 2154,13 \\
\hline P2-10,0-120 & 46,08 & 40,56 & 20 & 20 & 4,71 & 590,0 & 0,880 & 1881,20 \\
\hline P2-12,5-150 & 45,01 & 41,29 & 15 & 30 & 7,36 & 556,5 & 0,917 & 2237,18 \\
\hline P2-12,5-100 & 43,18 & 40,47 & 15 & 30 & 7,36 & 556,5 & 0,937 & 2201,11 \\
\hline P2-12,5-075 & 43,07 & 42,26 & 15 & 30 & 7,36 & 556,5 & 0,981 & 2280,34 \\
\hline P3-10,0-120 & 46,08 & 41,07 & 20 & 20 & 4,71 & 590,0 & 0,891 & 1901,48 \\
\hline P3-12,5-150 & 45,01 & 38,81 & 15 & 30 & 7,36 & 556,5 & 0,862 & 2127,63 \\
\hline P3-12,5-100 & 43,41 & 40,80 & 15 & 30 & 7,36 & 556,5 & 0,940 & 2215,72 \\
\hline P3-12,5-075 & 42,55 & 40,95 & 15 & 30 & 7,36 & 556,5 & 0,962 & 2222,36 \\
\hline P4-10,0-120 & 46,08 & 41,07 & 20 & 20 & 4,71 & 590,0 & 0,891 & 1901,48 \\
\hline P4-12,5-150 & 45,01 & 38,81 & 15 & 30 & 7,36 & 556,5 & 0,862 & 2127,63 \\
\hline P4-12,5-100 & 43,41 & 40,80 & 15 & 30 & 7,36 & 556,5 & 0,940 & 2215,72 \\
\hline P4-12,5-075 & 42,55 & 40,95 & 15 & 30 & 7,36 & 556,5 & 0,962 & 2222,36 \\
\hline \hline
\end{tabular}




$$
\mathrm{k}_{2}=\frac{\mathrm{f}_{\mathrm{c}, \mathrm{prisma}}}{\mathrm{f}_{\mathrm{c}, \mathrm{cp}}}
$$

\subsection{EQUIPAMENTOS DE ENSAIO}

Para os ensaios dos pilares à compressão centrada foi utilizada a máquina Instron, modelo 8506, do Laboratório de Estruturas da EESC/USP (Figura 4.39). Trata-se de um equipamento hidráulico, com controle eletrônico e computadorizado que permite a realização de ensaios estáticos com força nominal máxima de $2500 \mathrm{kN}$. Além de dispor de um espaço para ensaio de $822 \mathrm{~mm} \times 514 \mathrm{~mm} \times 4000 \mathrm{~mm}$, a Instron possibilita a aplicação da força sob velocidade de deslocamento constante do pistão ( $\mathrm{mm} / \mathrm{s}$ ou $\mathrm{mm} / \mathrm{min})$.

O sistema de aquisição dos valores dos deslocamentos e deformações que foram fornecidos, respectivamente, pelos transdutores e extensômetros, foi o System 5000, da Measurements Group (Figura 4.40).

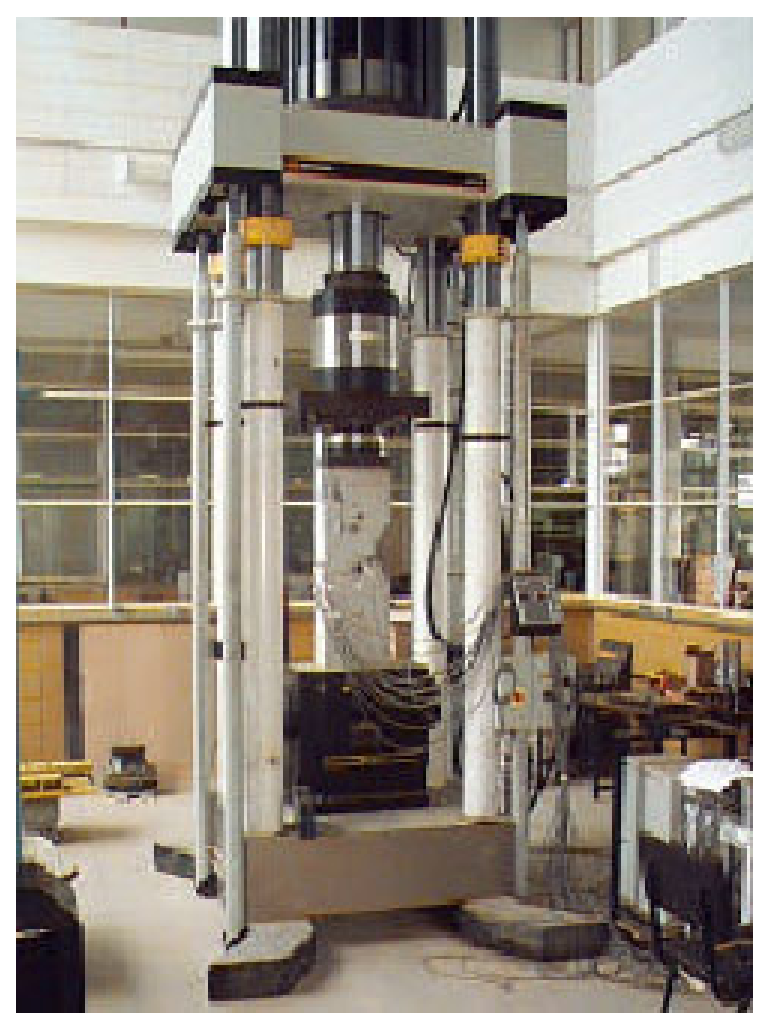

Figura 4.39 - Máquina de ensaios, marca INSTRON 


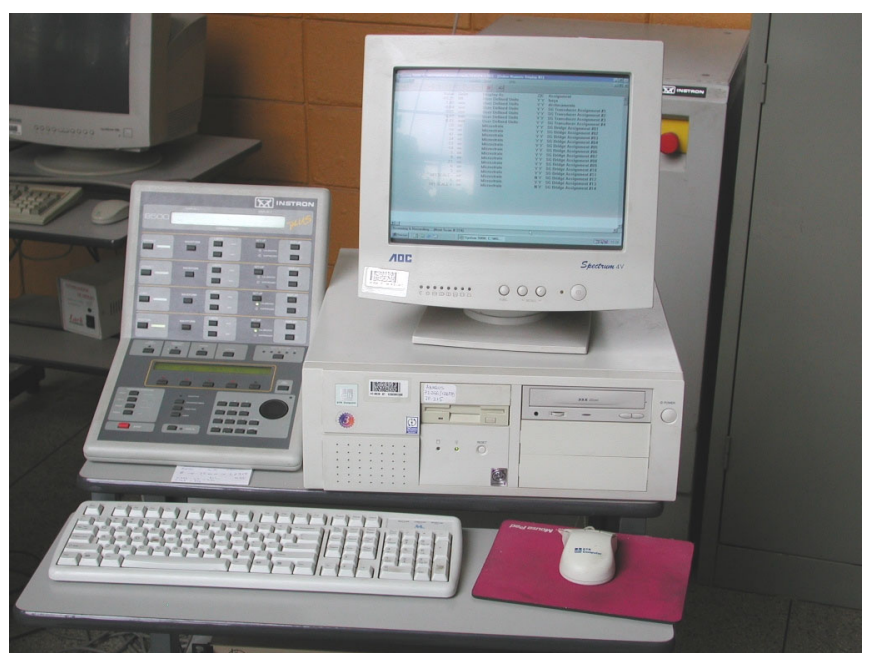

Figura 4.40 - Sistema de aquisição de dados 


\section{Capítulo 5}

\section{RESULTADOS EXPERIMENTAIS}

\subsection{PROPRIEDADES DO CONCRETO}

\subsubsection{Comportamento geral}

Como exposto no item 4.3 deste trabalho, a dosagem dos materiais para obtenção do concreto com resistência à compressão de $40 \mathrm{MPa}$ aos 14 dias foi de $1: 1,8: 2,82 \mathrm{e} \mathrm{a} / \mathrm{c}=0,58$. Todos os modelos foram concretados com essa dosagem, mas o valor da resistência final, medida por meio dos corpos-de-prova cilíndricos, variou $8,6 \%$.

Essa variação de resistência pode ter sido causada pelas variações climáticas nos dias das concretagens. Dias com umidade alta influem na fluidez da massa do concreto. Para cada concretagem foi medida a fluidez do concreto pelo abatimento do tronco de cone (slump), cujo procedimento está descrito na NBR NM 67:1998.

A tabela 5.1 apresenta a variação de resistência medida por meio dos corpos-de-prova cilíndricos, o slump medido em cada concretagem e a temperatura e a umidade medidas no dia da concretagem. 
Tabela 5.1 - Propriedades do concreto no dia da concretagem

\begin{tabular}{|c|c|c|c|c|c|}
\hline \hline Modelo & $\mathrm{T}\left({ }^{\circ} \mathrm{C}\right)$ & $\mathrm{U}(\%)$ & Slump $(\mathrm{cm})$ & $\begin{array}{c}\text { Idade do } \\
\text { concreto (dias) }\end{array}$ & $\mathrm{f}_{\mathrm{c}, \mathrm{cp}}(\mathrm{MPa})$ \\
\hline \hline P1-10,0-120 & 22 & 64 & 18,83 & 15 & 46,57 \\
\hline P1-12,5-200 & 21 & 75 & 19,58 & 14 & 46,29 \\
\hline P1-12,5-150 & 18 & 75 & 20,58 & 15 & 46,3 \\
\hline P1-12,5-100 & 20 & 85 & 21,83 & 14 & 43,89 \\
\hline P2-10,0-120 & 22 & 64 & 18,83 & 14 & 46,08 \\
\hline P2-12,5-150 & 21 & 75 & 19,58 & 13 & 45,01 \\
\hline P2-12,5-100 & 18 & 75 & 20,58 & 14 & 43,18 \\
\hline P2-12,5-075 & 20 & 85 & 21,83 & 13 & 43,07 \\
\hline \hline P3-10,0-120 & 22 & 64 & 18,83 & 14 & 46,08 \\
\hline P3-12,5-150 & 21 & 75 & 19,58 & 13 & 45,01 \\
\hline P3-12,5-100 & 18 & 75 & 20,58 & 14 & 43,41 \\
\hline P3-12,5-075 & 20 & 85 & 21,83 & 13 & 42,55 \\
\hline \hline P4-10,0-120 & 22 & 64 & 18,83 & 14 & 46,08 \\
\hline P4-12,5-150 & 21 & 75 & 19,58 & 13 & 45,01 \\
\hline P4-12,5-100 & 18 & 75 & 20,58 & 14 & 43,41 \\
\hline P4-12,5-075 & 20 & 85 & 21,83 & 13 & 42,55 \\
\hline \hline
\end{tabular}

Em cada dia de concretagem eram moldados 4 (quatro) pilares de concreto armado, 2 (dois) prismas não armados e 16 (dezesseis) corpos-de-prova cilíndricos, para os ensaios complementares (resistência à compressão e módulo de elasticidade). A capacidade da betoneira utilizada não era suficiente para a mistura de todos os modelos assim, em cada dia de concretagem, a betoneira era utilizada duas vezes, e o slump era medido em cada uma delas. Nos dias dos ensaios, não era possível fazer todos os ensaios no mesmo dia, assim, eram ensaiados 4 (quatro) pilares e 8 (oito) corpos-de-prova em um dia e o restante no outro. Quando a concretagem acontecia na sexta-feira, os ensaios eram realizados aos 13 e 14 dias, e quando a concretagem acontecia na segunda-feira, os ensaios eram realizados aos 14 e 15 dias.

As diferentes idades do concreto (entre 13 e 15 dias), não têm influência significativa para a variação da resistência do concreto, pois o concreto atingia 
aproximadamente $75 \%$ da sua resistência final aos 3 dias de idade, assim o ganho em resistência entre 13 e 15 dias de idade pode ser desprezado.

Os dados da tabela 5.1 mostram a influência da temperatura e da umidade no slump da massa do concreto e, conseqüentemente, na resistência final do mesmo. Para melhorar a visualização dos dados da tabela 5.1, a figura 5.1 apresenta uma superfície desenhada com os dados do slump em função da temperatura e da umidade. Essa superfície apresenta uma correlação, $\mathrm{r}^{2}$, de $100 \%$ sobre os pontos da tabela 5.1.

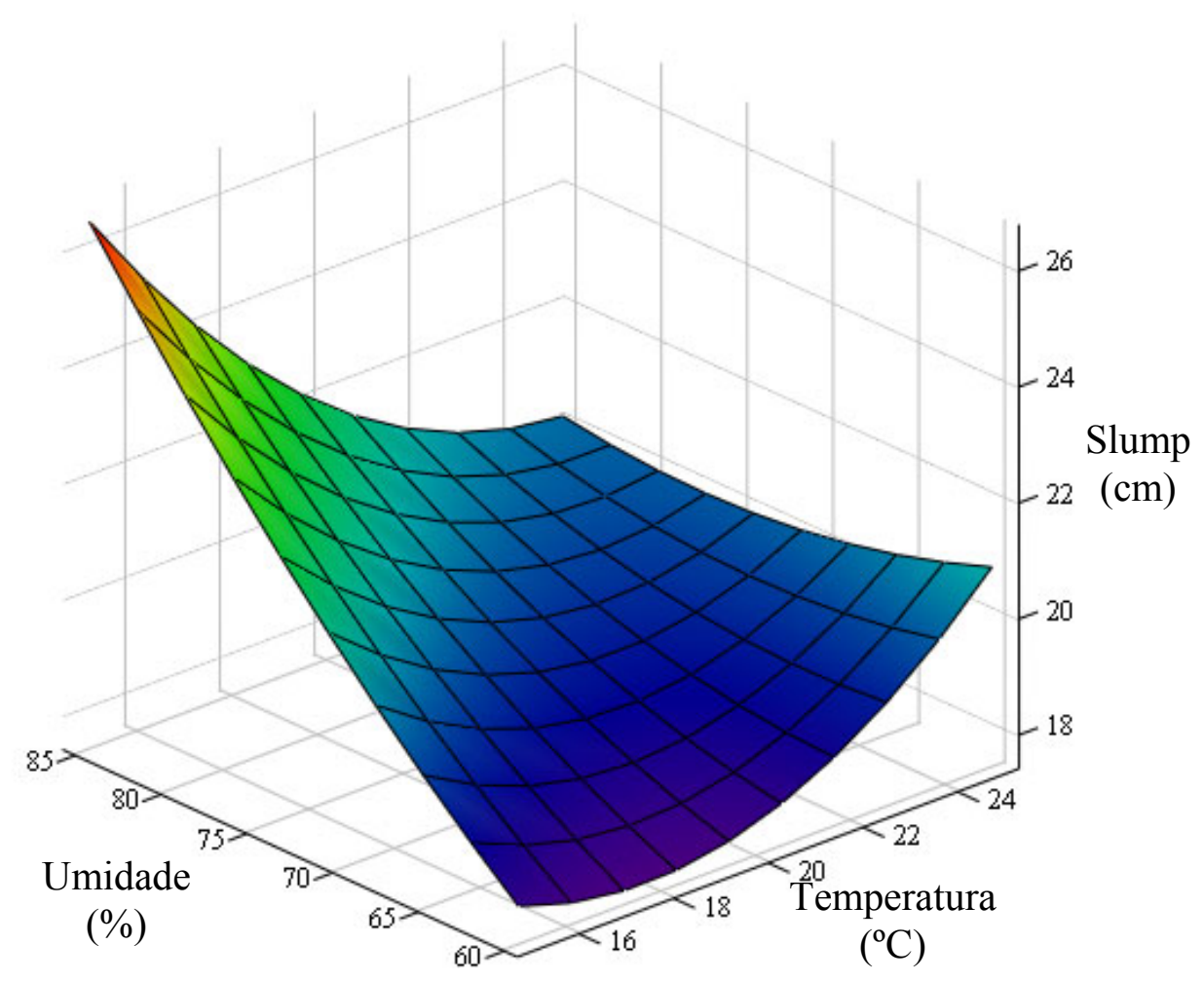

Figura 5.1 - Abatimento da massa de concreto em função da temperatura e umidade ambiente

Pela figura pode-se notar a influência que a umidade ambiente exerce sobre o slump do concreto, e conseqüentemente na resistência, como visto na tabela 5.1. A equação 5.1 foi obtida com base na superfície gerada, na qual x é a temperatura $\left({ }^{\circ} \mathrm{C}\right)$ e y é a umidade $(\%)$.

$$
S=0,01+0,099 \cdot x+0,404 \cdot y-0,037 \cdot x \cdot y+0,06 \cdot x^{2}+0,00335 \cdot y^{2}
$$


Os dezesseis corpos-de-prova cilíndricos moldados em cada concretagem eram ensaiados seguindo o esquema apresentado na tabela 5.2.

Tabela 5.2 - Esquema de ensaio dos corpos-de-prova cilíndricos

\begin{tabular}{c|c}
\hline Quantidade & $\begin{array}{c}\text { Idade do ensaio } \\
\text { (dias) }\end{array}$ \\
\hline \hline 2 & 3 \\
\hline 2 & 7 \\
\hline 3 & 14 \\
\hline 3 & 13 ou 15 \\
\hline 2 & 28 \\
\hline $2 *$ & 14 \\
\hline $2 *$ & 13 ou 15 \\
\hline \hline
\end{tabular}

* Corpos-de-prova ensaiados com controle de deformação para cálculo do módulo de elasticidade.

O maior número de corpos-de-prova aos 13, 14 ou 15 dias, é para ter melhor caracterização da resistência à compressão do concreto no dia do ensaio do modelo, pela média dos valores das resistências em cada corpo-de-prova. Este valor médio de resistência foi tomado como um dos dados de entrada no programa computacional usado.

A figura 5.2 apresenta a variação da resistência média à compressão do concreto com o tempo, medidas aos 3, 7, 14 e 28 dias em corpos-de-prova cilíndricos.

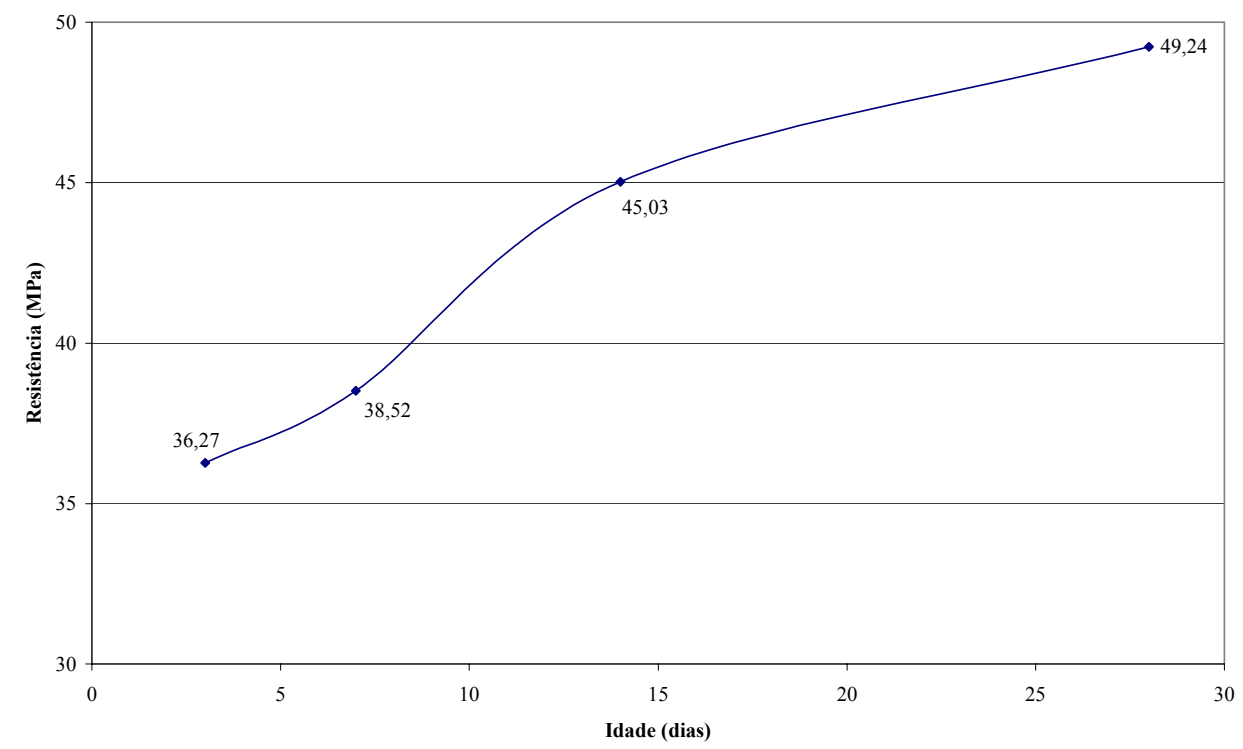

Figura 5.2 - Acréscimo da resistência com o tempo 


\subsubsection{Diagrama tensão vs. deformação do concreto}

Para a avaliação dos diagramas tensão vs. deformação dos corpos-deprova de cada concretagem, menos da primeira, ensaiaram-se, com controle de deformação, dois corpos-de-prova cilíndricos $15 \mathrm{~cm} \times 30 \mathrm{~cm}$ e dois prismas de concreto simples. As deformações nos corpos-de-prova cilíndricos foram avaliadas por meio de três LVDTs, com sensibilidade de $0,001 \mathrm{~mm}$, dispostos de forma triangular em pontos eqüidistantes, tendo como comprimento de avaliação todos os $30 \mathrm{~cm}$ da altura dos corpos-de-prova.

A metodologia utilizada para o ensaio dos prismas de concreto foi igual a metodologia do ensaio dos pilares. Foram dispostos colares metálicos nas extremidades dos prismas, aos quais foram acoplados 4 LVDTs com precisão de 0,01mm, um em cada face. O comprimento de avaliação das deformações foi de $80 \mathrm{~cm}$ para os prismas de seção quadrada e de $50 \mathrm{~cm}$ para 0 prismas de seção retangular. Nas figuras 5.3a e 5.3b, apresentam-se detalhes dos ensaios dos corpos-de-prova cilíndricos e nas figuras 5.4a, 5.4b e 5.4c. apresentam-se os detalhes dos ensaios dos prismas de concreto simples.

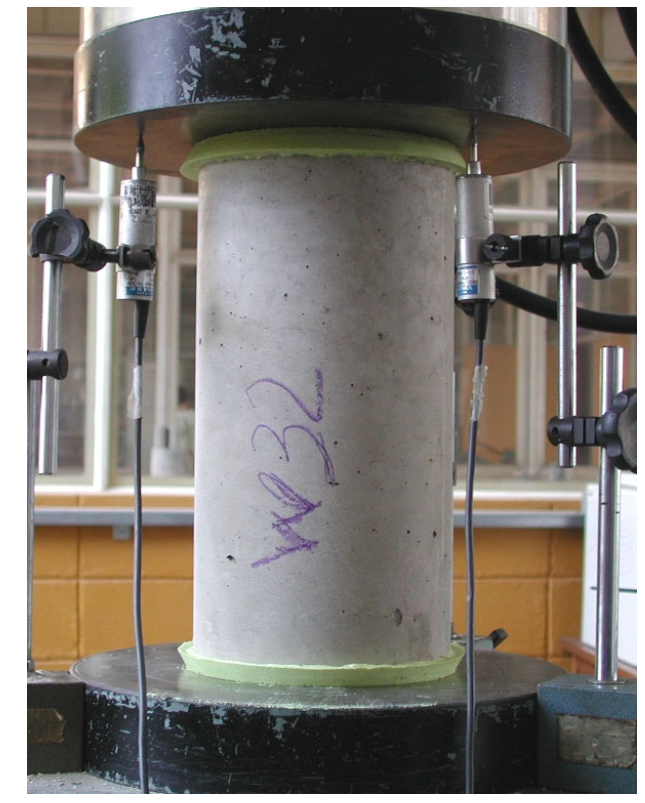

a

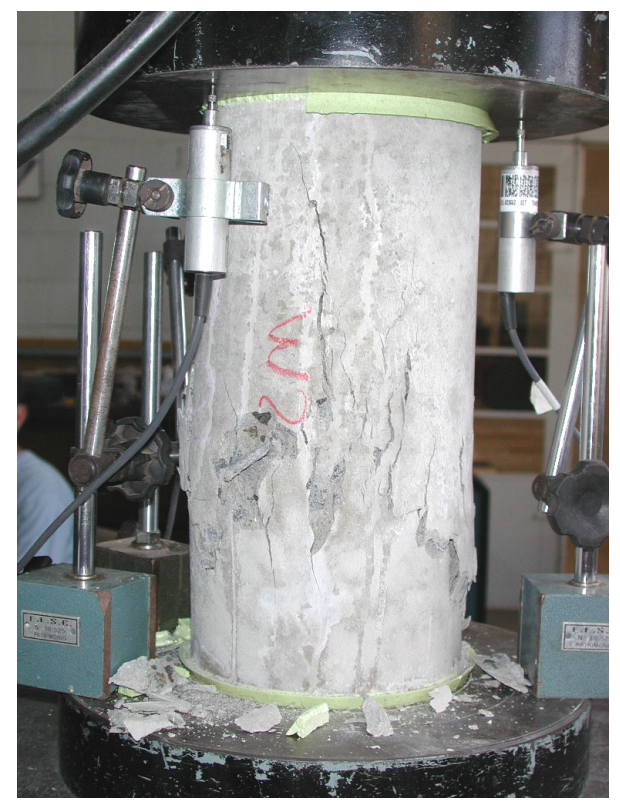

b

Figura 5.3 - a) Detalhe dos ensaios à compressão, com controle de deformação, dos corpos-de-prova cilíndricos; b) corpo-de-prova após a ruína. 


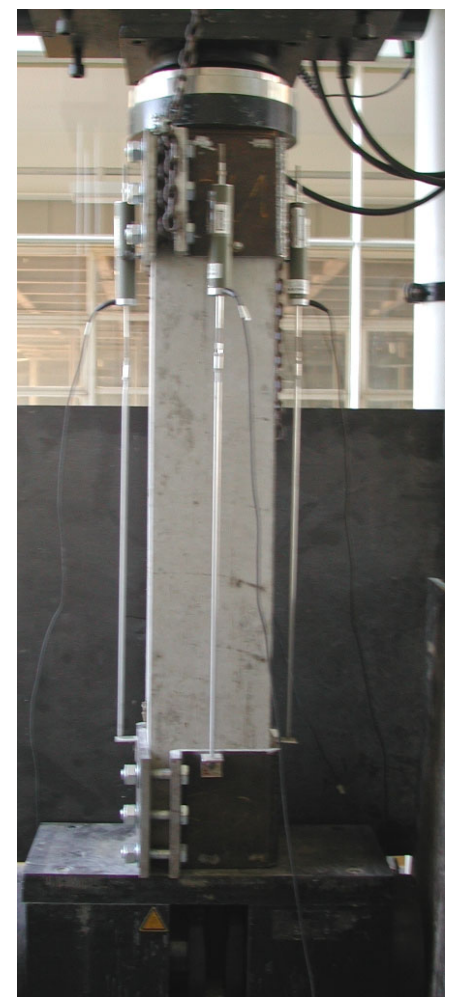

$\mathbf{a}$

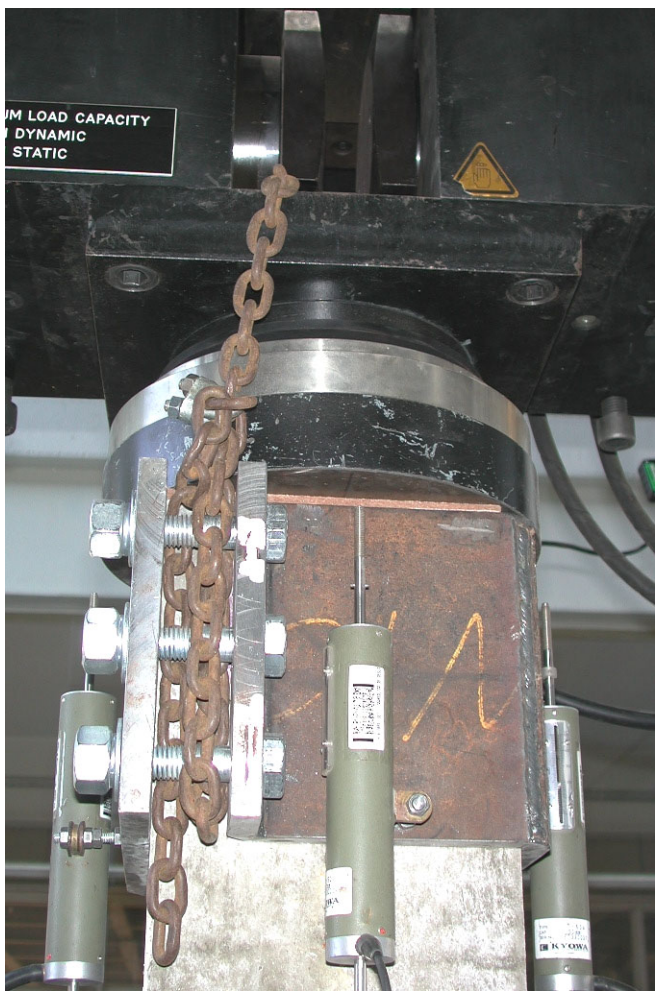

b

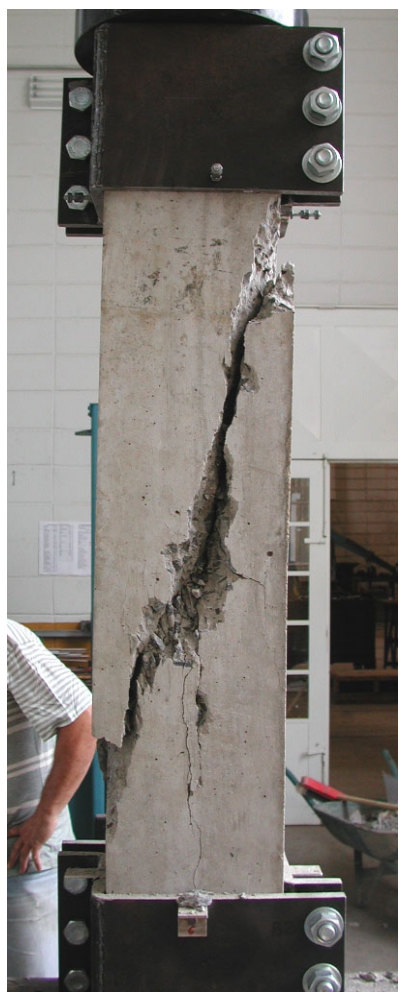

c

Figura 5.4 - a) prisma de concreto simples com dimensões $20 \mathrm{~cm} \times 20 \mathrm{~cm} \times 120 \mathrm{~cm}$ montado sobre a prensa; b) detalhe da corrente presa aos parafusos do colete metálico; c) modelo após o ensaio.

$\mathrm{Na}$ figura $5.4 \mathrm{a}$, nota-se a colocação de uma chapa de madeira atrás do prisma para impedir que algumas conexões da máquina de ensaio fossem atingidas por pedaços de concreto que se desprendiam dos prismas, por ocasião da ruína. A corrente usada no colar metálico, mostrada na figura 5.4b, impediu que a parte superior do prisma mostrado na figura $5.4 \mathrm{c}$ despencasse de cima da máquina de ensaio. Na figura 5.5a é apresentado o pilar da figura $5.4 \mathrm{c}$ sem a parte superior na máquina de ensaio e na figura 5.5b o mesmo prisma já colocado no chão. 


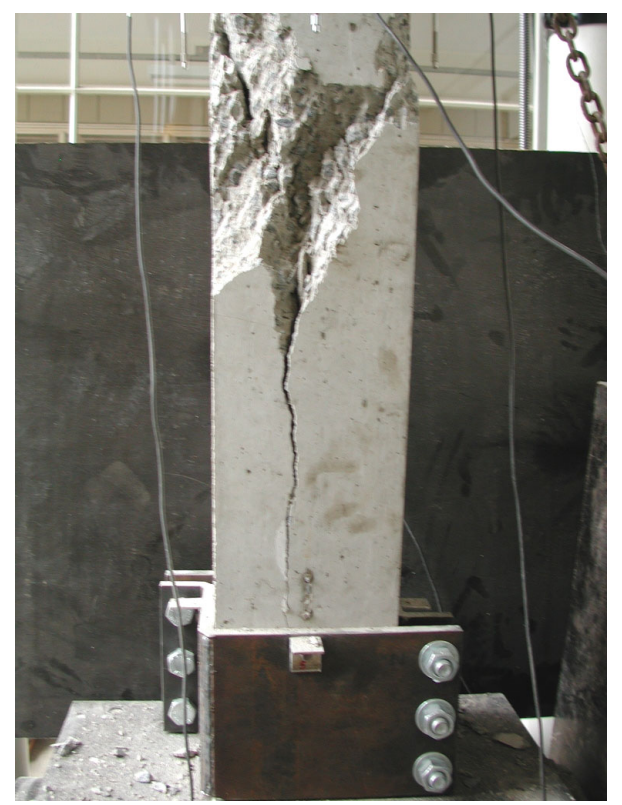

a

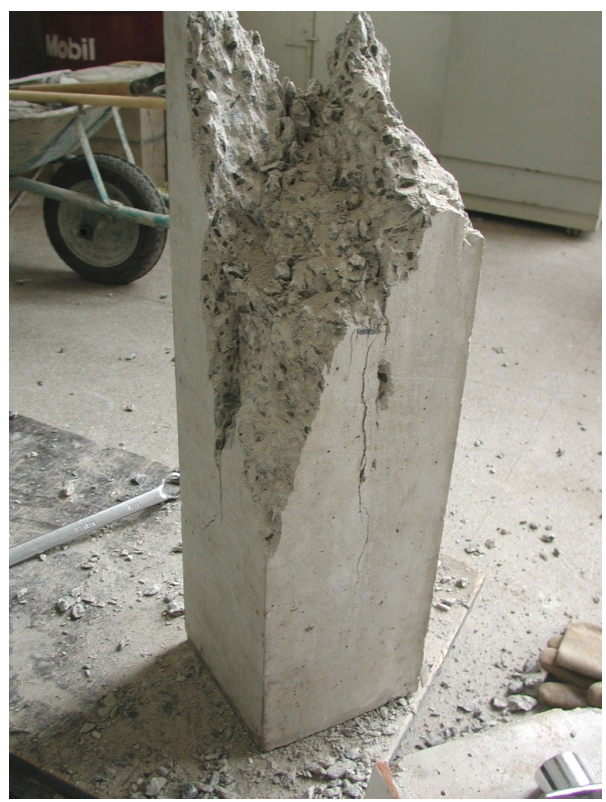

b

Figura 5.5 - a) prisma de concreto simples sem a metade superior; b) o mesmo prisma já no chão.

$\mathrm{Na}$ figura 5.5a nota-se uma grande fissura que se encaminhou para o colar metálico. Se o prisma não possuísse o colar, o mesmo poderia se dividir em dois na direção longitudinal. A figura 5.5b apresenta a extremidade inferior do prisma sem danos aparentes, ou seja, o colar metálico confinou a região da extremidade impedindo que a mesma fosse danificada.

Mesmo com a utilização de corrente para segurar a parte superior dos prismas de concreto e a aplicação da taxa mínima de deformação possível na máquina de ensaio $(0,001 \mathrm{~mm} / \mathrm{m} \cdot \mathrm{s})$, os ensaios de alguns prismas, por precaução, não foram levados até a ruína da peça, pois poderia haver ruptura brusca do mesmo por não haver confinamento do núcleo de concreto. Os diagramas tensão vs. deformação, tomando a média dos três corpos-de-prova e dos prismas, na segunda, terceira e quarta concretagens, são apresentados nas figuras 5.6, 5.7 e 5.8 , respectivamente. 


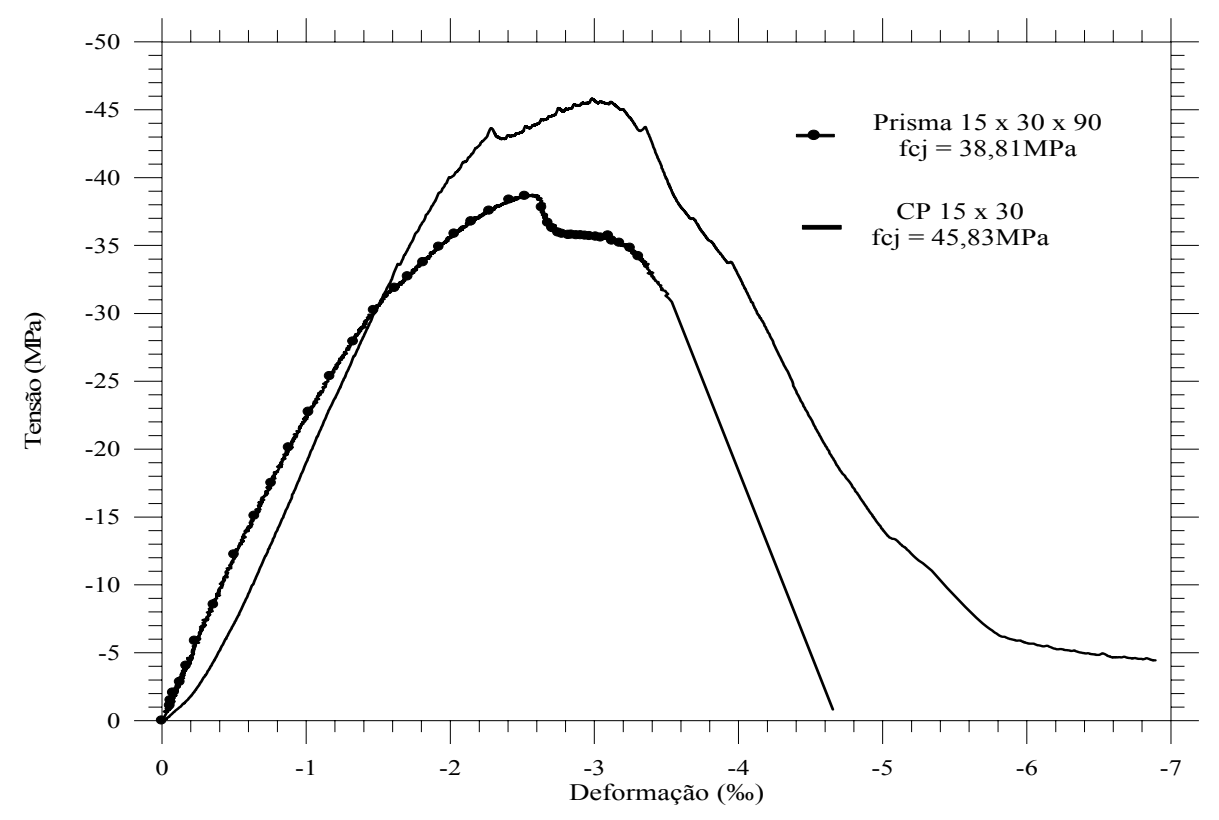

Figura 5.6 - Diagrama tensão vs. deformação do corpo-de-prova e do prisma da segunda concretagem

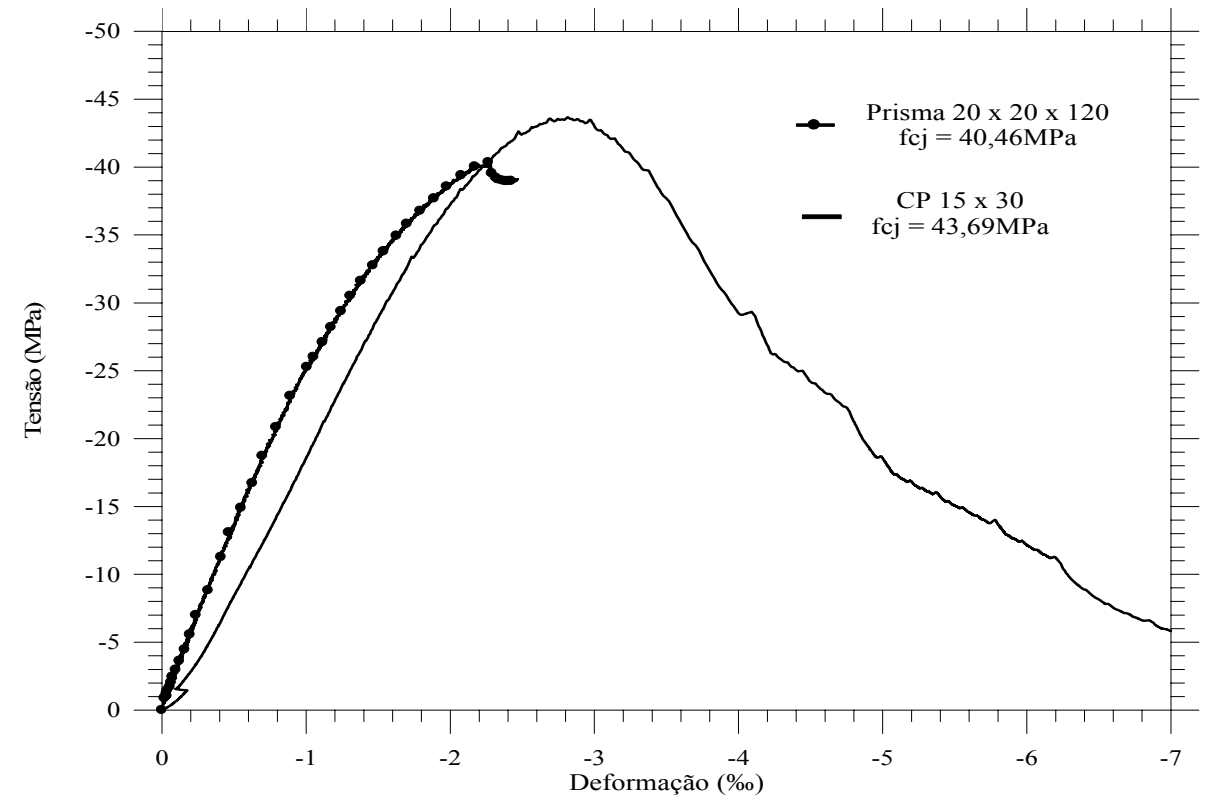

Figura 5.7 - Diagrama tensão vs. deformação do corpo-de-prova e do prisma da terceira concretagem 


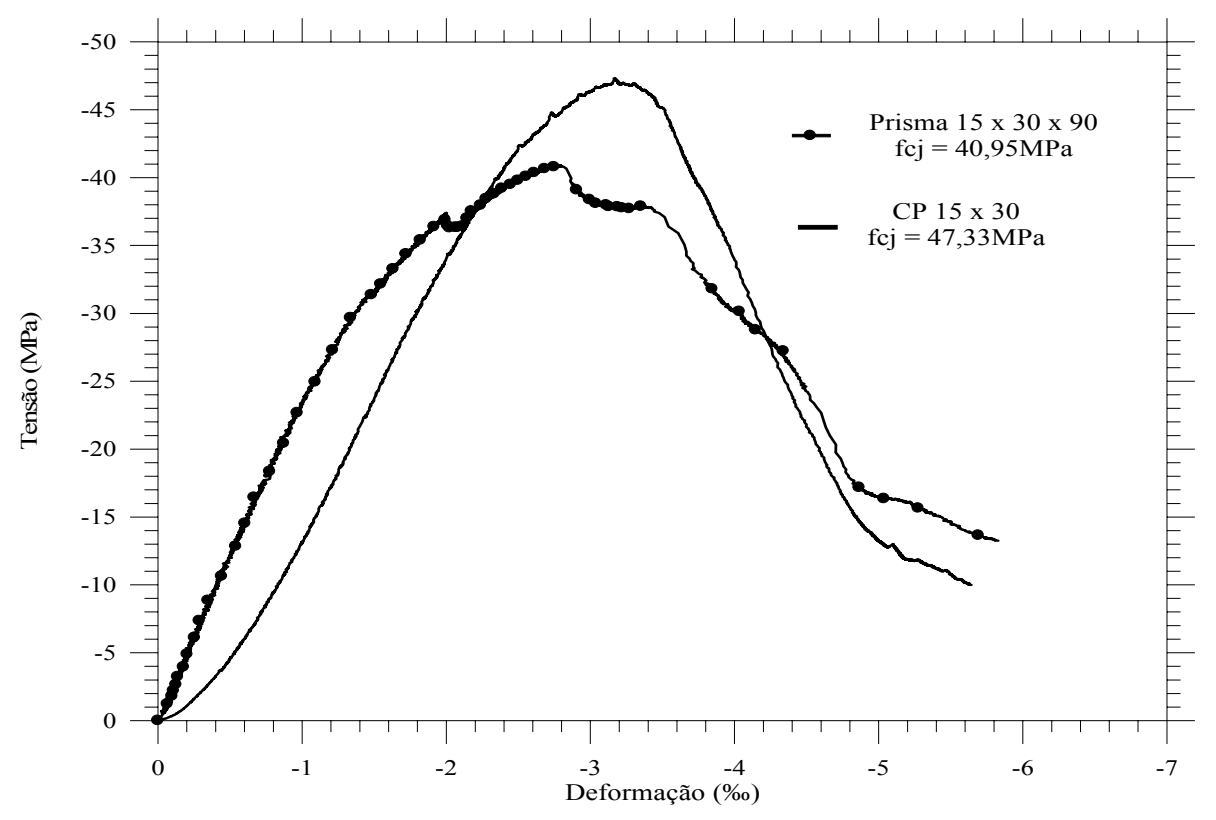

Figura 5.8 - Diagrama tensão vs. deformação do corpo-de-prova e do prisma da quarta concretagem

Em todos os casos, a resistência do concreto medida nos prismas de concreto simples foi inferior à resistência medida por meio dos corpos-de-prova cilíndricos. Em média, para os oito prismas de concreto simples ensaiados, a relação entre as duas resistências, que representa o coeficiente $\mathrm{k}_{2}$, foi igual a 0,914, como visto na tabela 4.4, no item 4.8 deste trabalho, fazendo-se a média dos valores da coluna $\mathrm{k}_{2}$. Esta relação será discutida com mais detalhes no item 6.2 deste trabalho.

\subsection{COMPORTAMENTO DOS PILARES}

Com o procedimento de ensaio utilizado, foi possível obter o comportamento pós-pico de todos os pilares de concreto armado. A taxa de deformação aplicada foi de $0,01 \mathrm{~mm} / \mathrm{m} \cdot \mathrm{s}$ até a ser atingida $80 \%$ da capacidade resistente do pilar, a partir daí a taxa de deformação foi reduzida para $0,005 \mathrm{~mm} / \mathrm{m} \cdot \mathrm{s}$, para melhor caracterização do trecho descendente do diagrama força aplicada vs. deformação. Depois de ser atingida a força, no trecho descendente, correspondente a $70 \%$ da força de pico, a taxa de deformação era 
incrementada para $0,01 \mathrm{~mm} / \mathrm{m} \cdot \mathrm{s}$, e o pilar levado à ruína. O ensaio era interrompido quando a deformação medida pelos quatro transdutores atingia o valor correspondente a três vezes o valor da deformação na força última do pilar, para que pudessem ser calculados os índices de ductilidade pós-pico dos pilares, como visto no item 2.8.5.2 deste trabalho.

Os colares metálicos serviram ao propósito de confinar as extremidades dos pilares e permitir o apoio dos transdutores. Em nenhum caso foi detectado escorregamento, fissuras ou ruptura das extremidades por conta dos ensaios. As figuras 5.9a e 5.9b apresentam os pilares P2-12,5-100 e P1-12,5-100, respectivamente, após atingirem o pico de resistência com os transdutores ainda posicionados. A figura 5.10 apresenta detalhes das extremidades dos pilares após o ensaio. O pedaço de concreto que falta na extremidade em um dos pilares da figura 5.10 se soltou quando as chapas foram retiradas.

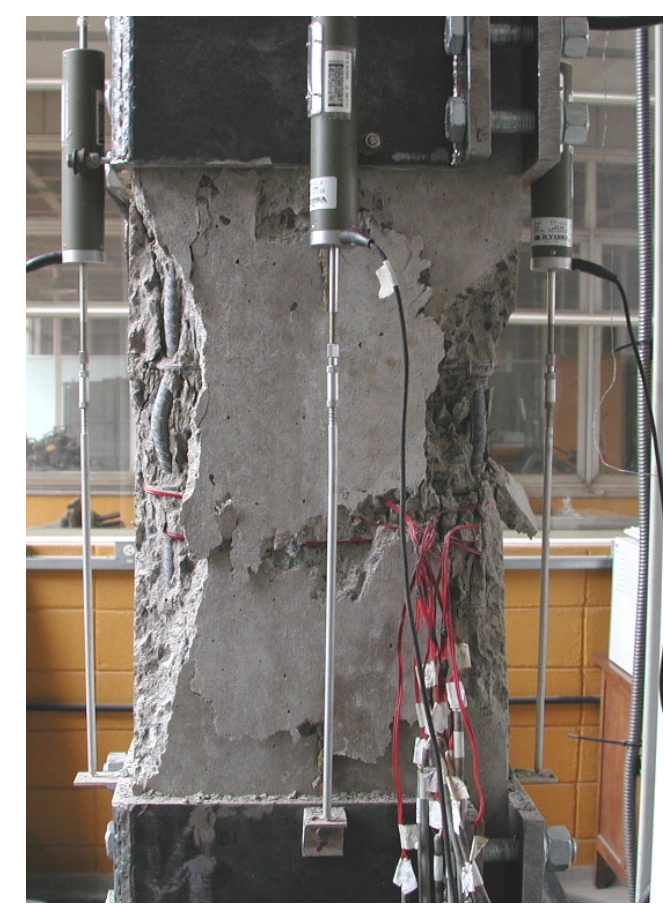

$\mathbf{a}$

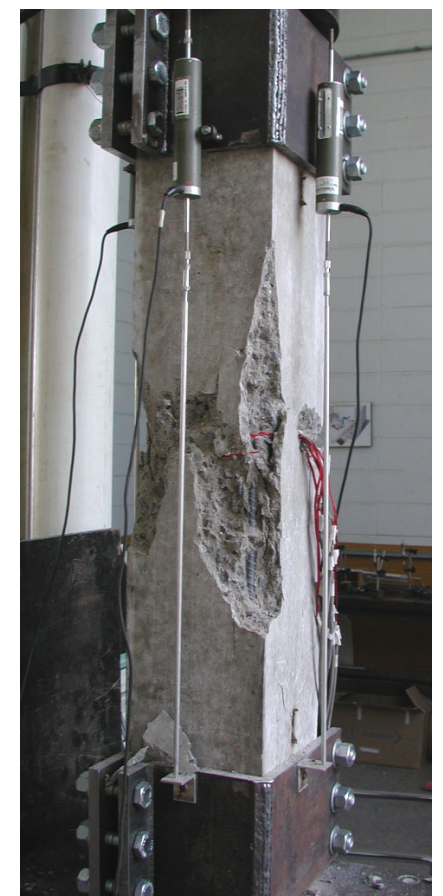

b

Figura 5.9 - Pilares com os transdutores ainda posicionados após serem atingidos os picos de resistência 


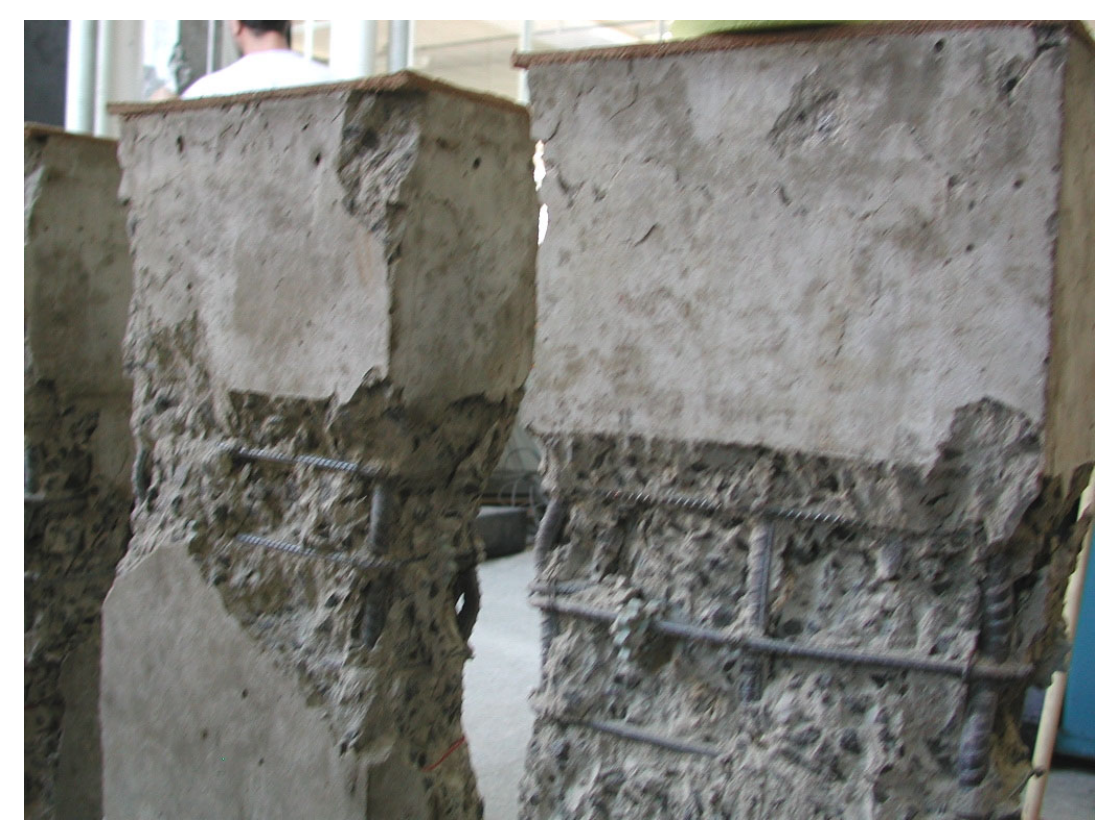

Figura 5.10 - Extremidades intactas dos pilares após o ensaio

A figura 5.11 apresenta os pilares moldados na segunda concretagem, e entre eles está o pilar que foi dimensionado não considerando as recomendações da NBR 6118:2003 (quinto da esquerda para direita - P1-12,5-200). Por causa do espaçamento entre os estribos desse pilar, as barras da armadura longitudinal flambaram com força inferior às dos outros pilares. Os resultados da análise experimental dos pilares serão discutidos individualmente no item 5.4 deste trabalho.

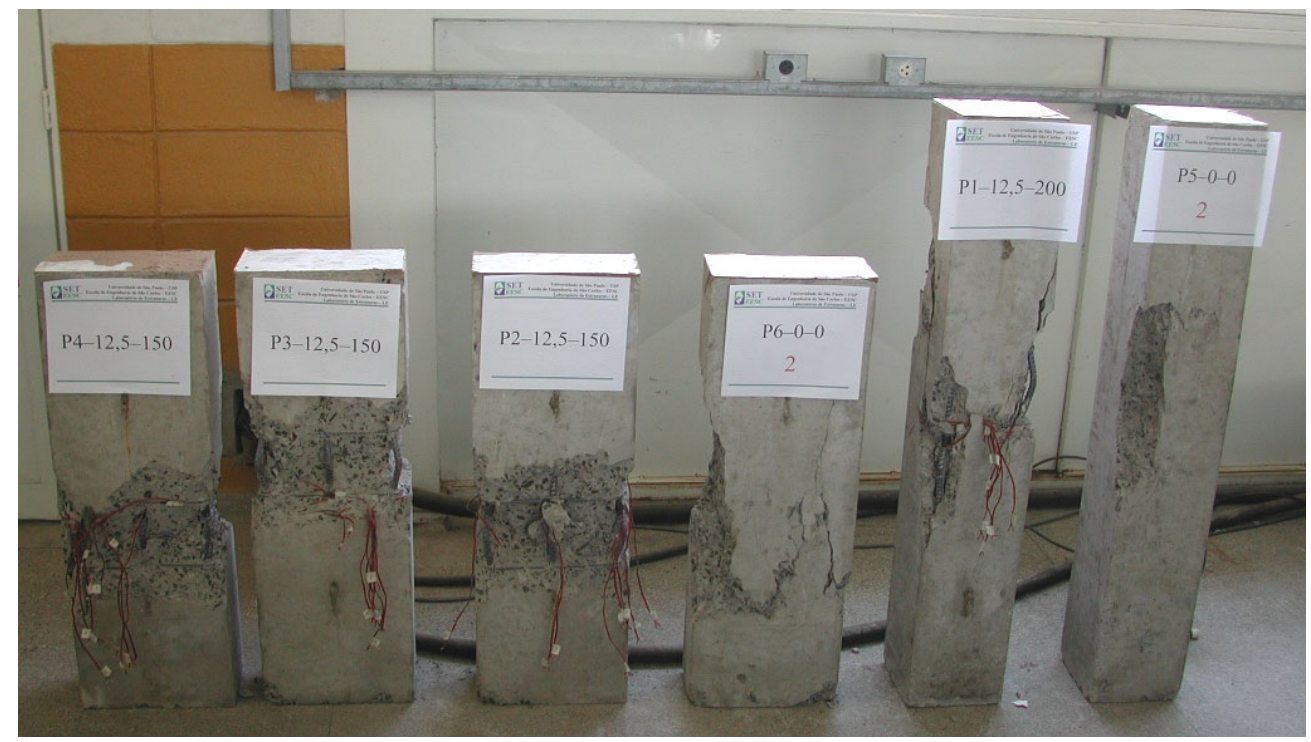

Figura 5.11 - Pilares da segunda concretagem 


\subsection{AVALIAÇÃO DA PREVISÃO DAS FORÇAS ÚLTIMAS}

No item 4.8 a tabela 4.4 apresenta a previsão da força última dos pilares, calculadas com os critérios adotados naquele item. A força última experimental foi comparada com a força última teórica calculada com três critérios diferentes:

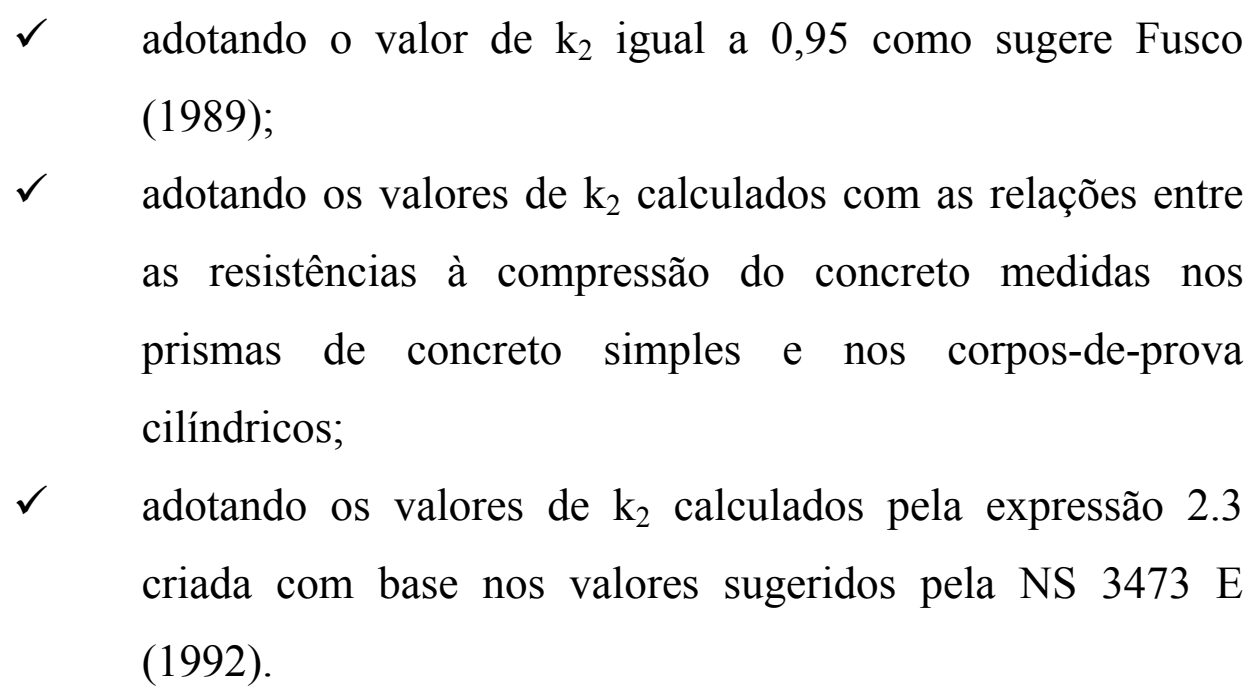

A tabela 5.3 apresenta os valores das forças últimas teóricas calculadas com os três critérios citados e os valores das forças últimas experimentais. Os dados de resistência do concreto, resistência do aço e demais dados para o cálculo das forças últimas estão na tabela 4.4. 
Tabela 5.3 - Previsão da força última adotando três critérios diferentes e resultados das forças últimas experimentais

\begin{tabular}{|c|c|c|c|c|c|c|c|}
\hline Modelo & $\begin{array}{c}\mathrm{k}_{2} \\
\text { Fusco } \\
(1989)\end{array}$ & $\begin{array}{c}\mathrm{F}_{\text {teo }}(\mathrm{kN}) \\
\text { Fusco } \\
(1989)\end{array}$ & $\begin{array}{c}\mathrm{k}_{2} \\
\text { deste } \\
\text { autor }\end{array}$ & $\begin{array}{c}\mathrm{F}_{\text {teo }}(\mathrm{kN}) \\
\text { deste } \\
\text { autor }\end{array}$ & $\begin{array}{c}\mathrm{k}_{2} \\
\text { NS } 3473 \text { E } \\
(1992)\end{array}$ & $\begin{array}{c}\mathrm{F}_{\text {teo }}(\mathrm{kN}) \\
\mathrm{NS} 3473 \mathrm{E} \\
(1992)\end{array}$ & $\begin{array}{l}\mathrm{F}_{\exp } \\
(\mathrm{kN})\end{array}$ \\
\hline P1-10,0-120 & 0,95 & 1941,12 & 0,871 & 1794,89 & 0,824 & 1709,09 & 1732,4 \\
\hline P1-12,5-200 & 0,95 & 2230,48 & 0,892 & 2110,73 & 0,825 & 1973,51 & 1810,6 \\
\hline P1-12,5-150 & 0,95 & 2230,91 & 0,874 & 2074,46 & 0,825 & 1973,82 & 1939,1 \\
\hline P1-12,5-100 & 0,95 & 2129,00 & 0,963 & 2154,40 & 0,833 & 1899,51 & 1880,1 \\
\hline P2-10,0-120 & 0,95 & 2008,44 & 0,880 & 1881,20 & 0,826 & 1782,39 & 2022,7 \\
\hline P2-12,5-150 & 0,95 & 2302,45 & 0,917 & 2237,18 & 0,829 & 2061,56 & 2335,1 \\
\hline P2-12,5-100 & 0,95 & 2225,50 & 0,937 & 2201,11 & 0,835 & 2005,20 & 1985,5 \\
\hline $\mathrm{P} 2-12,5-075$ & 0,95 & 2220,87 & 0,981 & 2279,97 & 0,835 & 2001,80 & 2099 \\
\hline P3-10,0-120 & 0,95 & 2008,44 & 0,891 & 1901,48 & 0,826 & 1782,39 & 2054,6 \\
\hline P3-12,5-150 & 0,95 & 2302,45 & 0,862 & 2127,63 & 0,829 & 2061,56 & 2266,5 \\
\hline P3-12,5-100 & 0,95 & 2235,17 & 0,940 & 2215,72 & 0,834 & 2012,31 & 2283,2 \\
\hline P3-12,5-075 & 0,95 & 2199,01 & 0,962 & 2221,61 & 0,837 & 1985,69 & 2159,3 \\
\hline P4-10,0-120 & 0,95 & 2008,44 & 0,891 & 1901,48 & 0,826 & 1782,39 & 1951,9 \\
\hline P4-12,5-150 & 0,95 & 2302,45 & 0,862 & 2127,63 & 0,829 & 2061,56 & 2295,7 \\
\hline P4-12,5-100 & 0,95 & 2235,17 & 0,940 & 2215,72 & 0,834 & 2012,31 & 2084,9 \\
\hline P4-12,5-075 & 0,95 & 2199,01 & 0,962 & 2221,61 & 0,837 & 1985,69 & 2042,4 \\
\hline Médias & 0,95 & & 0,91 & & $\mathbf{0 , 8 3}$ & & \\
\hline
\end{tabular}

A figura 5.12 apresenta o gráfico traçado com os valores da tabela 5.3. 


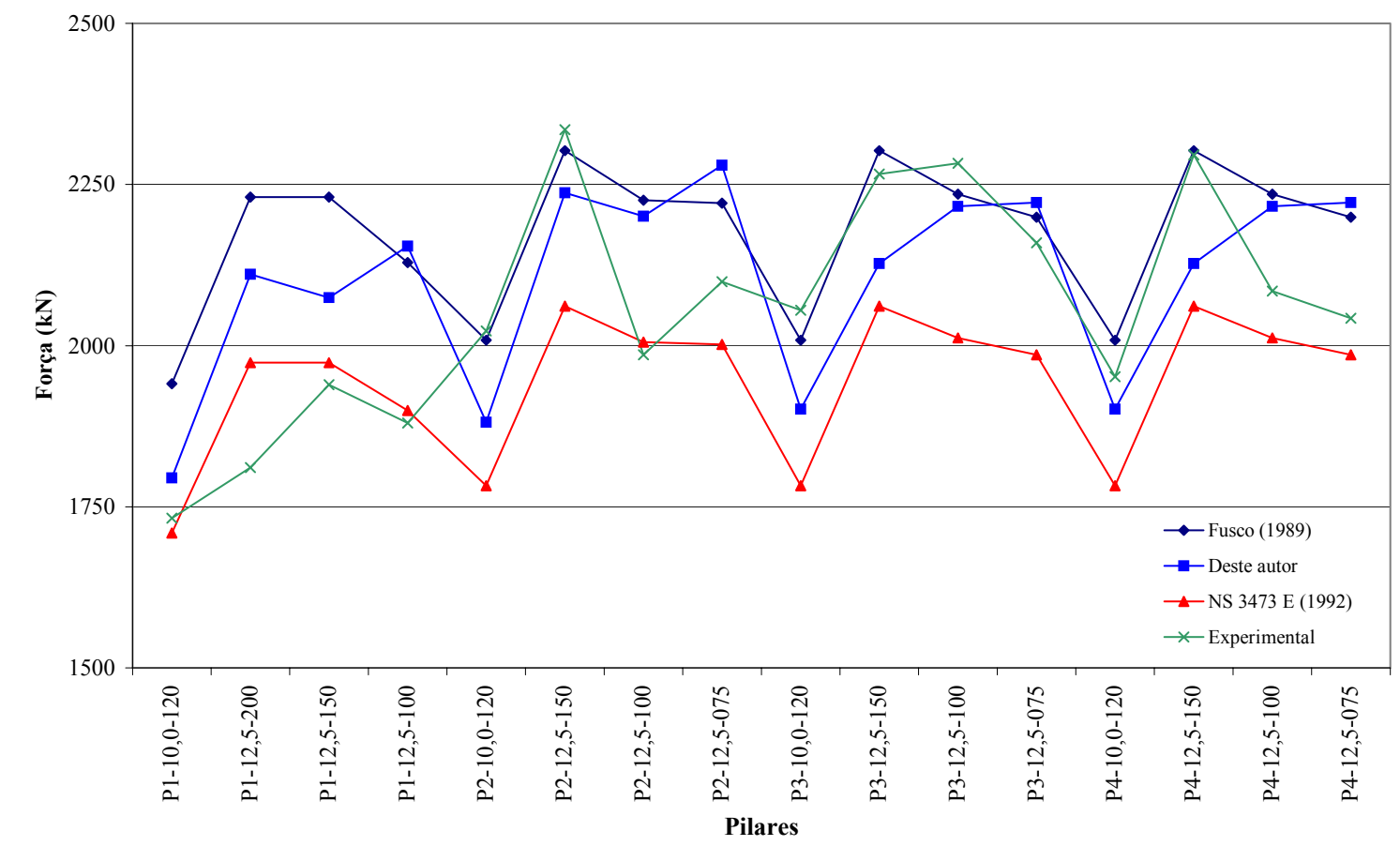

Figura 5.12 - Diagrama com os valores teóricos e experimentais das forças últimas dos pilares de concreto armado

A tabela 5.4 apresenta a relação entre as forças últimas calculadas com os critérios adotados e a força última experimental.

Em média, os valores indicados na tabela 5.4 da relação entre a força última teórica calculados com o critério da NS 3473 E (1992) se mostraram mais conservativos dos que os dos outros critérios, ficando, em média 5,3\% abaixo dos valores experimentais. Os valores das forças últimas calculadas com o $\mathrm{k}_{2}$ sugerido por Fusco (1989) apresentaram os piores resultados, ficando em média $6 \%$ acima dos valores experimentais. Com o valor de $\mathrm{k}_{2}$ obtido pela relação entre a resistência medida nos prismas de concreto simples e a resistência medida nos corpos-de-prova cilíndricos, os valores das forças últimas teóricas ficaram, em média, 2,6\% acima dos valores experimentais, ou seja, apesar de não serem conservativos como os da NS 3473 E (op. cit.) foram os que mais se aproximaram, em média, dos valores experimentais. 
Tabela 5.4 - Relação entre as forças últimas calculadas com os critérios adotados e a força última experimental

\begin{tabular}{|c|c|c|c|}
\hline \hline Modelo & $\frac{F_{\text {teo }}(\text { Fusco })}{F_{\text {exp }}}$ & $\frac{F_{\text {teo }}(\text { Deste autor })}{F_{\text {exp }}}$ & $\frac{F_{\text {teo }}(\text { NS3473) }}{F_{\text {exp }}}$ \\
\hline \hline P1-10,0-120 & 1,120 & 1,036 & 0,987 \\
\hline P1-12,5-200 & 1,232 & 1,166 & 1,090 \\
\hline P1-12,5-150 & 1,150 & 1,070 & 1,018 \\
\hline P1-12,5-100 & 1,132 & 1,146 & 1,010 \\
\hline P2-10,0-120 & 0,993 & 0,930 & 0,881 \\
\hline P2-12,5-150 & 0,986 & 0,958 & 0,883 \\
\hline P2-12,5-100 & 1,121 & 1,109 & 1,010 \\
\hline P2-12,5-075 & 1,058 & 1,086 & 0,954 \\
\hline \hline P3-10,0-120 & 0,978 & 0,925 & 0,868 \\
\hline P3-12,5-150 & 1,016 & 0,939 & 0,910 \\
\hline P3-12,5-100 & 0,979 & 0,970 & 0,881 \\
\hline P3-12,5-075 & 1,018 & 1,029 & 0,920 \\
\hline P4-10,0-120 & 1,029 & 0,974 & 0,913 \\
\hline P4-12,5-150 & 1,003 & 0,927 & 0,898 \\
\hline P4-12,5-100 & 1,072 & 1,063 & 0,965 \\
\hline P4-12,5-075 & 1,077 & 1,088 & 0,972 \\
\hline \hline Médias & $\mathbf{1 , 0 6 0}$ & $\mathbf{1 , 0 2 6}$ & $\mathbf{0 , 9 4 7}$ \\
\hline \hline
\end{tabular}

No item 6.2 deste trabalho será feito o cálculo da variável $\mathrm{k}_{2}$ em pilares de concreto armado com base nos dados experimentais de Lima (1997), Queiroga (1999), Ramos e Giongo (2002) e deste trabalho, tomando os valores das forças últimas experimentais desses autores e subtraindo o valor da resistência correspondente à contribuição das armaduras longitudinais, obtendo assim uma resistência do prisma de concreto. Essa resistência foi dividida pela resistência média medida nos corpos-de-prova cilíndricos, e, com isso foram calculados novos coeficientes $\mathrm{k}_{2}$. 


\subsection{DESCRIÇÃO INDIVIDUAL DOS RESULTADOS}

\section{EXPERIMENTAIS DOS PILARES DE CONCRETO ARMADO}

Com o objetivo de tornar a leitura deste item mais dinâmica, optou-se por apresentar os diagramas de tensão vs. deformação das armaduras longitudinais e transversais, obtidos por meio dos ensaios experimentais, no apêndice B deste trabalho.

Para o traçado do diagrama tensão vs. deformação dos pilares, foi tomada a média dos valores medidos pelos quatro transdutores, e esses diagramas serão apresentados no item 6.3 juntamente com os dados obtidos por meio da análise numérica. A discussão a respeito da ductilidade dos pilares será feita no item 6.1.

Antes dos ensaios as extremidades dos pilares foram regularizadas para que não houvesse flexões indesejadas, mas este procedimento não evitou que acontecessem, como pode ser visto nos diagramas deste item.

Para melhorar a regularidade das extremidades superiores dos pilares, foram usadas almofadas de madeira flexível. A extremidade inferior possuía acabamento liso, pois ficava em contato com a base da fôrma, não necessitando de cuidados maiores antes do ensaio. As fotografias das figuras 5.13 e 5.14 apresentam detalhes das almofadas usadas na extremidade superior dos pilares.

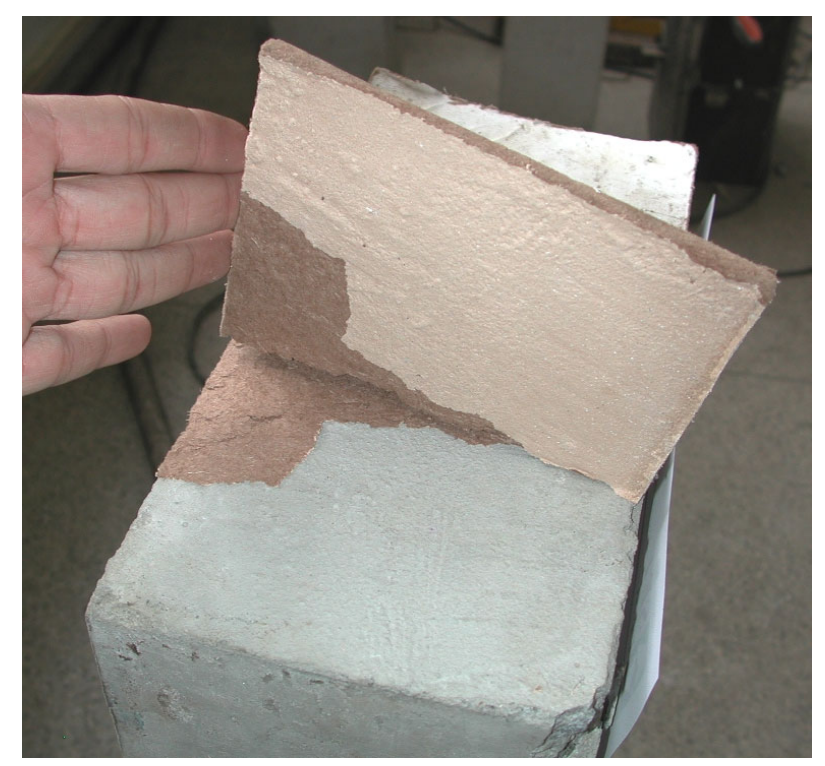

Figura 5.13 - Almofada da extremidade do pilar após o ensaio 


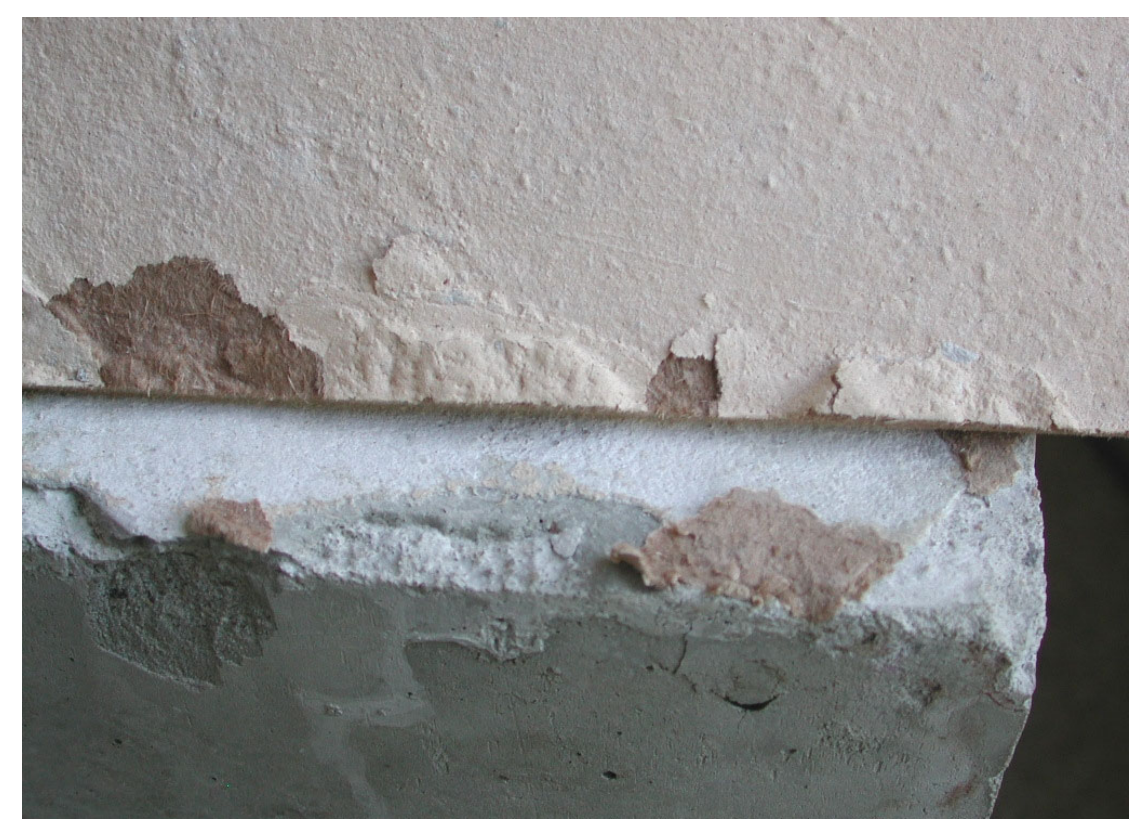

Figura 5.14 - Detalhe de como a almofada se adaptou a irregularidade da extremidade

A fotografia da figura 5.15 apresenta os modelos dos ensaios da quarta concretagem. Nota-se as regiões intermediárias, as quais se propôs estudar, totalmente danificadas. Entre os pilares de concreto armado se encontram os prismas de concreto simples.

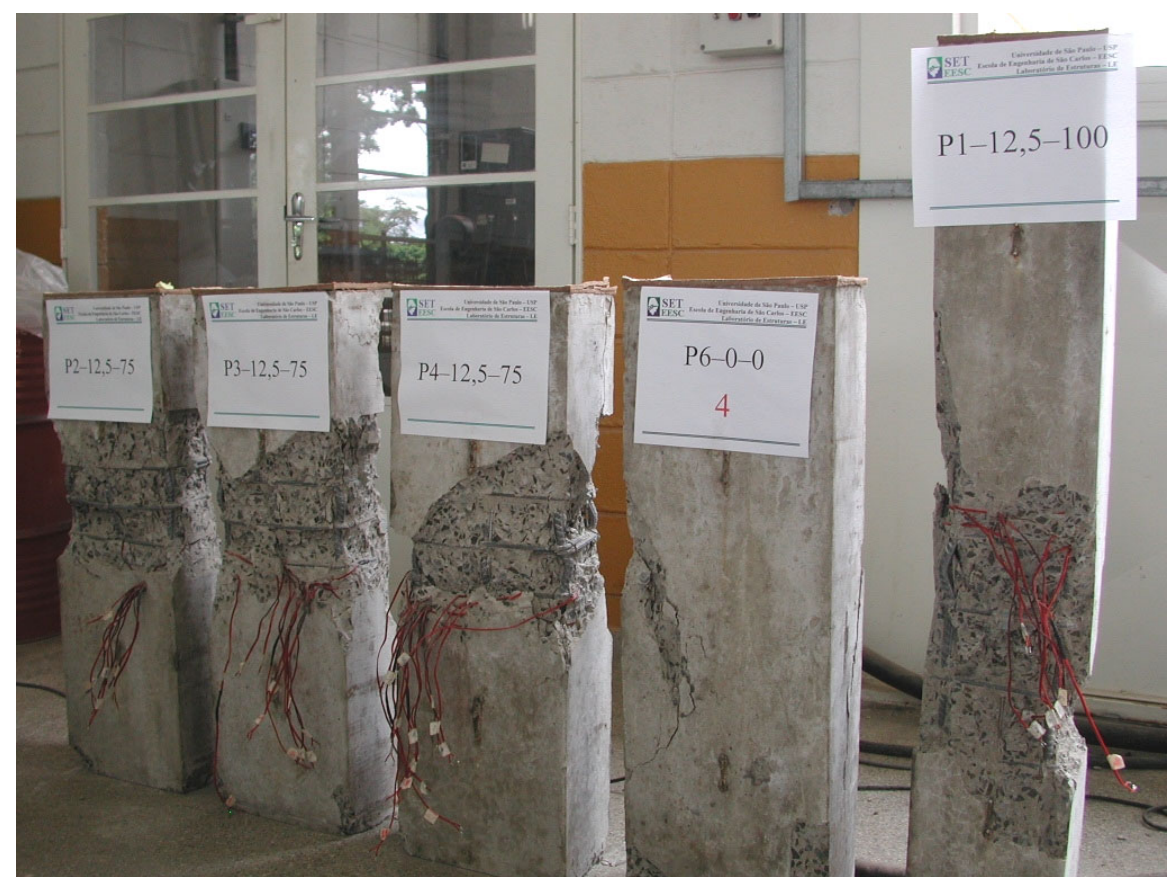

Figura 5.15 - Modelos da quarta concretagem após os ensaios 
Neste capítulo serão apresentados os diagramas tensão vs. deformação dos pilares com os dados coletados pelos quatro LVDTs. Nesses diagramas, observa-se uma certa discrepância entre os valores medidos por cada LVDT, principalmente nos modelos das últimas concretagens. Isso se deve ao fato de os pilares das últimas concretagens apresentarem falta de linearidade decorrente do desgaste das fôrmas. Mesmo com a regularização das extremidades dos pilares, alguns apresentaram flexões indesejadas, que podem ser comprovadas pelas leituras dos LVDTs. Para facilitar a compreensão, a numeração adotada para as faces do pilar foi igual à numeração dos transdutores nelas posicionados.

\subsubsection{Série P1}

A figura 5.16 apresenta a seção transversal dos pilares da série P1 com a numeração utilizada para os transdutores e extensômetros.

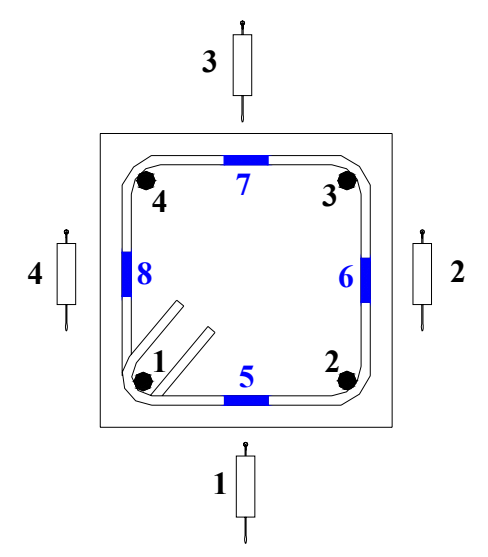

Figura 5.16 - Numeração dos transdutores e dos extensômetros das barras de armadura dos pilares da série $\mathbf{P 1}$.

\subsubsection{Pilar P1-10,0-120}

Este pilar foi concretado no dia 22 de setembro de 2003 e ensaiado no dia 7 de outubro de 2003. Todos os extensômetros funcionaram perfeitamente, não havendo perda de dados iniciais. 
$\mathrm{Na}$ figura 5.17 é possível notar maior deformação na direção do transdutor 4 (quatro). A deformação para a força de pico anotada pelo transdutor 4 (quatro) foi de 3,84\%o, enquanto que a anotada pelo transdutor 2 (dois) foi de $2,59 \%$, 32\% menor que a do transdutor 4 (quatro).

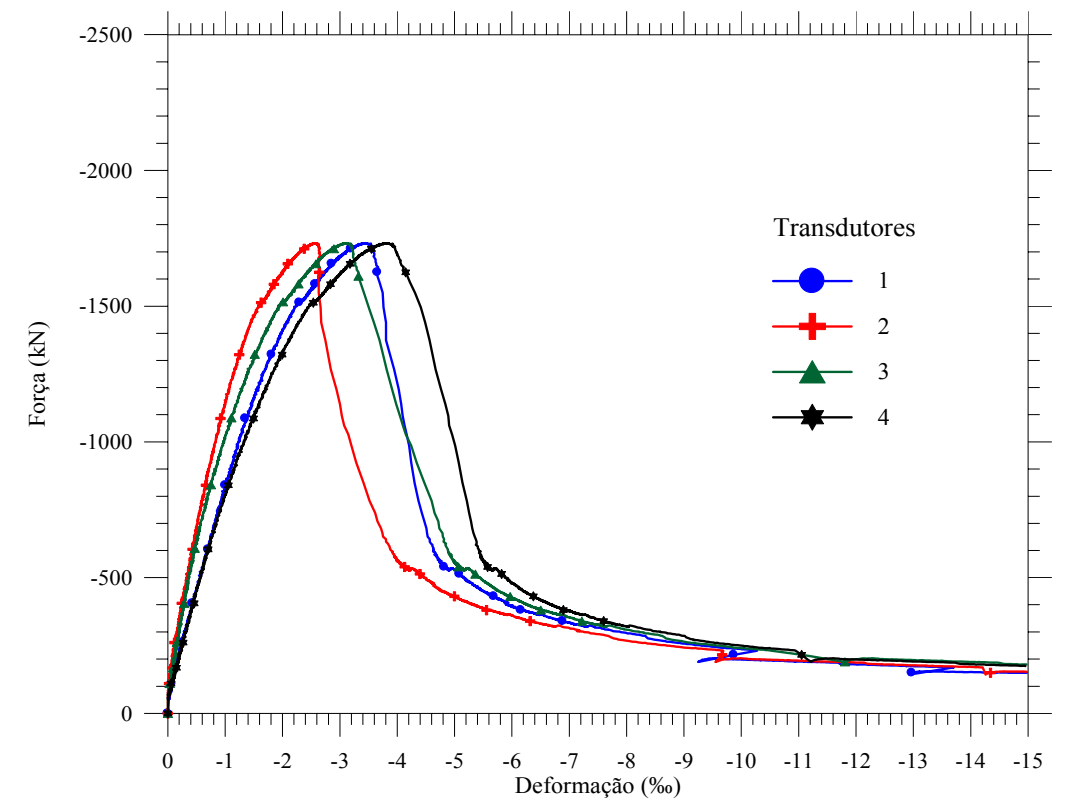

Figura 5.17 - Diagramas força aplicada vs. deformação do pilar P1-10,0-120, traçados por cada transdutor

Mesmo com a queda brusca da resistência ao ser atingida a força de pico, os quatro transdutores continuaram coletando os dados de deformação. A figura 5.18 apresenta a fotografia do ensaio desse pilar.

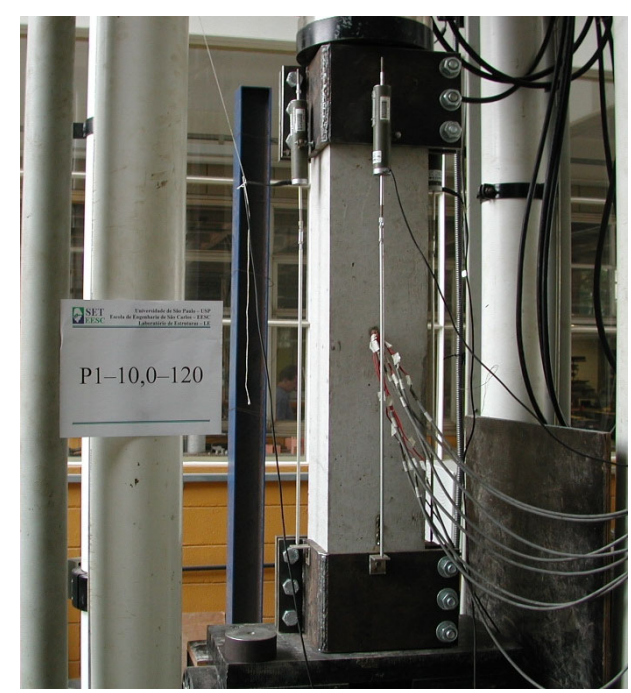

Figura 5.18 - Ensaio do pilar P1-10,0-120 


\subsubsection{Pilar P1-12,5-200}

O pilar foi concretado no dia 26 de setembro de 2003 e ensaiado no dia 10 de outubro de 2003. O extensômetro número oito não funcionou, pois foi afetado pela umidade.

A armadura transversal não atende as exigências da NBR 6118:2003. Observando os dados da tabela 5.4, esse pilar foi o que apresentou a maior diferença entre a força teórica e a experimental nos três casos analisados. A força última teórica calculada com o $\mathrm{k}_{2}$ da NS 3473 E (1992) foi conservativa para 12 (doze) dos 16 (dezesseis) pilares ensaiados, mas para esse pilar ela foi $9 \%$ maior do que a força última experimental. A figura 5.19 apresenta a fotografia do pilar quando era atingida a força de pico e a figura 5.20 apresenta a fotografia do detalhe das barras da armadura longitudinal na face do transdutor 3 (face 3 ).

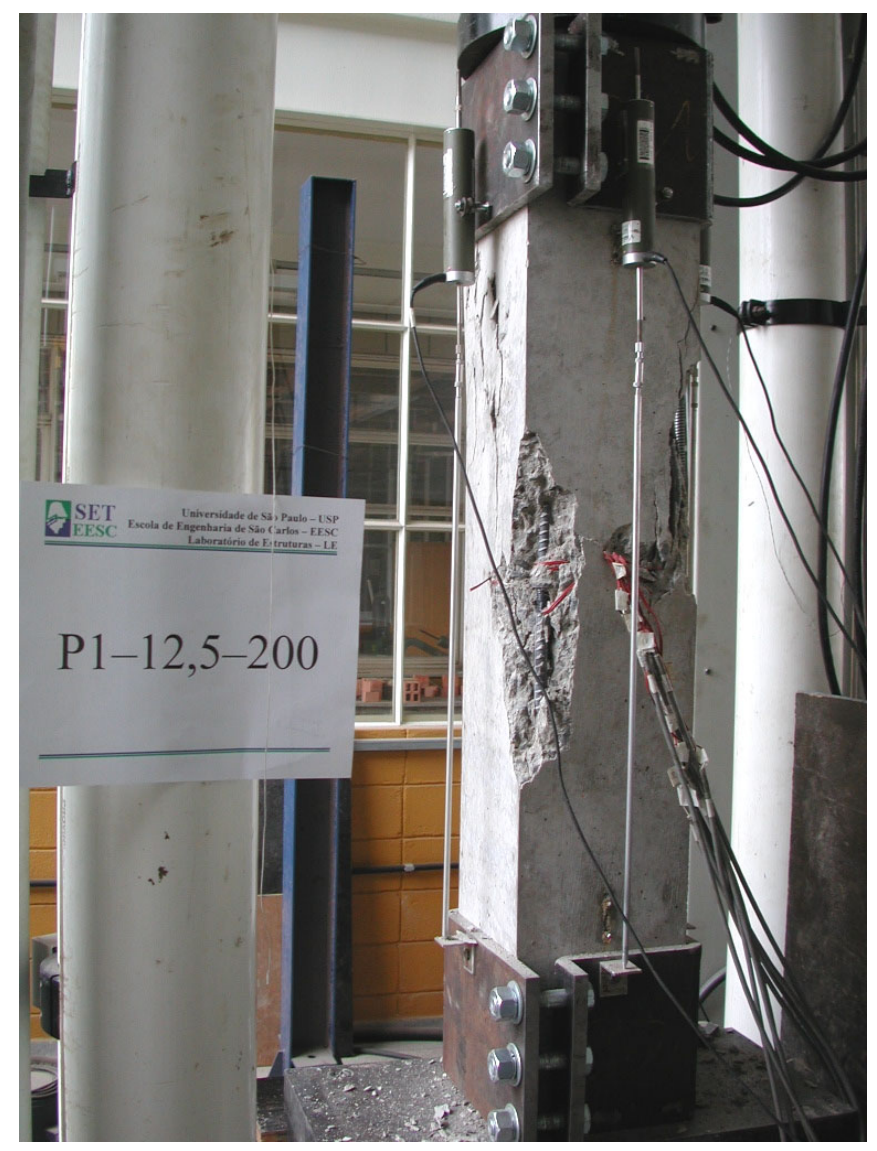

Figura 5.19 - Ensaio do pilar P1-12,5-200 


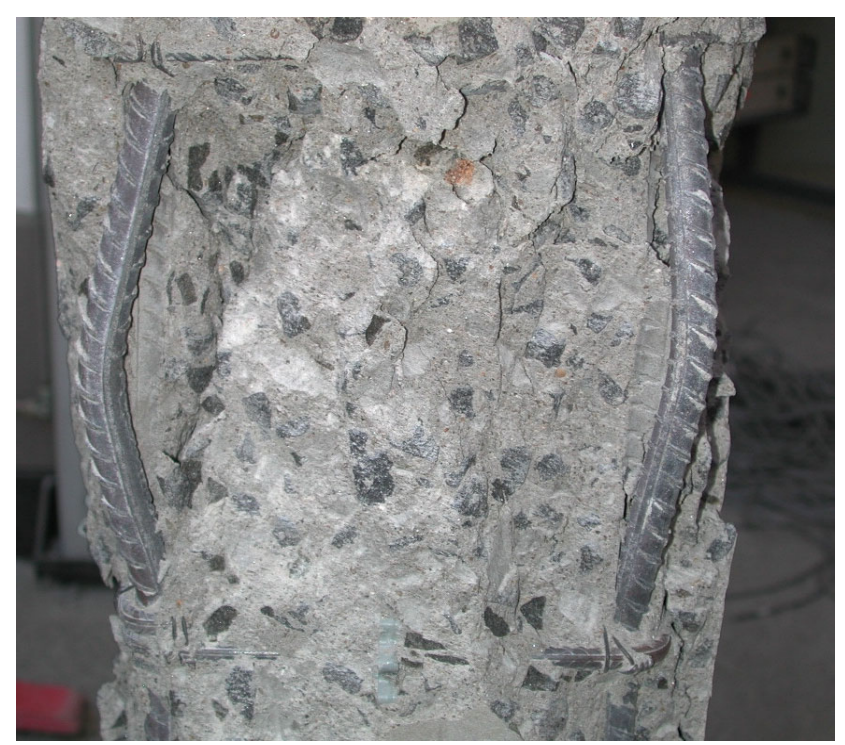

Maior espaçamento entre

estribos causou a

flambagem prematura

das barras da armadura

longitudinal

Figura 5.20 - Detalhe das barras da armadura longitudinal da face 3 do pilar P1-12,5-200

O diagrama da figura 5.21 vem confirmar a flexão na direção da face 3 (três) do pilar. Neste pilar houve flexo-compressão obliqua, pois os transdutores de duas faces adjacentes apresentaram as maiores deformações (faces 3 e 4).

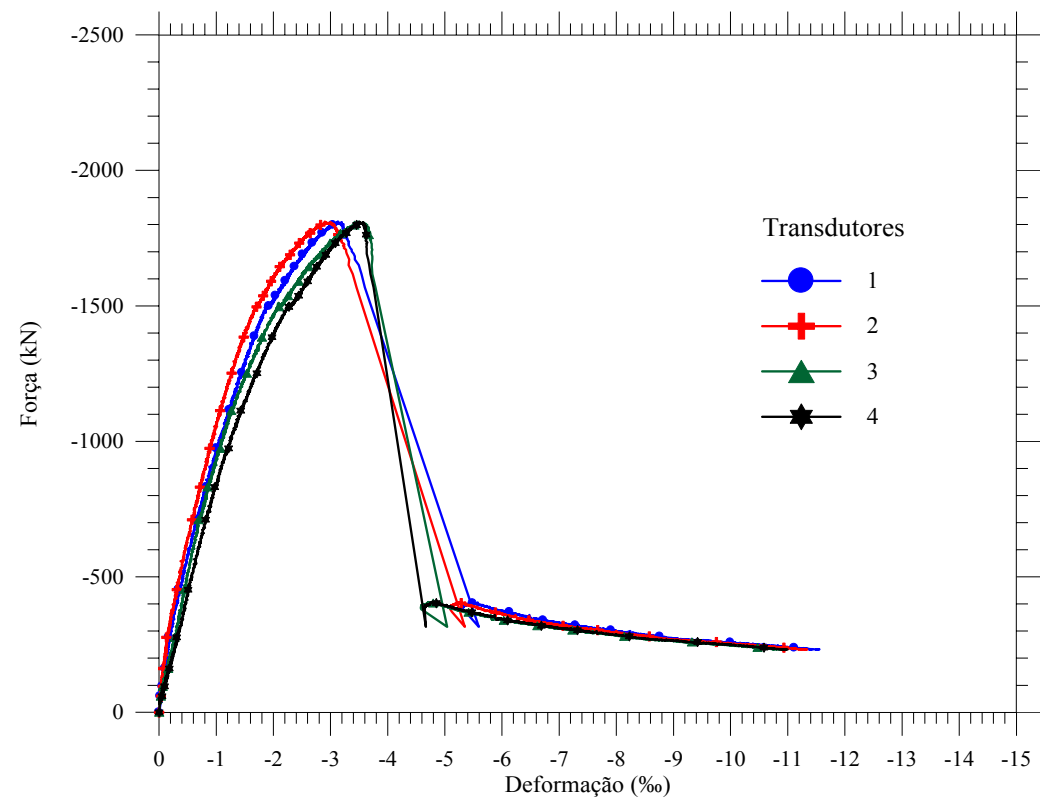

Figura 5.21 - Diagramas força aplicada vs. deformação do pilar P1-12,5-200, traçados por cada transdutor 


\subsubsection{Pilar P1-12,5-150}

A moldagem ocorreu no dia 15 de outubro de 2003 e ensaiado no dia 30 de outubro de 2003. Todos os extensômetros funcionaram perfeitamente, não havendo perda de dados iniciais.

Assim como o pilar anterior, este apresentou maior deformação em faces adjacentes, caracterizando flexo-compressão obliqua na intersecção das faces 2 (dois) e 3 (três). A figura 5.22 apresenta os diagramas força aplicada vs. deformação do pilar medidos pelos transdutores.

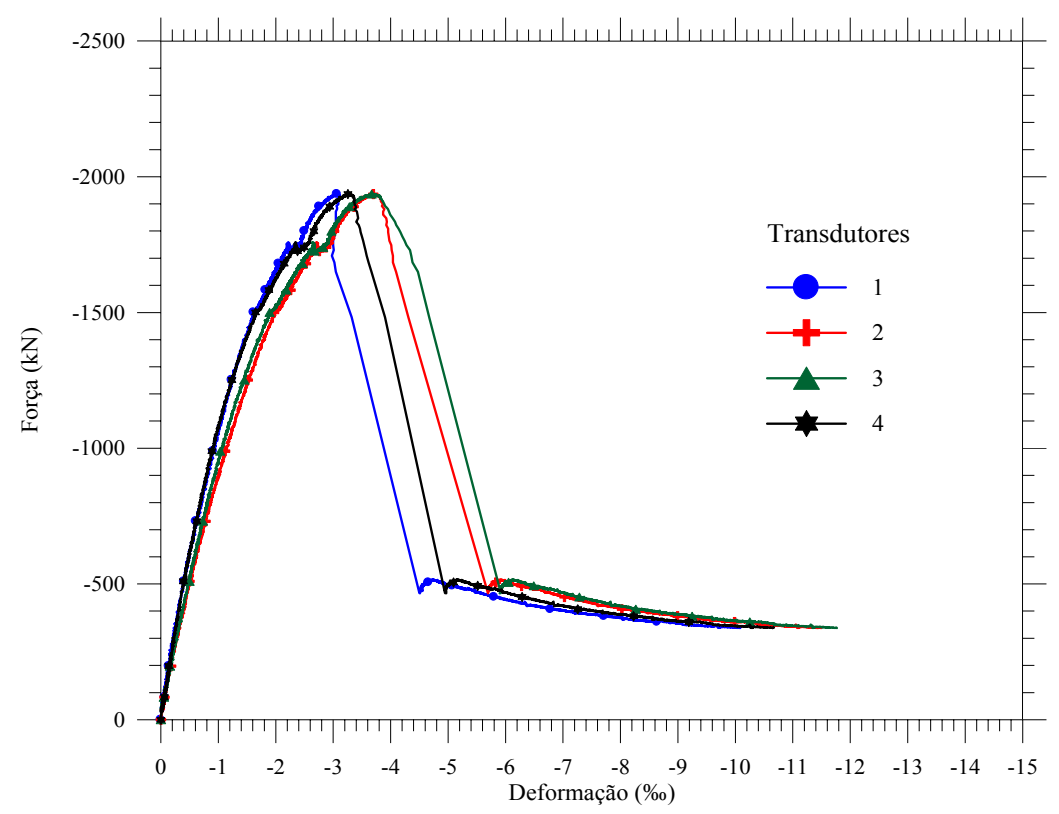

Figura 5.22 - Diagramas força aplicada vs. deformação do pilar P1-12,5-150, traçados por cada transdutor

\subsubsection{Pilar P1-12,5-100}

A concretagem ocorreu no dia 24 de outubro de 2003 e o pilar foi ensaiado no dia 7 de novembro de 2003. Todos os extensômetros funcionaram perfeitamente, não havendo perda de dados iniciais.

O modelo apresentou maior deformação em faces adjacentes, caracterizando flexo-compressão obliqua na intersecção das faces 1 (um) e 4 (quatro). As deformações medidas pelos transdutores das faces 1 (um) e 4 
(quatro) tiveram comportamento semelhante, assim como as deformações medidas pelos transdutores das faces opostas (2 e 3). Como o pilar possui seção transversal quadrada, a flexão se deu numa direção aproximada à diagonal da seção transversal. A figura 5.23 apresenta os diagramas força aplicada vs. deformação do pilar medidos pelos transdutores

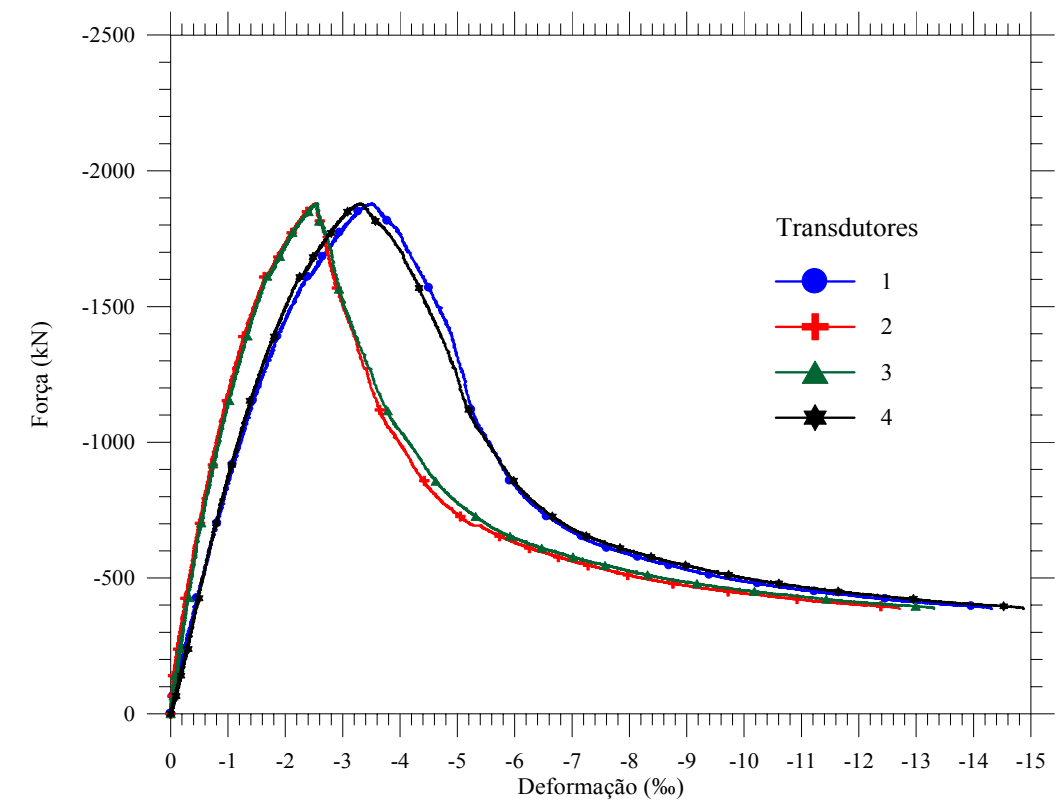

Figura 5.23 - Diagramas força aplicada vs. deformação do pilar P1-12,5-100, traçados por cada transdutor

\subsubsection{Série P2}

A instrumentação usada nas faces e nas armaduras dos pilares da série P2 é mostrada na figura 5.24 com a respectiva numeração.

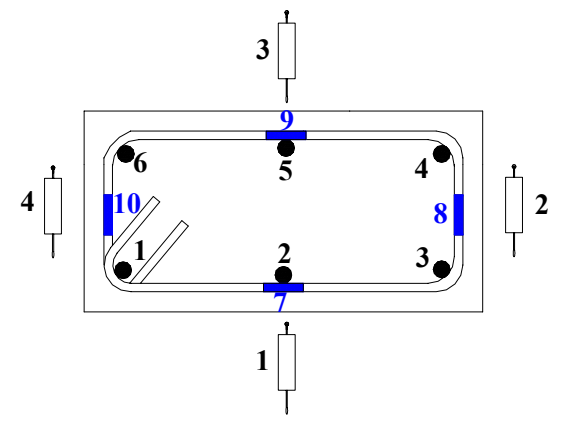

Figura 5.24 - Numeração dos transdutores e dos extensômetros das barras de armadura dos pilares da série $\mathbf{P 2}$. 


\subsubsection{Pilar P2-10,0-120}

O pilar foi concretado no dia 22 de setembro de 2003 e ensaiado no dia 6 de outubro de 2003 sem que houvesse problemas com a instrumentação.

Neste pilar, houve ruptura brusca da face 2 (dois) ao ser atingida a força de pico. A flexo-compressão reta nesta direção provocou maior deformação, fazendo com que este lado rompesse antes dos demais. A figura 5.25 apresenta os diagramas força aplicada vs. deformação medidos pelos transdutores deste pilar.

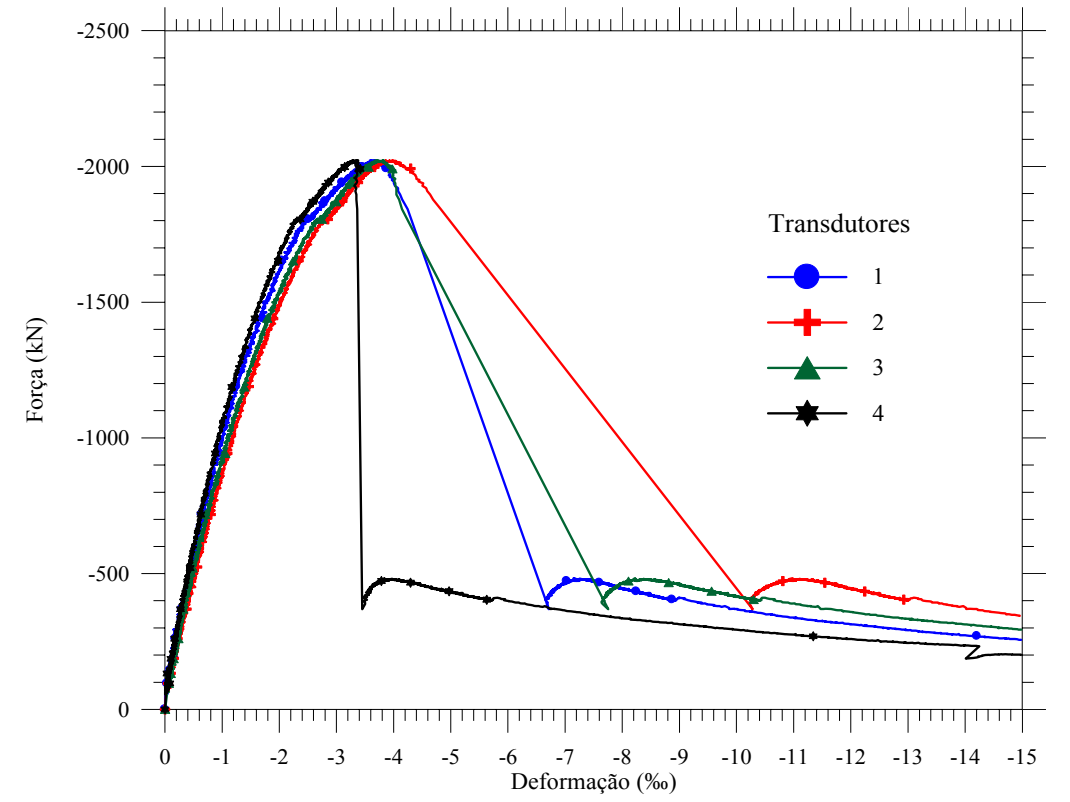

Figura 5.25 - Diagramas força aplicada vs. deformação do pilar P2-10,0-120, traçados por cada transdutor

\subsubsection{Pilar P2-12,5-150}

A moldagem foi no dia 26 de setembro de 2003 e ensaiado no dia 9 de outubro de 2003. O extensômetro número dez não funcionou, pois houve entrada de umidade na região.

Os transdutores das faces adjacentes 1 (um) e 4 (quatro) apresentaram as maiores deformações na força de pico, 3,93\% e 4,36\%, respectivamente, enquanto que os outros transdutores não chegaram a anotar 3\% nessa força (Figura 5.26). Isso caracteriza comportamento de flexo-compressão obliqua na 
direção das faces 1 (um) e 4 (quatro). Depois de ser atingido o pico de força, os transdutores dessas faces anotaram acréscimo de deformação significativa até que se estabilizassem com deformações superiores a $8 \%$, enquanto que os transdutores das faces 2 (dois) e 3 (três) anotaram perda de capacidade resistente sem que se deformassem.

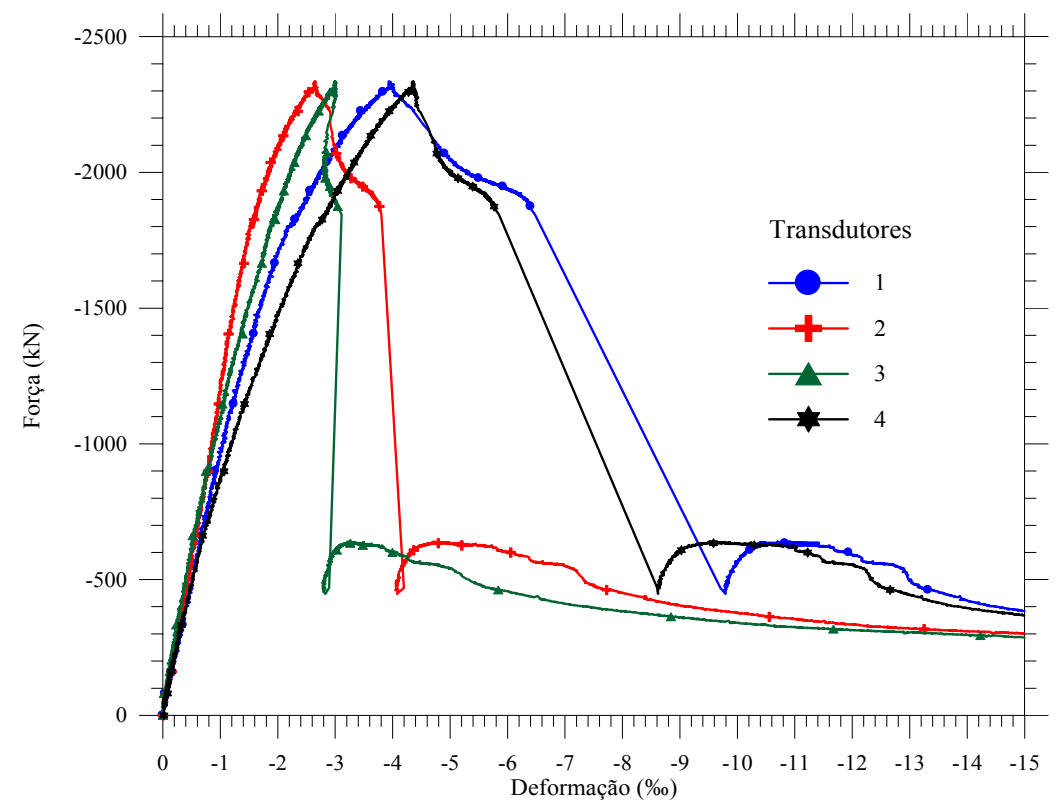

Figura 5.26 - Diagramas força aplicada vs. deformação do pilar P2-12,5-150, traçados por cada transdutor

\subsubsection{Pilar P2-12,5-100}

O pilar foi concretado no dia 15 de outubro de 2003 e ensaiado no dia 29 de outubro de 2003. Todos os extensômetros funcionaram perfeitamente, não havendo perda de dados iniciais.

Pela figura 5.27 é possível notar comportamento similar entre os diagramas força aplicada vs. deformação das faces opostas 2 (dois) e 4 (quatro) e comportamentos bem diferentes entre as faces 1 (um) e 3 (três). Isso caracteriza flexo-compressão reta na direção da face 1 (um). $\mathrm{O}$ transdutor dessa face anotou deformação de 6,2\% na força de pico, enquanto que o da face oposta anotou 1,3\%. A figura 5.28a mostra a fissuração na região das barras da armadura longitudinal da face 1 (um) e é possível notar uma pequena inclinação do pilar 
nessa direção. A figura 5.28b mostra a face 1 (um) após ser atingida a força de pico.

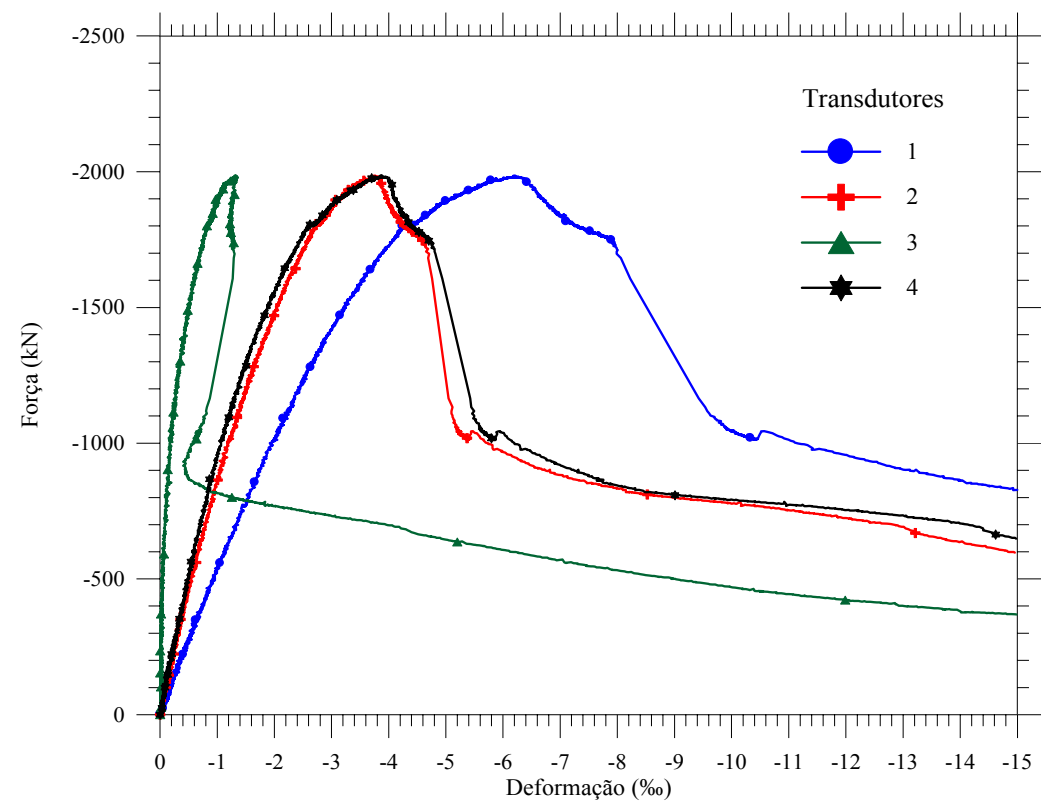

Figura 5.27 - Diagramas força aplicada vs. deformação do pilar P2-12,5-100,

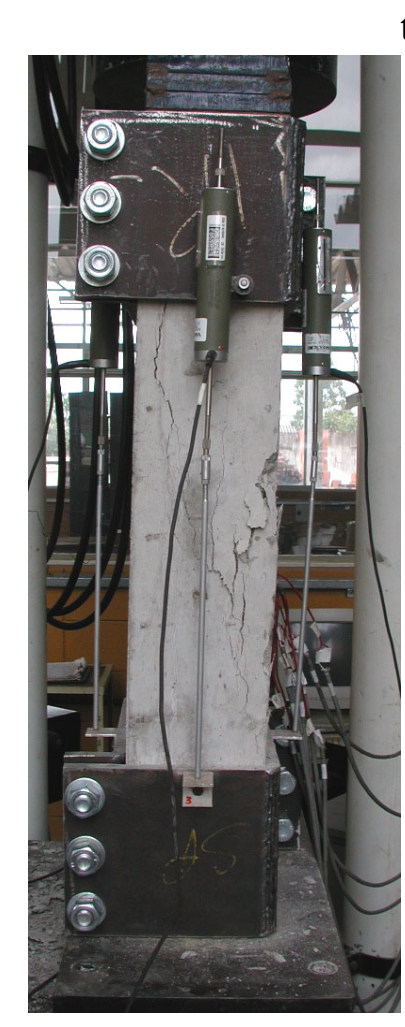

a

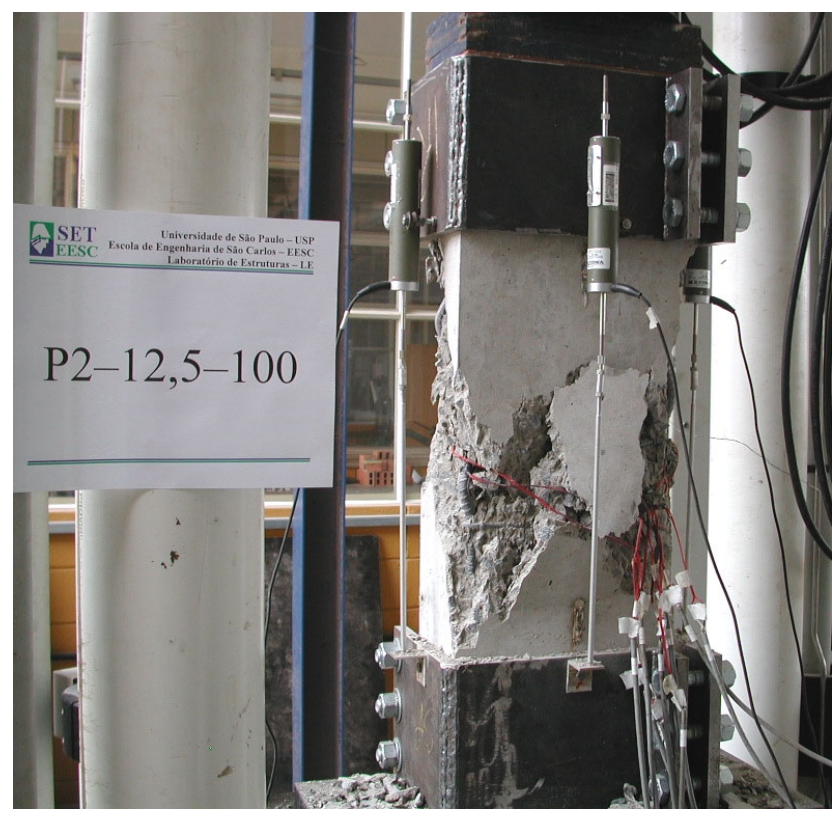

b

Figura 5.28 - a) fissuração decorrente da flexo-compressão reta na direção da face 1 (um); b) descolamento do concreto do cobrimento após ser atingida a força de pico. 


\subsubsection{Pilar P2-12,5-075}

A concretagem do pilar foi no dia 24 de outubro de 2003 e o ensaio no dia 6 de novembro de 2003. Todos os extensômetros funcionaram perfeitamente.

A flexo-compressão reta neste pilar não teve a intensidade da que ocorreu com o pilar anterior. Os diagramas da figura 5.29 mostram pequena diferença entre os comportamentos das faces do pilar, mesmo assim ocorreu flexo-compressão reta na direção da face 3 (três). Os transdutores das outras faces não anotaram perda brusca de capacidade resistente ao ser atingida a força de pico, apenas o transdutor da face 3 (três), que anotou queda de $2099 \mathrm{kN}$ até, aproximadamente, $1100 \mathrm{kN}$ com pouca deformação.

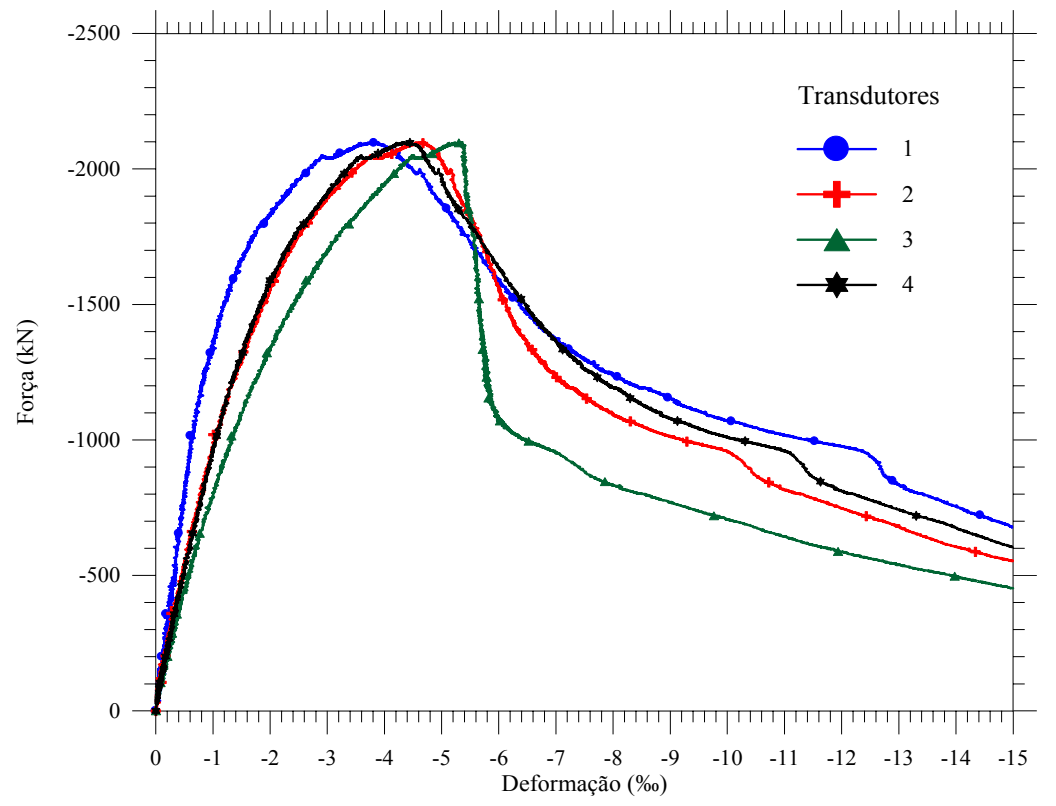

Figura 5.29 - Diagramas força aplicada vs. deformação do pilar P2-12,5-075, traçados por cada transdutor 


\subsubsection{Série P3}

A instrumentação e a respectiva numeração usadas nos pilares da série P3 são apresentadas na figura 5.30.

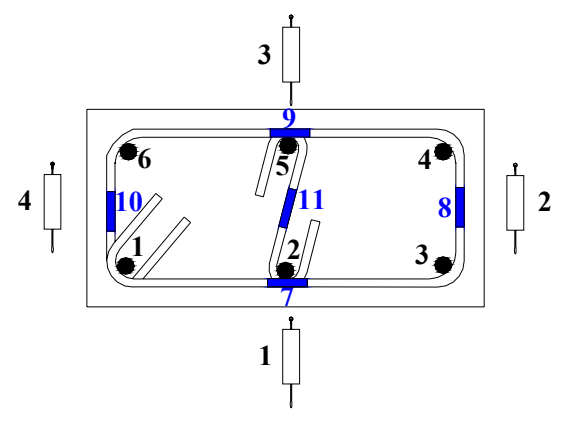

Figura 5.30 - Numeração dos transdutores e dos extensômetros das barras de armadura dos pilares da série P3.

\subsubsection{Pilar P3-10,0-120}

Este pilar foi concretado no dia 22 de setembro de 2003 e ensaiado no dia 6 de outubro de 2003, sem que houvesse danos com a instrumentação.

A figura 5.31 apresenta os diagramas força aplicada vs. deformação anotados pelos transdutores deste pilar. Um fato interessante aconteceu com este pilar, houve flexo-compressão reta na direção da face 3 (três) e os transdutores anotaram comportamentos diferentes para as quatro faces até a queda da capacidade resistente, mas a partir da deformação de, aproximadamente, 8,5\%, os quatro transdutores apresentaram comportamento quase que idêntico, isso significa que pode ter havido regularização das extremidades do pilar e conseqüentemente das leituras dos transdutores. 


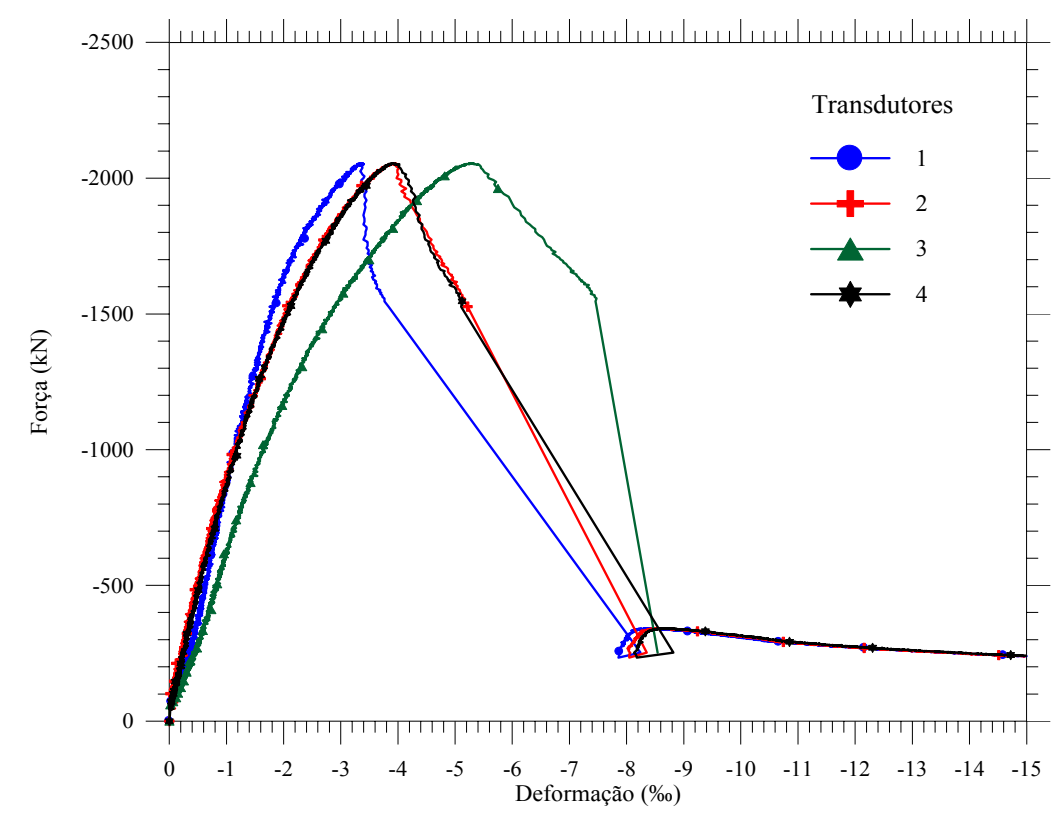

Figura 5.31 - Diagramas força aplicada vs. deformação do pilar P3-10,0-120, traçados por cada transdutor

\subsubsection{Pilar P3-12,5-150}

O pilar foi concretado no dia 26 de setembro de 2003 e ensaiado no dia 9 de outubro de 2003. O extensômetro número oito não funcionou, pois houve entrada de umidade na região.

Não houve perda busca da capacidade resistente. A figura 5.32 apresenta os diagramas força aplicada vs. deformação das leituras dos transdutores deste pilar. A diferença dos valores das deformações de pico anotadas pelos transdutores das faces 1 (um) e 4 (quatro) e das faces 2 (dois) e 3 (três) é de aproximadamente $1 \%$, maior na direção das faces 2 (dois) e 3 (três). Isso caracteriza comportamento de flexo-compressão obliqua na direção dessas faces. 


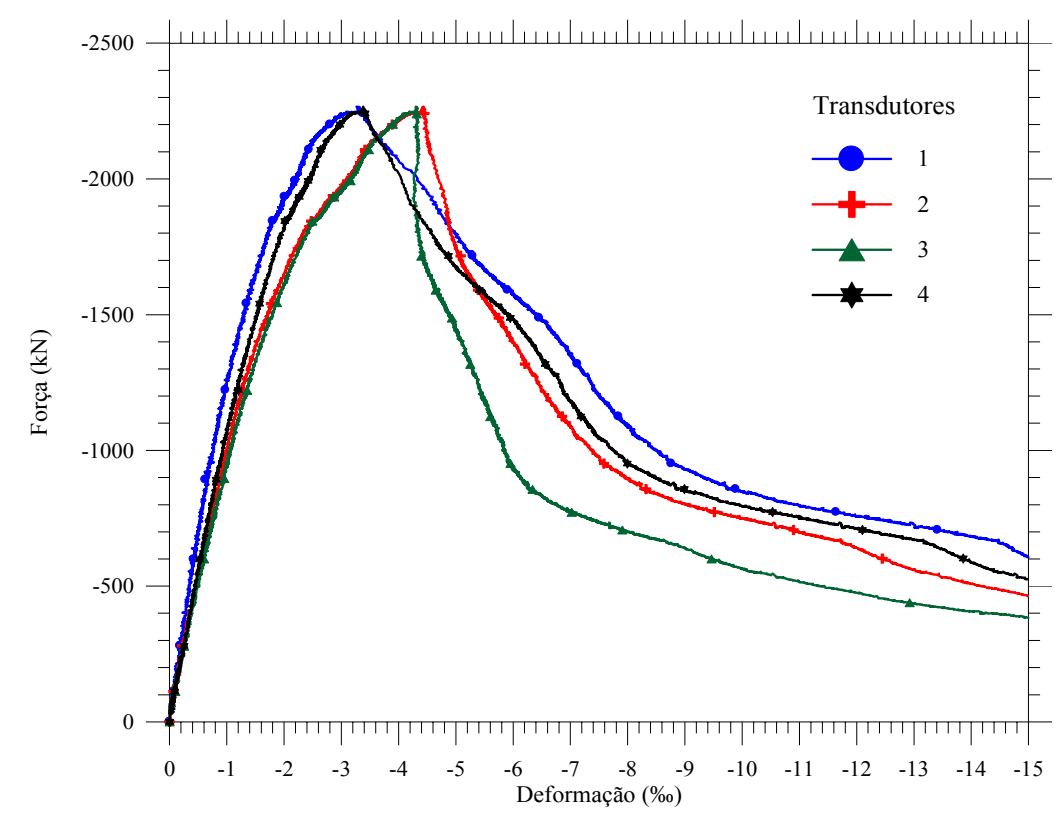

Figura 5.32 - Diagramas força aplicada vs. deformação do pilar P3-12,5-150, traçados por cada transdutor

\subsubsection{Pilar P3-12,5-100}

Este pilar foi concretado no dia 15 de outubro de 2003 e ensaiado no dia 29 de outubro de 2003. Todos os extensômetros funcionaram perfeitamente.

A flexo-compressão reta ocorreu na direção da face 4 (quatro), o que não era comum. Isso pode ser observado nos diagramas da figura 5.33. 


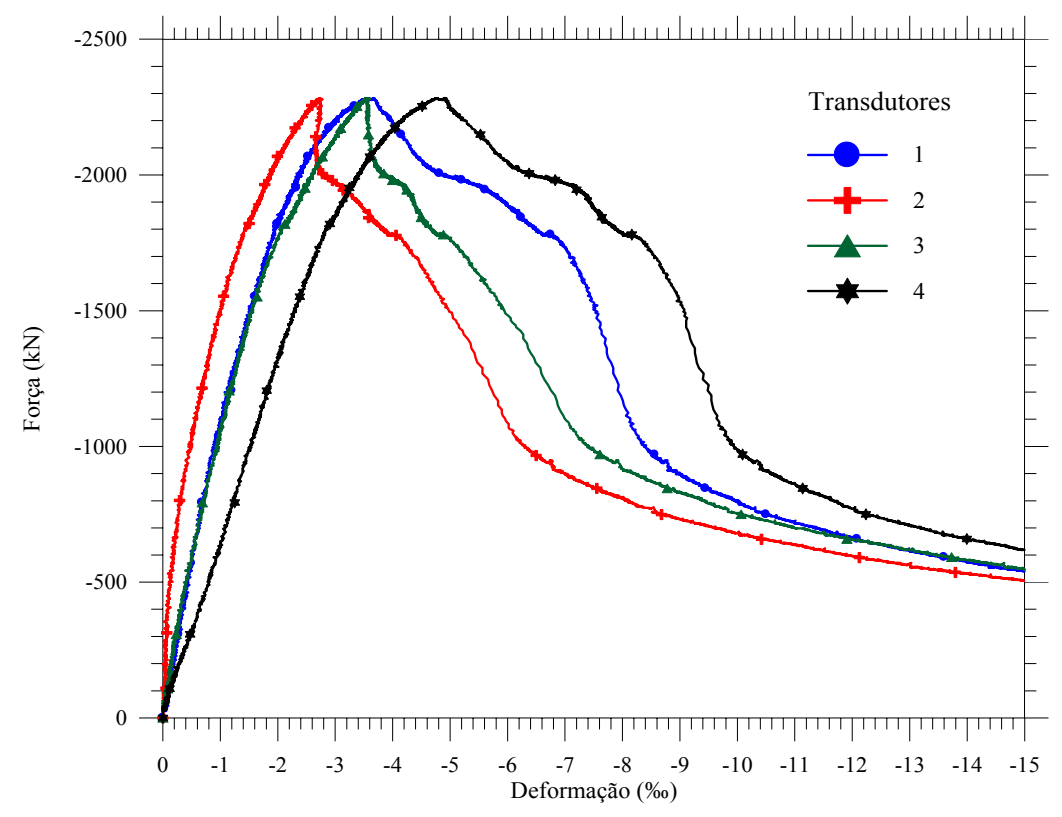

Figura 5.33 - Diagramas força aplicada vs. deformação do pilar P3-12,5-100, traçados por cada transdutor

\subsubsection{Pilar P3-12,5-075}

A concretagem aconteceu no dia 15 de outubro de 2003 e o ensaio no dia 29 de outubro de 2003. Todos os extensômetros funcionaram perfeitamente.

O melhor comportamento dos diagramas força aplicada vs. deformação foi apresentado por este pilar (Figura 5.34). Nota-se leve flexo-compressão obliqua na direção das faces 3 (três) e 4 (quatro), mas, no geral foi que melhor se aproximou da compressão centrada. 


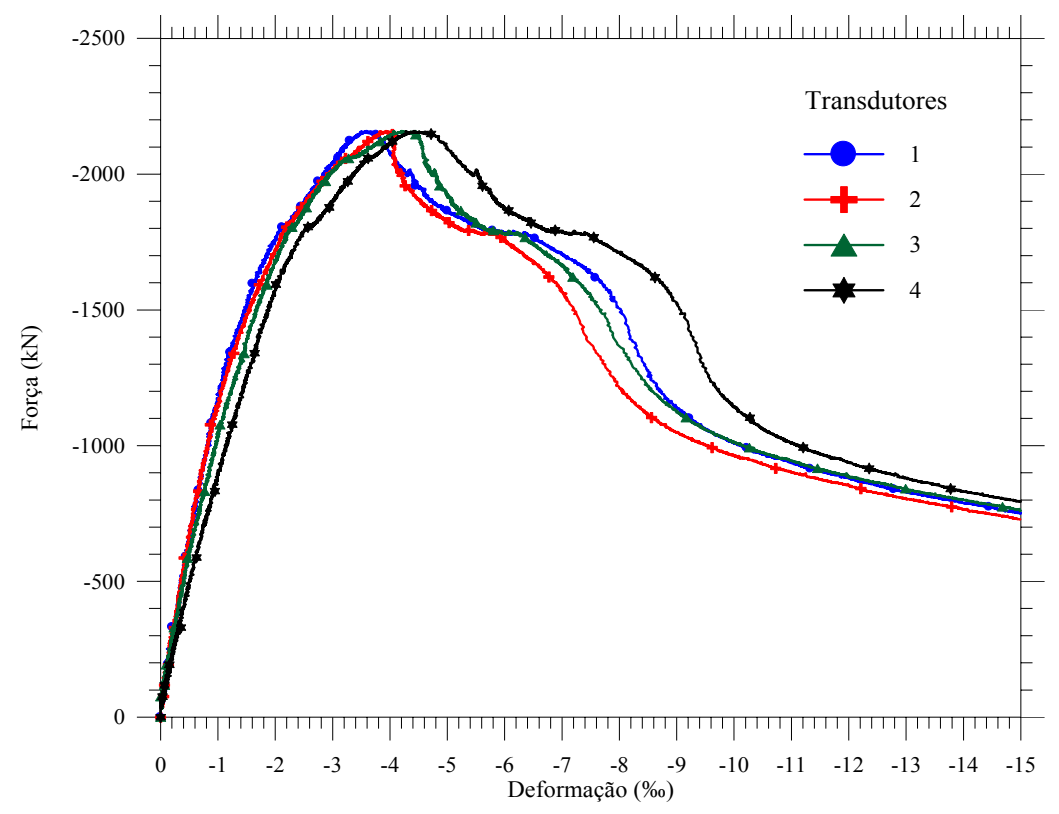

Figura 5.34 - Diagramas força aplicada vs. deformação do pilar P3-12,5-075, traçados por cada transdutor

\subsubsection{Série P4}

$\mathrm{Na}$ figura 5.35 são apresentadas a instrumentação e a numeração adotadas para os pilares da série P4.

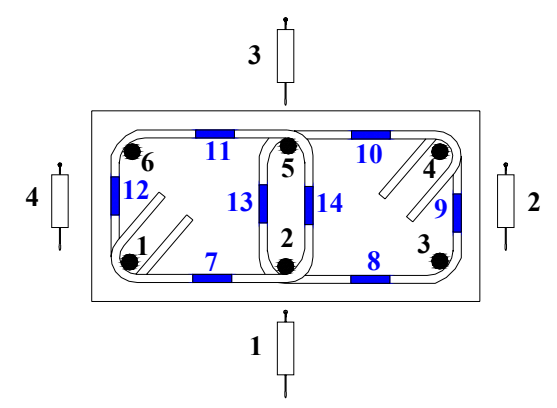

Figura 5.35 - Numeração dos transdutores e dos extensômetros das barras de armadura dos pilares da série $\mathbf{P 4}$. 


\subsubsection{Pilar P4-10,0-120}

O modelo foi concretado no dia 22 de setembro de 2003 e ensaiado no dia 6 de outubro de 2003, sem que houvesse dano com a instrumentação.

Os diagramas da figura 5.36 mostram que apenas o transdutor da face 2 (dois) apresentou comportamento diferente, anotando valores inferiores aos demais. Isso significa que houve flexo-compressão reta na direção da face 4 (quatro), com os valores de deformação dessa face semelhantes aos valores de deformação das faces 1 (um) e 3 (três).

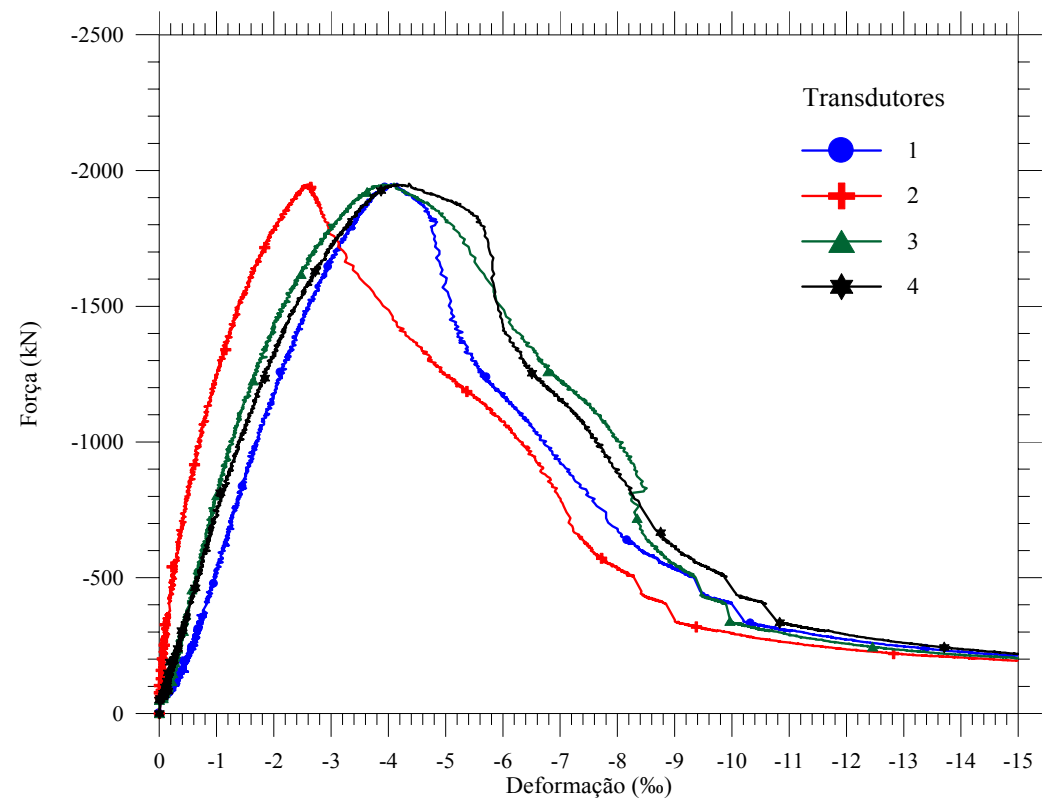

Figura 5.36 - Diagramas força aplicada vs. deformação do pilar P4-10,0-120, traçados por cada transdutor

\subsubsection{Pilar P4-12,5-150}

A moldagem do pilar foi feita no dia 26 de setembro de 2003 e foi ensaiado no dia 9 de outubro de 2003. Todos os extensômetros funcionaram corretamente. 
Neste pilar, como pode ser visto nos diagramas da figura 5.37, houve pequena flexão na direção da face 2 (dois), caracterizando flexo-compressão reta nessa direção.

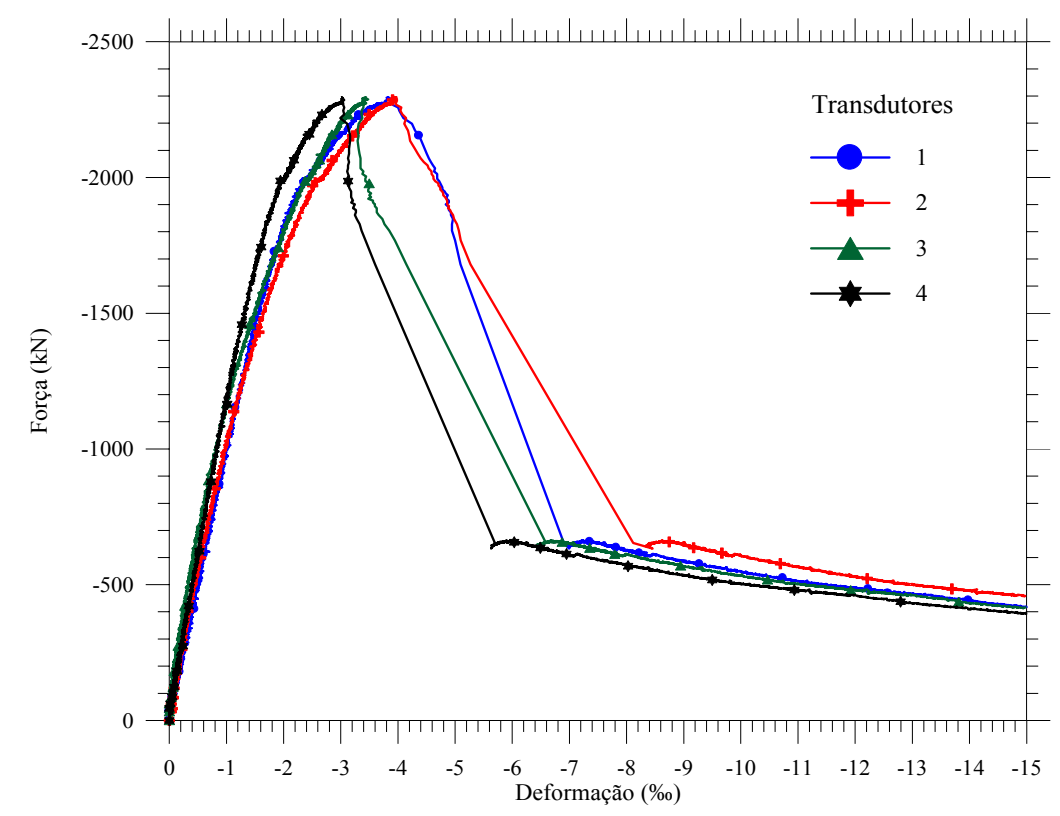

Figura 5.37 - Diagramas força aplicada vs. deformação do pilar P4-12,5-150, traçados por cada transdutor

\subsubsection{Pilar P4-12,5-100}

A concretagem foi no dia 15 de outubro de 2003 e o ensaio no dia 29 de outubro de 2003.

Os diagramas da figura 5.38 mostram que este pilar apresentou acréscimo de resistência após ser atingida a capacidade resistente, se deformando e mantendo força equivalente a aproximadamente $91 \%$ da força última. Este comportamento é similar ao apresentado na figura 3.3 no item 3.1 deste trabalho, corroborando com a afirmação de Cusson e Paultre (1994). 


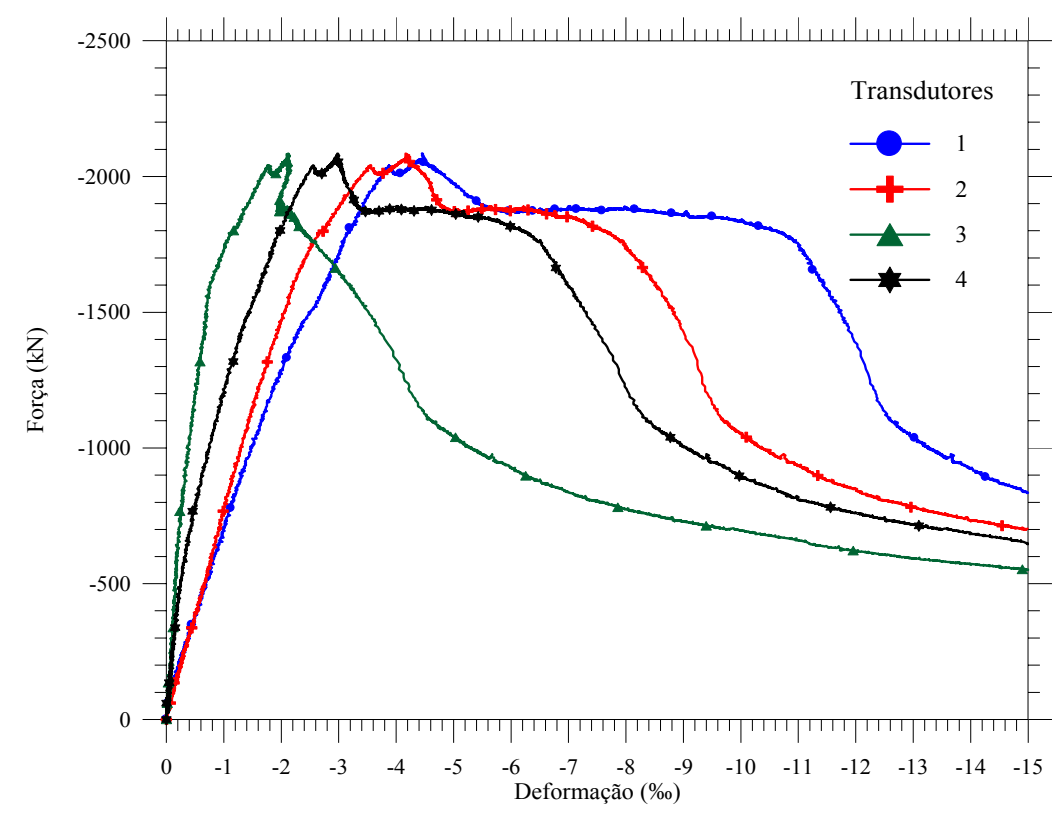

Figura 5.38 - Diagramas força aplicada vs. deformação do pilar P4-12,5-100, traçados por cada transdutor

\subsubsection{Pilar P4-12,5-075}

O pilar foi concretado no dia 24 de outubro de 2003 e ensaiado no dia 6 de novembro de 2003.

$\mathrm{O}$ acréscimo de resistência também foi percebido neste pilar (Figura 5.39), mas não com a intensidade do pilar descrito anteriormente. Este pilar apresentou flexo-compressão obliqua na direção das faces 1 (um) e 2 (dois). Esse acréscimo de resistência influi na avaliação da ductilidade pós-pico do pilar, como será apresentado no item 6.1 deste trabalho. 


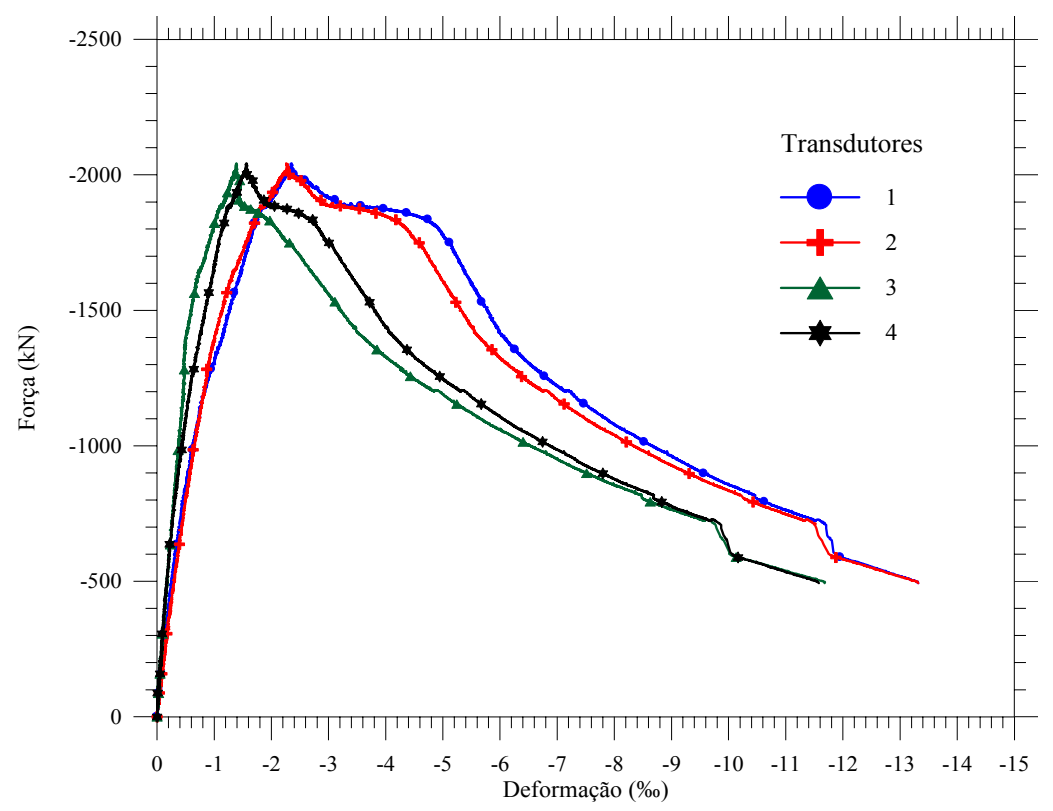

Figura 5.39 - Diagramas força aplicada vs. deformação do pilar P4-12,5-075, traçados por cada transdutor 


\section{Capítulo 6}

\section{ANÁLISE DOS RESULTADOS}

\subsection{AVAliaÇÃo Da DUCTILIDADE}

O critério usado para avaliação da ductilidade dos pilares foi apresentado no item 2.8.5 deste trabalho. Para ser feita a avaliação, foi criado um arquivo de dados, no software Mathcad, que faz regressão polinomial, no grau do polinômio desejado, a partir dos dados de força aplicada vs. deformação lida experimentalmente.

Para todos os pilares foram feitas regressões com polinômios de décimo grau obtendo, assim, curvas mais próximas possível à curva experimental.

As figuras 6.1 e 6.2 exemplificam as regressões feitas sobre os dados experimentais dos pilares $\mathrm{P} 1-12,5-100$ e P3-12,5-150, respectivamente. O coeficiente de correlação, $\mathrm{r}^{2}$, de todas as curvas foi superior a $99 \%$. As curvas experimentais são apresentadas por linhas contínuas e as regressões polinomiais por linhas tracejadas. 


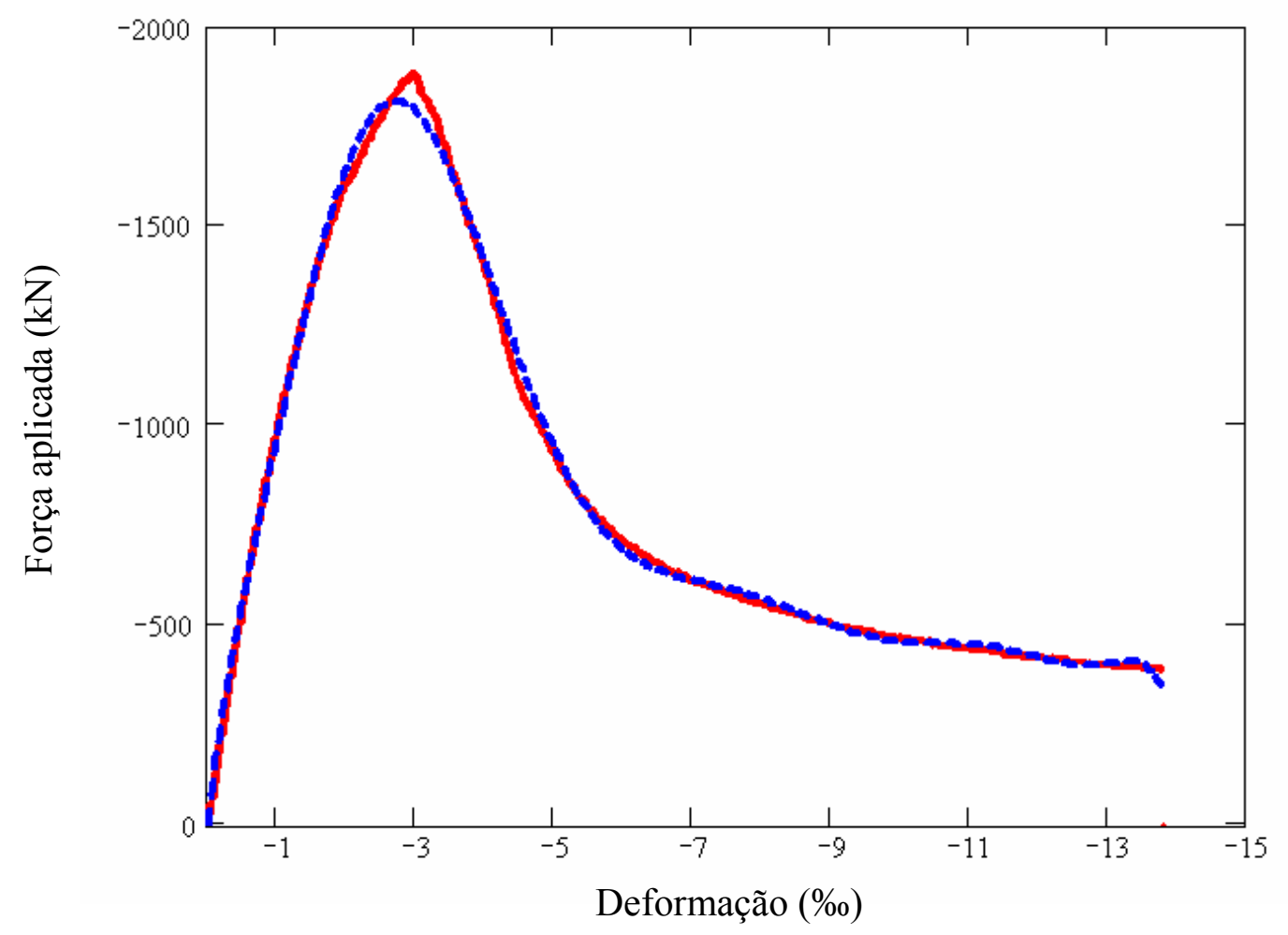

Figura 6.1 - Diagrama força aplicada vs. deformação experimental e regressão polinomial de grau 10 do pilar P1-12,5-100

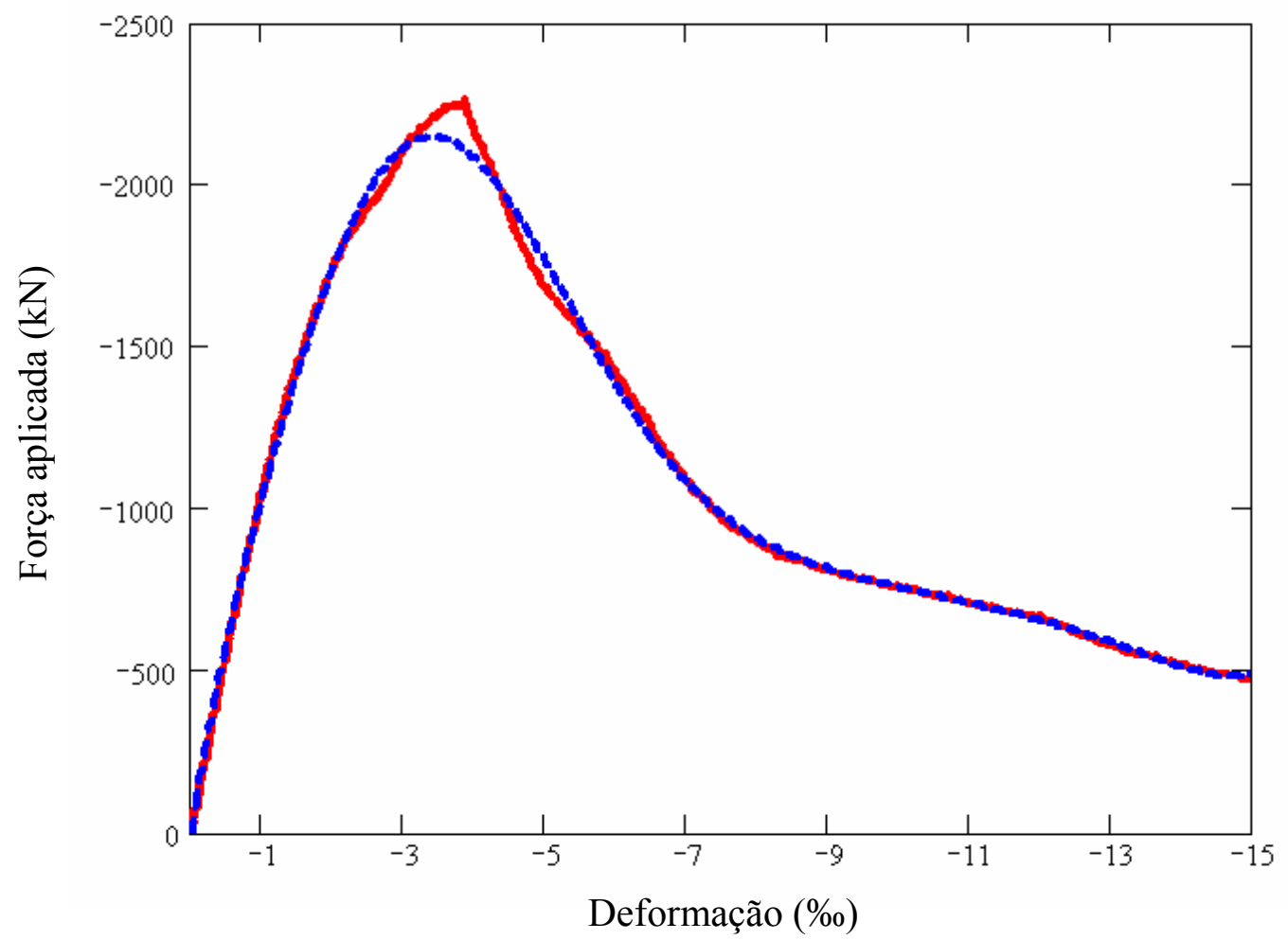

Figura 6.2 - Diagrama força aplicada vs. deformação experimental e regressão polinomial de grau 10 do pilar P3-12,5-150 
Após serem feitas as regressões polinomiais para todos os pilares, no mesmo arquivo são calculados os índices de ductilidade pré-pico e pós-pico. A tabela 6.1 apresenta os resultados obtidos para os índices de ductilidade dos pilares.

Tabela 6.1 - Índices de ductilidades dos pilares ensaiados

\begin{tabular}{|c|c|c|c|c|c|}
\hline \hline Pilar & $\begin{array}{c}\rho_{\mathrm{w}} \\
(\%)\end{array}$ & $\begin{array}{c}\mathrm{f}_{\mathrm{c}, \mathrm{cp}} \\
(\mathrm{MPa})\end{array}$ & $\mathrm{ID}_{\text {pré }}$ & $\mathrm{ID}_{\text {pós }}$ & $\begin{array}{c}\mathrm{r}^{2} \\
(\%)\end{array}$ \\
\hline P1-10,0-120 & 0,198 & 46,57 & 1,341 & 0,640 & 99,88 \\
\hline P1-12,5-200 & 0,189 & 46,29 & 1,313 & 0,593 & 99,92 \\
\hline P1-12,5-150 & 0,252 & 46,30 & 1,316 & 0,666 & 99,94 \\
\hline P1-12,5-100 & 0,378 & 43,89 & 1,282 & 0,962 & 99,97 \\
\hline P2-10,0-120 & 0,172 & 46,08 & 1,328 & 0,801 & 99,90 \\
\hline P2-12,5-150 & 0,219 & 45,01 & 1,233 & 0,844 & 99,92 \\
\hline P2-12,5-100 & 0,328 & 43,18 & 1,336 & 0,995 & 99,94 \\
\hline P2-12,5-075 & 0,438 & 43,07 & 1,421 & 1,049 & 99,99 \\
\hline P3-10,0-120 & 0,215 & 46,08 & 1,267 & 0,691 & 99,98 \\
\hline P3-12,5-150 & 0,274 & 45,01 & 1,318 & 1,008 & 99,97 \\
\hline P3-12,5-100 & 0,412 & 43,41 & 1,300 & 1,166 & 99,97 \\
\hline P3-12,5-075 & 0,549 & 42,55 & 1,372 & 1,323 & 99,97 \\
\hline P4-10,0-120 & 0,259 & 46,08 & 1,269 & 0,955 & 99,97 \\
\hline P4-12,5-150 & 0,330 & 45,01 & 1,307 & 0,870 & 99,98 \\
\hline P4-12,5-100 & 0,495 & 43,41 & 1,309 & 1,516 & 99,98 \\
\hline P4-12,5-075 & 0,660 & 42,55 & 1,310 & 1,635 & 99,99 \\
\hline \hline
\end{tabular}

Pelos dados da tabela, pode-se notar que o índice de ductilidade pós-pico está diretamente ligado à taxa de armadura transversal. O pilar P1-12,5-200, que foi moldado fora das recomendações da NBR 6118:2003, apresentou o menor valor para o índice de ductilidade pós-pico, caracterizando comportamento frágil.

O pilar P4-12,5-075, que possui maior taxa de armadura transversal, obteve o melhor comportamento no tocante a ductilidade, com o valor igual a 1,635 para o índice de ductilidade pós-pico. 
Além de estar diretamente ligado à taxa de armadura transversal, o índice de ductilidade pós-pico é influenciado, também, pela resistência do concreto, sendo que essa é inversamente proporcional.

Para possibilitar o traçado de uma superfície que caracterize o comportamento dos pilares quanto ao índice de ductilidade pós-pico em função da taxa de armadura transversal e da resistência do concreto, foram acrescentados aos dados deste trabalho, os resultados experimentais das pesquisas de Ramos e Giongo (2002) e Lima Júnior (2003), que são apresentados na tabela 6.2.

Tabela 6.2 - Valores do índice de ductilidade pós-pico dos ensaio de Ramos e Giongo (2002) e Lima Júnior (2003)

\begin{tabular}{|c|c|c|c|c|}
\hline Autor & Pilar & $\begin{array}{c}\mathrm{f}_{\mathrm{c}, \mathrm{cp}} \\
(\mathrm{MPa})\end{array}$ & $\begin{array}{c}\rho_{\mathrm{w}} \\
(\%)\end{array}$ & $\mathrm{ID}_{\text {pós }}$ \\
\hline \multirow{16}{*}{$\begin{array}{c}\text { Ramos e } \\
\text { Giongo (2002) }\end{array}$} & P1-10,0-120 & 23,65 & 0,198 & 1,51 \\
\hline & P1-12,5-200 & 23,65 & 0,189 & 1,44 \\
\hline & P1-12,5-150 & 27,06 & 0,252 & - \\
\hline & P1-12,5-100 & 27,06 & 0,378 & - \\
\hline & P2-10,0-120 & 22,29 & 0,172 & - \\
\hline & P2-12,5-150 & 22,29 & 0,219 & 1,36 \\
\hline & P2-12,5-100 & 23,26 & 0,328 & 1,49 \\
\hline & P2-12,5-075 & 23,26 & 0,438 & 1,69 \\
\hline & P3-10,0-120 & 26,08 & 0,215 & 1,26 \\
\hline & P3-12,5-150 & 26,08 & 0,274 & 1,58 \\
\hline & P3-12,5-100 & 22,84 & 0,412 & 1,72 \\
\hline & P3-12,5-075 & 22,84 & 0,549 & 1,88 \\
\hline & P4-10,0-120 & 22,11 & 0,259 & 1,50 \\
\hline & P4-12,5-150 & 22,11 & 0,330 & 1,54 \\
\hline & $\mathrm{P} 4-12,5-100$ & 22,47 & 0,495 & 1,83 \\
\hline & $\mathrm{P} 4-12,5-075$ & 22,47 & 0,660 & 1,85 \\
\hline \multirow{8}{*}{$\begin{array}{l}\text { Lima Júnior } \\
\text { (2003) }\end{array}$} & P160150 & 61,85 & 0,32 & 1,05 \\
\hline & P260150 & 61,85 & 0,32 & 0,92 \\
\hline & P16050 & 61,85 & 0,96 & 1,41 \\
\hline & P26050 & 61,85 & 0,96 & 1,33 \\
\hline & P180150 & 82,05 & 0,32 & 0,87 \\
\hline & P280150 & 82,05 & 0,32 & 0,70 \\
\hline & P18050 & 82,05 & 0,96 & 1,39 \\
\hline & P28050 & 82,05 & 0,96 & 1,39 \\
\hline
\end{tabular}


A partir dos dados das tabelas 6.1 e 6.2, foi traçada uma superfície (Figura 6.3) que mostra a variação do índice de ductilidade pós-pico com a taxa de armadura transversal e com a resistência média à compressão do concreto, determinada em ensaios de corpos-de-prova cilíndricos.

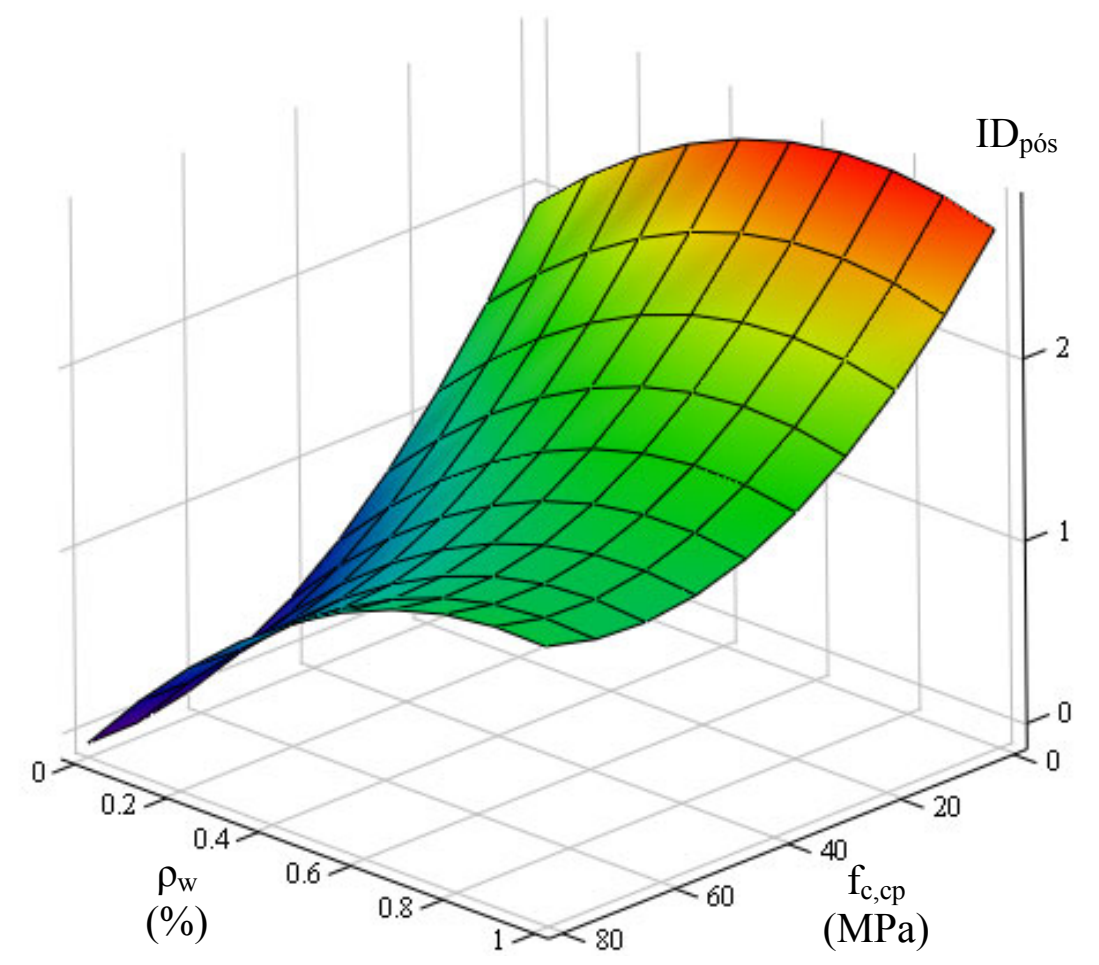

Figura 6.3 - Índice de ductilidade pós-pico em função da taxa de armadura transversal e da resistência do concreto à compressão

Essa superfície foi desenhada fazendo-se uma regressão polinomial considerando duas variáveis obtendo-se, assim, a equação 6.1 que apresenta uma correlação de $96,8 \%$ para os pontos fornecidos.

$$
\mathrm{ID}_{\text {pós }}=1,91-0,052 \cdot \mathrm{x}+2,49 \cdot \mathrm{y}+0,0083 \cdot \mathrm{x} \cdot \mathrm{y}+0,000338 \cdot \mathrm{x}^{2}-1,7 \cdot \mathrm{y}^{2} \quad \text { eq. } 6.1
$$

onde, $x$ representa a resistência do concreto $f_{c j}(\mathrm{MPa})$ e y a taxa de armadura transversal $\rho_{\mathrm{w}}(\%)$.

Pode-se notar no gráfico que o índice de ductilidade é diretamente proporcional a taxa de armadura transversal e inversamente proporcional a resistência do concreto, assim, para que se tenha um comportamento dúctil em 
pilares de concreto de alta resistência, é necessário a utilização de uma maior taxa de armadura transversal para promover esse ganho de ductilidade.

$\mathrm{O}$ ganho de ductilidade em virtude do aumento da taxa de armadura transversal, mantendo-se a resistência do concreto constante, pode ser observado nas figuras 6.4, 6.5, 6.6 e 6.7, para os pilares das séries P1, P2, P3 e P4, respectivamente, sendo que apenas os pilares com armadura longitudinal de 12,5mm de diâmetro foram analisados, para que não houvesse influência pela variação do diâmetro e pela taxa de armadura longitudinal. O que diferencia cada modelo em uma série é o espaçamento da armadura transversal. Os diagramas foram traçados com a média dos valores das leituras dos quatro transdutores.

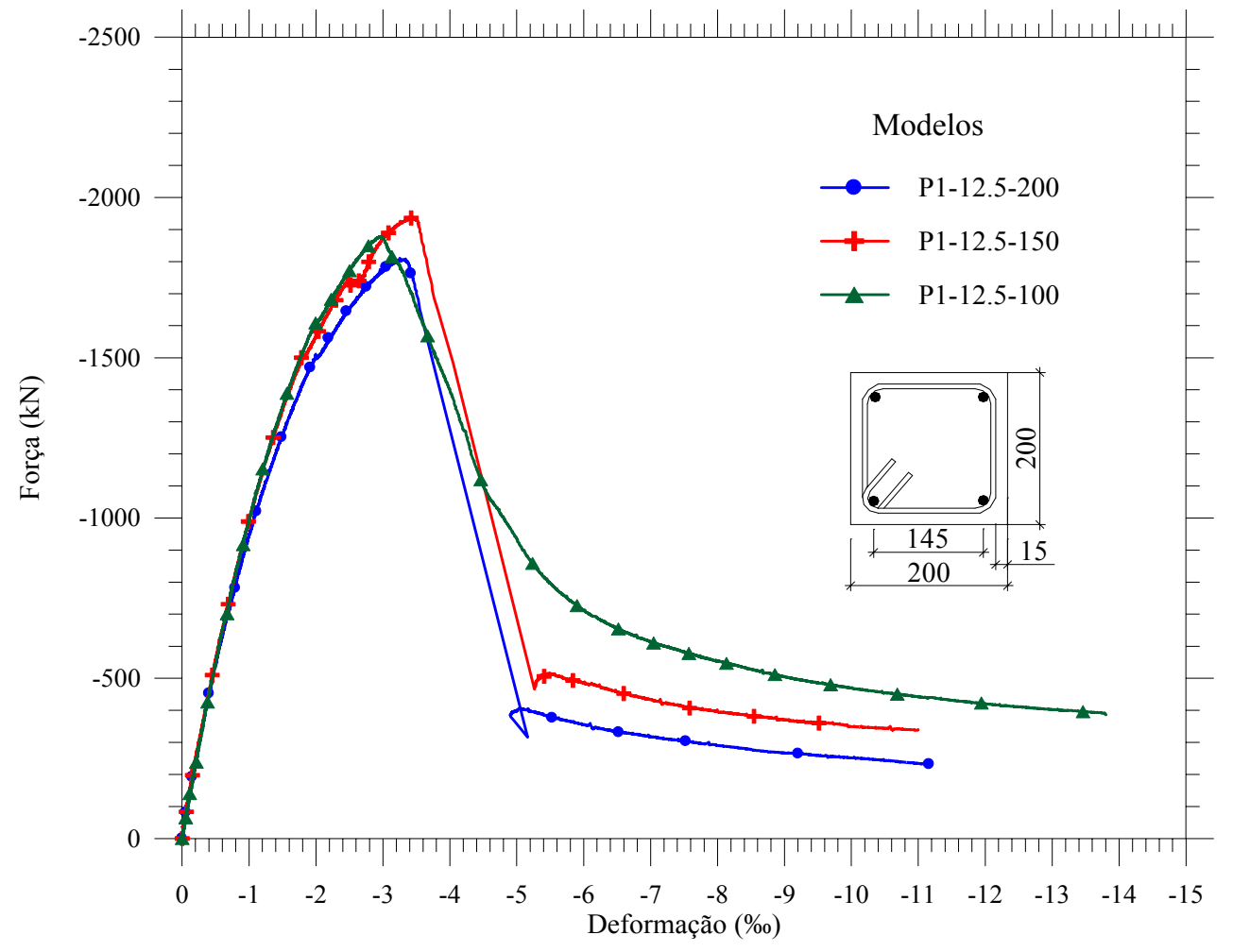

Figura 6.4 - Pilares da série P1 


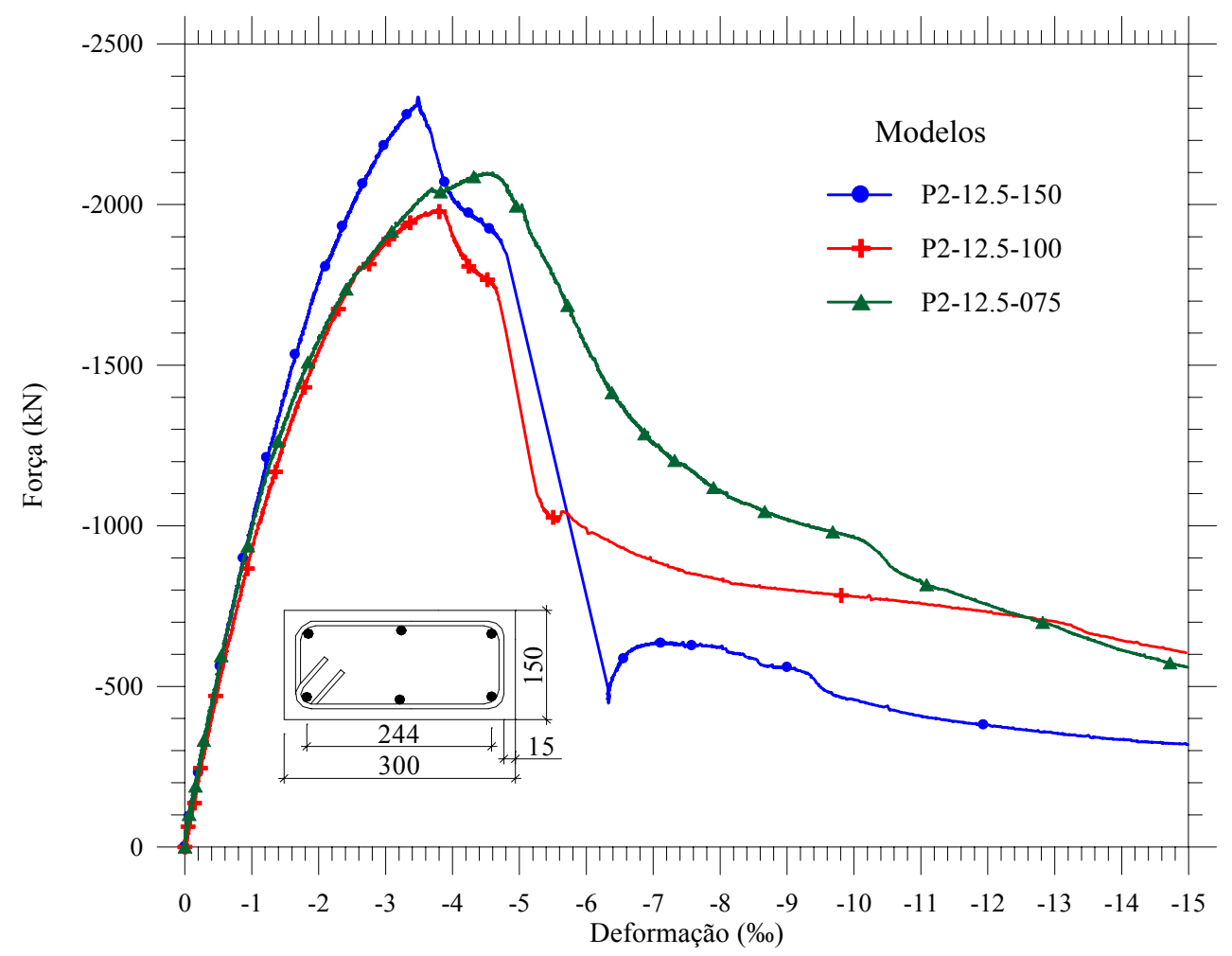

Figura 6.5 - Pilares da série P2

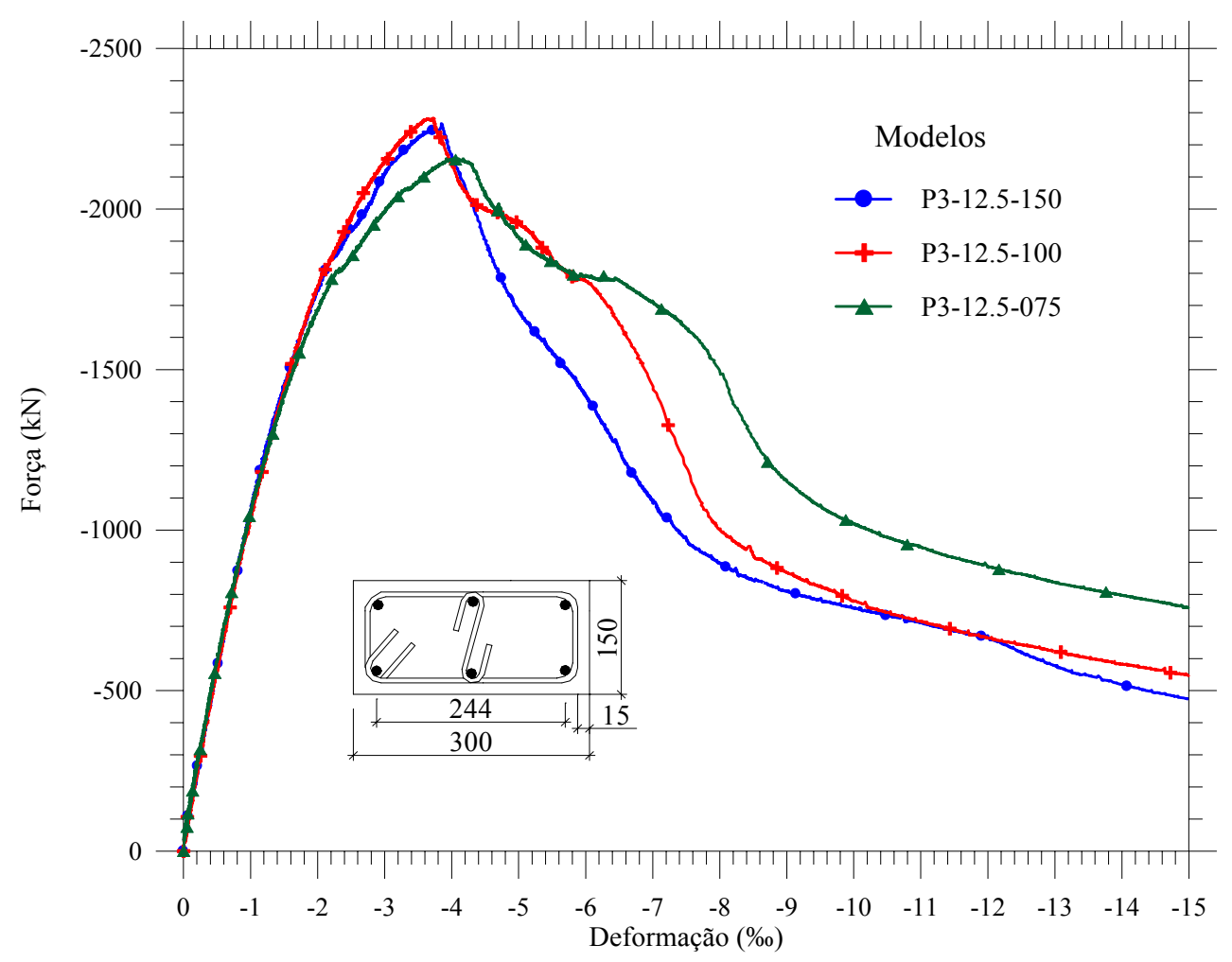

Figura 6.6 - Pilares da série P3 


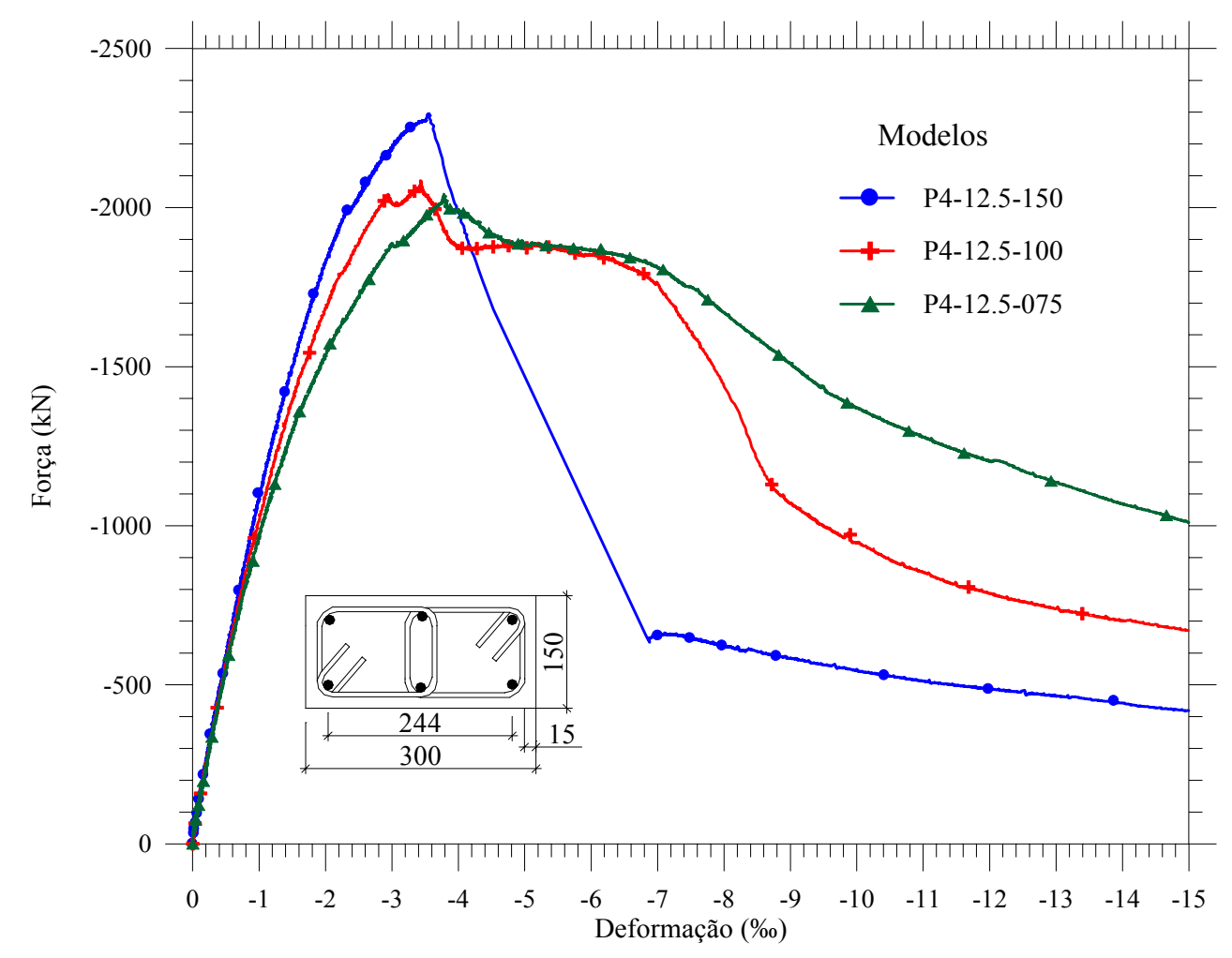

Figura 6.7 - Pilares da série P4

Os pilares P4-12,5-100 e P4-12,5-075, com taxas de armaduras transversais iguais a $0,495 \%$ e $0,66 \%$, respectivamente, apresentaram os melhores comportamentos no tocante a ductilidade. Seus índices de ductilidade superaram 1,5, caracterizando comportamento plástico quase perfeito. Esses pilares, após atingirem os seus picos de resistência, apresentaram acréscimo na capacidade resistente, deformando-se sem perder resistência até, aproximadamente, a deformação média de 7\%o, calculada com as deformações nas faces do pilar, como visto na figura 6.7.

Para avaliar o comportamento do índice de ductilidade pré-pico em função da taxa de armadura transversal e da resistência do concreto, foram acrescentados aos dados deste trabalho os resultados experimentais de Ramos e Giongo (2002), Queiroga, Giongo e Takeya (1999) e Lima, Giongo e Takeya (1997). A superfície que caracteriza esse comportamento é apresentada na figura 6.8. O coeficiente de correlação, $\mathrm{r}^{2}$, dos pontos dados foi igual a $85 \%$. 


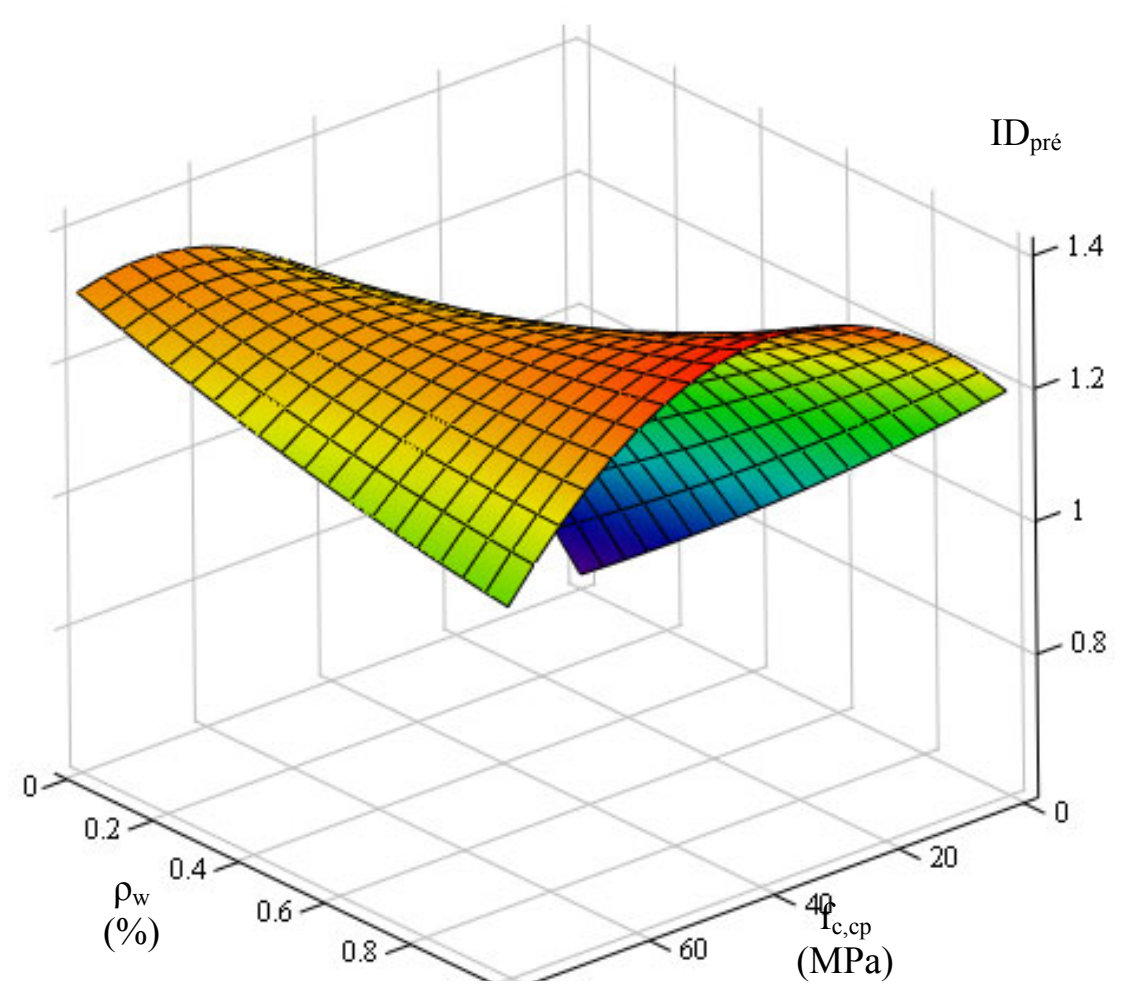

Figura 6.8 - Índice de ductilidade pré-pico em função da taxa de armadura transversal e da resistência do concreto à compressão

O menor valor para o índice de correlação, em relação ao valor encontrado para o índice de ductilidade pós-pico, se deve ao fato de que os pilares de Queiroga, Giongo e Takeya (1999) e Lima, Giongo e Takeya (1997) apresentam altas taxas de armadura longitudinal (valores entre 2,18\% e 2,45\%), enquanto que os pilares de Ramos e Giongo (2002) e os estudados neste trabalho apresentam valores para a taxa de armadura longitudinal aquém dos valores dos outros autores, variando entre $0,79 \%$ e 1,64\%. O valor da taxa de armadura longitudinal influi no comportamento pré-pico dos pilares, assim, para melhor análise desta característica, seriam necessários resultados experimentais em que a taxa de armadura longitudinal não fosse tão variável. 


\subsection{ANÁLISE DOS PILARES CONSIDERANDO O CORFICIENTE $\mathrm{K}_{2}$}

No item 4.8 foi apresentada a tabela 4.4, onde foi feita a previsão da força última dos pilares levando em consideração o valor da variável $\mathrm{k}_{2}$ calculada pela equação 4.4. No item 5.3 foi feita a avaliação dos valores da previsão da força última nos pilares e foram apresentados três critérios diferentes para adoção do valor da variável $k_{2}$, como indicados na tabela 5.3.

Nos trabalhos de Lima (1997), Queiroga (1999) e Ramos e Giongo (2002), foi adotado o valor de 0,95 para a variável $\mathrm{k}_{2}$, com isso, Lima (op. cit.) e Queiroga (op. cit.) concluíram que a seção resistente no pilar era a seção do núcleo e Ramos e Giongo (op. cit.) concluíram que a seção resistente era a seção íntegra.

Calculando-se os valores de $\mathrm{k}_{2}$ com os dados experimentais desses autores, verifica-se que houve equivoco, na opinião deste autor, ao adotarem o valor de $\mathrm{k}_{2}$ igual e constante para todas as resistências do concreto estudadas. Com base nos dados de suas pesquisas e utilizando a expressão 6.2 , foram calculados os valores de $\mathrm{k}_{2}$ para todos os pilares dos autores citados.

A expressão 6.2 consiste em dividir a resistência do prisma de concreto (pilar sem a contribuição da armadura longitudinal) pela resistência medida por meio dos corpos-de-prova cilíndricos. As tabelas 6.3 e 6.4 apresentam os valores de $\mathrm{k}_{2}$ calculados para os autores citados e para os pilares desta pesquisa.

$$
\mathrm{k}_{2}=\frac{\frac{\mathrm{F}_{\text {exp }}-\mathrm{A}_{\mathrm{s}} \cdot \sigma_{\mathrm{s}}}{\mathrm{A}_{\mathrm{c}}-\mathrm{A}_{\mathrm{s}}}}{\mathrm{f}_{\mathrm{c}, \mathrm{cp}}}
$$


Tabela 6.3 - Valores de $\mathrm{k}_{2}$ calculados com base nos ensaios experimentais de Lima (1997) e Queiroga (1999).

\begin{tabular}{|c|c|c|c|c|c|c|c|}
\hline Autor & Pilar & $\begin{array}{c}\mathrm{A}_{\mathrm{c}} \\
\left(\mathrm{cm}^{2}\right)\end{array}$ & $\begin{array}{c}\mathrm{f}_{\mathrm{c}, \mathrm{cp}} \\
(\mathrm{MPa})\end{array}$ & $\begin{array}{l}F_{\text {exp }} \\
(\mathrm{kN})\end{array}$ & $\begin{array}{c}\mathrm{A}_{\mathrm{s}} \\
\left(\mathrm{cm}^{2}\right)\end{array}$ & $\begin{array}{c}\sigma_{\mathrm{s}} \\
(\mathrm{MPa})\end{array}$ & $\mathrm{k}_{2}$ \\
\hline \multirow{12}{*}{$\begin{array}{c}\text { Queiroga } \\
\text { (1999) }\end{array}$} & $\mathrm{P} 1$ & 400 & 59,6 & 2278 & 9,82 & 502 & 0,77 \\
\hline & $\mathrm{P} 2$ & 400 & 64,35 & 2292 & 9,82 & 502 & 0,72 \\
\hline & P3 & 400 & 53,40 & 1835 & 9,82 & 502 & 0,64 \\
\hline & $\mathrm{P} 4$ & 400 & 53,40 & 1864 & 9,82 & 502 & 0,66 \\
\hline & $\mathrm{P} 5$ & 400 & 55,90 & 2158 & 9,82 & 502 & 0,76 \\
\hline & P6 & 400 & 55,90 & 2312 & 9,82 & 502 & 0,83 \\
\hline & P7 & 450 & 66,90 & 2373 & 9,82 & 502 & 0,64 \\
\hline & P8 & 450 & 66,90 & 2496 & 9,82 & 502 & 0,68 \\
\hline & P9 & 450 & 63,88 & 2446 & 9,82 & 502 & 0,69 \\
\hline & $\mathrm{P} 10$ & 450 & 63,88 & 2440 & 9,82 & 502 & 0,69 \\
\hline & P11 & 450 & 65,47 & 2288 & 9,82 & 502 & 0,62 \\
\hline & $\mathrm{P} 12$ & 450 & 65,47 & 2497 & 9,82 & 502 & 0,70 \\
\hline \multicolumn{7}{|c|}{ Média } & 0,70 \\
\hline \multirow{13}{*}{$\begin{array}{c}\text { Lima } \\
\text { (1997) }\end{array}$} & P11 & 400 & 83,80 & 2630 & 9,82 & 543 & 0,64 \\
\hline & P12 & 400 & 83,80 & 2701 & 9,82 & 543 & 0,66 \\
\hline & $\mathrm{P} 13$ & 400 & 83,80 & 2834 & 9,82 & 543 & 0,70 \\
\hline & P1r2 & 400 & 85,10 & 3063 & 9,82 & 543 & 0,76 \\
\hline & P1r3 & 400 & 85,10 & 2820 & 9,82 & 543 & 0,69 \\
\hline & P22 & 400 & 87,94 & 2950 & 9,82 & 543 & 0,70 \\
\hline & $\mathrm{P} 23$ & 400 & 92,00 & 3210 & 9,82 & 543 & 0,75 \\
\hline & P31 & 450 & 94,90 & 3415 & 9,82 & 543 & 0,69 \\
\hline & P32 & 450 & 94,90 & 3750 & 9,82 & 543 & 0,77 \\
\hline & P33 & 450 & 94,90 & 3230 & 9,82 & 543 & 0,65 \\
\hline & $\mathrm{P} 41$ & 450 & 80,50 & 3000 & 9,82 & 543 & 0,70 \\
\hline & $\mathrm{P} 42$ & 450 & 80,50 & 2650 & 9,82 & 543 & 0,60 \\
\hline & $\mathrm{P} 43$ & 450 & 80,50 & 2610 & 9,82 & 543 & 0,59 \\
\hline \multicolumn{7}{|c|}{ Média } & 0,68 \\
\hline
\end{tabular}


Tabela 6.4 - Valores de $k_{2}$ calculados com base nos ensaios experimentais de Ramos e Giongo (2002) e deste trabalho.

\begin{tabular}{|c|c|c|c|c|c|c|c|}
\hline Autor & Pilar & $\begin{array}{c}\mathrm{A}_{\mathrm{c}} \\
\left(\mathrm{cm}^{2}\right)\end{array}$ & $\begin{array}{c}\mathrm{f}_{\mathrm{c}, \mathrm{cp}} \\
(\mathrm{MPa})\end{array}$ & $\begin{array}{l}\mathrm{F}_{\exp } \\
(\mathrm{kN})\end{array}$ & $\begin{array}{c}\mathrm{A}_{\mathrm{s}} \\
\left(\mathrm{cm}^{2}\right)\end{array}$ & $\begin{array}{c}\sigma_{\mathrm{s}} \\
(\mathrm{MPa})\end{array}$ & $\mathrm{k}_{2}$ \\
\hline \multirow{16}{*}{$\begin{array}{c}\text { Ramos e } \\
\text { Giongo } \\
(2002)\end{array}$} & P1-10,0-120 & 400 & 23,65 & 1072 & 3,14 & 458 & 0,99 \\
\hline & P1-12,5-200 & 400 & 23,65 & 1085 & 4,91 & 382 & 0,96 \\
\hline & P1-12,5-150 & 400 & 27,06 & 1223 & 4,91 & 500 & 0,91 \\
\hline & P1-12,5-100 & 400 & 27,06 & 1292 & 4,91 & 561 & 0,95 \\
\hline & P2-10,0-120 & 450 & 22,29 & 1325 & 4,71 & 600 & 1,05 \\
\hline & $\mathrm{P} 2-12,5-150$ & 450 & 22,29 & 1400 & 7,36 & 515 & 1,03 \\
\hline & P2-12,5-100 & 450 & 23,26 & 1175 & 7,36 & 526 & 0,77 \\
\hline & P2-12,5-075 & 450 & 23,26 & 1215 & 7,36 & 554 & 0,78 \\
\hline & P3-10,0-120 & 450 & 26,08 & 1265 & 4,71 & 583 & 0,85 \\
\hline & P3-12,5-150 & 450 & 26,08 & 1322 & 7,36 & 533 & 0,81 \\
\hline & P3-12,5-100 & 450 & 22,84 & 1468 & 7,36 & 550 & 1,05 \\
\hline & P3-12,5-075 & 450 & 22,84 & 1485 & 7,36 & 537 & 1,08 \\
\hline & P4-10,0-120 & 450 & 22,11 & 1238 & 4,71 & 577 & 0,98 \\
\hline & P4-12,5-150 & 450 & 22,11 & 1340 & 7,36 & 550 & 0,96 \\
\hline & P4-12,5-100 & 450 & 22,47 & 1355 & 7,36 & 540 & 0,96 \\
\hline & P4-12,5-075 & 450 & 22,47 & 1365 & 7,36 & 547 & 0,97 \\
\hline \multicolumn{7}{|c|}{ Média } & 0,94 \\
\hline \multirow{16}{*}{$\begin{array}{l}\text { Deste } \\
\text { autor }\end{array}$} & P1-10,0-120 & 400 & 46,57 & 1732,4 & 3,14 & 578,96 & 0,84 \\
\hline & $P 1-12,5-200$ & 400 & 46,29 & 1810,6 & 4,91 & 556,50 & 0,84 \\
\hline & $\mathrm{P} 1-12,5-150$ & 400 & 46,3 & 1939,1 & 4,91 & 556,50 & 0,91 \\
\hline & P1-12,5-100 & 400 & 43,89 & 1880,1 & 4,91 & 556,50 & 0,93 \\
\hline & P2-10,0-120 & 450 & 46,08 & 2022,7 & 4,71 & 590,00 & 0,85 \\
\hline & P2-12,5-150 & 450 & 45,01 & 2335,1 & 7,36 & 556,50 & 0,97 \\
\hline & P2-12,5-100 & 450 & 43,18 & 1985,5 & 7,36 & 556,50 & 0,82 \\
\hline & P2-12,5-075 & 450 & 43,07 & 2099 & 7,36 & 556,50 & 0,89 \\
\hline & P3-10,0-120 & 450 & 46,08 & 2054,6 & 4,71 & 590,00 & 0,87 \\
\hline & P3-12,5-150 & 450 & 45,01 & 2266,5 & 7,36 & 556,50 & 0,93 \\
\hline & P3-12,5-100 & 450 & 43,41 & 2283,2 & 7,36 & 556,50 & 0,97 \\
\hline & P3-12,5-075 & 450 & 42,55 & 2159,3 & 7,36 & 556,50 & 0,93 \\
\hline & P4-10,0-120 & 450 & 46,08 & 1951,9 & 4,71 & 590,00 & 0,82 \\
\hline & P4-12,5-150 & 450 & 45,01 & 2295,7 & 7,36 & 556,50 & 0,95 \\
\hline & P4-12,5-100 & 450 & 43,41 & 2084,9 & 7,36 & 556,50 & 0,87 \\
\hline & P4-12,5-075 & 450 & 42,55 & 2042,4 & 7,36 & 556,50 & 0,87 \\
\hline \multicolumn{7}{|c|}{ Média } & $0, \mathbf{0 , 8 9}$ \\
\hline
\end{tabular}


No item 5.3 foram calculados os valores de $\mathrm{k}_{2}$ a partir da relação entre as resistências dos prismas de concreto simples e dos corpos-de-prova cilíndricos, e o valor médio de $\mathrm{k}_{2}$ na tabela 5.3 para essa relação foi igual a 0,91 . Na tabela 6.4 , o valor médio da variável $\mathrm{k}_{2}$ para os pilares deste trabalho é igual a 0,89 . Essa pequena diferença se deve ao fato de que as armaduras longitudinais geram descontinuidade na estrutura de concreto.

Os dados das tabelas 6.3 e 6.4 mostram que a variável $\mathrm{k}_{2}$ é influenciada pela resistência do concreto e o gráfico da figura 6.9 apresenta as curvas traçadas com os valores médios de $\mathrm{k}_{2}$ das tabelas 6.3 e 6.4 , os valores recomendados pela NS 3473 E (1992) e por Fusco (1989).

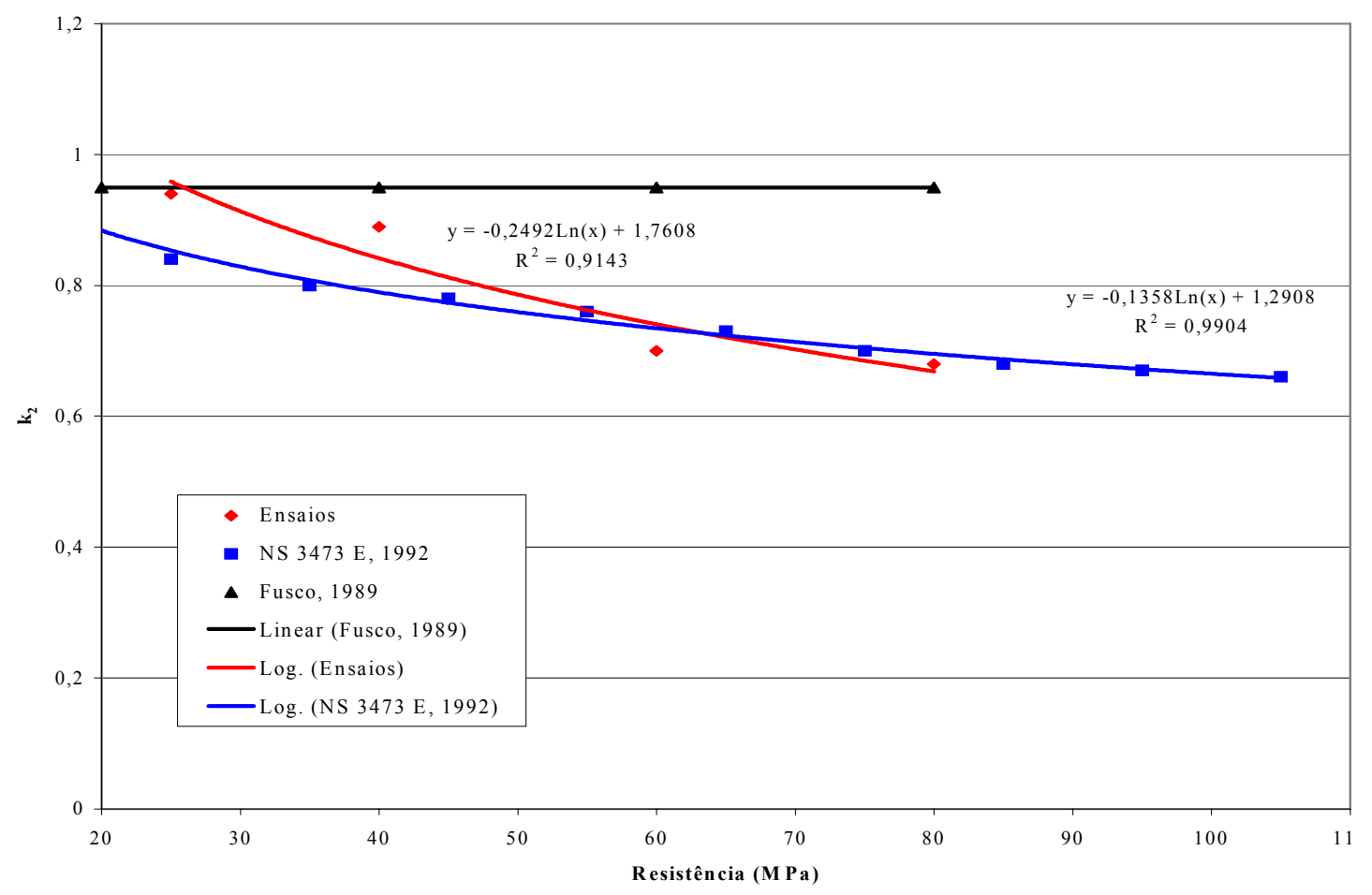

Figura 6.9 - Valores de $k_{2}$ segundo Fusco (1989), NS 3473 E (1992) e diversos autores

A consideração do coeficiente $\mathrm{k}_{2}$ em função da resistência do concreto demonstrou ser a maneira adequada quando se deseja prever a força última teórica em um pilar. As forças últimas teóricas avaliadas na tabela 5.4 (com os valores de $\mathrm{k}_{2}$ calculados com os prismas de concreto simples) apresentaram valores muito bons quando comparados às forças experimentais, resultando em 
uma diferença de 2,6\%, em média. $\mathrm{O}$ valor 0,95 é seguro quando se trabalha com concretos de resistências inferiores a $25 \mathrm{MPa}$, para concretos com resistências superiores esse valor tende a ser menor como sugere a NS 3473 E (1992).

Com base no exposto anteriormente é possível afirmar que a variável $\mathrm{k}_{2}$ não pode ser considerada uma constante para diferentes resistências do concreto. São necessários mais estudos para melhor consideração dessa variável, verificar a influência das taxas de armaduras longitudinais e transversais, além, é claro, da influência da resistência do concreto.

Se Lima (1997) e Queiroga (1999) tivessem considerado o valor de $k_{2}$ variável com a resistência do concreto e esses valores fossem iguais aos valores médios apresentados na tabela 6.3 ou iguais aos sugeridos pela NS $3473 \mathrm{E}$ (1992), eles concluiriam que as seções resistentes seriam as seções integras e não as seções dos núcleos. Segundo Cusson e Paultre (1994), a seção do núcleo começa a trabalhar de fato depois que o pilar atinge seu pico de resistência, antes disso a armadura de confinamento do núcleo é solicitada com $50 \%$ da resistência de escoamento, como visto na figura 3.3 no item 3.1 deste trabalho.

Ramos e Giongo (2002) concluíram que a seção resistente é a seção íntegra do pilar. A previsão da força última nos modelos desse autor foi feita utilizando o valor da variável $\mathrm{k}_{2}$ igual a 0,95 . $\mathrm{O}$ valor médio de $\mathrm{k}_{2}$ calculado para os pilares de Ramos e Giongo (op. cit.) apresentado na tabela 6.4 foi igual a 0,94. Essa pequena diferença não influenciou na conclusão, diferente do acontecido com Lima (1997) e Queiroga (1999). 


\subsection{ANÁLISE CONSIDERANDO O MODELO NUMÉRICO}

De modo geral, o programa computacional com o modelo de confinamento de Cusson e Paultre (1995) modificado por Lima Júnior (2003) representou de modo razoável as curvas experimentais. A tabela 6.5 apresenta os valores das forças últimas experimentais e os valores das forças últimas calculadas com o programa numérico.

Tabela 6.5 - Resumo dos resultados dos ensaios e do programa utilizado

\begin{tabular}{|c|c|c|c|c|c|c|}
\hline \hline Modelo & $\begin{array}{c}\mathrm{f}_{\mathrm{c}, \mathrm{cp}} \\
(\mathrm{MPa})\end{array}$ & $\begin{array}{c}\mathrm{A}_{\mathrm{s}} \\
\left(\mathrm{cm}^{2}\right)\end{array}$ & $\begin{array}{c}\sigma_{\mathrm{s}} \\
(\mathrm{MPa})\end{array}$ & $\begin{array}{c}\mathrm{F}_{\text {num }} \\
(\mathrm{kN})\end{array}$ & $\begin{array}{c}\mathrm{F}_{\text {exp }} \\
(\mathrm{kN})\end{array}$ & $\frac{\mathrm{F}_{\text {num }}}{\mathrm{F}_{\text {exp }}}$ \\
\hline P1-10,0-120 & 46,57 & 3,14 & 578,96 & 1683,83 & 1732,4 & 0,972 \\
\hline P1-12,5-200 & 46,29 & 4,91 & 556,50 & 1771,41 & 1810,6 & 0,978 \\
\hline P1-12,5-150 & 46,30 & 4,91 & 556,50 & 1767,91 & 1939,1 & 0,912 \\
\hline P1-12,5-100 & 43,89 & 4,91 & 556,50 & 1699,36 & 1880,1 & 0,904 \\
\hline P2-10,0-120 & 46,08 & 4,71 & 590,00 & 1936,66 & 2022,7 & 0,957 \\
\hline P2-12,5-150 & 45,01 & 7,36 & 556,50 & 2043,04 & 2335,1 & 0,875 \\
\hline P2-12,5-100 & 43,18 & 7,36 & 556,50 & 1984,24 & 1985,5 & 0,999 \\
\hline P2-12,5-075 & 43,07 & 7,36 & 556,50 & 1980,70 & 2099,0 & 0,944 \\
\hline P3-10,0-120 & 46,08 & 4,71 & 590,00 & 1936,66 & 2054,6 & 0,943 \\
\hline P3-12,5-150 & 45,01 & 7,36 & 556,50 & 2043,04 & 2266,5 & 0,901 \\
\hline P3-12,5-100 & 43,41 & 7,36 & 556,50 & 1991,55 & 2283,2 & 0,872 \\
\hline P3-12,5-075 & 42,55 & 7,36 & 556,50 & 1963,91 & 2159,3 & 0,910 \\
\hline \hline P4-10,0-120 & 46,08 & 4,71 & 590,00 & 1936,66 & 1951,9 & 0,992 \\
\hline P4-12,5-150 & 45,01 & 7,36 & 556,50 & 2043,04 & 2295,7 & 0,890 \\
\hline P4-12,5-100 & 43,41 & 7,36 & 556,50 & 1991,55 & 2084,9 & 0,955 \\
\hline P4-12,5-075 & 42,55 & 7,36 & 556,50 & 1963,91 & 2042,4 & 0,962 \\
\hline \hline
\end{tabular}

Os valores das forças teóricas obtidas com o programa computacional mostraram-se conservativos. Para todos os modelos os valores das forças últimas calculadas pelo programa foram inferiores aos valores experimentais ficando, em média, $6,5 \%$ menores. 
O comportamento dos diagramas tensão vs. deformação dos modelos numéricos em relação aos ensaios experimentais são apresentados nas figuras 6.10 a 6.25. As curvas experimentais foram desenhadas tomando-se a média dos valores lidos pelos quatro transdutores.

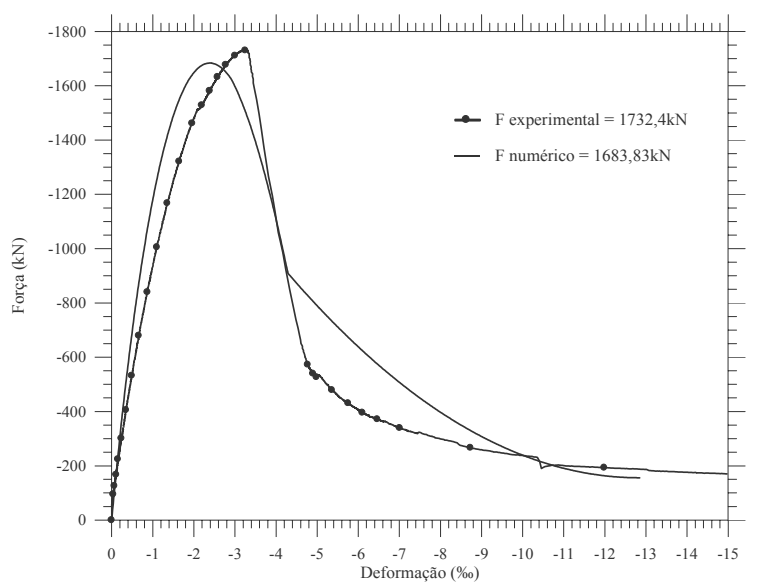

Figura 6.10 - Curvas do pilar P1-10,0-120

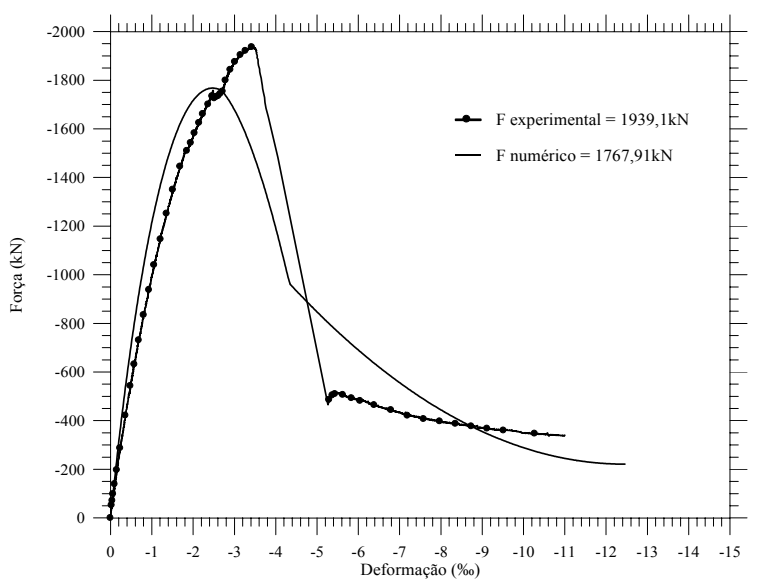

Figura 6.12 - Curvas do pilar P1-12,5-150

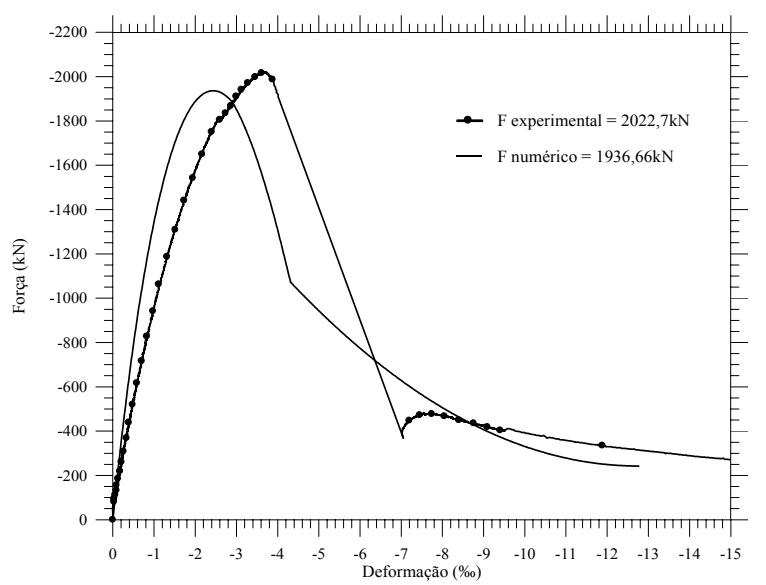

Figura 6.14 - Curvas do pilar P2-10,0-120

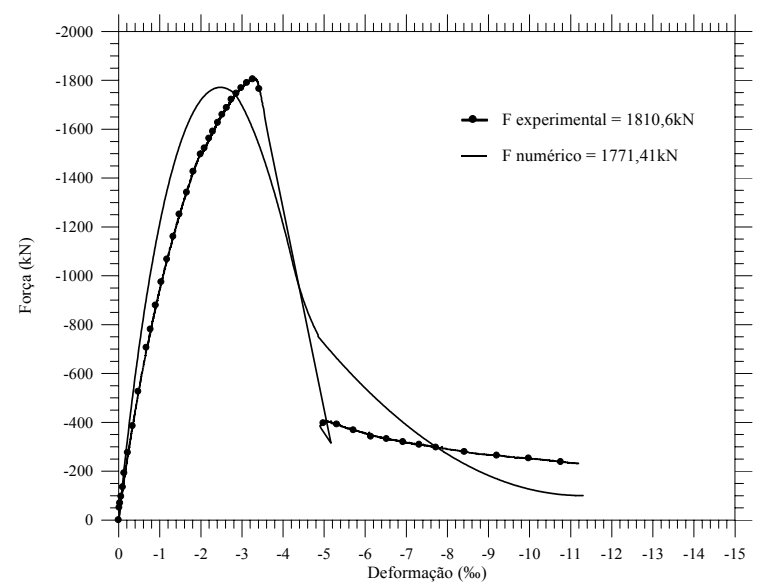

Figura 6.11 - Curvas do pilar P1-12,5-200

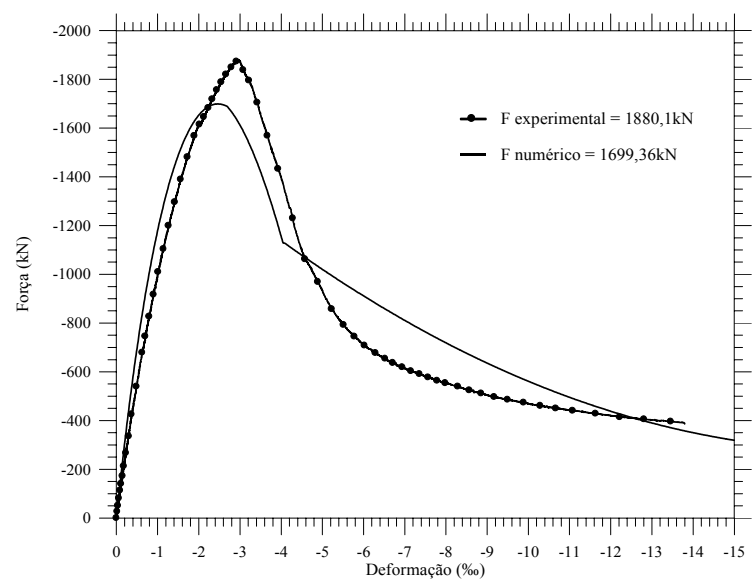

Figura 6.13 - Curvas do pilar P1-12,5-100

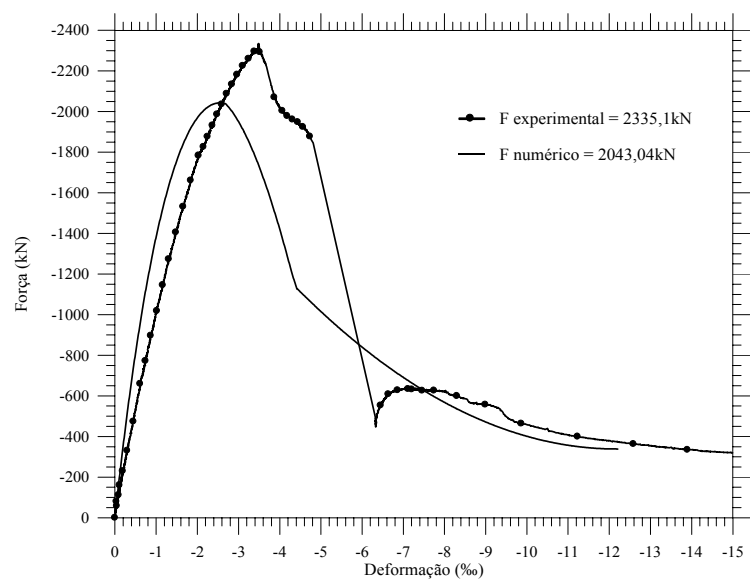

Figura 6.15 - Curvas do pilar P2-12,5-150 


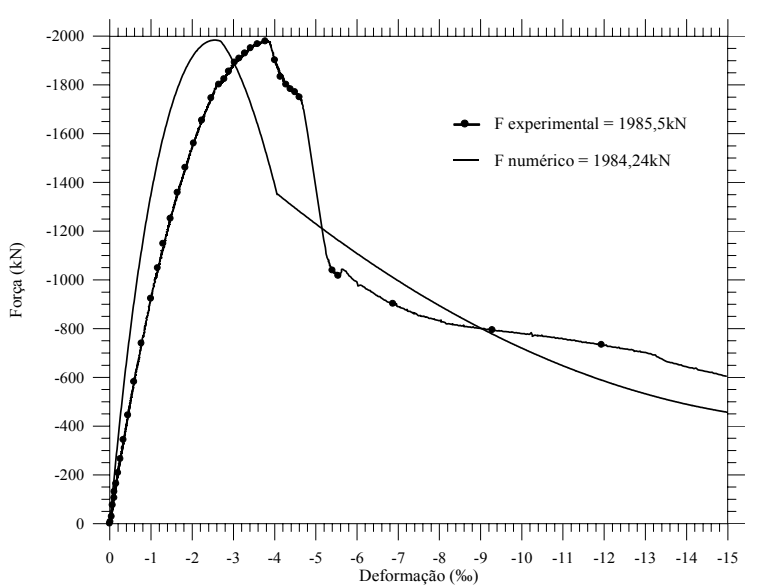

Figura 6.16 - Curvas do pilar P2-12,5-100

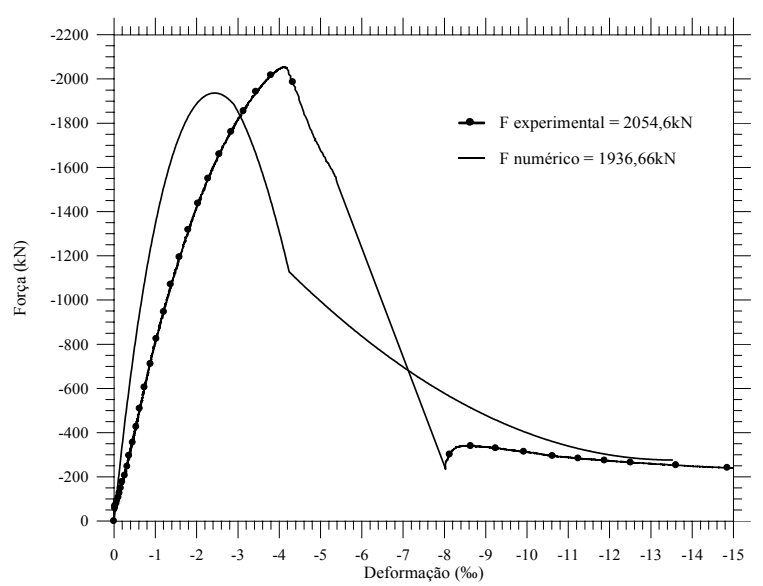

Figura 6.18 - Curvas do pilar P3-10,0-120

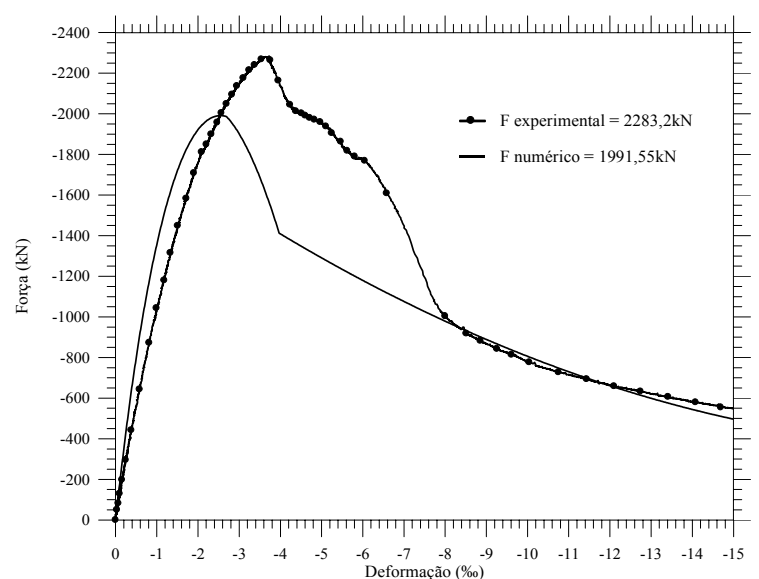

Figura 6.20 - Curvas do pilar P3-12,5-100

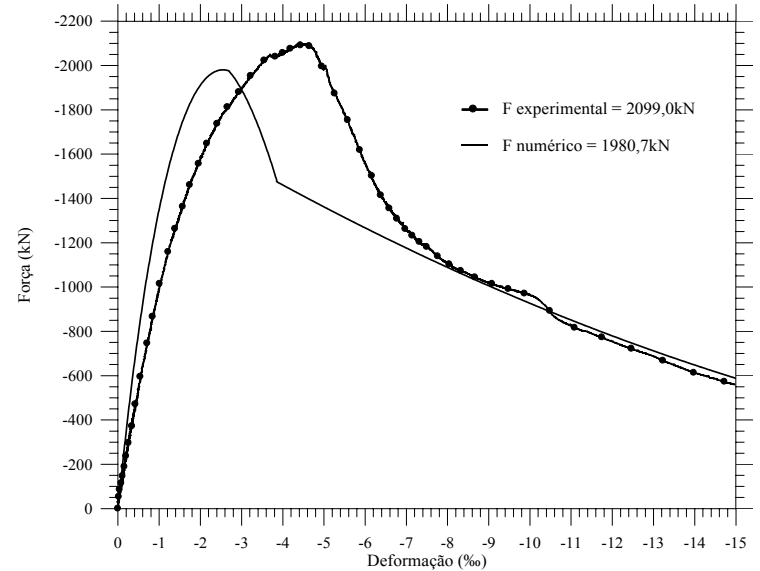

Figura 6.17 - Curvas do pilar P2-12,5-075

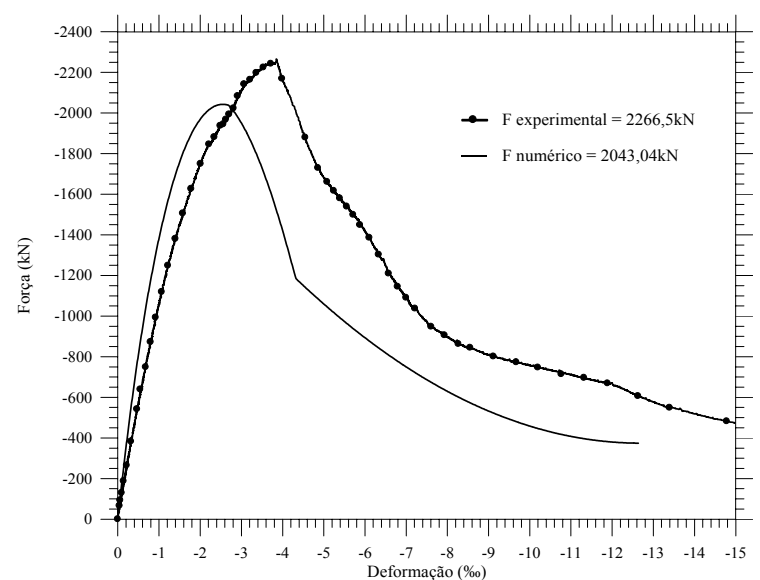

Figura 6.19 - Curvas do pilar P3-12,5-150

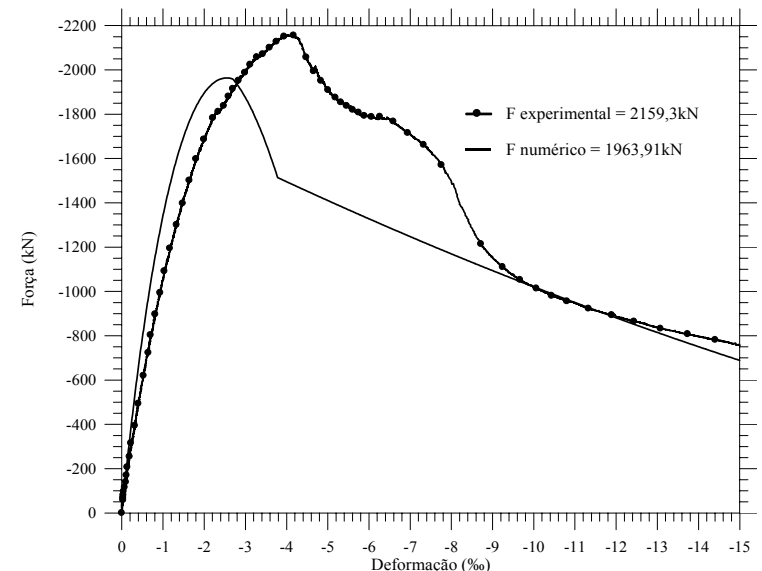

Figura 6.21 - Curvas do pilar P3-12,5-075 


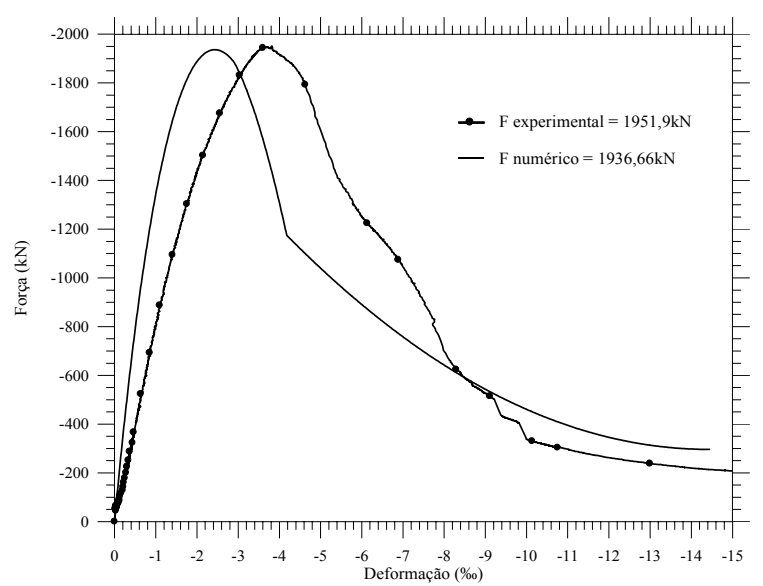

Figura 6.22 - Curvas do pilar P4-10,0-120

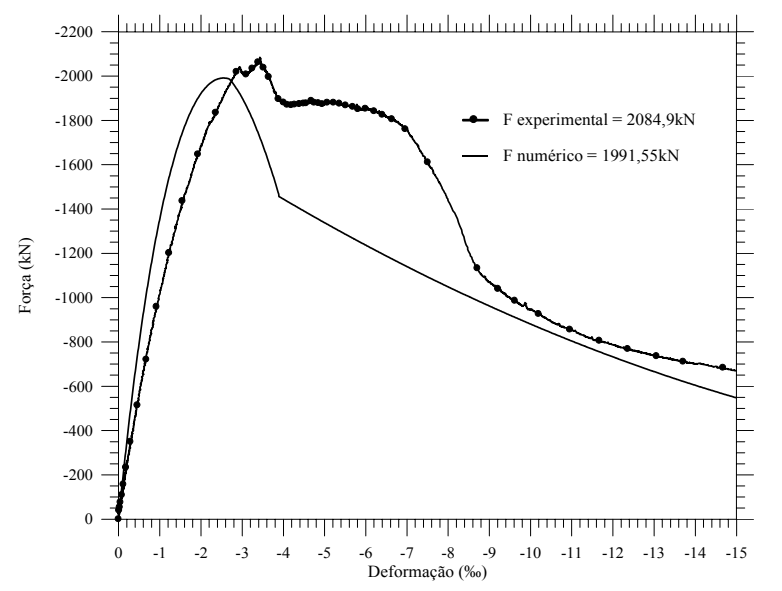

Figura 6.24 - Curvas do pilar P4-12,5-100

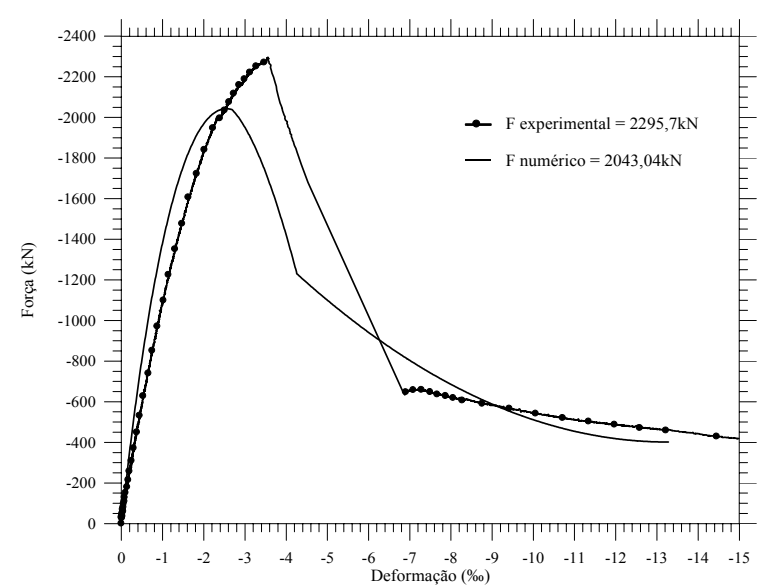

Figura 6.23 - Curvas do pilar P4-12,5-150

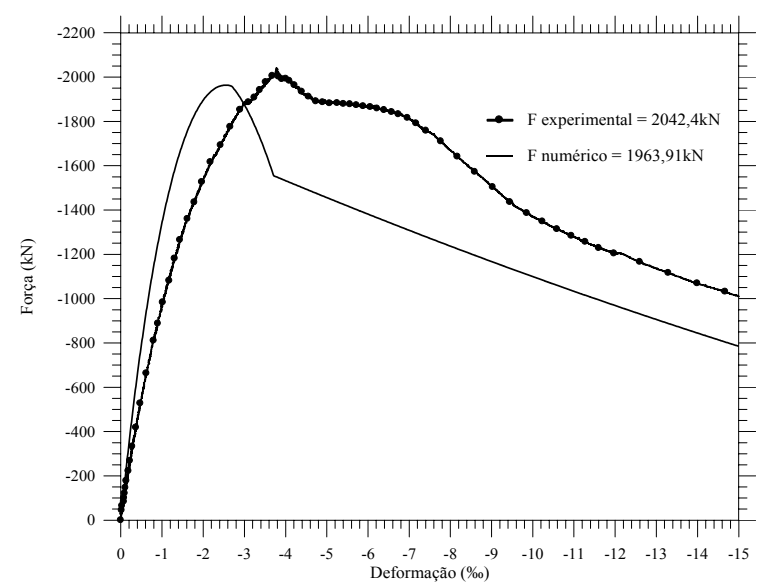

Figura 6.25 - Curvas do pilar P4-12,5-075

Em todos os casos os trechos ascendentes dos diagramas experimentais possuem menor inclinação do que os diagramas desenhados com o modelo numérico, isso se deve ao fato de que o modelo numérico não considera a excentricidade da aplicação da força. $\mathrm{Na}$ análise experimental há deformações do equipamento de ensaio e a acomodação das extremidades dos pilares às prensas da máquina, estas causam excentricidades que aumentam as deformações em uma ou mais faces do pilar. 


\section{Capítulo 7}

\section{CONCLUSÃO}

\subsection{CONSIDERAÇÕES INICIAIS}

As forças axiais (tração ou compressão) constituem, na verdade, idealizações de cálculo. $\mathrm{Na}$ prática, existem sempre excentricidades nas solicitações, decorrentes de imprecisões construtivas, excentricidade das forças nos extremos e de momentos por causa das ligações. No caso dos ensaios realizados, isso pôde ser constatado nos pilares das últimas concretagens, que apresentaram falta de linearidade decorrente do desgaste das fôrmas. Mesmo com a regularização das extremidades dos pilares, todos apresentaram flexões indesejadas, que puderam ser comprovadas pelas leituras individuais dos LVDTs dispostos nas faces dos pilares.

No item 5.1.1 foram discutidas as influências da temperatura e da umidade ambiente no slump e, conseqüentemente, na resistência final do concreto. A figura 7.1 apresenta um gráfico das resistências nos dias dos ensaios, medidas por meio dos corpos-de-prova cilíndricos, vs. os valores dos abatimentos das massas dos concretos nos dias das concretagens. 


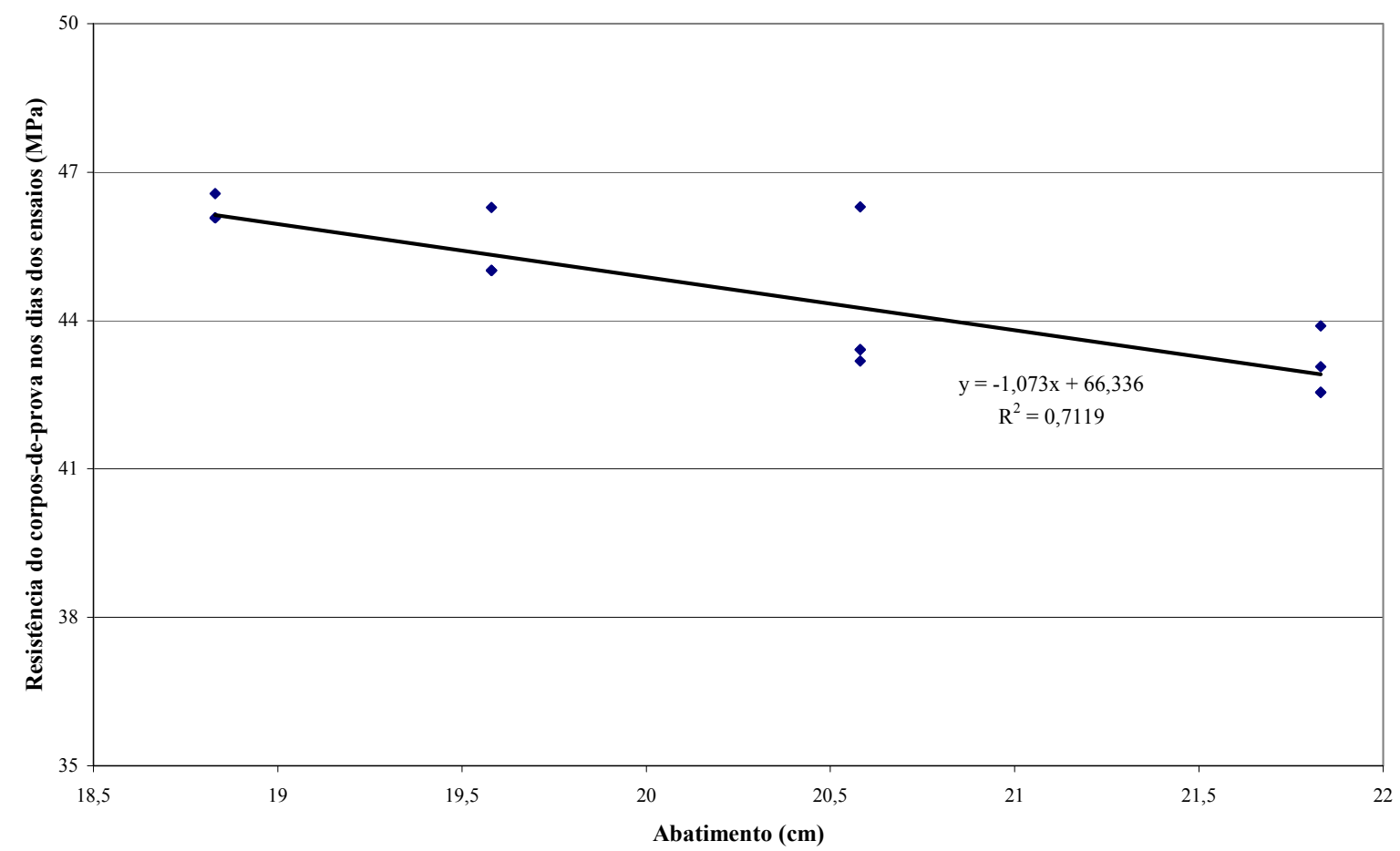

Figura 7.1 - Variação da resistência do concreto à compressão com o slump

Esse gráfico foi desenhado com os dados da tabela 5.1 e sobre esses pontos foi traçada uma linha de tendência de $1^{\circ}$ grau, cuja equação é apresentada na figura 7.1, que apresentou uma correlação, $\mathrm{r}^{2}$, de $71,2 \%$ com os pontos fornecidos. Isso permite concluir que mesmo com maior cuidado na preparação da massa do concreto, utilizando adequado fator água/cimento e fazendo a secagem dos agregados para não haver influência da umidade da pedra britada e da areia, o fator ambiente é crucial para obtenção da resistência à compressão desejada para o concreto.

\subsection{RESISTÊNCIA DO PILAR E INFLUÊNCIA DO K2}

Nos estudos de pilares feitos por Queiroga (1999) e Lima (1997), com resistência à compressão do concreto de $60 \mathrm{MPa}$ e $80 \mathrm{MPa}$, respectivamente, os autores utilizaram o valor $\mathrm{k}_{2}$ igual a 0,95, como sugere Fusco (1989), para ponderar o valor da resistência média do concreto à compressão, medida por meio de corpos-de-prova cilíndricos, quando do cálculo da resistência do 
concreto à compressão no prisma. Foi apresentado que o valor de $\mathrm{k}_{2}$ varia com a resistência do concreto, e pela equação 2.3 , obtida com os dados fornecidos pela norma Norueguesa NS 3473 E (1992), os valores de $k_{2}$ para as resistências de $60 \mathrm{MPa}$ e $80 \mathrm{MPa}$ são iguais a 0,79 e 0,75 , respectivamente.

Na tabela 6.3, no item 6.2, foram calculados os valores de $\mathrm{k}_{2}$ para os pilares de Queiroga (1999) e Lima (1997), a partir dos resultados experimentais desses autores. Foram encontrados os valores médios de $\mathrm{k}_{2}$ iguais a 0,70 e 0,68 para as resistências de $60 \mathrm{MPa}$ e $80 \mathrm{MPa}$, respectivamente. Esses autores concluíram que havia formação de núcleo resistente nos pilares de concreto armado, com resistência média à compressão do concreto de $60 \mathrm{MPa}$ e $80 \mathrm{MPa}$, pois os valores das resistência na previsão da força última, considerando a seção integra, ficaram, em média, $18 \%$ e $21 \%$, respectivamente, maiores do que os valores experimentais, enquanto que os valores da previsão da força última considerando o núcleo de concreto ficaram, em média, 21\%, para ambos os autores, menores que os valores experimentais, como mostra a tabela 7.1.

Tabela 7.1 - Relação entre a previsão da força última, com a seção íntegra e a seção do núcleo, e a força última experimental

\begin{tabular}{|c|c|c|c|}
\hline Autor & $\begin{array}{c}\text { Resistência } \\
(\mathrm{MPa})\end{array}$ & $\frac{\mathrm{F}_{\text {teo,íntegra }}}{\mathrm{F}_{\text {exp erimental }}}$ & $\frac{\mathrm{F}_{\text {teo,núcleo }}}{\mathrm{F}_{\text {experimental }}}$ \\
\hline \hline Queiroga (1999) & 60 & 0,82 & 1,21 \\
\hline Lima (1997) & 80 & 0,79 & 1,21 \\
\hline \hline
\end{tabular}

O dimensionamento do pilar considerando a seção resistente como sendo a seção do núcleo está a favor da segurança, mas causaria aumento da seção transversal do elemento estrutural.

Ramos (2001) fez a previsão da força última considerando o valor de $k_{2}$, sugerido por Fusco (1989), igual a 0,95, então ele concluiu que não há formação de núcleo resistente, pois os valores da previsão da força última considerando a seção íntegra ficaram, em média, 3,8\% maiores que os valores experimentais, 
enquanto que os valores da previsão da força última considerando o núcleo de concreto ficaram, em média, 29\% menores que os valores experimentais.

Na tabela 6.4 foram calculados os valores de $\mathrm{k}_{2}$ para os pilares de Ramos (2001) e deste trabalho, a partir dos dados experimentais. O valor médio de $\mathrm{k}_{2}$ para os pilares de Ramos (op. cit.) foi igual a 0,94. Isso mostra que a conclusão feita por Ramos (2001) está correta.

A previsão da força última para os pilares deste trabalho considerando as seções íntegras, apresentada na tabela 4.4 no item 4.9 , foi feita considerando os valores de $\mathrm{k}_{2}$ calculados dividindo-se os valores de resistência à compressão dos prismas de concreto pelos valores de resistência medidos por meio dos corposde-prova cilíndricos. A tabela 7.2 apresenta as médias dos valores das relações entre as previsões das forças últimas calculadas na tabela 4.4, as calculadas com $\mathrm{k}_{2}$ sugerido por Fusco (1989) e pela NS 3473 E (1992) e as forças últimas experimentais.

Tabela 7.2 - Relação entre as forças últimas calculadas com os critérios adotados e a força última experimental

\begin{tabular}{|c|c|c|c|}
\hline & $\frac{\mathrm{F}_{\text {teo }}(\text { Fusco })}{\mathrm{F}_{\text {exp }}}$ & $\frac{\mathrm{F}_{\text {teo }}(\text { Deste autor })}{\mathrm{F}_{\exp }}$ & $\frac{\mathrm{F}_{\text {teo }}(\mathrm{NS} 3473)}{\mathrm{F}_{\exp }}$ \\
\hline Médias & 1,060 & 1,026 & 0,947 \\
\hline
\end{tabular}

Em média, os valores indicados na tabela 7.2 da relação entre a força última teórica calculados com o critério da NS 3473 E (1992) se mostraram mais conservativos que os outros critérios, ficando, em média 5,3\% abaixo dos valores experimentais. Os valores das forças últimas calculadas com $\mathrm{k}_{2}$ sugerido por Fusco (1989) apresentaram os piores resultados, ficando em média 6\% acima dos valores experimentais. Com o valor de $\mathrm{k}_{2}$ obtido pela relação entre a resistência medida nos prismas de concreto simples e a resistência medida nos corpos-deprova cilíndricos, os valores das forças últimas teóricas ficaram, em média, 2,6\% acima dos valores experimentais, ou seja, apesar de não serem conservativos 
como os da NS 3473 E (op. cit.) foram os que mais se aproximaram, em média, dos valores experimentais.

A consideração do coeficiente $\mathrm{k}_{2}$ em função da resistência do concreto demonstrou ser a maneira mais correta quando se deseja prever a força última teórica em um pilar. As forças últimas teóricas avaliadas na tabela 5.4 (com os valores de $\mathrm{k}_{2}$ calculados com os prismas de concreto simples) apresentaram valores muito bons quando comparados às forças experimentais, resultando em uma diferença de $2,6 \%$, em média. O valor 0,95 é seguro quando se trabalha com concretos de resistências inferiores a $25 \mathrm{MPa}$, para concretos com resistências superiores esse valor tende a ser menor como sugere a NS 3473 E (1992).

Em face do exposto é possível afirmar que a variável $\mathrm{k}_{2}$ não pode ser considerada constante para diferentes resistências do concreto. São necessários mais estudos para melhor caracterização dessa variável, verificar a influência das armaduras longitudinais e transversais, além, é claro, da influência da resistência do concreto.

\subsection{DUCTILIDADE}

$\mathrm{O}$ critério para quantificação da ductilidade apresentou-se adequado à análise proposta. Os dados experimentais mostraram que a ductilidade é um fator ligado diretamente a taxa de armadura transversal e inversamente proporcional à resistência do concreto. Para uma mesma taxa de armadura transversal, o valor do índice de ductilidade pós-pico em um pilar de concreto de resistência usual pode ser duas vezes maior do que em um pilar de concreto de alta resistência, assim é necessário que se utilize alta taxa de armadura transversal, maior em um pilar de concreto de alta resistência, para que esse apresente a mesma ductilidade do pilar de menor resistência. Considerando a equação 6.1, um concreto com resistência $30 \mathrm{MPa}$ e taxa de armadura transversal de 0,25\% apresenta índice de ductilidade pós-pico igual a 1,23. Para que um pilar moldado com concreto de resistência $60 \mathrm{MPa}$ apresente o mesmo valor para o índice de ductilidade, é necessário que ele possua uma taxa de armadura transversal de 0,65\%. 
Para uma mesma resistência, variando apenas a taxa de armadura transversal, os índices de ductilidade pós-pico apresentaram diferenças em seus valores para os pilares de uma mesma série, como visto nas figuras 6.4 a 6.7 e disposto na tabela 6.1 .

O pilar P1-12,5-200, que foi dimensionado fora das exigências da NBR 6118:2003, apresentou o pior comportamento dentre todos os estudados. Com taxa de armadura transversal de 0,189\%, apresentou índice de ductilidade póspico igual a 0,593 , que caracteriza um comportamento frágil. Os outros pilares da série P1 se mostraram melhores, com, por exemplo, índice de ductilidade de 0,962 para o P1-12,5-100.

Os pilares P4-12,5-100 e P4-12,5-075, com taxas de armaduras transversais iguais a $0,495 \%$ e $0,66 \%$, respectivamente, apresentaram os melhores comportamentos no tocante a ductilidade. Seus índices de ductilidade superaram 1,5, caracterizando comportamento plástico quase perfeito. Esses pilares, após atingirem os seus picos de resistência, apresentaram acréscimo na capacidade resistente, deformando-se sem perder resistência até, aproximadamente, a deformação média de 7\%o, calculada com as deformações nas faces do pilar, como visto na figura 6.7.

Para todos os pilares de concreto armado foi constatado o confinamento do núcleo de concreto. O confinamento do núcleo se apresentou maior nos pilares com maiores taxas de armadura transversal. Após ser atingida a força de pico, os pilares apresentaram perda de resistência, descolamento do cobrimento e flambagem das barras da armadura longitudinal, fazendo as barras da armadura transversal trabalharem para impedir maior deslocamento das longitudinais e impedir o colapso do núcleo de concreto, como pode ser notado nos diagramas força aplicada vs. deformação das barras da armadura transversal no apêndice B deste trabalho. 


\subsection{ANÁLISE NUMÉRICA}

Os valores das forças teóricas obtidas com o programa computacional mostraram-se conservativos. Para todos os modelos os valores das forças últimas calculadas pelo programa foram, em média, 6,5\% inferiores aos das forças últimas experimentais, como visto na tabela 6.5. O modelo de Cusson e Paultre (1995) modificado por Lima Júnior (2003) conseguiu representar as curvas experimentais de modo razoável, como visto nas figuras 6.10 a 6.25.

Em todos os casos os trechos ascendentes dos diagramas experimentais possuem menor inclinação do que os diagramas desenhados com o modelo numérico, isso se deve ao fato de que o modelo numérico não considera a excentricidade da aplicação da força. $\mathrm{Na}$ análise experimental há deformações do equipamento de ensaio e a acomodação das extremidades dos pilares às prensas da máquina, estas causam excentricidades que aumentam as deformações em uma ou mais faces do pilar.

Antes dos ensaios as extremidades dos pilares foram regularizadas para que não houvessem flexões indesejadas, mas isso não evitou que essas acontecessem, como pode ser visto nos diagramas do item 6.3.

\subsection{SUGESTÕES PARA PROJETO}

Para o projeto de pilares de concreto armado sugere-se a consideração do valor de $\mathrm{k}_{2}$ variando com a resistência à compressão do concreto. $\mathrm{O}$ coeficiente $\mathrm{k}_{2}$ dividiria o valor da força normal de cálculo majorando-a. $\mathrm{O}$ aumento nas taxas de armadura transversal e longitudinal provocaria, conseqüentemente, melhora no comportamento dúctil dos pilares.

A utilização da variável $\mathrm{k}_{2}$ em função da resistência do concreto torna possível o dimensionamento de pilares de concreto de alta resistência considerando-se a seção íntegra ao invés da seção do núcleo, mas para isso são necessários mais ensaios para melhor caracterização dessa variável. 


\subsection{SUGESTÕES PARA CONTINUIDADE DA PESQUISA}

A seguir são apresentadas sugestões para continuidade da pesquisa.

$\checkmark$ refazer a análise teórica e experimental dos modelos de pilares para atuação de forças de longa duração;

$\checkmark$ fazer análise experimental para melhor caracterização da variável $\mathrm{k}_{2}$, estudando a influência da taxa de armadura longitudinal e, se possível, a influência da adição de fibras metálicas no concreto quando do cálculo do valor dessa variável;

$\checkmark$ estudar a influência da taxa de armadura longitudinal no comportamento dúctil de pilares de concreto armado. 


\section{Referências Bibliográficas}

AGOSTINI, L.R.S. (1992). Pilares de concreto de alta resistência. Tese (Doutorado) - Escola Politécnica, Universidade de São Paulo. São Paulo.

AMERICAN CONCRETE INSTITUTE (1989). ACI-ASCE Joint Committee 318. Building code requirements for reinforced concrete. ACI - Detroit - USA, p. 353.

AMERICAN CONCRETE INSTITUTE (1997). ACI-ASCE Joint Committee 441. State-of-the-art report on high-strength concrete columns. ACI Structural Journal, v.94, n.3, p. 323-335, May-June.

ASSOCIAÇÃO BRASILEIRA DE NORMAS TÉCNICAS (1982). NBR 7251:1982: Agregado em estado solto - determinação da massa unitária. Rio de Janeiro.

ASSOCIAÇÃO BRASILEIRA DE NORMAS TÉCNICAS (1982). NBR 7477:1982: Determinação do coeficiente de conformação superficial de barras e fios de aço destinados a armaduras de concreto armado - método de ensaio. Rio de Janeiro. 
ASSOCIAÇÃO BRASILEIRA DE NORMAS TÉCNICAS (1983).

NBR 7211:1983: Agregado para concreto. Rio de Janeiro.

ASSOCIAÇÃO BRASILEIRA DE NORMAS TÉCNICAS (1984).

NBR 8522:1984: Concreto - determinação do módulo de deformação estática e diagrama tensão deformação - método de ensaio. Rio de Janeiro.

ASSOCIAÇÃO BRASILEIRA DE NORMAS TÉCNICAS (1986).

NBR 7480:1986: Barras e fios de aço destinados a armaduras para concreto armado - especificação. Rio de Janeiro.

ASSOCIAÇÃO BRASILEIRA DE NORMAS TÉCNICAS (1987). NBR 7217:1987: Agregados - determinação da composição granulométrica. Rio de Janeiro.

ASSOCIAÇÃO BRASILEIRA DE NORMAS TÉCNICAS (1987). NBR 9776:1987: Agregados - determinação da massa específica de agregados miúdos por meio do frasco de Chapman. Rio de Janeiro.

ASSOCIAÇÃO BRASILEIRA DE NORMAS TÉCNICAS (1987). NBR 9778:1987: Argamassa e concreto endurecidos - determinação da absorção de água por imersão - índice de vazios e massa específica - método de ensaio. Rio de Janeiro.

ASSOCIAÇÃO BRASILEIRA DE NORMAS TÉCNICAS (1991). NBR 12142:1991: Concreto - determinação da resistência à tração na flexão em corpos-de-prova prismáticos - método de ensaio. Rio de Janeiro.

ASSOCIAÇÃO BRASILEIRA DE NORMAS TÉCNICAS (1992). NBR 8953:1992: Concreto para fins estruturais - classificação por grupos de resistência. Rio de Janeiro. 
ASSOCIAÇÃO BRASILEIRA DE NORMAS TÉCNICAS (1994). NBR 5738:1994: Moldagem e cura de corpos-de-prova cilíndricos ou prismáticos de concreto - procedimento. Rio de Janeiro.

ASSOCIAÇÃO BRASILEIRA DE NORMAS TÉCNICAS (1994). NBR 5739:1994: Concreto - ensaio de compressão de corpos-deprova cilíndricos - método de ensaio. Rio de Janeiro.

ASSOCIAÇÃO BRASILEIRA DE NORMAS TÉCNICAS (1994). NBR 7222:1994: Argamassa de concreto - determinação da resistência à tração por compressão diametral de corpos-de-prova cilíndricos - método de ensaio. Rio de Janeiro.

ASSOCIAÇÃO BRASILEIRA DE NORMAS TÉCNICAS (1996). NBR 6122:1996: Projeto e execução de fundações - procedimento. Rio de Janeiro.

ASSOCIAÇÃO BRASILEIRA DE NORMAS TÉCNICAS (1998). NBR NM 67:1998: Concreto - determinação da consistência pelo abatimento do tronco de cone. Rio de Janeiro.

ASSOCIAÇÃO BRASILEIRA DE NORMAS TÉCNICAS (2003). NBR 6118:2003: Projeto de estruturas de concreto. Rio de Janeiro.

BAE, S.; BAYRAK, O. (2003). Early cover spalling in high-strength concrete columns. Journal of Structural Engineering, ASCE, v.129, n.3, p.314-323, Mar.

BJERKELI, L.; TOMASZEWICZ, A.; JENSEN, J.J. (1990). Deformation properties and ductility of high strength concrete. In: INTERNATIONAL SYMPOSIUM ON HIGH-STRENGTH CONCRETE, $2^{\text {nd }}, 1990$, Berkeley, USA. Detroit: ACI. p.215-238 (ACI SP-121). 
CHUNG, H.S.; YANG, K.H; LEE, Y.H.; EUN, H.C. (2002). Strength and ductility of laterally confined concrete columns. Canadian Journal of Civil Engineering, v.29, n.6, p.820-830, Dec.

CLAESON, C.; GYLLTOFT, K. (2000). Slender concrete columns subjected to sustained and short-term eccentric loading. ACI Structural Journal, v.97, n.1, p.45-52, Jan.-Feb.

CUSSON, D.; PAULTRE, P. (1992). Behavior of high-strength concrete columns confined by rectangular ties under concentric loading. Internal report of Department of Civil Engineering, University of Sherbrooke, SMS-92/2.47p.

CUSSON, D.; PAULTRE, P. (1993). Confinement model for highstrength concrete tie columns. Internal report of Department of Civil Engineering, University of Sherbrooke, SMS-93/2. 54p.

CUSSON, D.; PAULTRE, P. (1994). High-strength concrete columns confined by retangular ties. Journal of Structural Engineering, ASCE, v.120, n.3, p.783-804, Mar.

CUSSON, D.; PAULTRE, P. (1995). Stress-strain model for confined high-strength concrete, Journal of Structural Engineering, ASCE, v.121, n.3, p.468-477. Mar.

DEGUSSA, Construction Chemicals. E-TOWER: Recorde de resistência do concreto (149MPa). (2004). Disponível em:

$<$ http://www.masterbuilders.com.br/mbt_viewprojetos.asp?idProjetos= 23>. Acesso em 29 Jan. 2004.

DE NARDIN, S. (2003). Pilares mistos preenchidos: estudo da flexocompressão e de ligações viga-pilar. Tese (Doutorado) - Escola de Engenharia de São Carlos, Universidade de São Paulo, São Carlos. 
DINIZ, S.M.C.; FRANGOPOL, D.M. (1997). Strength and ductility simulation of high-strength concrete columns. Journal of Structural Engineering, ASCE, v.123, n.10, p.1365-1374, Oct.

ESSAWY, A.S.; EL-HAWARY, M. (1998). Strength and ductility of spirally reinforced rectangular concrete columns. Construction and Building Materials, v.12, n.1, p.31-37, Feb.

FAFITIS, A.; SHAH, S.P. (1985). Lateral reinforcement for highstrengh concrete columns. In: RUSSEL, H.G. (ed.) High-strength concrete. Detroit: ACI. p.213-232. (ACI SP-87).

FOSTER, S.J.; LIU, J.; SHEIKH, S.A. (1988). Cover spalling in HSC columns loaded in concentric compression. Journal of Structural Engineering, ASCE, v.124, n.12, p.1431-1437, Dec.

FOSTER, S.J. (2001). On behavior of high-strength concrete columns: cover spalling, steel fibers, and ductility. ACI Structural Journal, v.98, n.4, p.583-589, July-Aug.

FUSCO, P.B. (1981). Estruturas de concreto: solicitações normais, estados limites últimos, teoria e aplicação. Rio de Janeiro: Guanabara Dois.

FUSCO, P.B. (1989). O cálculo de concreto armado em regime de ruptura. In: SIMPÓSIO EPUSP SOBRE ESTRUTURAS DE CONCRETO, São Paulo. Anais... v.1, p.239-310.

GUIMARÃES, A.E.P. (1999). Análise experimental de pilares de concreto de alta resistência com adição de fibras metálicas submetidos à compressão centrada. Tese (Doutorado) - Escola de Engenharia de São Carlos, Universidade de São Paulo, São Carlos.

HELENE, P.R.L.; TERZIAN, P. (1995). Manual de dosagem e controle do concreto. São Paulo: Pini. 
KENT, D.C.; PARK, R. (1971). Flexural members with confined concrete. Journal of Structural Division, ASCE, v.97, n.7, p.19691990.

LÉGERON, F.; PAULTRE, P. (2003). Uniaxial confinement model for normal- and high-strength concrete columns. Journal of Structural Engineering, ASCE, v.129, n.2, p.241-252, Feb.

LEONHARDT, F.; MÖNNING, E. (1978). Construções de concreto armado. Rio de Janeiro: Interciência. v.1 e v.3.

LIMA, F.B. (1997). Pilares de concreto de alto desempenho: fundamentos e experimentação. Tese (Doutorado) - Escola de Engenharia de São Carlos, Universidade de São Paulo, São Carlos.

LIMA, F.B.; GIONGO, J.S.; TAKEYA, T. (1997). Análise experimental de pilares de concreto de alto desempenho solicitados a compressão centrada. In: CONGRESSO BRASILEIRO DO CONCRETO, 39., 1997, São Paulo. Anais... São Paulo: IBRACON. v.2, p.521-536.

LIMA JÚNIOR, H.C. (1997). Instabilidade de arcos segmentados de concreto armado. Dissertação (Mestrado) - Departamento de Engenharia de Civil, Pontifícia Universidade Católica do Rio de Janeiro, Rio de Janeiro.

LIMA JÚNIOR, H.C. (2003). Avaliação da ductilidade de pilares de concreto armado, submetidos a flexo-compressão reta com e sem adição de fibras metálicas. Tese (Doutorado) - Escola de Engenharia de São Carlos, Universidade de São Paulo, São Carlos.

LIMA JÚNIOR, H.C.; GIONGO, J.S. (2001). Avaliação da ductilidade do concreto de alta resistência reforçado com fibra de aço. In: CONGRESSO BRASILEIRO DO CONCRETO, 43., 2001, Foz do Iguaçu. Anais... Foz do Iguaçu: IBRACON. 1 CD-ROM. 
LIU, J.; FOSTER, S.J.; ATTARD, M.M. (2000). Strength of tied highstrength concrete columns loaded in concentric compression. ACI Structural Journal, v.97, n.1, p.149-156, Jan.-Feb.

LLOYD, N.A.; RANGAN, B.V. (1996). Studies on high-Strength concrete columns under Eccentric Compression. ACI Structural Journal, v.93, n.6, p. 631-638, Nov.-Dec.

MANDER, J.B.; PRIESTLEY, M.J.N.; PARK, R. (1988a). Theoretical stress-strain model for confined concrete. Journal of Structural Engineering, ASCE, v.114, n.8, p.1804-1826, Aug.

MANDER, J.B.; PRIESTLEY, M.J.N.; PARK, R. (1988b). Observed stress-strain behavior of confined concrete. Journal of Structural Engineering, ASCE, v.114, n.8, p.1827-1849, Aug.

MAU, S.T. (1990). Effect of tie spacing on inelastic buckling of reinforcing bars. ACI Structural Journal, v.87, n.6, p.671-677, Nov.Dec.

MEHTA, P.K.; MONTEIRO, P.J.M. (1993). Concrete: structure, properties, and materials. $2^{\text {nd }}$ ed. New Jersey: Prentice-Hall.

MEHTA, P.K.; MONTEIRO, P.J.M. (1994). Concreto: estrutura, propriedades, e materiais. 1 ed. São Paulo: Pini.

MÖRSCH, E. (1952). Teoria y prática del hormigón armado. Buenos Aires: Gustavo Gili.

NAGASHIMA, T.; SUGANO, S.; KIMURA, H.; ICHIKAWA, A. (1992). Monotonic axial compression test on ultra-high-strength concrete tied columns. In: WORLD CONFERENCE ON EARTHQUAKE ENGINEERING, 10 ${ }^{\text {th }}$, Rotterdam. p.2983-2988. 
NORWEGIAN COUNCIL FOR BUILDING STANDARDIZATION (1992). NS 3473 E: Concrete structures: design rules. 4.ed. Oslo: NSF, $78 \mathrm{p}$.

PAIVA, N.M.B. (1994). Pilares de concreto de alta resistência com seção transversal retangular solicitados à compressão simples. Dissertação (Mestrado) - Escola de Engenharia de São Carlos, Universidade de São Paulo, São Carlos.

PARK, R.; PRIESTLEY, M.J.N.; GILL, W.D. (1982). Ductility of square confined concrete columns. Journal of Structural Division, ASCE, v.108, n.4, p.929-623.

PFEIL, W. (1988b). Concreto armado. 5.ed. Rio de Janeiro: LTC. v.2.

POPOVICS, S. (1973). A numerical aproach to the complete stressstrain curve of concrete. Cement and Concrete Research, v.3, n.5, p.583-599.

QUEIROGA, M.V.M. (1999) Análise experimental de pilares de concreto de alto desempenho submetidos à compressão simples. Dissertação (Mestrado) - Escola de Engenharia de São Carlos, Universidade de São Paulo, São Carlos.

QUEIROGA, M.V.M.; GIONGO, J.S.; TAKEYA, T. (1999). Pilares de concreto com resistência média de $60 \mathrm{MPa}$ submetidos à compressão simples. In: CONGRESSO BRASILEIRO DO CONCRETO, 41., Salvador. Anais... Salvador: IBRACON. 1CDROM.

RAMOS, R. F. (2001). Análise experimental de pilares de concreto armado sob ação centrada com resistência do concreto de $25 \mathrm{MPa}$. Dissertação (Mestrado) - Escola de Engenharia de São Carlos, Universidade de São Paulo, São Carlos. 
RAMOS, R.F.; GIONGO, J.S. (2002). Pilares de concreto armado sob ação de força centrada com resistência do concreto de 25MPa. In: JORNADAS SUDAMERICANAS DE INGENIERIA ESTRUCTURAL, XXX., 2002., Brasília. Anais... 1 CD-ROM.

RAZVI, S.R.; SAATCIOGLU, M. (1999). Confinement model for high-strength concrete. Journal of Structural Engineering, ASCE, v.125, n.3, p. 281-289, Mar.

RILEM TC 148-SSC. (2000). Test method for measurement of strainsoftening behavior of concrete under uniaxial compression. Materials and Structures, v.33, p.347-351, July.

SAATCIOGLU, M.; RAZVI, S.R. (1992). Strength and ductility of confined concrete. Journal of Structural Engineering, ASCE, v.118, n.6, p.1590-1607, June.

SANTOS, L.M. (1983). Cálculo de concreto armado. São Paulo: LMS. v.1.

SARGIN, M.; GLOSH, S.K.; HANDA, V.K. (1971). Effects of lateral reinforcement upon strength and deformation properties of concrete. Magazine of Concrete Research, v.23, n.75-76, p.99-110.

SHAH S.P.; AHMAD, S.H. (1994). High performance concrete and applications. London: Edward Arnold.

SHEIKH, S.A. (1982). A comparative study of confinement models. Journal of the American Concrete Institute, v.79, n.4, p. 296-306.

SHEIKH, S.A.; UZUMERI, S.M. (1980). Strength and ductility of tied concrete columns. Journal of Structural Division, ASCE, v.106, n.5, p.1079-1102. 
SHEIKH, S.A.; UZUMERI, S.M. (1982). Analytical model for concrete confinement in tied columns. Journal of Structural Division, ASCE, v.108, n.12, p.2703-2722.

SILVA, R.C.; GIONGO, J.S. (2000). Modelos de bielas e tirantes aplicados a estruturas de concreto armado. São Carlos: EESC-USP.

SÜSSEKIND, J.C. (1980). Curso de concreto. Porto Alegre: Globo. $2 \mathrm{v}$.

TAKEUTI, A.R. (2003). Comportamento resistente imediato e ao longo do tempo de pilares reforçados por meio de encamisamento com concreto de alto desempenho. Tese (Doutorado) - Escola de Engenharia de São Carlos, Universidade de São Paulo, São Carlos. 


\section{Bibliografia Complementar}

AHMAD, S.H.; SHAH, S.P. (1982). Stress-strain curves of concrete confined by spiral reinforcement. ACI Journal, v.79, n.6, p.484-490.

AMARAL FILHO, E.M. (1993). Concreto de alta resistência. São Paulo: Associação Brasileira de Cimento Portland. 75p.

ASSA, B.; NISHIYAMA, M.; WATANABE, F. (2001). New aproach for modeling confined concrete - II: Rectangular columns. Journal of Structural Engineering, ASCE, v.127, n.7, p. 751-757, July.

ATTARD, M.M.; SETUNGE, S. (1996). Stress-strain relationship of confined and unconfined concrete. ACI Materials Journal, v.93, n.5, p. $432-442$, Sept.-Oct.

AUFIERI, F.A. (1998). Diretrizes para o dimensionamento e detalhamento de pilares de edifícios em concreto armado. Dissertação (Mestrado) - Escola de Engenharia de São Carlos, Universidade de São Paulo, São Carlos. 
BAYRAK, O.; SHEIKH, S.A. (1998). Confinement reinforcement design considerations for ductile HSC columns. Journal of Structural Engineering, ASCE, v.124, n.9, p.999-1010. Sept.

CÂMARA, E.; LIMA JÚNIOR, H.C.; WILLRICH, F.L.; FABRO, G.; GIONGO, J.S. (2002). Comportamento estrutural dos pilares dimensionados segundo o projeto de revisão da Norma NBR 6118:2001. Revista IBRACON, v.10, n.31, p.46-61, out.-nov.

CARREIRA, D.J.; CHU, K.H. (1985). Stress-strain relationship for plain concrete in compression. ACI Journal, v.82, n.6, p. 797-804, Nov.-Dec.

COMITÉ EURO-INTERNATIONAL DU BÉTON (1990). CEB-FIP model code 1990. Bulletin D' Information, n.203-205.

CUSSON, D.; DE LARRARD, F.; BOUlAy, C.; PAUlTRE, P. (1996). Strain localization in confined high-strength concrete columns. Journal of Structural Engineering, ASCE, v.122, n.9, p.1055-1061, Sept.

DELALIBERA, R.G. (2002). Análise teórica e experimental de vigas de concreto armado com armadura de confinamento. Dissertação (Mestrado) - Escola de Engenharia de São Carlos, Universidade de São Paulo, São Carlos.

EL-DASH, K.M.; AHMAD, S.H. (1994). A model for the stress-strain relationship of rectangular confined normal and high-strength concrete columns. Materials and Structures, v.27, n.174, p.572-579, Dec.

EUROCODE N.2 (1989). Design of concrete structures. Part 1: general rules and rules for buildings. Brussels: CEN. 
FIB Structural Concrete. (1999). Textbook on behavior, design and performance. Updated knowledge of the CEB/FIP Model Code 1990. Committee Euro-International du Beton. v.1.

FUSCO, P.B. (1995). Técnica de armar as estruturas de concreto. São Paulo: Pini.

LIMA JÚNIOR, H.C.; GIONGO, J.S. (2000a). Modelo teórico para análise de pilares de concretos de alta resistência com confinamento lateral. Engenharia: Estudo e Pesquisa. Juiz de Fora, v.3, n.1, jan.jun.

LIMA JÚNIOR, H.C.; GIONGO, J.S. (2000b). Fator de ductilidade para pilares de concreto de alta resistência. Engenharia: Estudo e Pesquisa. Juiz de Fora, v.3, n.2, jul.-dez.

MACGREGOR, J.G. (1988). Reinforced concrete: mechanics and design. Englewood Cliffs, New Jersey: Prentice-Hall.

MONTOYA, P.J.; MESEGUER, A.; CABRE, M. (2000). Hormigón armado. 14.ed. Barcelona: Gustavo Gili.

NEVILLE, A.M. (1997). Propriedades do concreto. São Paulo: Pini.

PFEIL, W. (1988a). Concreto armado. 5.ed. Rio de Janeiro: LTC. v.1.

ROCHA, A.M. (1958). Concreto armado. Rio de Janeiro: Livraria Nobel. $4 \mathrm{v}$.

RÜSCH, H. (1975). Hórmigon armado y hormigon pretensado. Barcelona: Continental.

SANTOS, L.M. (1991). Cálculo de concreto armado. São Paulo: LMS. v.2. 


\section{Apêndice A}

\section{PROGRAMA COMPUTACIONAL}

\section{CONSIDERAÇÕES INICIAIS}

Este capítulo foi retirado do capítulo 4 da tese do prof Humberto Correia Lima Júnior, defendida em 2003 na Escola de Engenharia de São Carlos, da Universidade de São Paulo.

O código fonte do programa foi cedido ao prof. Dr. Humberto Correia Lima Júnior, para que fosse possível a implementação do modelo teórico de confinamento, no programa citado. O programa foi desenvolvido para análise de pórticos planos de concreto armado e protendido; ele utiliza o método dos elementos finitos e leva em consideração as não-linearidades físicas do material e as geométricas da estrutura. A teoria utilizada é a teoria de vigas de BernoulliKirchhoff e o elemento finito utilizado é o de viga, que é inicialmente descrito em um sistema natural de coordenadas. Em seguida, este é transformado para um sistema auxiliar de coordenadas, cujas coordenadas de deslocamentos são dispostas segundo as coordenadas globais do pórtico e permitem a descrição de deslocamentos de corpo rígido. Logo após, ocorre a transformação para o sistema global de coordenadas e, a partir daí, segue-se o método da rigidez direta. $\mathrm{Na}$ 
figura A.1 é apresentado o elemento finito utilizado e os sistemas de coordenadas.
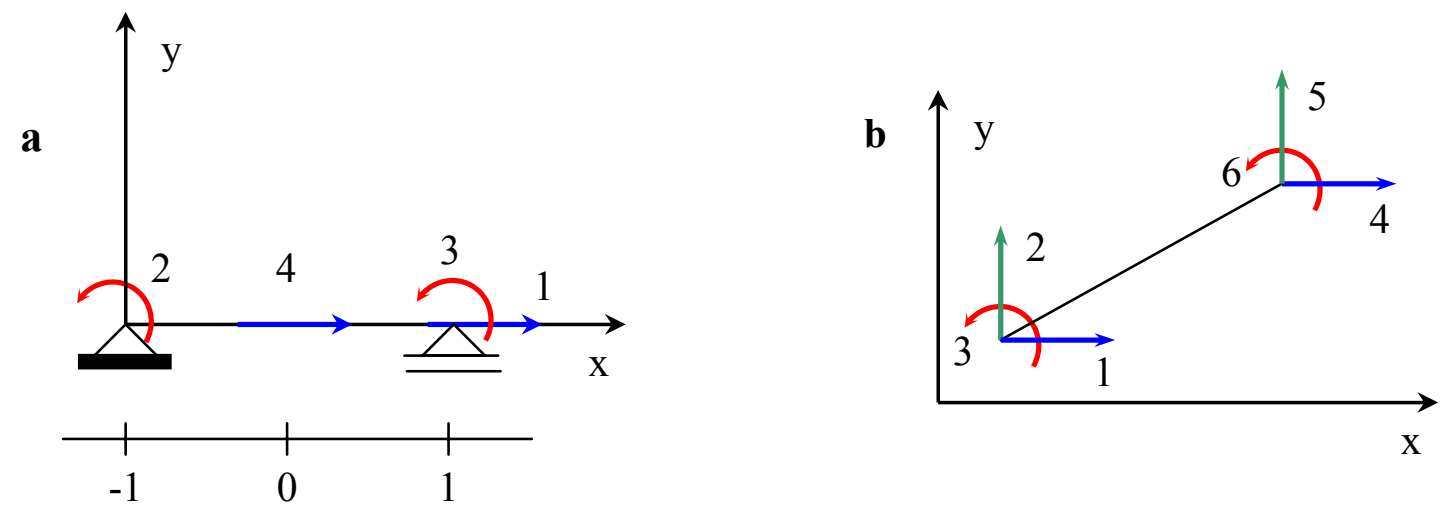

Figura A.1 - Sistema de coordenadas natural e auxiliar respectivamente.

\section{LIMA JÚNIOR (1997).}

A resolução do sistema não linear de equações, necessário para cada etapa do processo incremental, pode ser feita segundo alguns métodos a depender do usuário: Método de controle do trabalho das forças externas, Método das normas dos deslocamentos, Método de controle dos deslocamentos e Método de Newton Raphson.

Independentemente do método utilizado para resolução do sistema nãolinear de equações, processa-se o algoritmo apresentado na figura A.2, para a análise da estrutura numa etapa do carregamento. 


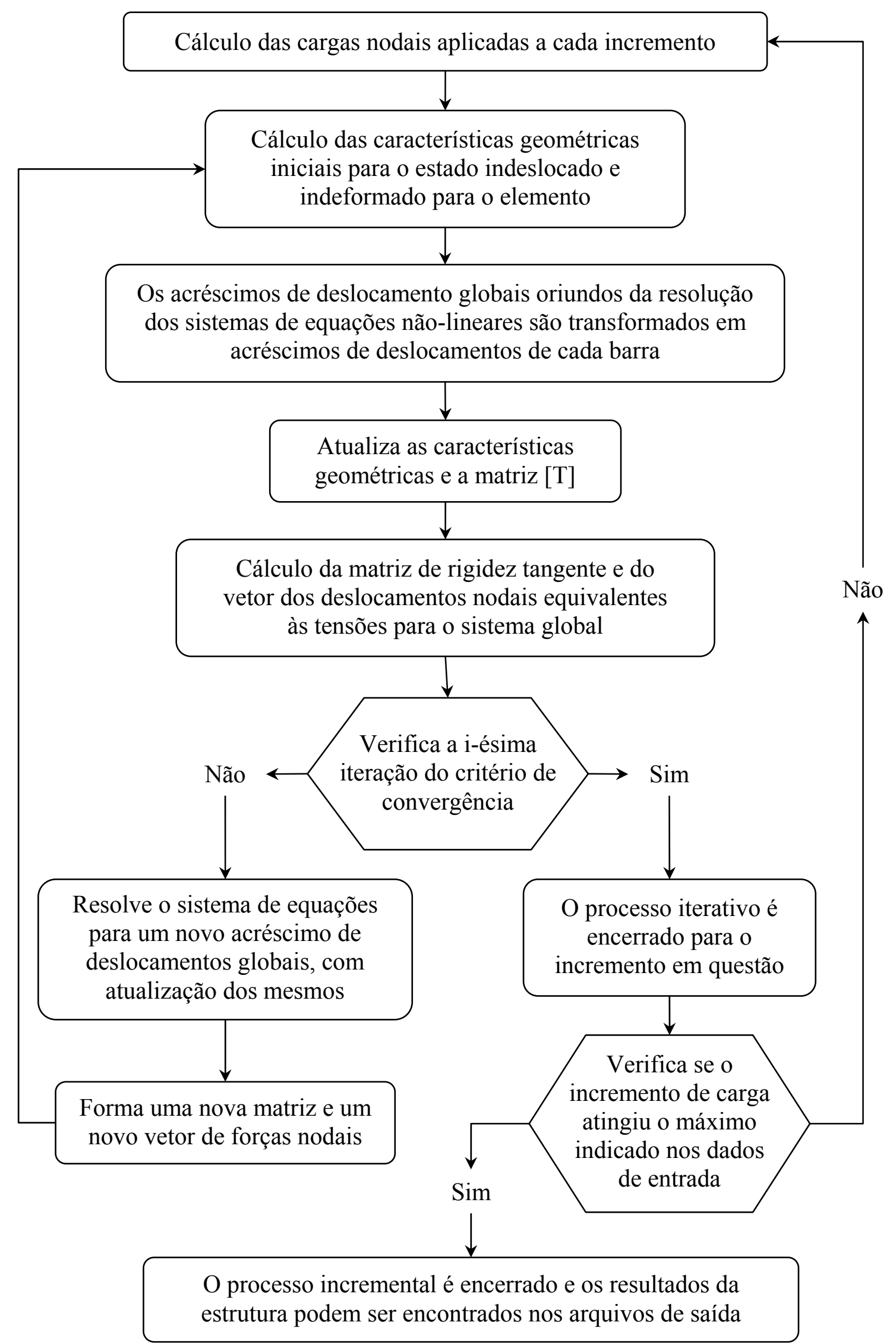

Figura A.2 - Algoritmo para a análise da estrutura numa etapa do carregamento utilizado pelo modelo computacional. LIMA JÚNIOR (1997) 


\section{PROCEDIMENTOS DE IMPLEMENTAÇÃO}

Foram implementadas sub-rotinas em Linguagem Fortran, que continham as leis constitutivas do concreto confinado e com adições de fibras. Em seguida, essas sub-rotinas foram acopladas ao programa ANAPROT. Para tanto, foram realizadas pequenas modificações no código do programa original, para que este pudesse se comunicar com as sub-rotinas. O procedimento de integração numérica utilizado foi o mesmo para todas as sub-rotinas e será descrito a seguir.

Definidas as leis constitutivas dos materiais e a seção transversal do elemento estrutural de concreto armado, podem-se obter os esforços resistentes, utilizando um sistema local de coordenada $(\xi, \eta, \zeta)$, que passa pelo centro de gravidade da seção transversal, por meio da integração das tensões definidas para o concreto e para o aço, em função das curvas tensão-deformação de cada material. Os esforços resistentes podem ser descritos pelas equações 1 e 2 .

$$
\begin{aligned}
& M_{\xi}=-\left(\int_{A_{c}} \sigma_{c}(\varepsilon) \cdot \eta \cdot d A+\sum_{n} A s_{n} \cdot \sigma_{s}(\varepsilon)_{n} \cdot \eta_{n}\right) \\
& N_{\xi}=-\left(\int_{A_{c}} \sigma_{c}(\varepsilon) \cdot d A+\sum_{n} A s_{n} \cdot \sigma_{s}(\varepsilon)_{n}\right)
\end{aligned}
$$

nas quais $\sigma_{\mathrm{c}}(\varepsilon)$ e $\sigma_{\mathrm{s}}(\varepsilon)$ são as tensões no concreto e na armadura, respectivamente; $A_{c}$ é a área do concreto; $\eta$ é a ordenada de um ponto qualquer da seção no sistema de coordenada local; $\mathrm{A}_{\mathrm{sn}} \mathrm{e} \eta_{\mathrm{n}}$ são a área e a ordenada da barra $\mathrm{n}$ da armadura, respectivamente. Na figura A.3 apresentam-se detalhes do sistema de coordenada local.

Analisando as equações 1 e 2, observa-se que os esforços resistentes contêm tanto contribuição da armadura quanto do concreto. Observa-se ainda que, para quantificar a parcela atribuída ao concreto, é necessária a resolução das integrais presentes nestas equações. $\mathrm{O}$ processo numérico utilizado para 
resolução das integrais consiste em transformar as integrais de superfície sobre o domínio em integrais de linha ao longo do contorno. Para tanto, aplica-se o teorema de Green no plano. Uma seção transversal qualquer é definida como uma poligonal fechada, percorrida no sentido anti-horário, sendo que, em caso de aberturas internas, essas são definidas por uma orientação horária. Na figura A.4 apresenta-se a definição do domínio de integração.

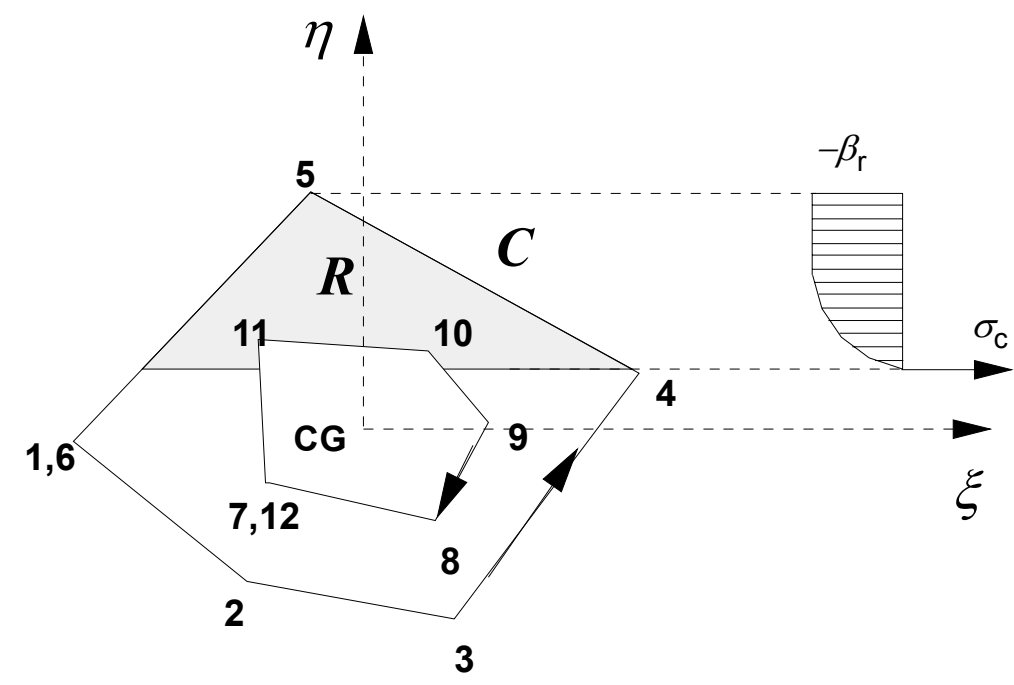

Figura A.3 - Detalhes do sistema de coordenada local

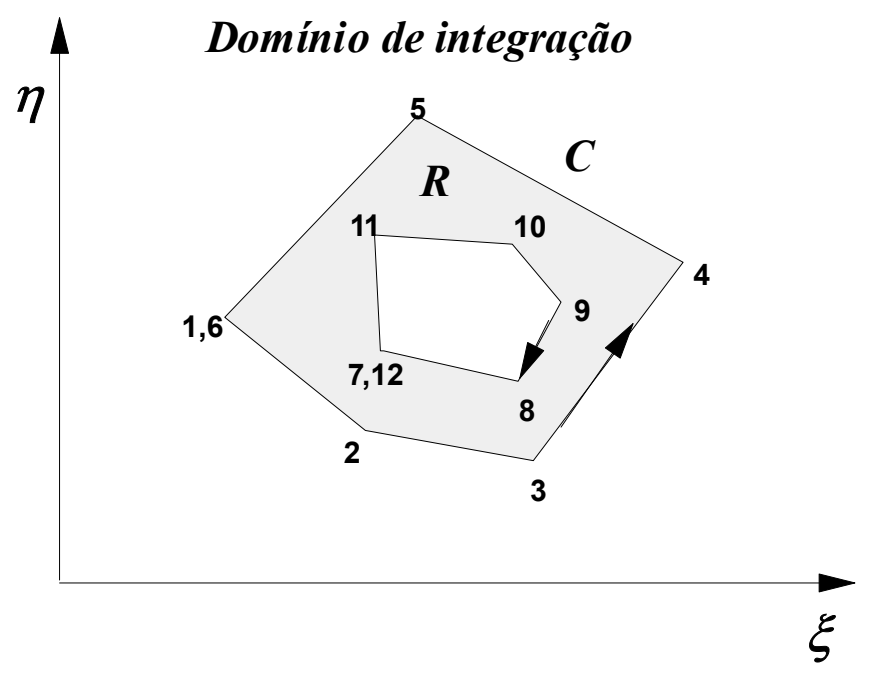

Figura A.4 - Domínio de integração da seção transversal analisada 
Pela aplicação do teorema de Green no plano, a expressão de um termo genérico de um polinômio transformado para uma integral de contorno é expressa pela equação 3 .

$$
\int_{R} \xi^{k} \cdot \eta^{m} d A=\int_{C} \frac{\xi^{k+1} \cdot \eta^{m}}{k+1} d \eta=\sum_{j=1}^{N} G_{k, m}
$$

na qual $\mathrm{N}$ representa o número de segmentos e $\mathrm{G}_{\mathrm{k}, \mathrm{m}}$ a integral de contorno do $\mathrm{j}$ ésimo segmento da poligonal, definido pelos vértices i e i+1, como apresentado na figura A.5. As integrais $G_{k, m}$ podem ser expressas pela equação 4 .

$$
\mathrm{G}_{\mathrm{k}, \mathrm{m}}=\frac{1}{\mathrm{k}+1} \cdot \int_{\eta_{\mathrm{i}}}^{\eta_{i+1}} \xi^{\mathrm{k}+1} \cdot \eta^{\mathrm{m}} \mathrm{d} \eta
$$

eq. 4

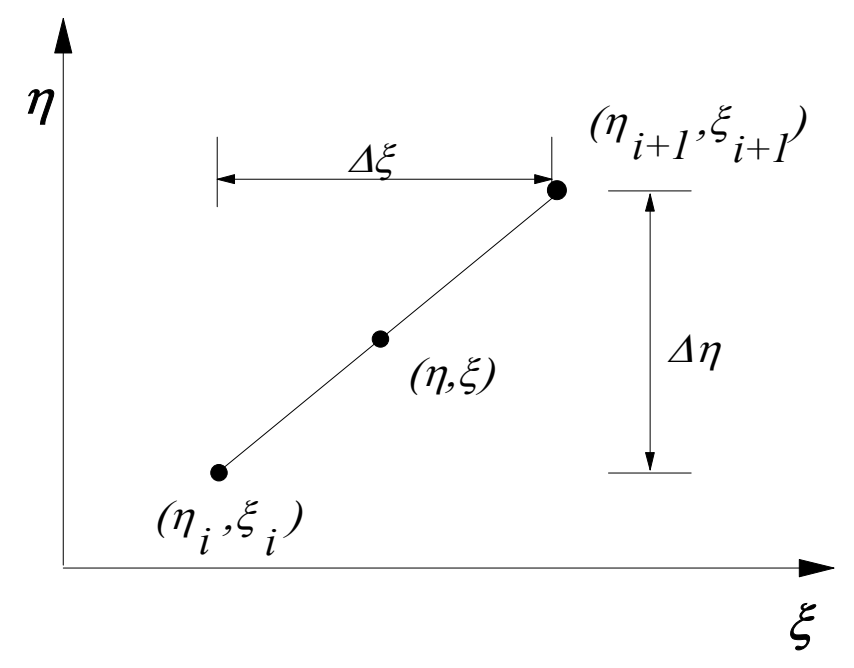

Figura A.5 - Parametrização de um segmento da poligonal

Considerando $\omega$ um incremento qualquer na ordenada $\eta$, pode-se escrever a equação 5 .

$$
\begin{aligned}
& \eta=\eta_{i}+\omega \\
& \xi=\xi_{i}+\frac{\Delta \xi}{\Delta \eta} \cdot \omega
\end{aligned}
$$


Substituindo a equação 5 na equação 4, obtém-se a equação 6.

$$
\mathrm{G}_{\mathrm{k}, \mathrm{m}}=\frac{1}{\mathrm{k}+1} \cdot \int_{0}^{\Delta \eta}\left(\xi_{\mathrm{i}}+\frac{\Delta \xi}{\Delta \eta} \cdot \omega\right)^{\mathrm{k}+1} \cdot\left(\eta_{\mathrm{i}}+\omega\right)^{\mathrm{m}} \mathrm{d} \omega
$$

na qual $\Delta \eta$ e $\Delta \xi$ são dados pela equação 7 .

$$
\begin{aligned}
& \Delta \eta=\eta_{i+1}-\eta_{i} \\
& \Delta \xi=\xi_{i+1}-\xi_{i}
\end{aligned}
$$

Utilizando o procedimento descrito acima, as equações 1 e 2 tornam-se um somatório de várias parcelas, funções de $G_{k, m}$. Após o cálculo dessas funções, segue-se o procedimento usual de utilização da integração numérica Gaussiana para resolução das matrizes de rigidez do sistema.

\section{LEIS CONSTITUTIVAS PARA O CONCRETO CONFINADO}

O modelo de Cusson e Paultre (1995), descrito no capítulo três, item 3.3.9 deste trabalho, foi implementado e acoplado ao programa ANAPROT. Observou-se que os autores não apresentaram equações para o cálculo da deformação $\varepsilon_{\text {máx }}$ correspondente à tensão de pico do concreto sem confinamento e nem para o cálculo do módulo de elasticidade do concreto. Baseado no exposto, optou-se por utilizar as expressões sugeridas pelo FIB (1999) para a deformação $\varepsilon_{\text {máx }}$ e o módulo de elasticidade do concreto, e que são expressos pelas equações 8 e 9 , respectivamente.

$$
\begin{aligned}
& \varepsilon_{\text {máx }}=-0,0017-0,0010\left(\frac{\mathrm{f}_{\mathrm{c}}}{\mathrm{f}_{\mathrm{cmo}}}\right) \\
& \mathrm{E}_{\mathrm{c}}=\alpha_{\mathrm{e}} \cdot \alpha_{\beta} \cdot \sqrt[3]{\frac{\mathrm{f}_{\mathrm{c}}}{\mathrm{f}_{\mathrm{cmo}}}} \quad(\mathrm{MPa})
\end{aligned}
$$


nas quais $\mathrm{f}_{\mathrm{cmo}}$ é igual a 70MPa, $\alpha_{\mathrm{e}}$ é igual a $21500 \mathrm{MPa}$ e $\alpha_{\beta}$ é um coeficiente que depende do tipo de agregado graúdo que constitui o concreto - para o agregado basáltico, $\alpha_{\beta}$ é igual a 1,2.

$\mathrm{O}$ comportamento à tração do concreto confinado é considerado semelhante ao do concreto sem confinamento; assim, foi utilizado o modelo do FIB (1999) sem nenhuma modificação e cuja tensão de tração pode ser expressa pelas equações 10 e 11 .

$$
\begin{gathered}
\sigma_{\mathrm{ct}}=\mathrm{E}_{\mathrm{c}} \cdot \varepsilon_{\mathrm{ct}} \quad \sigma_{\mathrm{ct}} \leq 0,9 \cdot \mathrm{f}_{\mathrm{ctm}} \\
\sigma_{\mathrm{ct}}=\mathrm{f}_{\mathrm{ctm}}-\frac{0,1 \cdot \mathrm{f}_{\mathrm{ctm}}}{0,00015-\frac{0,9 \cdot \mathrm{f}_{\mathrm{ctm}}}{\mathrm{E}_{\mathrm{c}}}} \cdot\left(0,00015-\varepsilon_{\mathrm{ct}}\right) \\
0,9 \cdot \mathrm{f}_{\mathrm{ctm}} \leq \sigma_{\mathrm{ct}} \leq \mathrm{f}_{\mathrm{ctm}}
\end{gathered}
$$

nas quais $\mathrm{f}_{\mathrm{ctm}}$ é a resistência à tração do concreto e $\varepsilon_{\mathrm{ct}}$ é a deformação à tração, deformação à qual o concreto está submetido.

\section{LEIS CONSTITUTIVAS PARA O CONCRETO NÃO CONFINADO}

Para a análise do concreto não-confinado pode ser utilizado o modelo de Cusson e Paultre (1995), considerando que a taxa de armadura de confinamento é nula. Contudo, o programa ANAPROT já disponibilizava as leis constitutivas do CEB (1990). A única modificação realizada no modelo do CEB (op. cit.) foi alterar o valor da deformação $\varepsilon_{\text {máx }}$, que é sugerido como 2,2\%o, para o valor calculado pela equação 8. Segundo o CEB (op. cit.), a tensão no concreto nãoconfinado pode ser expressa pelas equações 12 e 13 .

$$
\sigma_{\mathrm{c}}=\left[\frac{\left(\frac{\mathrm{E}_{\mathrm{c}}}{\mathrm{E}_{\mathrm{co}}}\right) \cdot\left(\frac{\varepsilon_{\mathrm{c}}}{\varepsilon_{\text {máx }}}\right)-\left(\frac{\varepsilon_{\mathrm{c}}}{\varepsilon_{\text {máx }}}\right)^{2}}{1+\left(\left(\frac{\mathrm{E}_{\mathrm{c}}}{\mathrm{E}_{\mathrm{co}}}\right)-2\right) \cdot\left(\frac{\varepsilon_{\mathrm{c}}}{\varepsilon_{\text {máx }}}\right)}\right] \cdot \mathrm{f}_{\mathrm{c}} \quad \varepsilon_{\mathrm{c}} \leq \varepsilon_{\mathrm{cu}}
$$




$$
\sigma_{\mathrm{c}}=\left[\begin{array}{l}
\left.\left(\frac{1}{\left(\frac{\varepsilon_{\mathrm{c}}}{\varepsilon_{\mathrm{co}}}\right)} \cdot \zeta-\frac{2}{\left(\frac{\varepsilon_{\mathrm{c}}}{\varepsilon_{\mathrm{co}}}\right)^{2}}\right) \cdot\left(\frac{\varepsilon_{\mathrm{c}}}{\varepsilon_{\mathrm{co}}}\right)^{2}+\right]^{-1} \cdot \mathrm{f}_{\mathrm{c}} \quad \varepsilon_{\mathrm{c}} \geq \varepsilon_{\mathrm{cu}} \\
+\left(\frac{4}{\left(\frac{\varepsilon_{\mathrm{c}}}{\varepsilon_{\mathrm{co}}}\right)}-\zeta\right) \cdot\left(\frac{\varepsilon_{\mathrm{c}}}{\varepsilon_{\mathrm{co}}}\right)
\end{array}\right]^{(-2)}
$$

nas quais $\mathrm{E}_{\mathrm{co}}$ é o módulo de elasticidade secante do concreto, $\mathrm{E}_{\mathrm{c}}$ é o módulo de elasticidade do concreto calculado pela equação $9, \varepsilon_{\mathrm{cu}}$ é a deformação última do concreto e $\zeta$ é um coeficiente função do módulo de elasticidade e das deformações do concreto. Essas variáveis podem ser expressas pelas equações 14,15 e 16 , respectivamente.

$$
\begin{aligned}
& \mathrm{E}_{\mathrm{co}}=\frac{\mathrm{f}_{\mathrm{c}}}{\varepsilon_{\text {máx }}}(\mathrm{MPa}) \\
& \frac{\varepsilon_{\mathrm{cu}}}{\varepsilon_{\text {máx }}}=\frac{1}{2} \cdot\left(\frac{1}{2} \cdot \frac{\mathrm{E}_{\mathrm{c}}}{\mathrm{E}_{\mathrm{co}}}+1\right)+\sqrt{\frac{1}{4} \cdot\left(\frac{1}{2} \cdot \frac{\mathrm{E}_{\mathrm{c}}}{\mathrm{E}_{\mathrm{co}}}+1\right)^{2}-\frac{1}{2}} \\
& \zeta=\frac{4 \cdot\left[\left(\frac{\varepsilon_{\mathrm{cu}}}{\varepsilon_{\text {máx }}}\right)^{2} \cdot\left(\frac{\mathrm{E}_{\mathrm{c}}}{\mathrm{E}_{\mathrm{co}}}-2\right)+2 \cdot\left(\frac{\varepsilon_{\mathrm{cu}}}{\varepsilon_{\text {máx }}}\right)-\left(\frac{\mathrm{E}_{\mathrm{c}}}{\mathrm{E}_{\mathrm{co}}}\right)\right]}{\left[\left(\frac{\varepsilon_{\mathrm{cu}}}{\varepsilon_{\text {máx }}}\right) \cdot\left(\frac{\mathrm{E}_{\mathrm{c}}}{\mathrm{E}_{\mathrm{co}}}-2\right)+1\right]^{2}}
\end{aligned}
$$

As leis constitutivas do concreto não-confinado submetido à tração sugeridas pelo CEB (1990) são semelhantes às do FIB (1999) e expressas pelas equações 10 e 11 . 


\section{LEIS CONSTITUTIVAS PARA A ARMADURA}

O programa já continha as leis constitutivas para aços classe A e aços classe B. Todavia, utilizaram-se apenas os aços classe A neste trabalho, uma vez que a nova norma NBR 7480:1986 especifica apenas os aços classe A para o reforço de elementos de concreto armado. Segundo essa norma, a tensão na armadura é expressa pela equação 17.

$$
\begin{array}{ll}
\sigma_{\mathrm{s}}=\mathrm{E}_{\mathrm{s}} \cdot \varepsilon_{\mathrm{s}} & \varepsilon_{\mathrm{s}}<\varepsilon_{\mathrm{y}} \\
\sigma_{\mathrm{s}}=\mathrm{f}_{\mathrm{y}} & \varepsilon_{\mathrm{s}} \geq \varepsilon_{\mathrm{y}}
\end{array}
$$

na qual $\mathrm{E}_{\mathrm{s}}$ é o módulo de elasticidade do aço, $\mathrm{f}_{\mathrm{y}}$ é a tensão de escoamento do aço, $\varepsilon_{\mathrm{y}}$ é a deformação de escoamento do aço e $\varepsilon_{\mathrm{s}}$ é a deformação imposta à armadura metálica. 


\section{Apêndice B}

Aqui são apresentados os diagramas força aplicada vs. deformação nas armaduras dos pilares (Figuras B.2 a B.33). Para melhor visualização do posicionamento dos extensômetros ver figura B.1.

Série P1

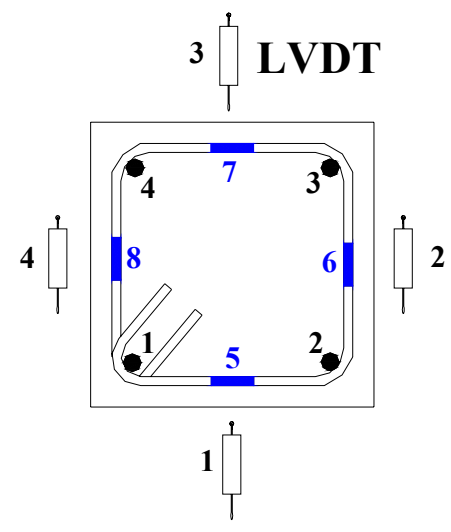

Série P3

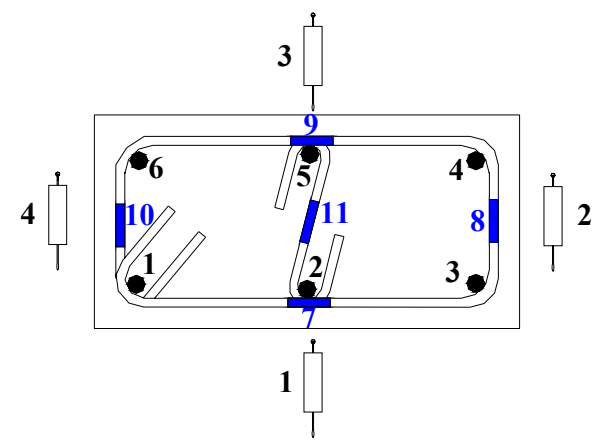

Série P2

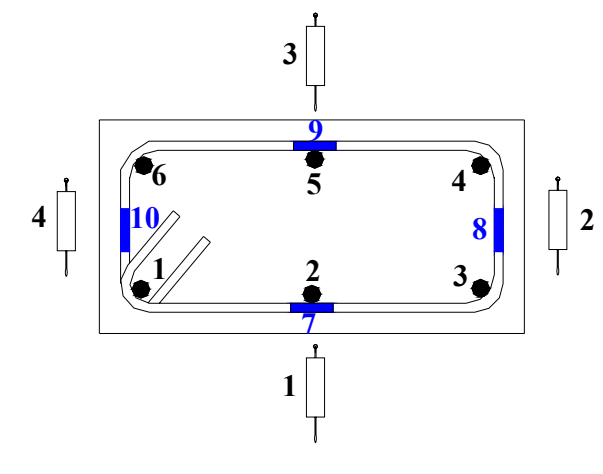

Série P4

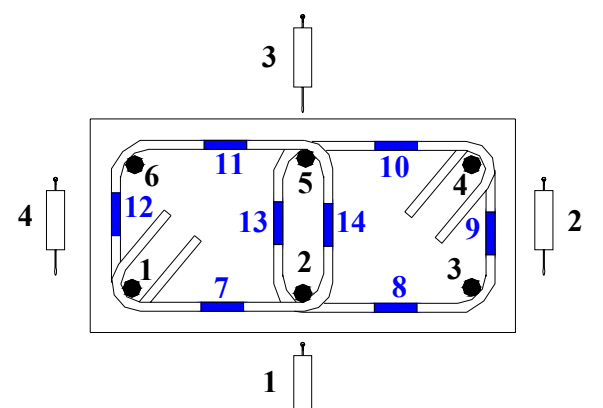

Figura B.1 - Numeração dos extensômetros das barras de armadura longitudinal e transversal 
Pilar P1-10,0-120

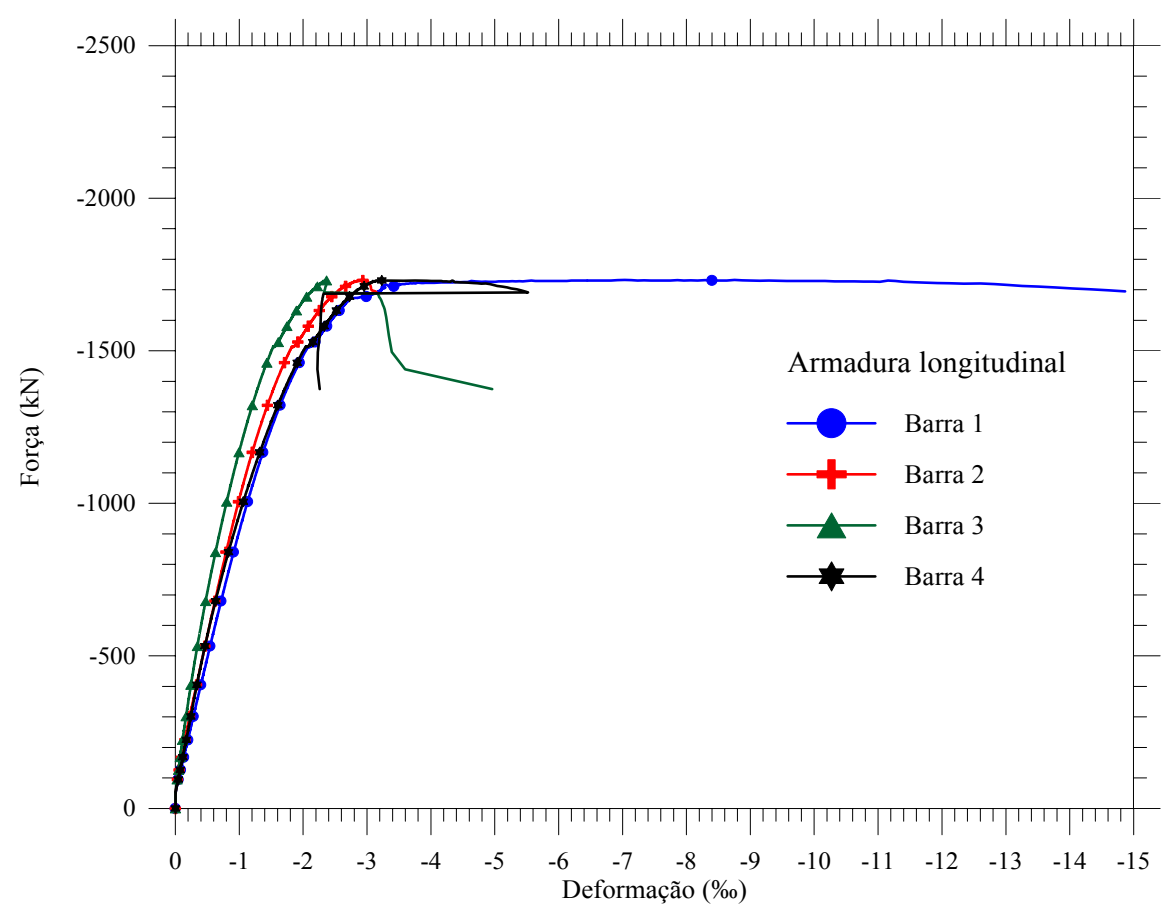

Figura B.2 - Diagrama força aplicada vs. deformação lida pelos extensômetros da armadura longitudinal

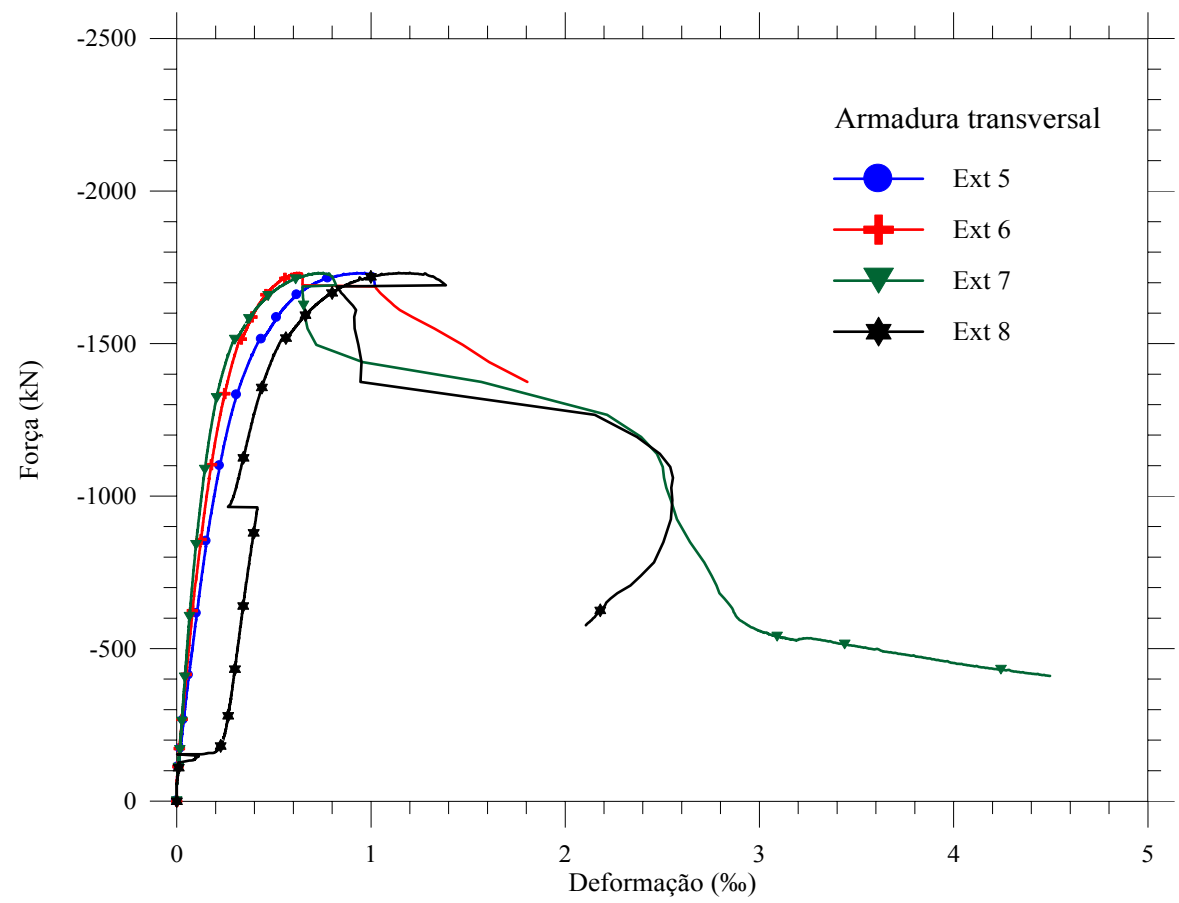

Figura B.3 - Diagrama força aplicada vs. deformação lida pelos extensômetros da armadura transversal 
Pilar P1-12,5-200

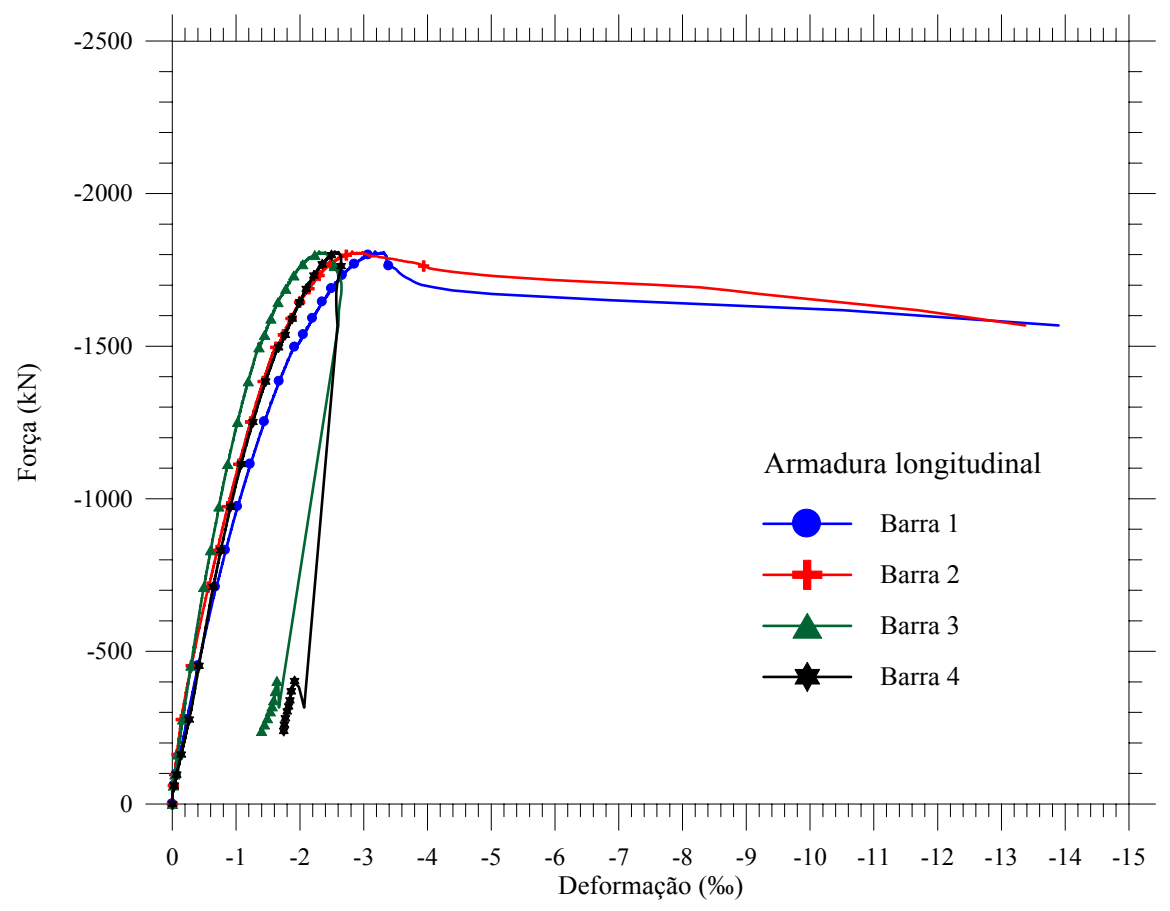

Figura B.4 - Diagrama força aplicada vs. deformação lida pelos extensômetros da armadura longitudinal

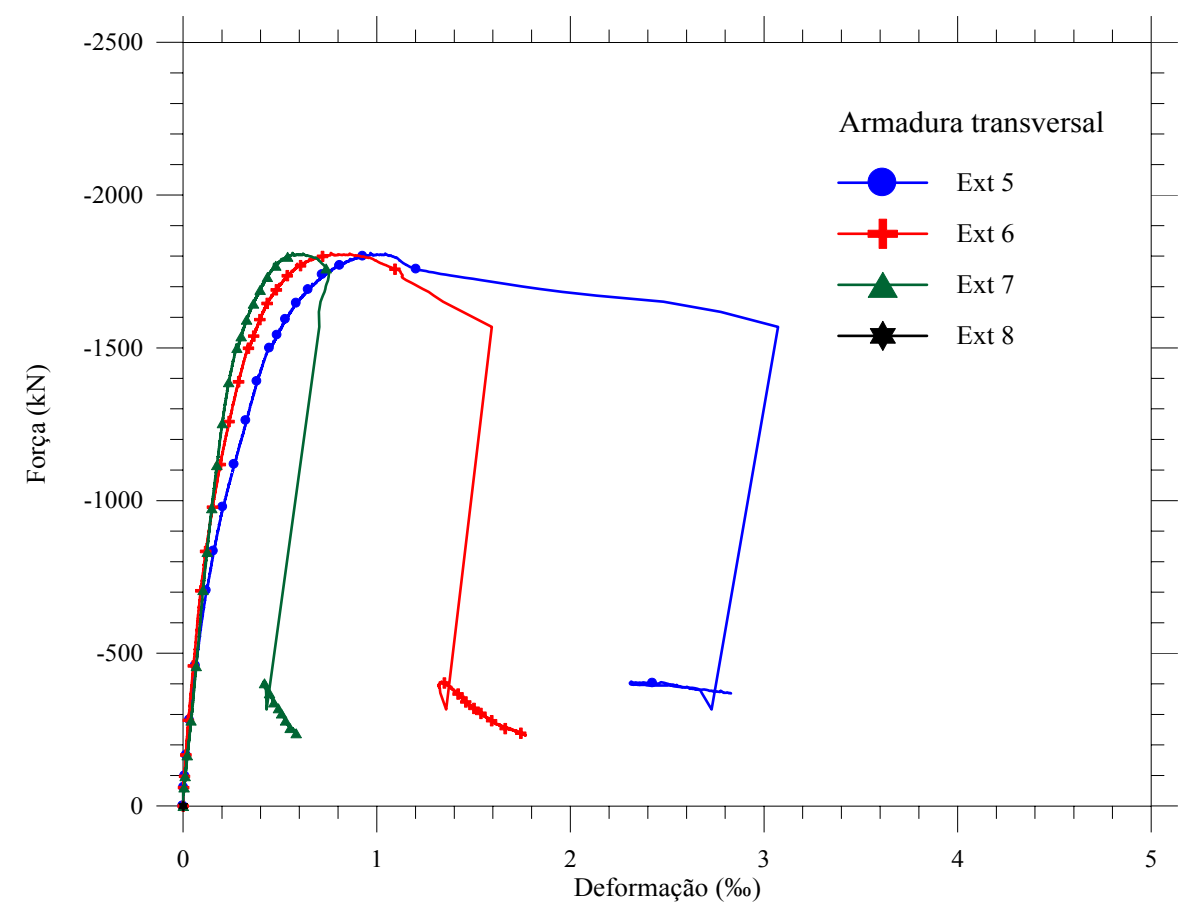

Figura B.5 - Diagrama força aplicada vs. deformação lida pelos extensômetros da armadura transversal 
Pilar P1-12,5-150

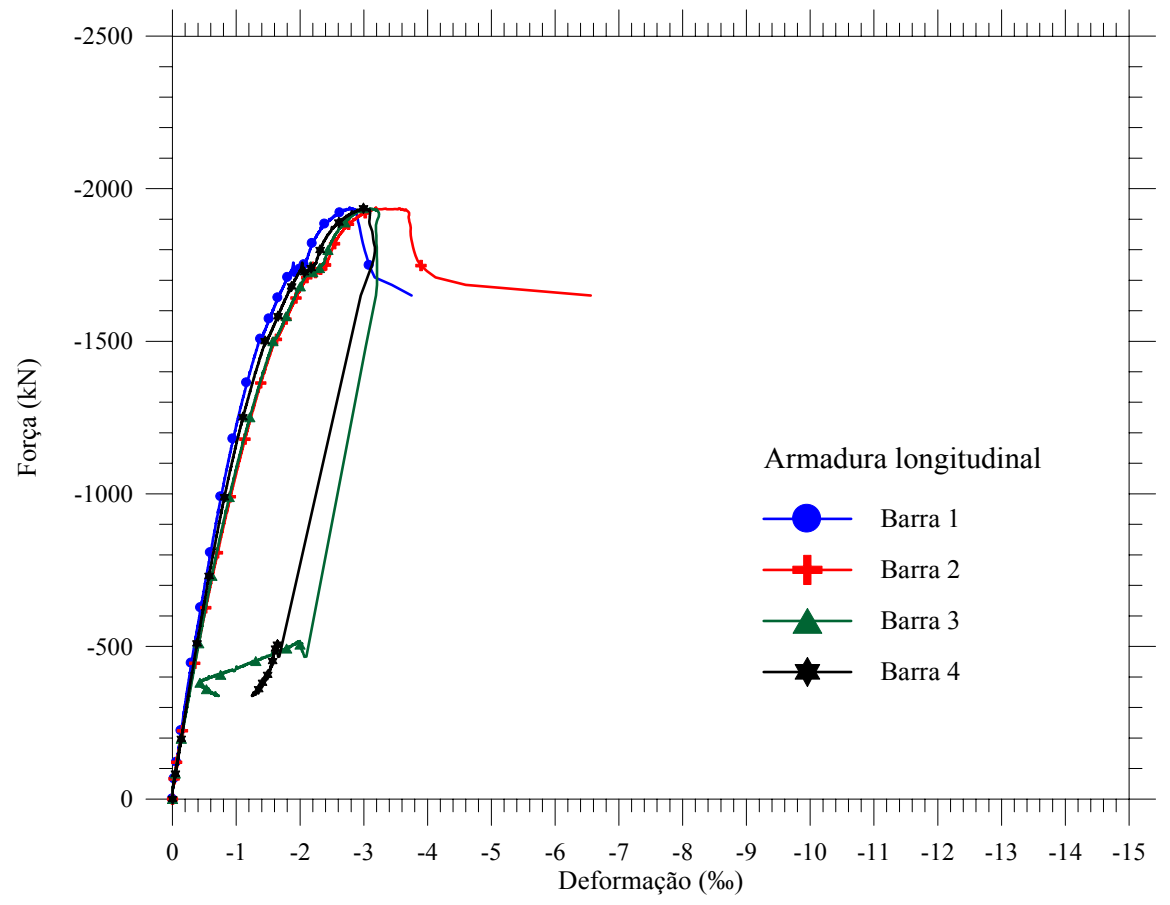

Figura B.6 - Diagrama força aplicada vs. deformação lida pelos extensômetros da armadura longitudinal

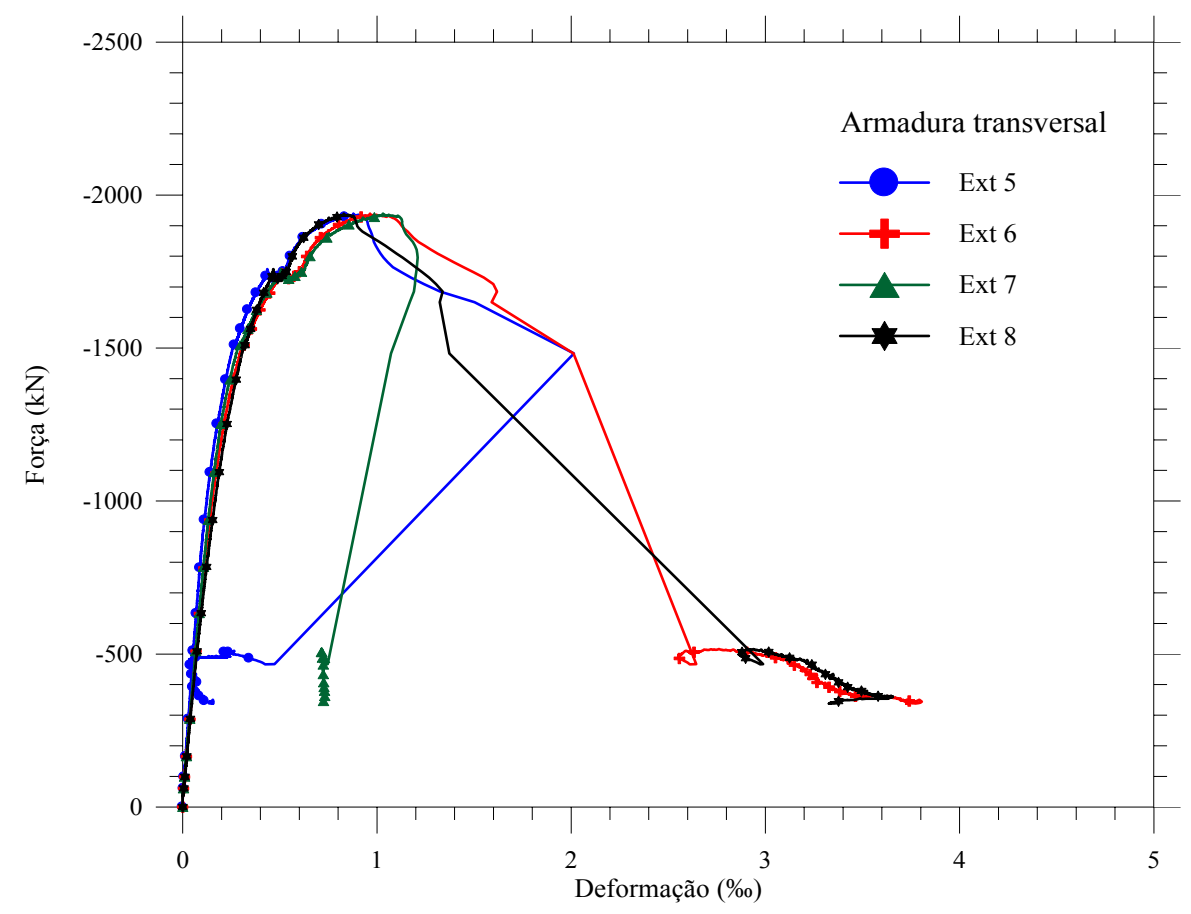

Figura B.7 - Diagrama força aplicada vs. deformação lida pelos extensômetros da armadura transversal 
Pilar P1-12,5-100

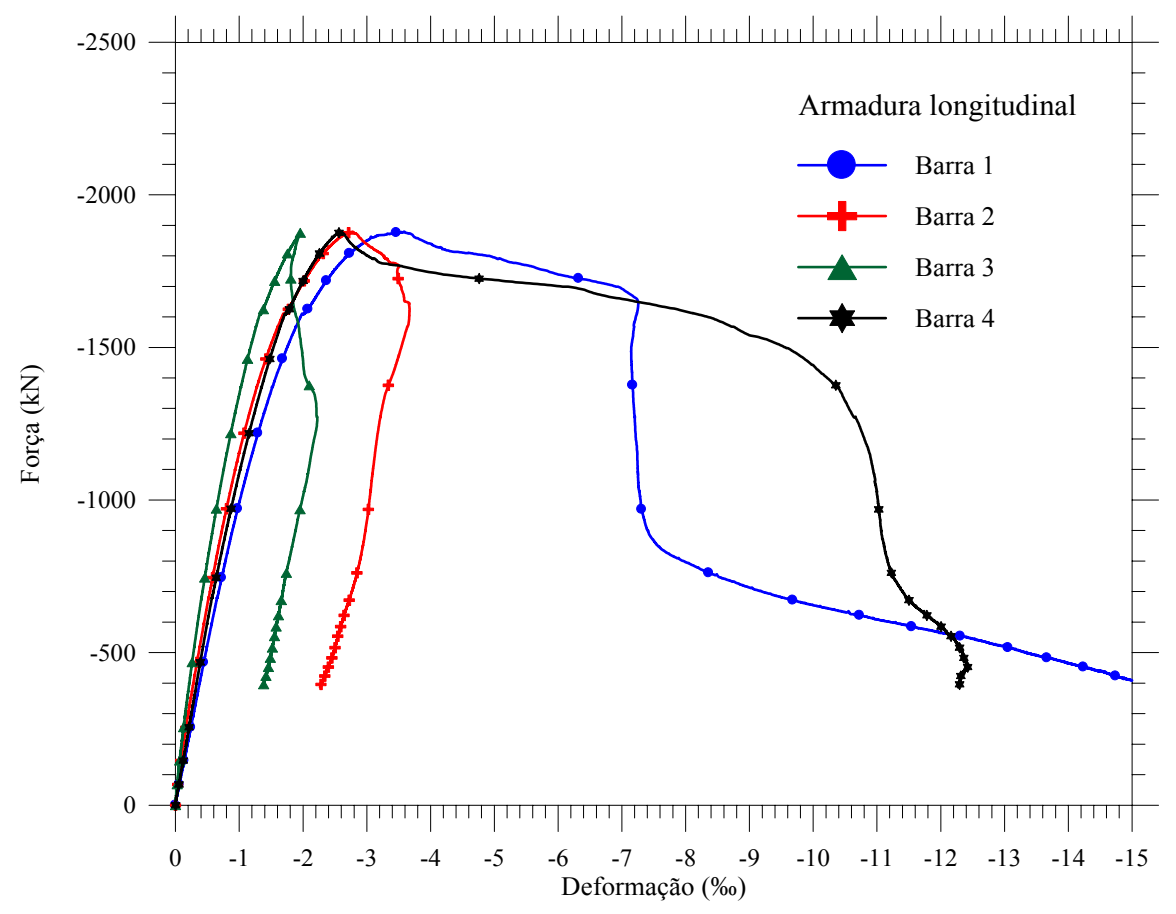

Figura B.8 - Diagrama força aplicada vs. deformação lida pelos extensômetros da armadura longitudinal

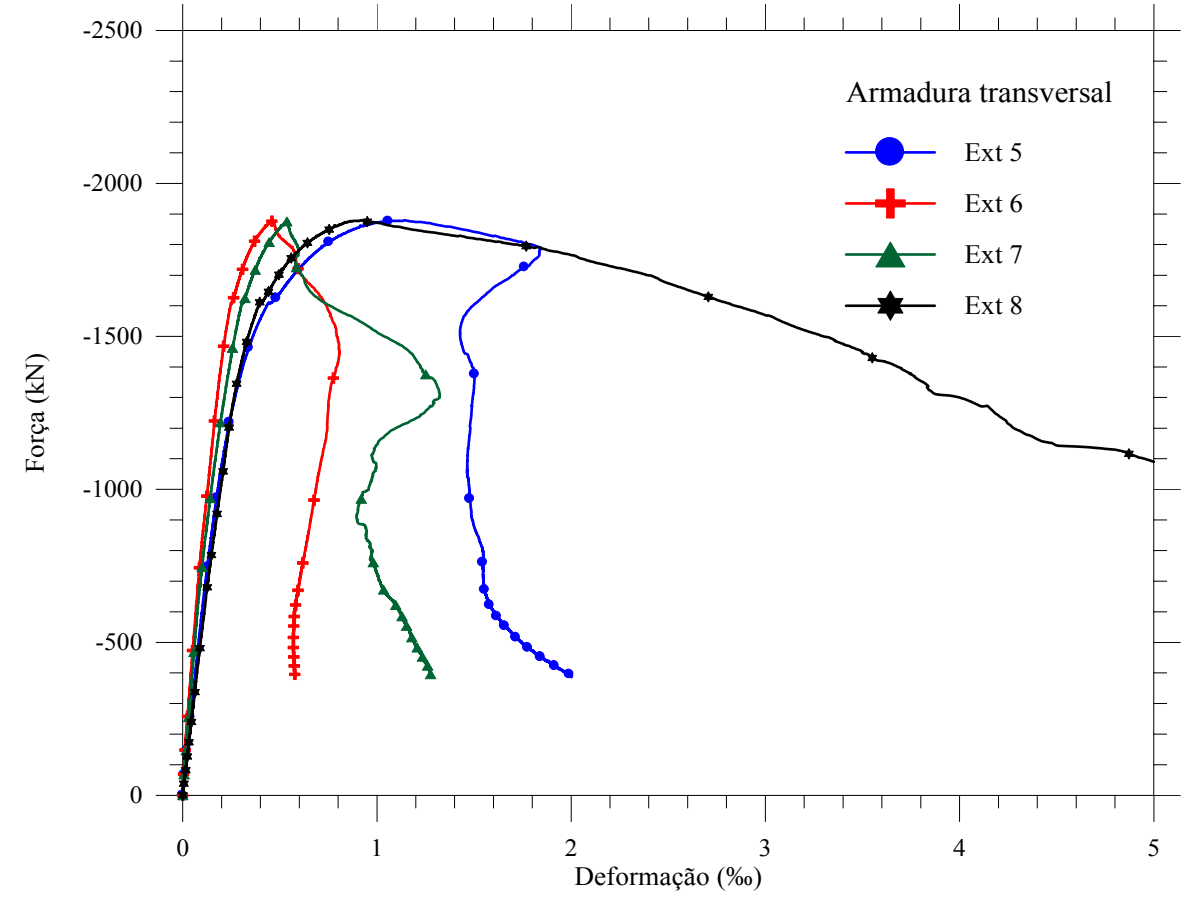

Figura B.9 - Diagrama força aplicada vs. deformação lida pelos extensômetros da armadura transversal 
Pilar P2-10,0-120

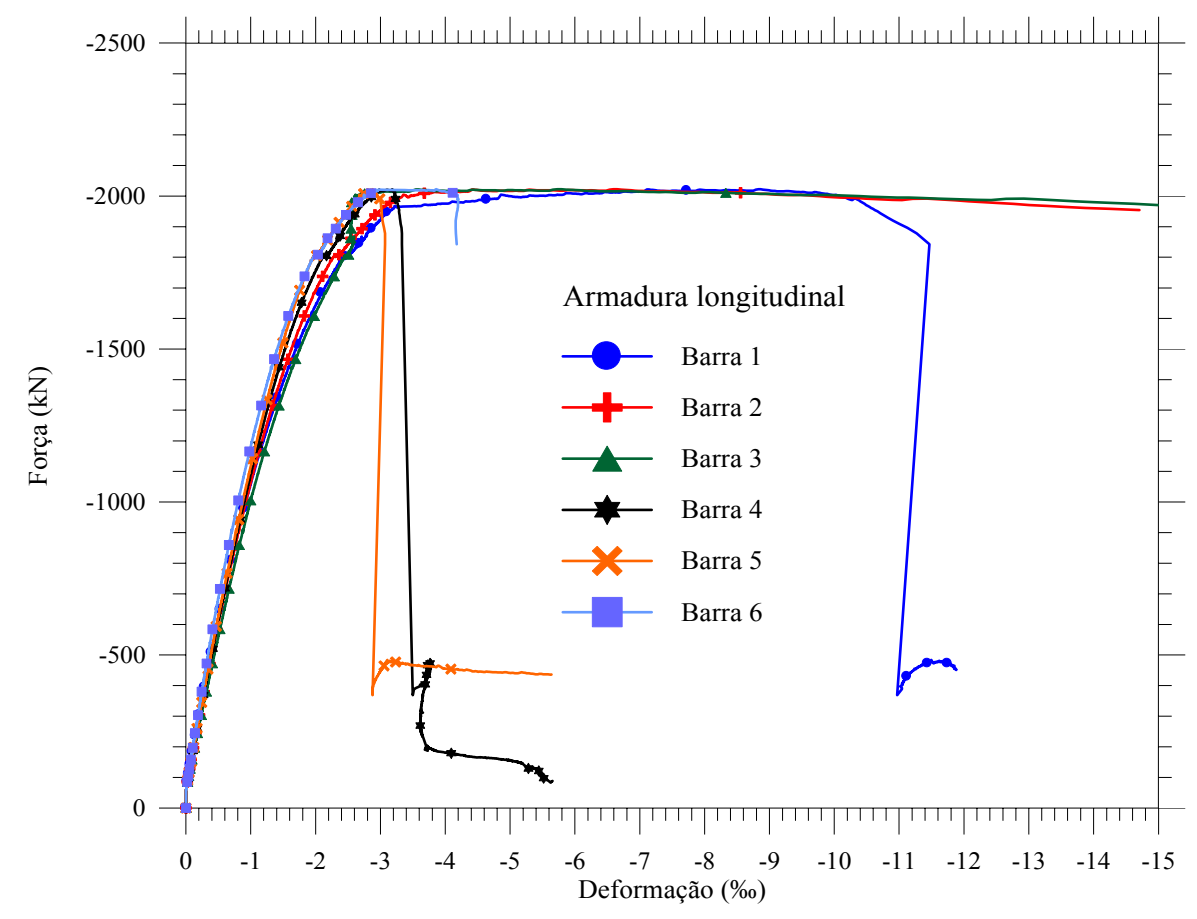

Figura B.10 - Diagrama força aplicada vs. deformação lida pelos extensômetros da armadura longitudinal

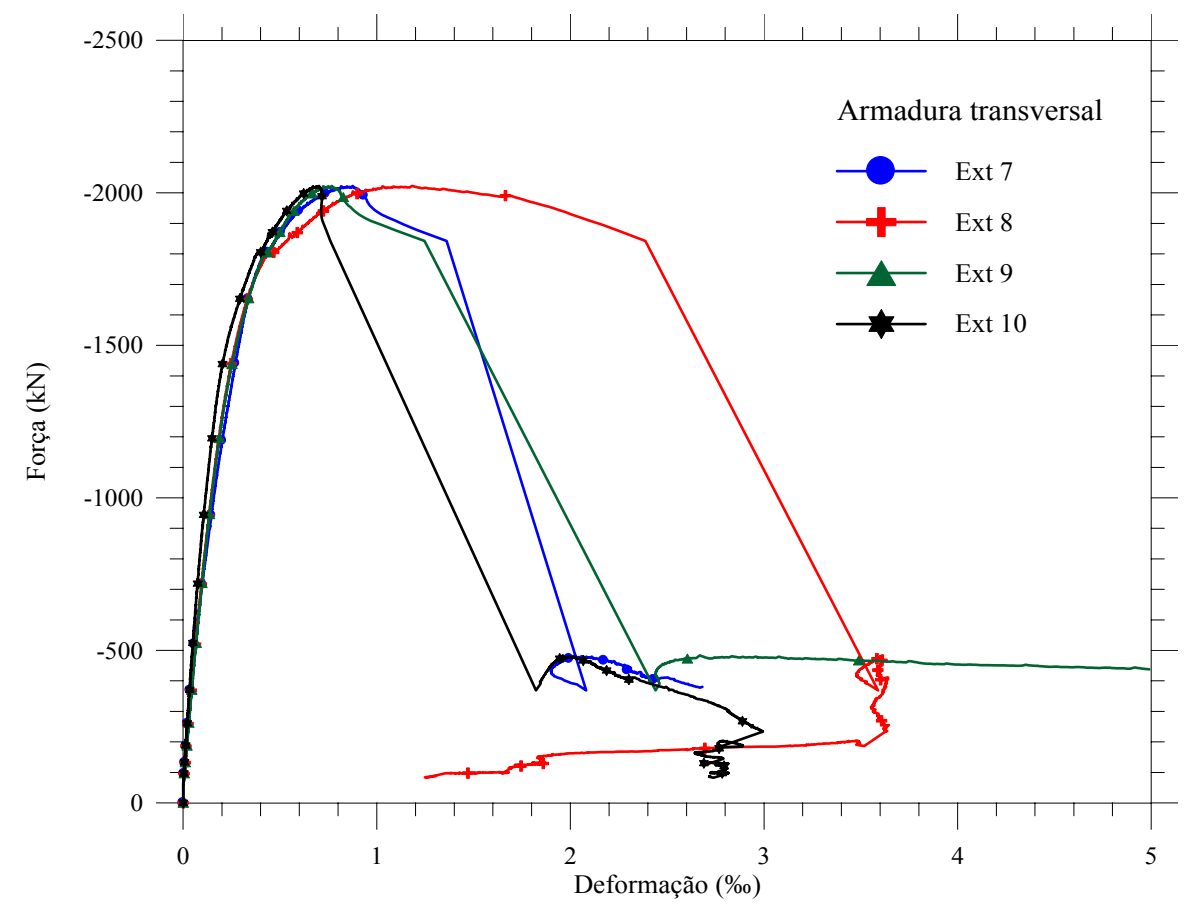

Figura B.11 - Diagrama força aplicada vs. deformação lida pelos extensômetros da armadura transversal 
Pilar P2-12,5-150

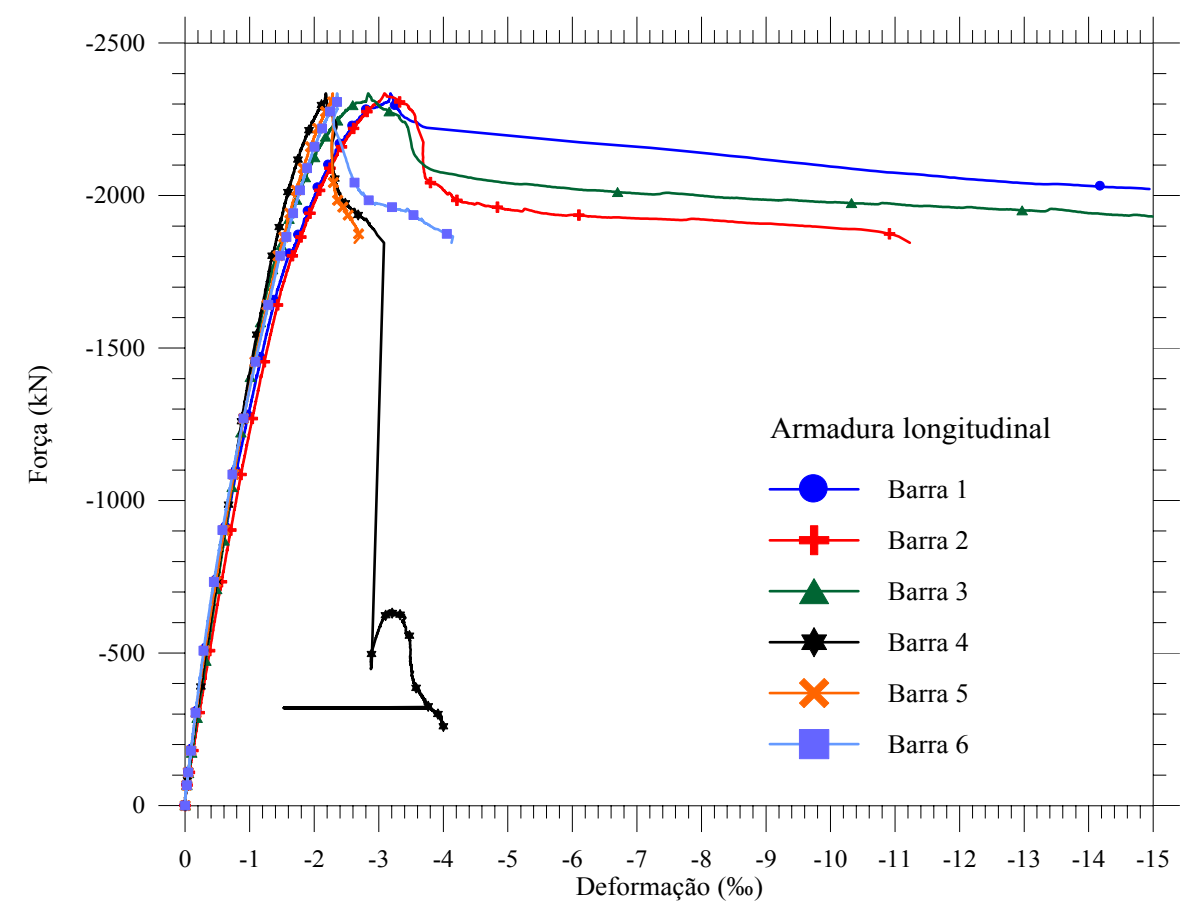

Figura B.12 - Diagrama força aplicada vs. deformação lida pelos extensômetros da armadura longitudinal

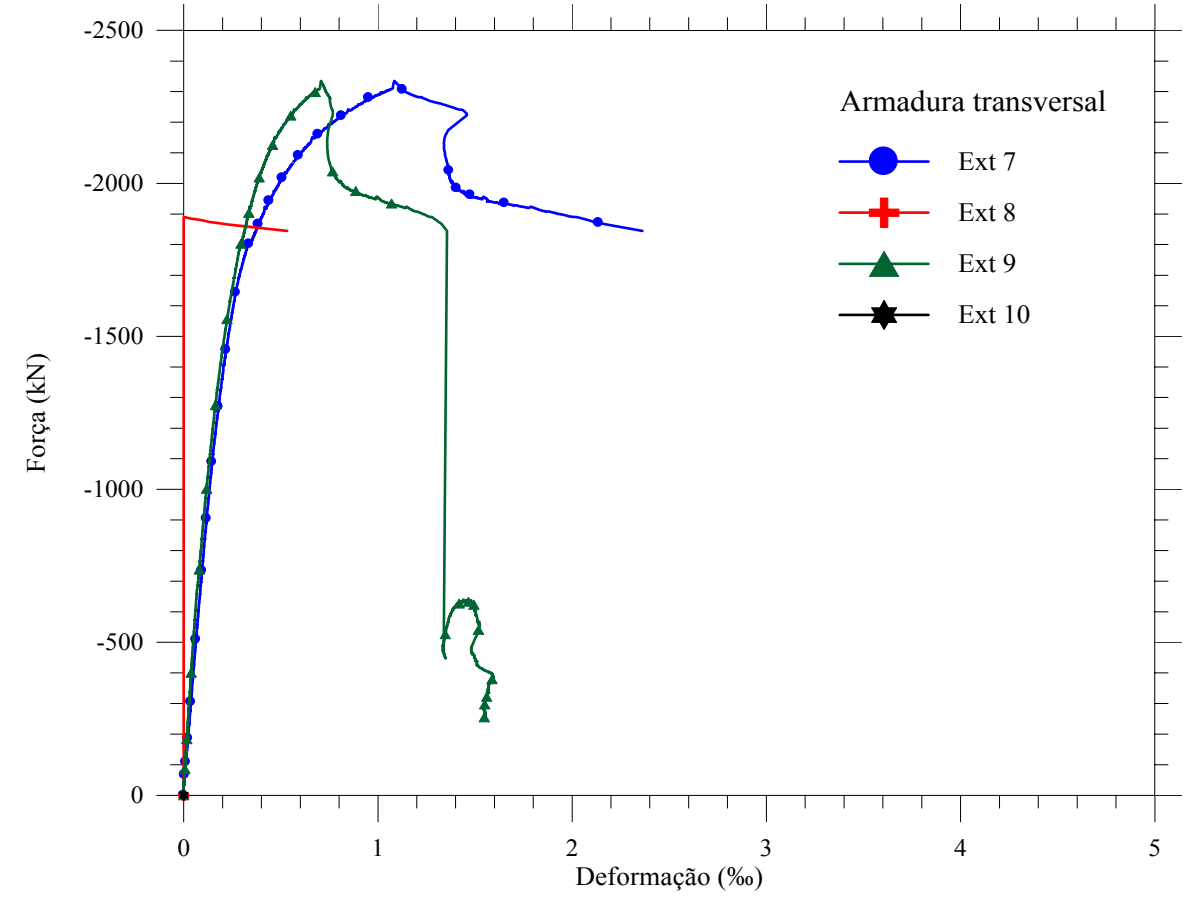

Figura B.13 - Diagrama força aplicada vs. deformação lida pelos extensômetros da armadura transversal 
Pilar P2-12,5-100

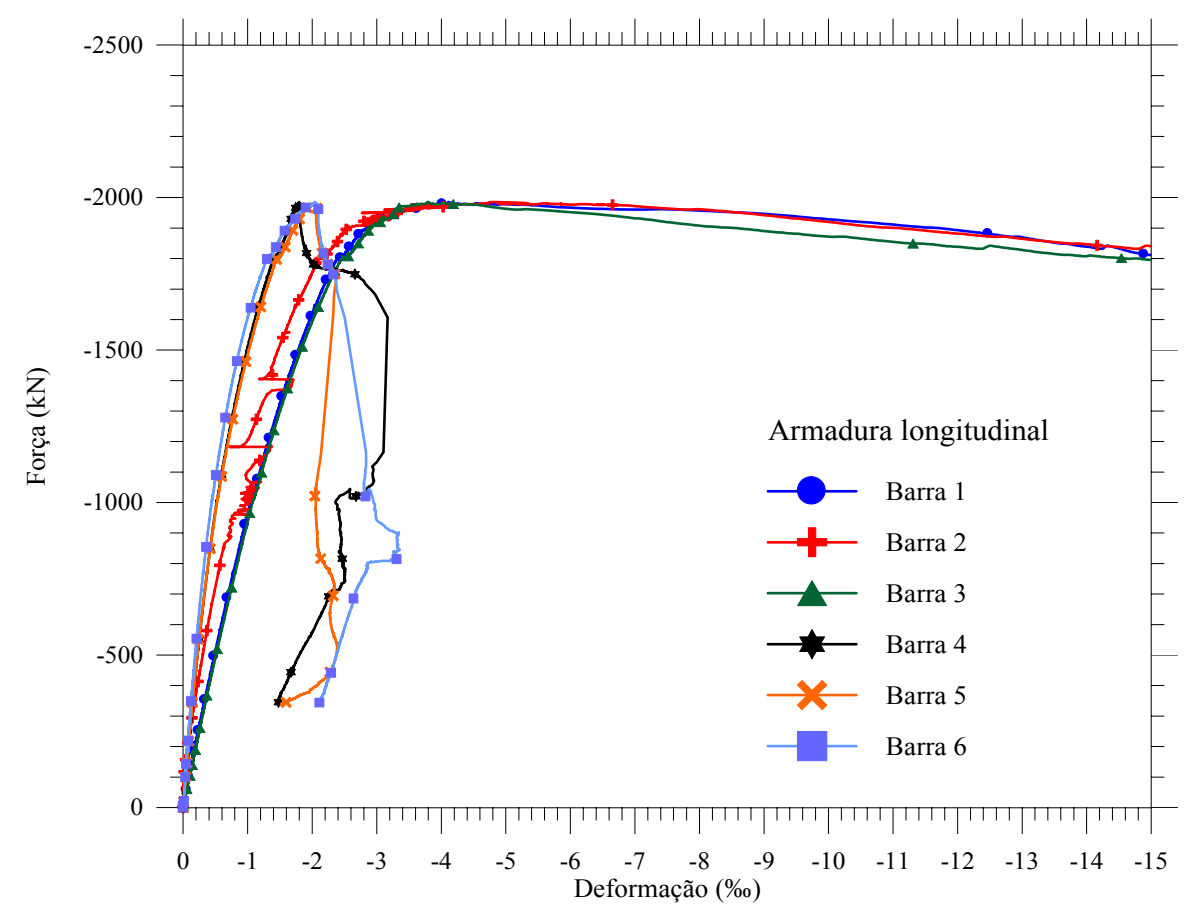

Figura B.14 - Diagrama força aplicada vs. deformação lida pelos extensômetros da armadura longitudinal

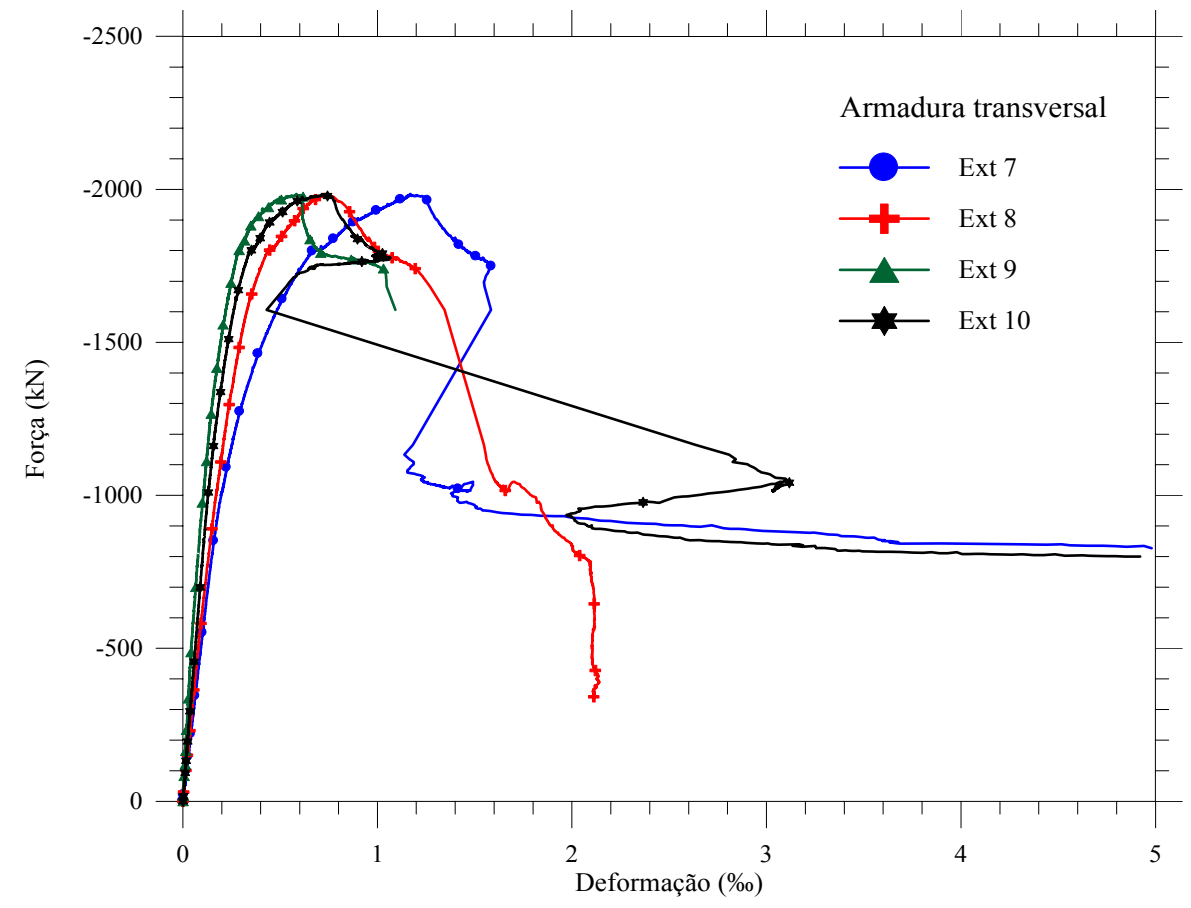

Figura B.15 - Diagrama força aplicada vs. deformação lida pelos extensômetros da armadura transversal 
Pilar P2-12,5-075

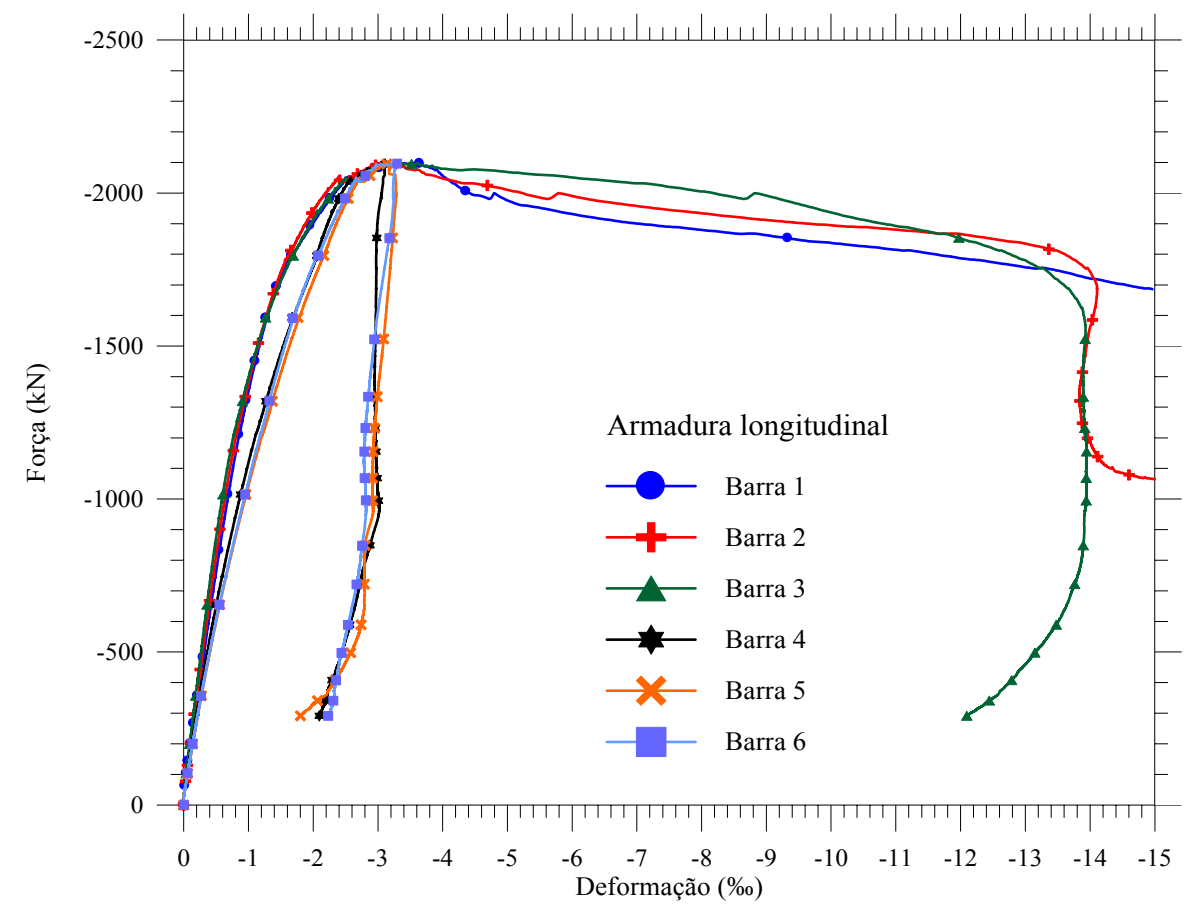

Figura B.16 - Diagrama força aplicada vs. deformação lida pelos extensômetros da armadura longitudinal

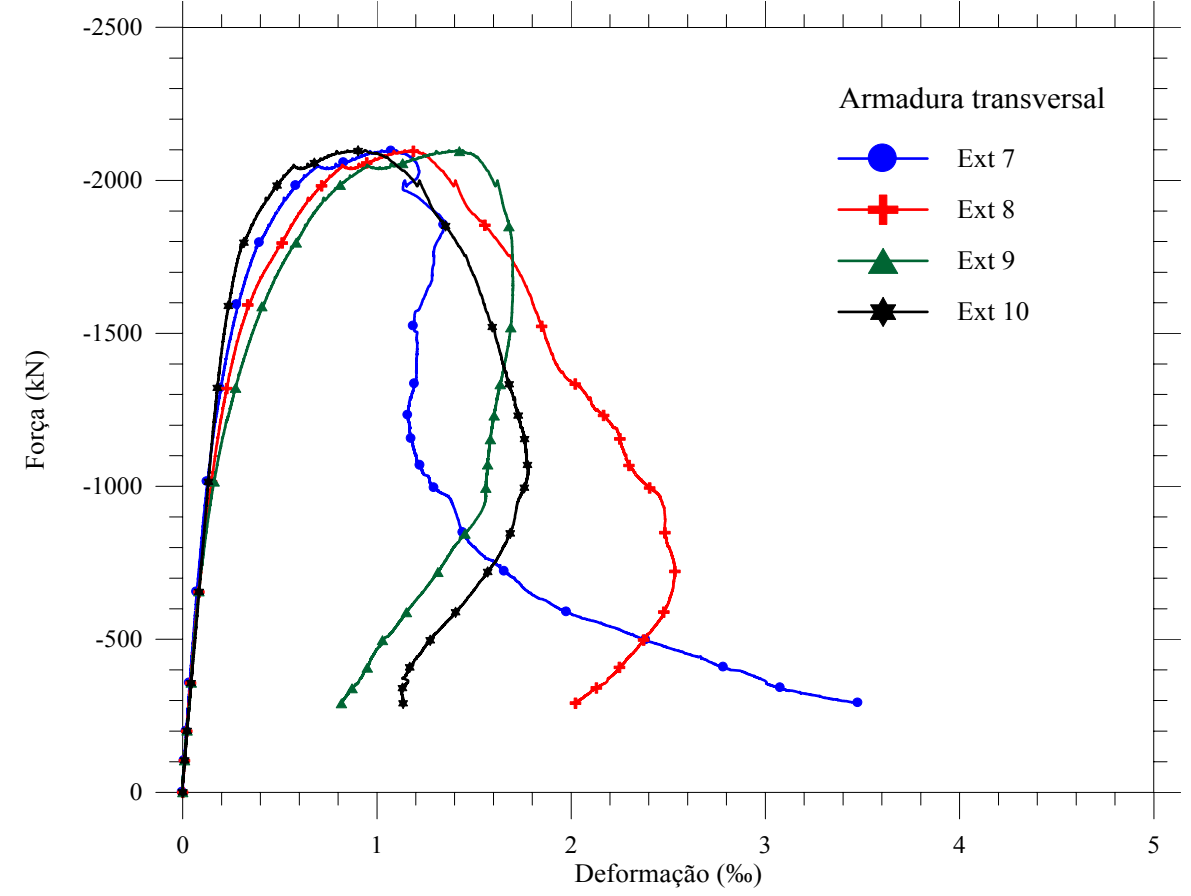

Figura B.17 - Diagrama força aplicada vs. deformação lida pelos extensômetros da armadura transversal 
Pilar P3-10,0-120

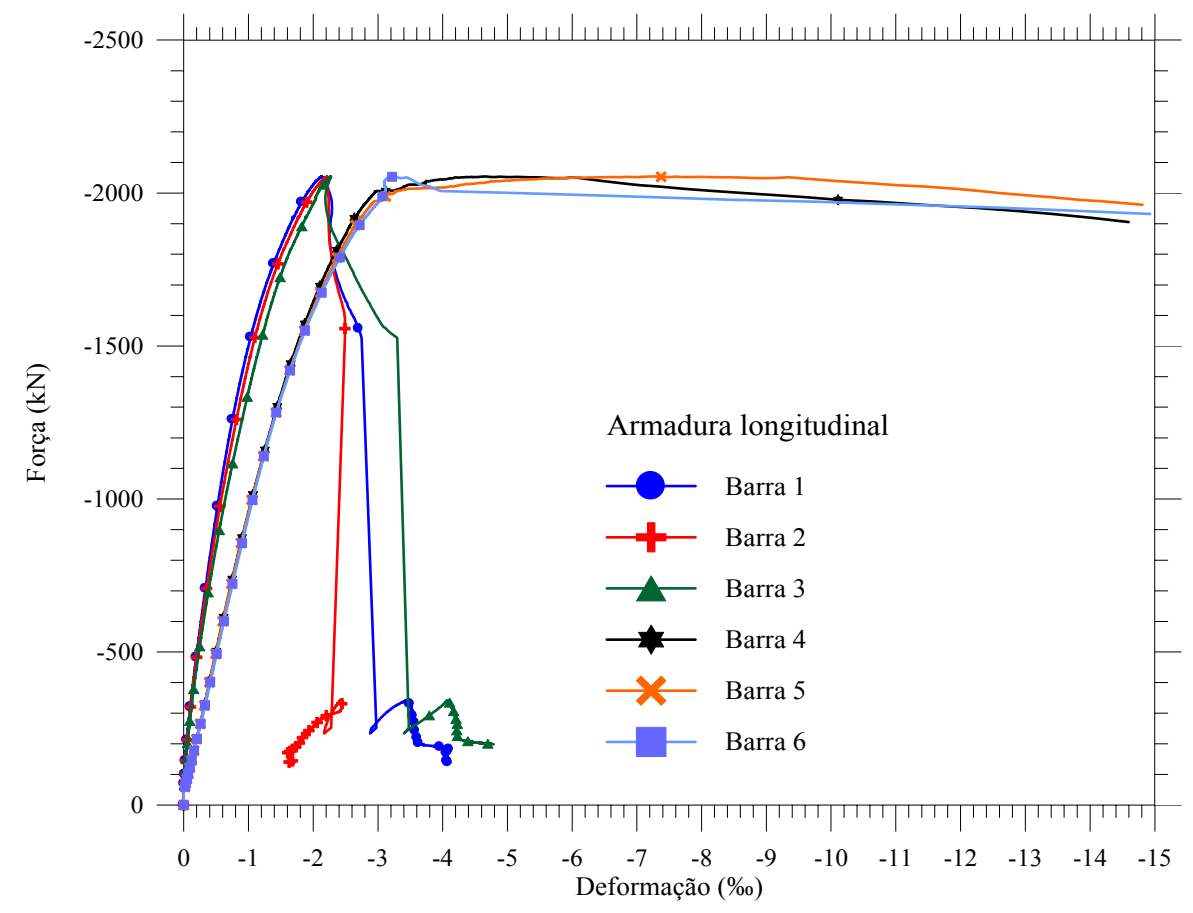

Figura B.18 - Diagrama força aplicada vs. deformação lida pelos extensômetros da armadura longitudinal

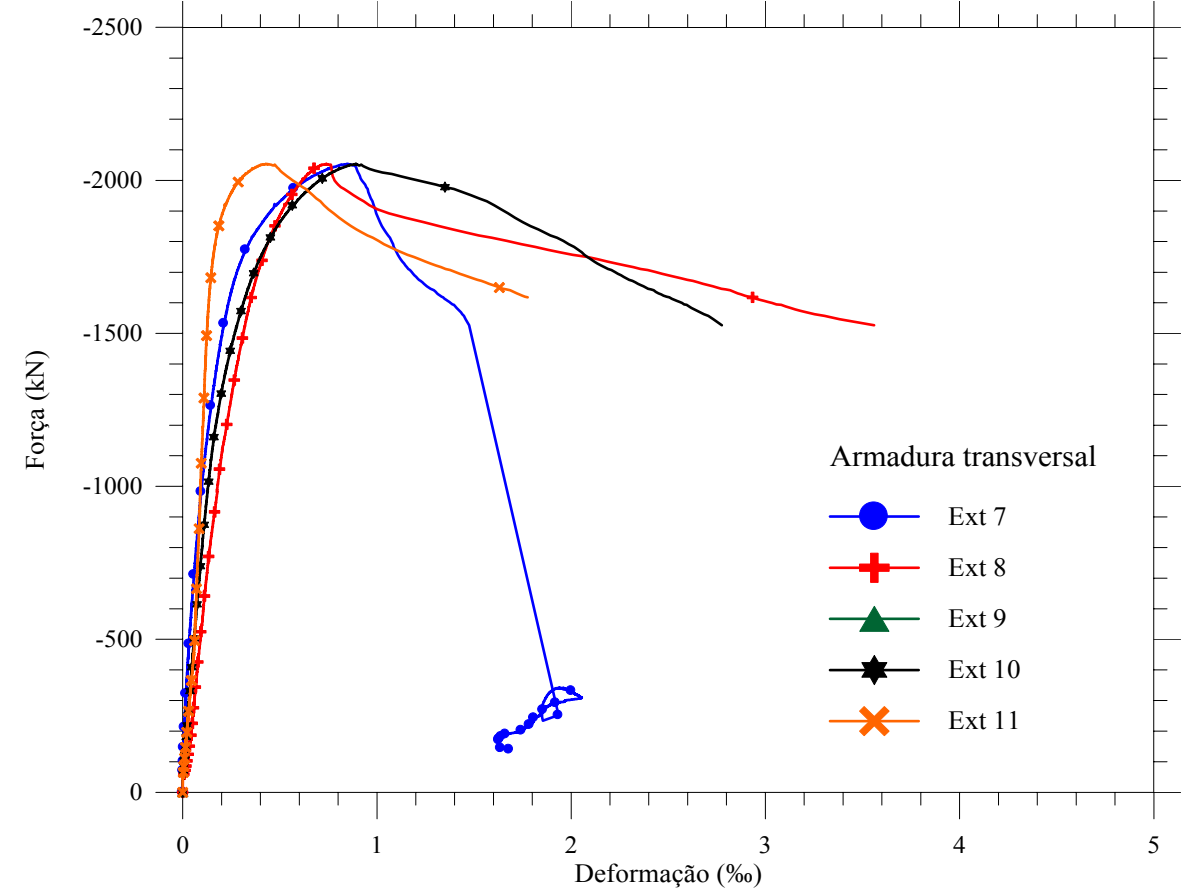

Figura B.19 - Diagrama força aplicada vs. deformação lida pelos extensômetros da armadura transversal 
Pilar P3-12,5-150

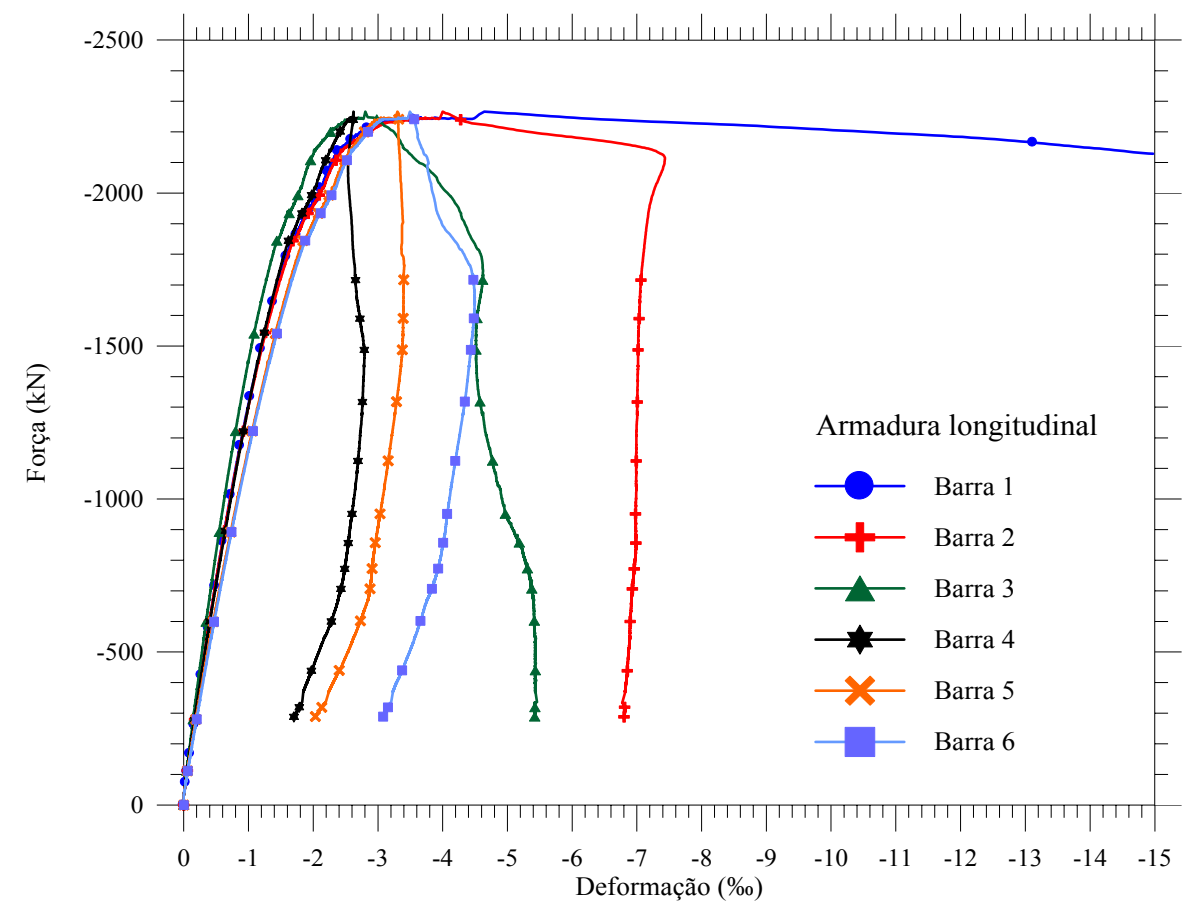

Figura B.20 - Diagrama força aplicada vs. deformação lida pelos extensômetros da armadura longitudinal

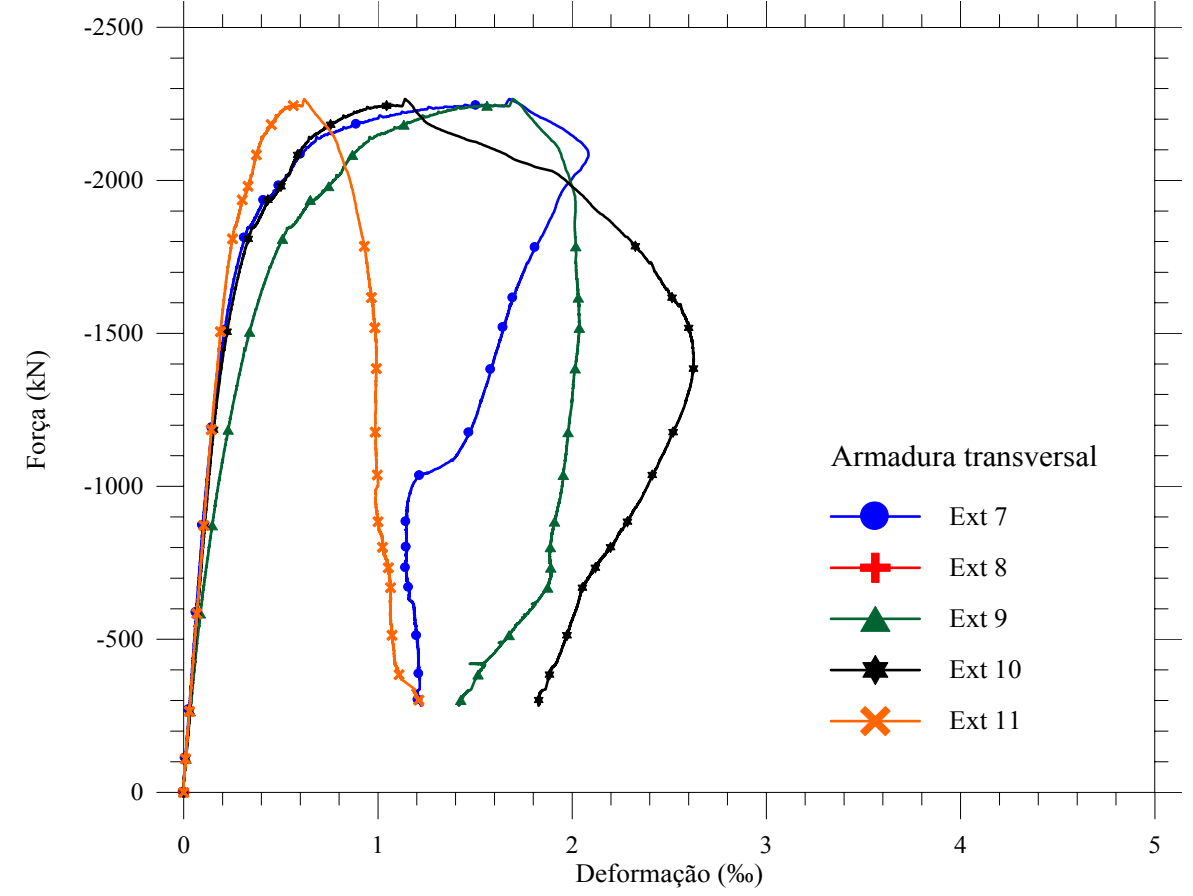

Figura B.21 - Diagrama força aplicada vs. deformação lida pelos extensômetros da armadura transversal 
Pilar P3-12,5-100

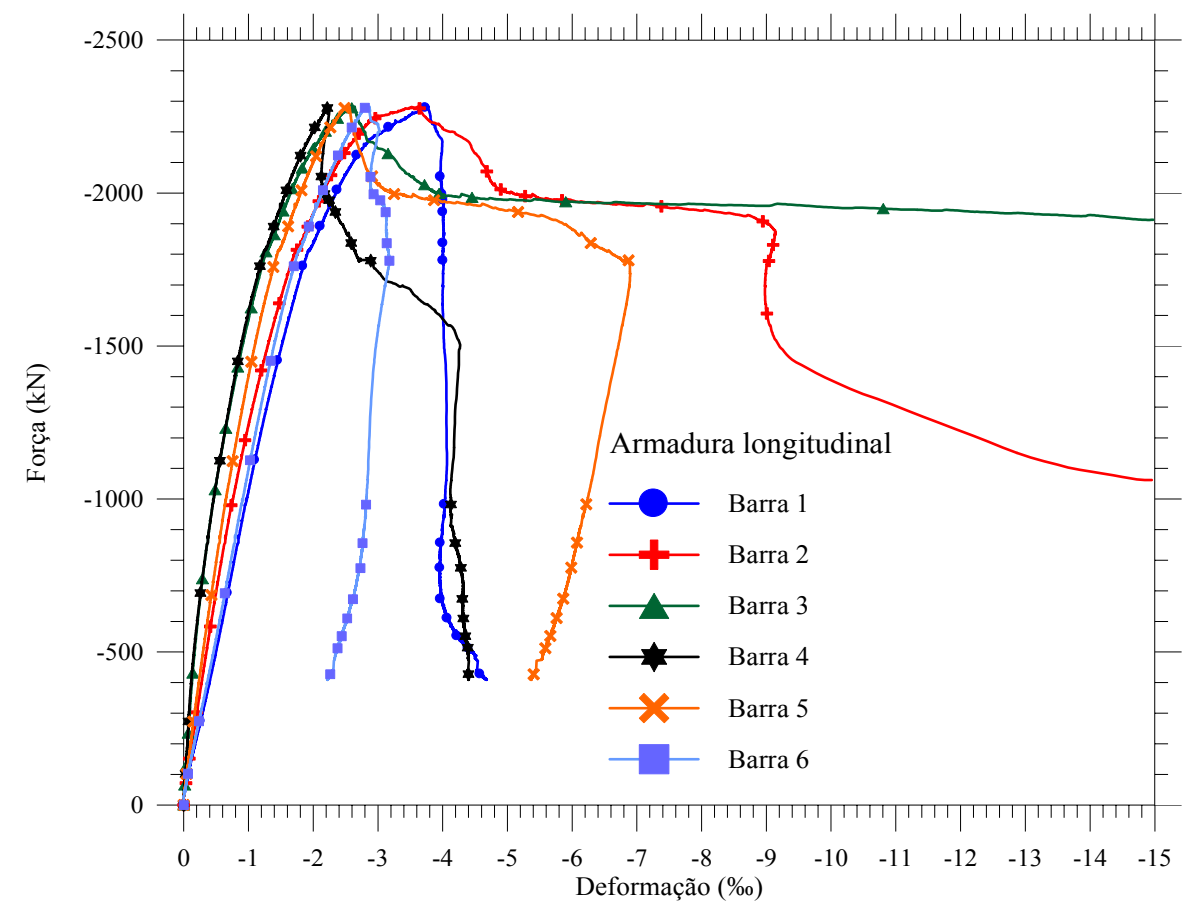

Figura B.22 - Diagrama força aplicada vs. deformação lida pelos extensômetros da armadura longitudinal

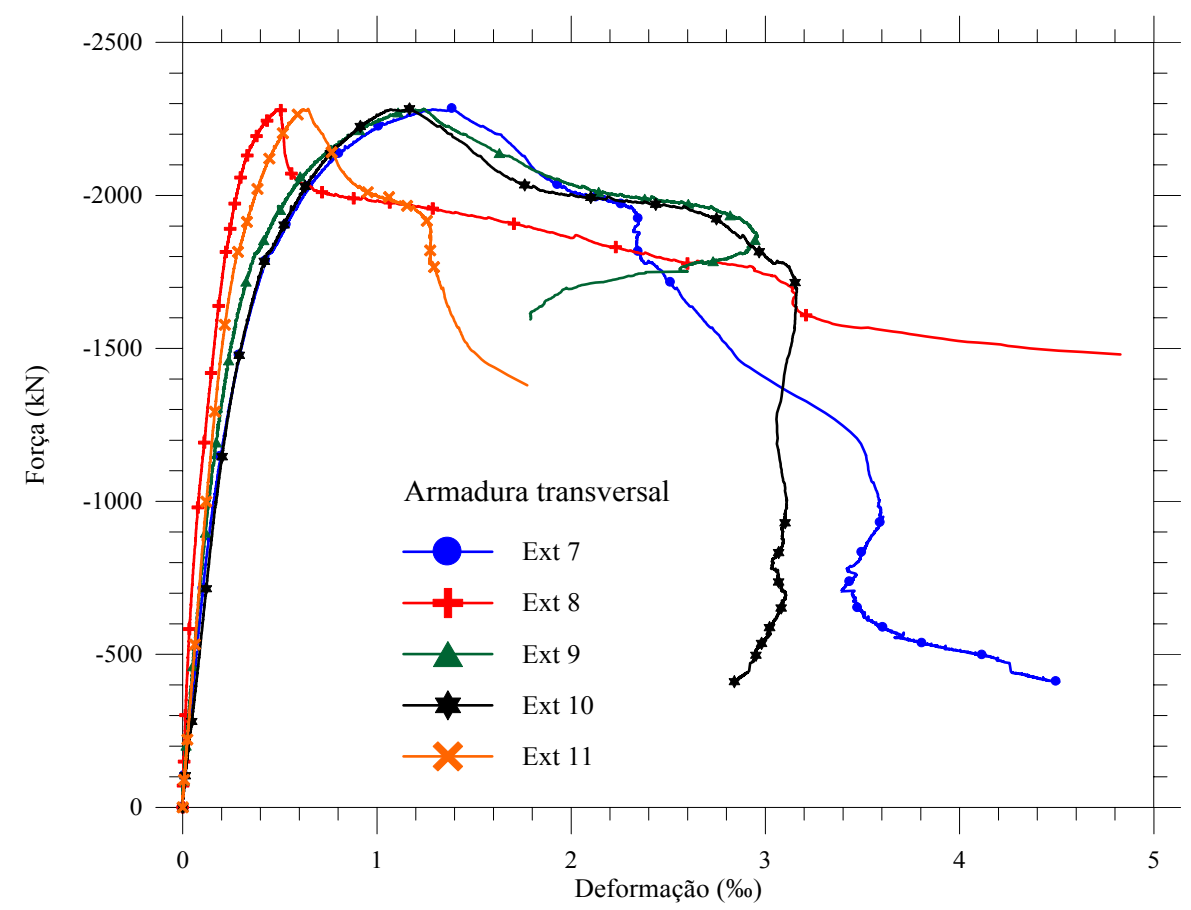

Figura B.23 - Diagrama força aplicada vs. deformação lida pelos extensômetros da armadura transversal 


\section{Pilar P3-12,5-075}

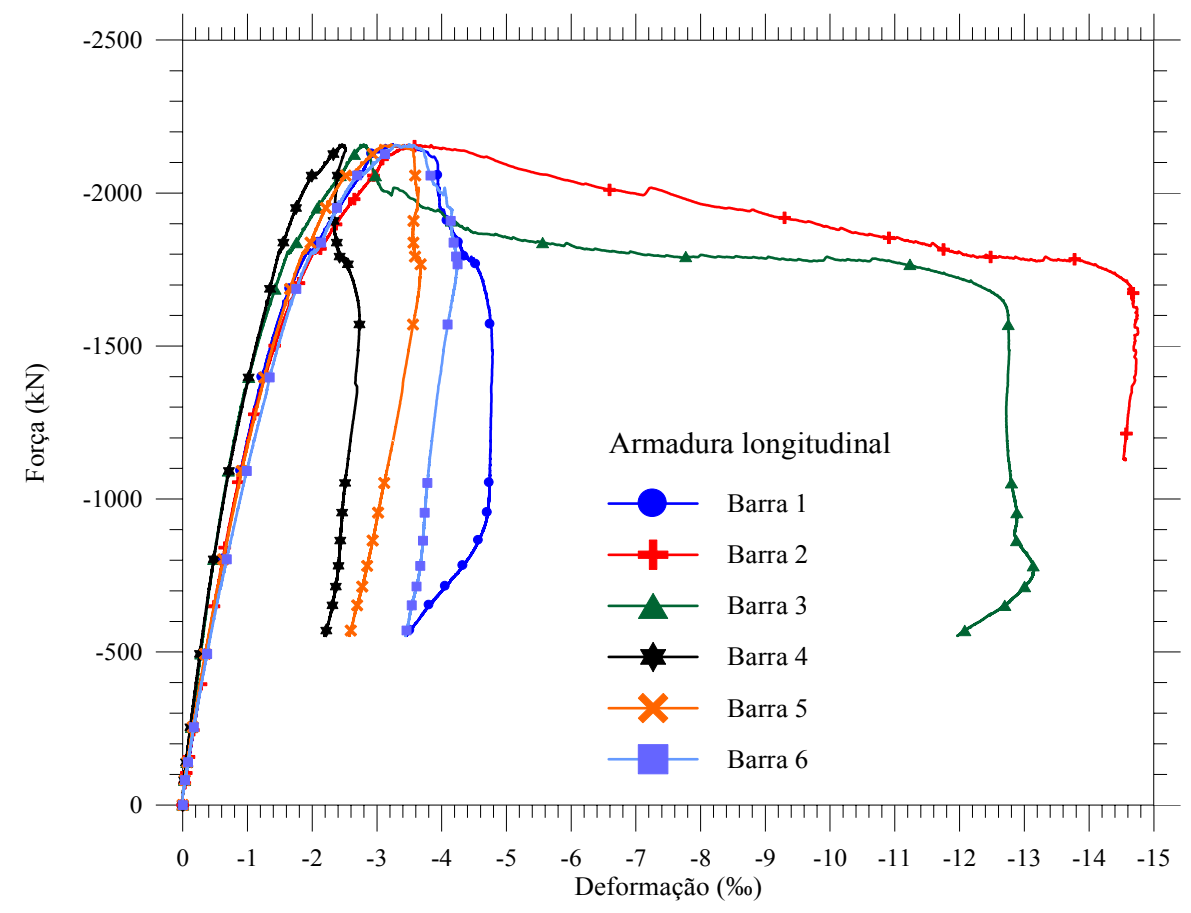

Figura B.24 - Diagrama força aplicada vs. deformação lida pelos extensômetros da armadura longitudinal

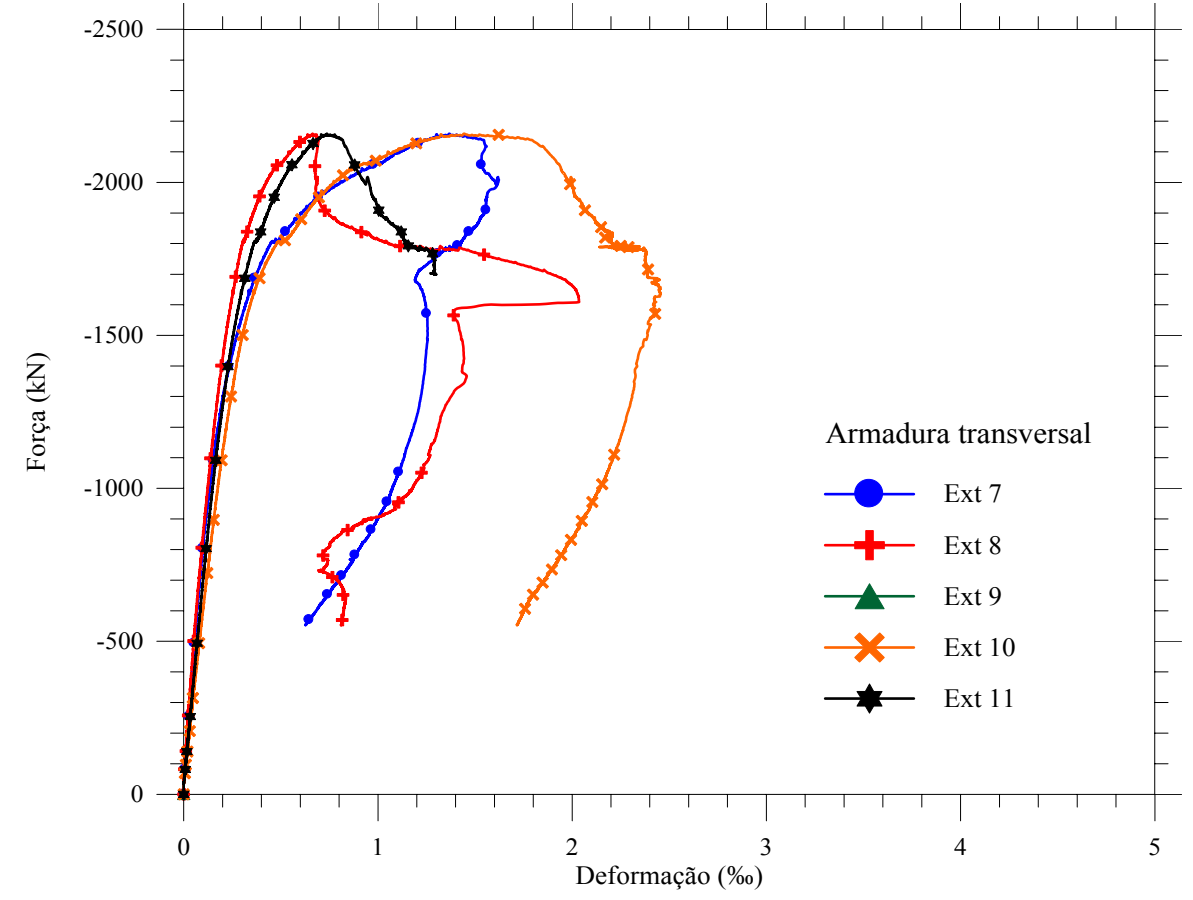

Figura B.25 - Diagrama força aplicada vs. deformação lida pelos extensômetros da armadura transversal 
Pilar P4-10,0-120

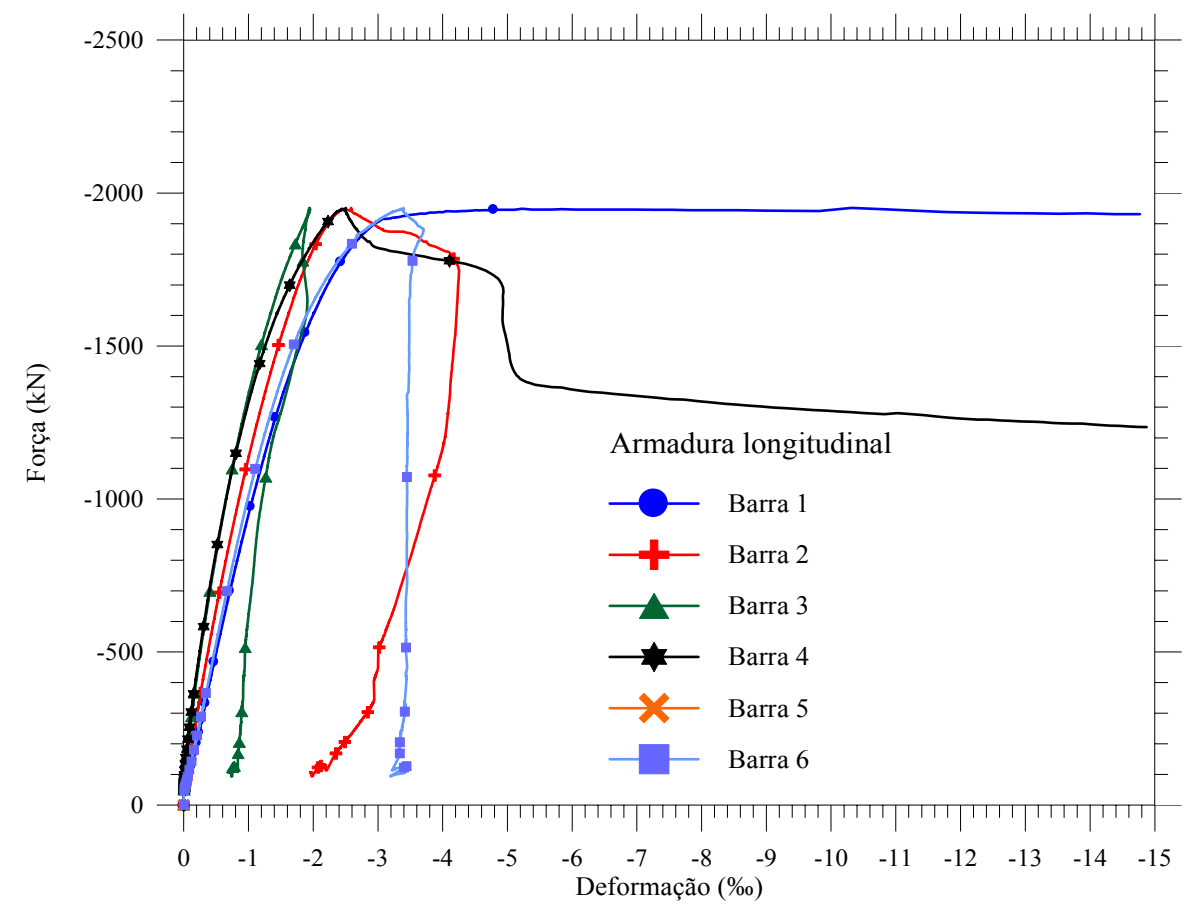

Figura B.26 - Diagrama força aplicada vs. deformação lida pelos extensômetros da armadura longitudinal

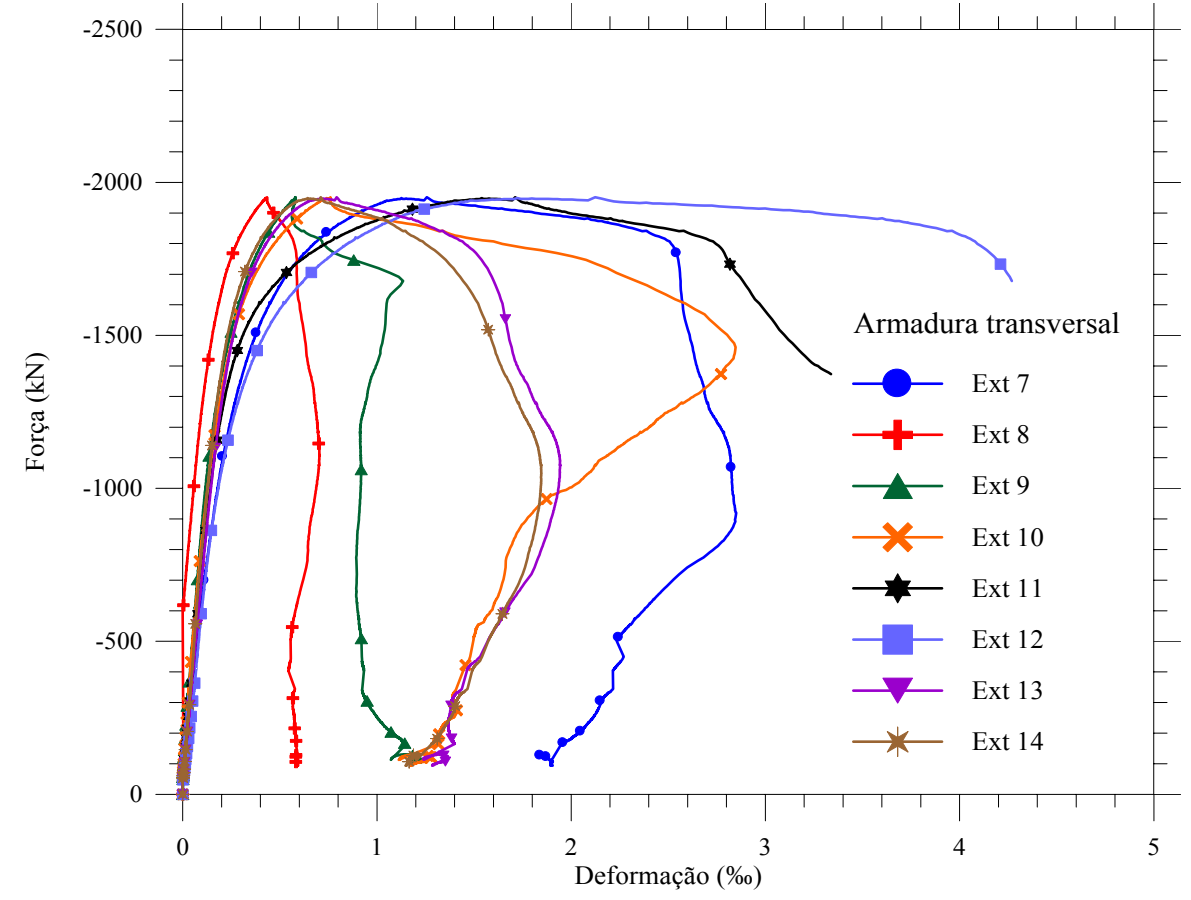

Figura B.27 - Diagrama força aplicada vs. deformação lida pelos extensômetros da armadura transversal 
Pilar P4-12,5-150

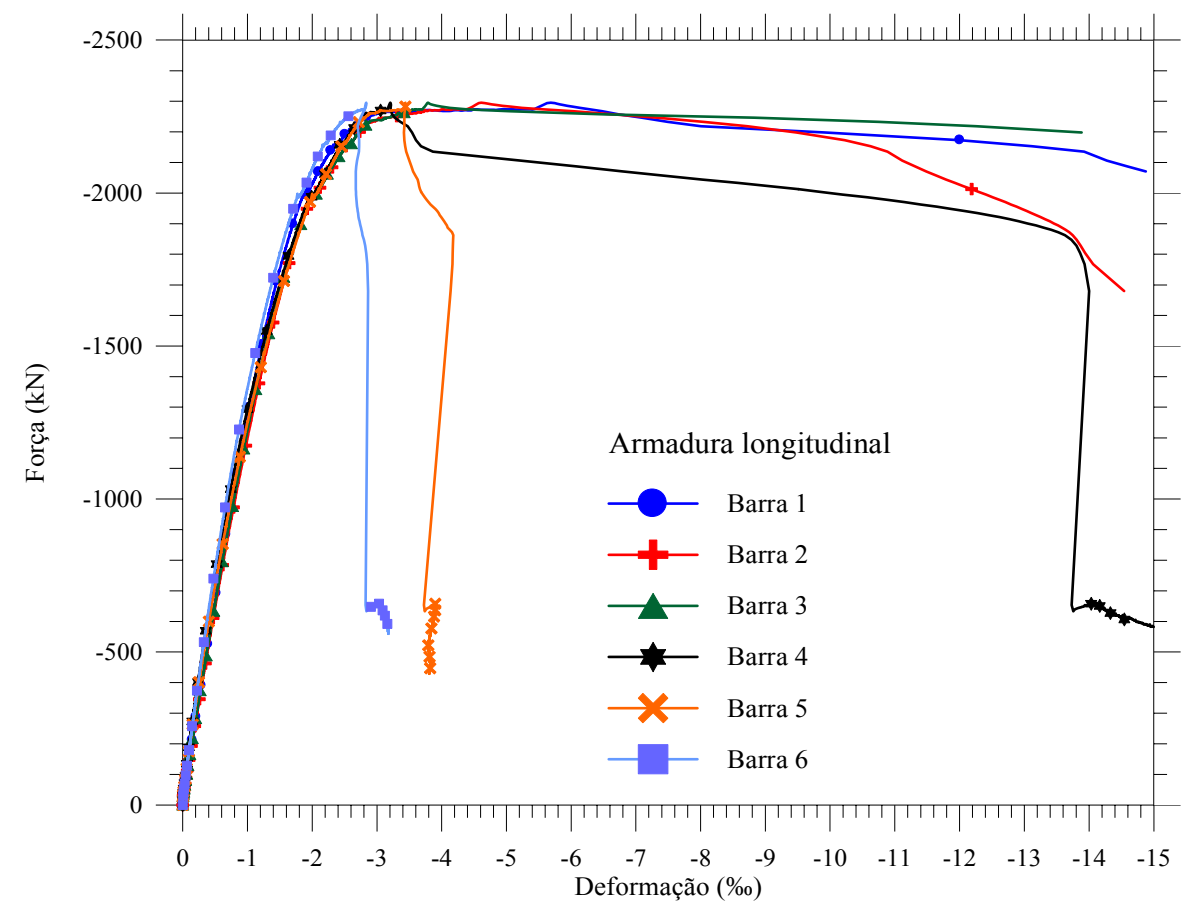

Figura B.28 - Diagrama força aplicada vs. deformação lida pelos extensômetros da armadura longitudinal

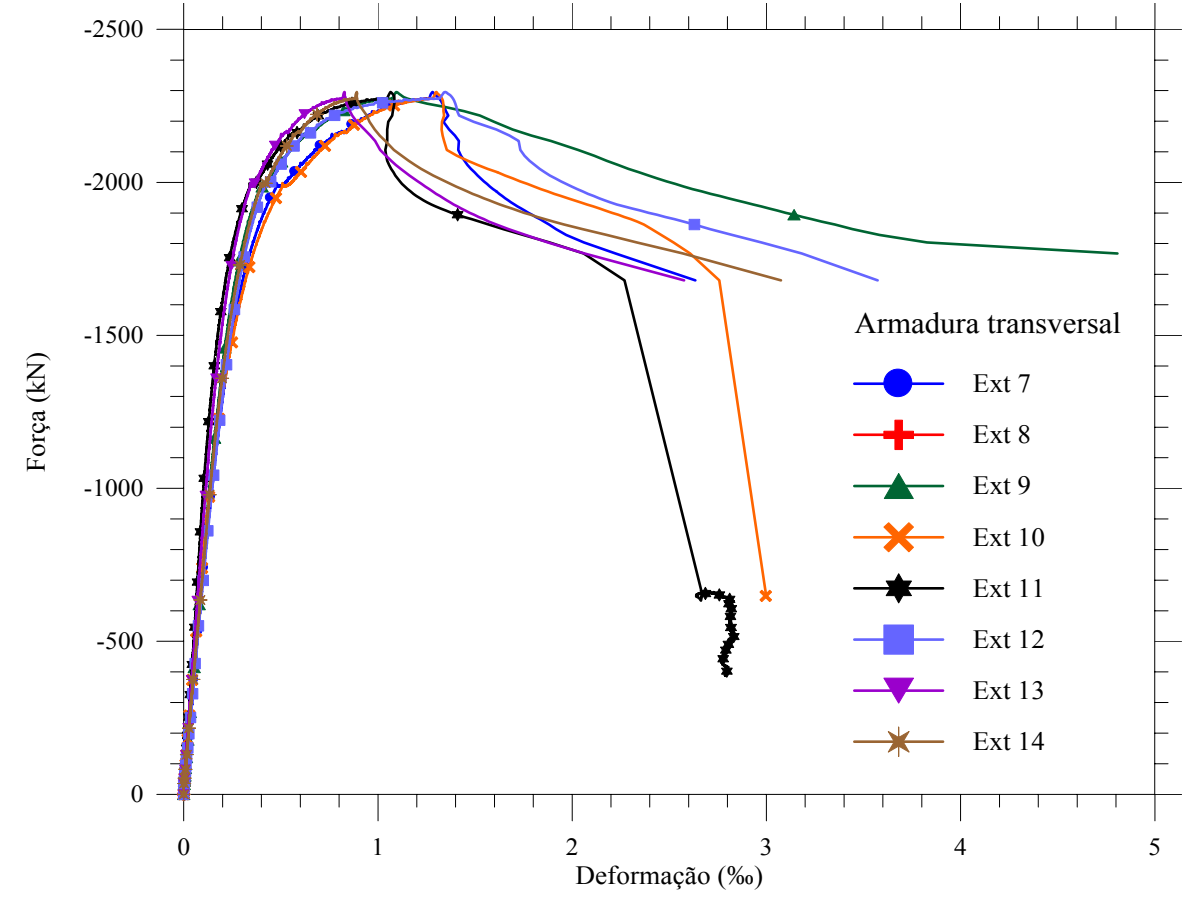

Figura B.29 - Diagrama força aplicada vs. deformação lida pelos extensômetros da armadura transversal 
Pilar P4-12,5-100

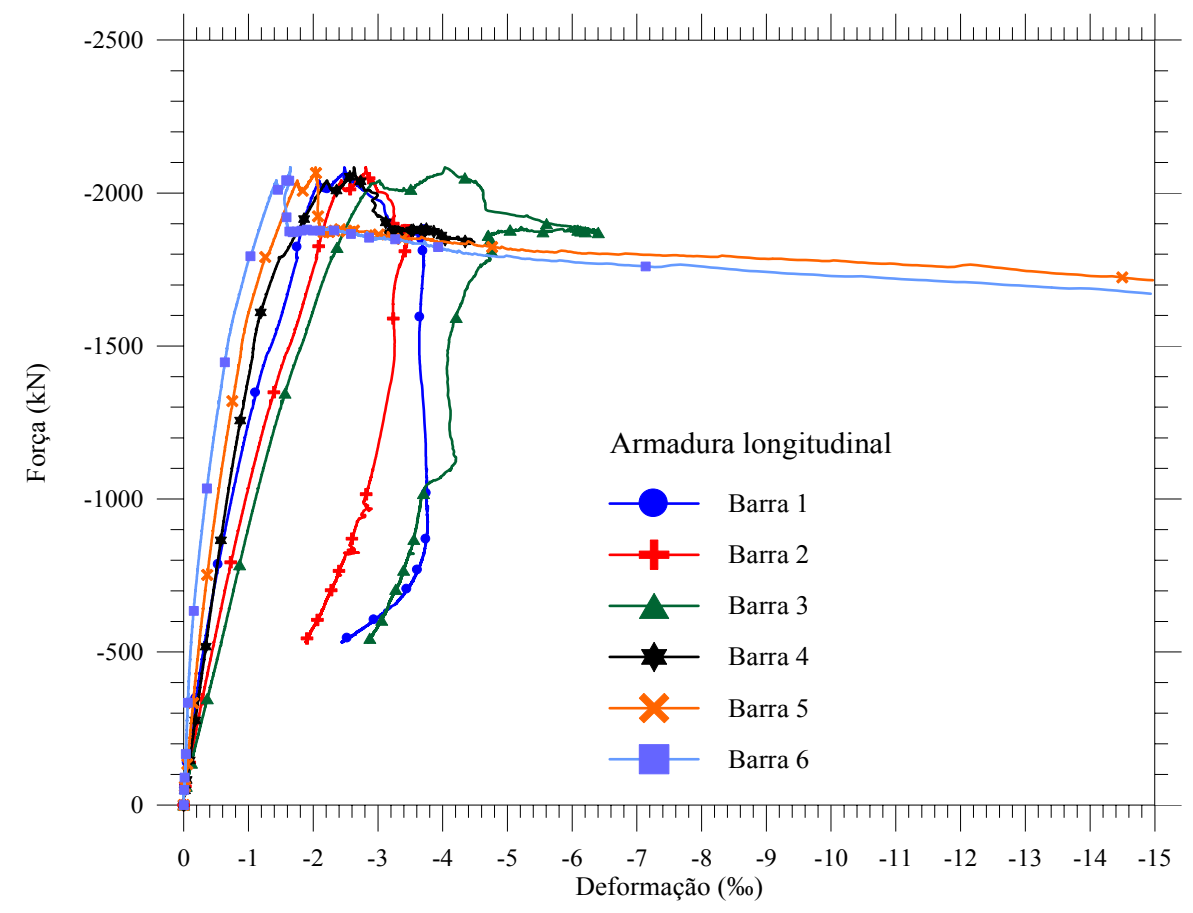

Figura B.30 - Diagrama força aplicada vs. deformação lida pelos extensômetros da armadura longitudinal

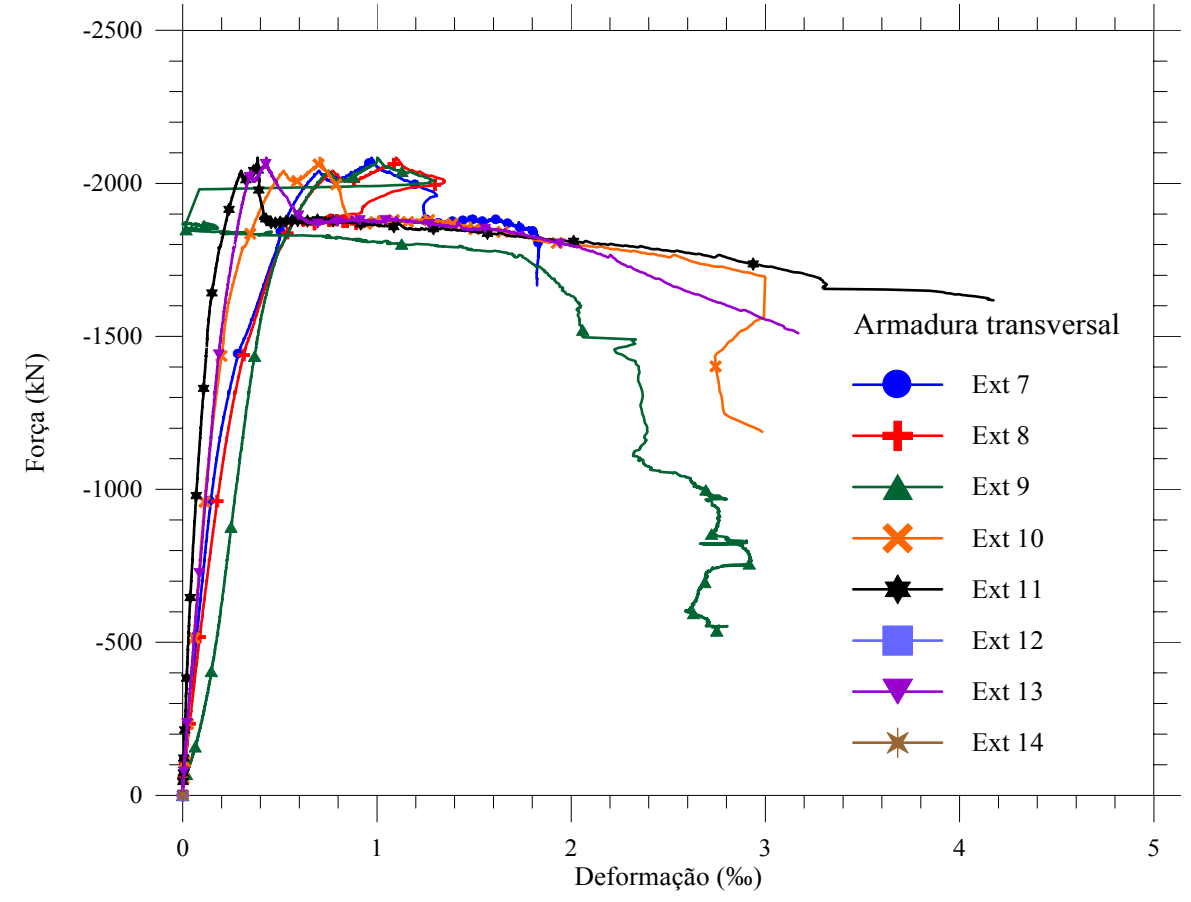

Figura B.31 - Diagrama força aplicada vs. deformação lida pelos extensômetros da armadura transversal 
Pilar P4-12,5-075

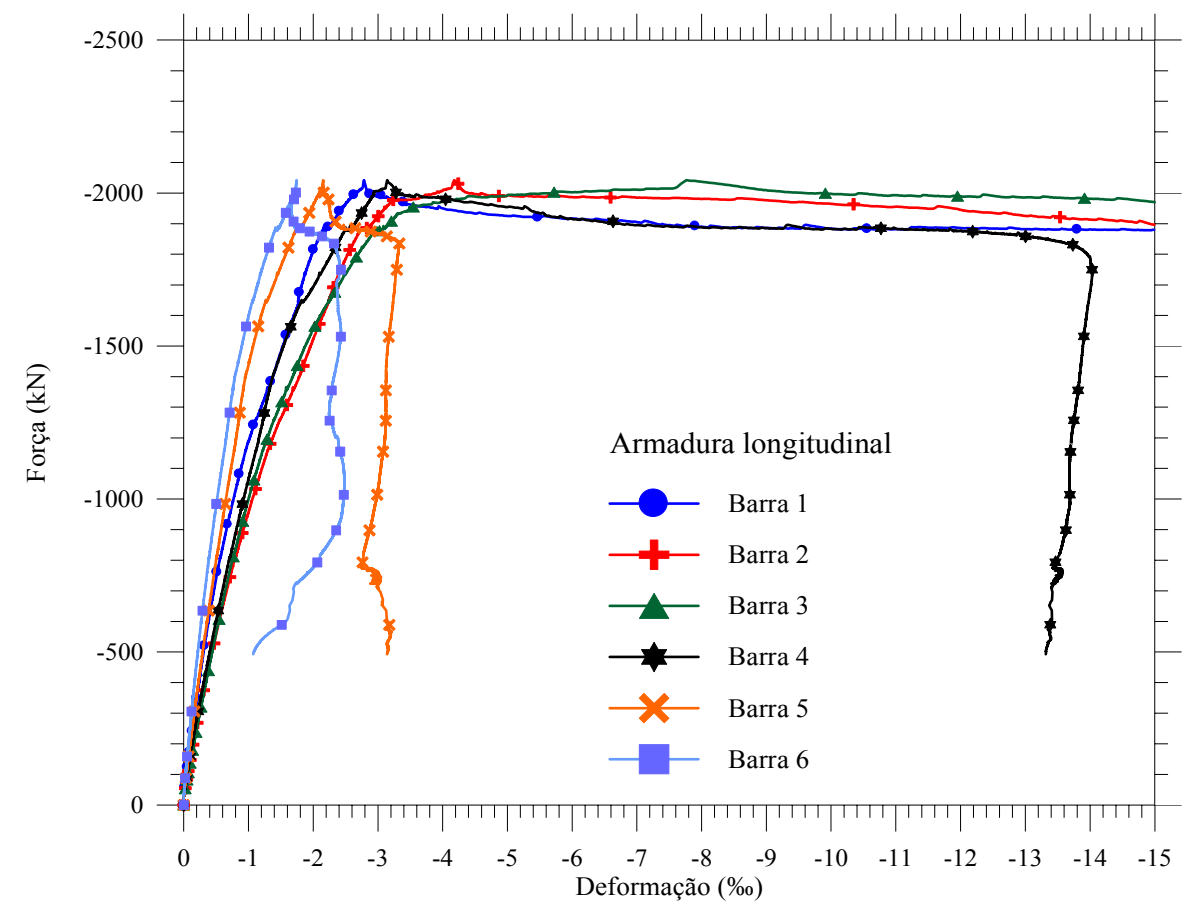

Figura B.32 - Diagrama força aplicada vs. deformação lida pelos extensômetros da armadura longitudinal

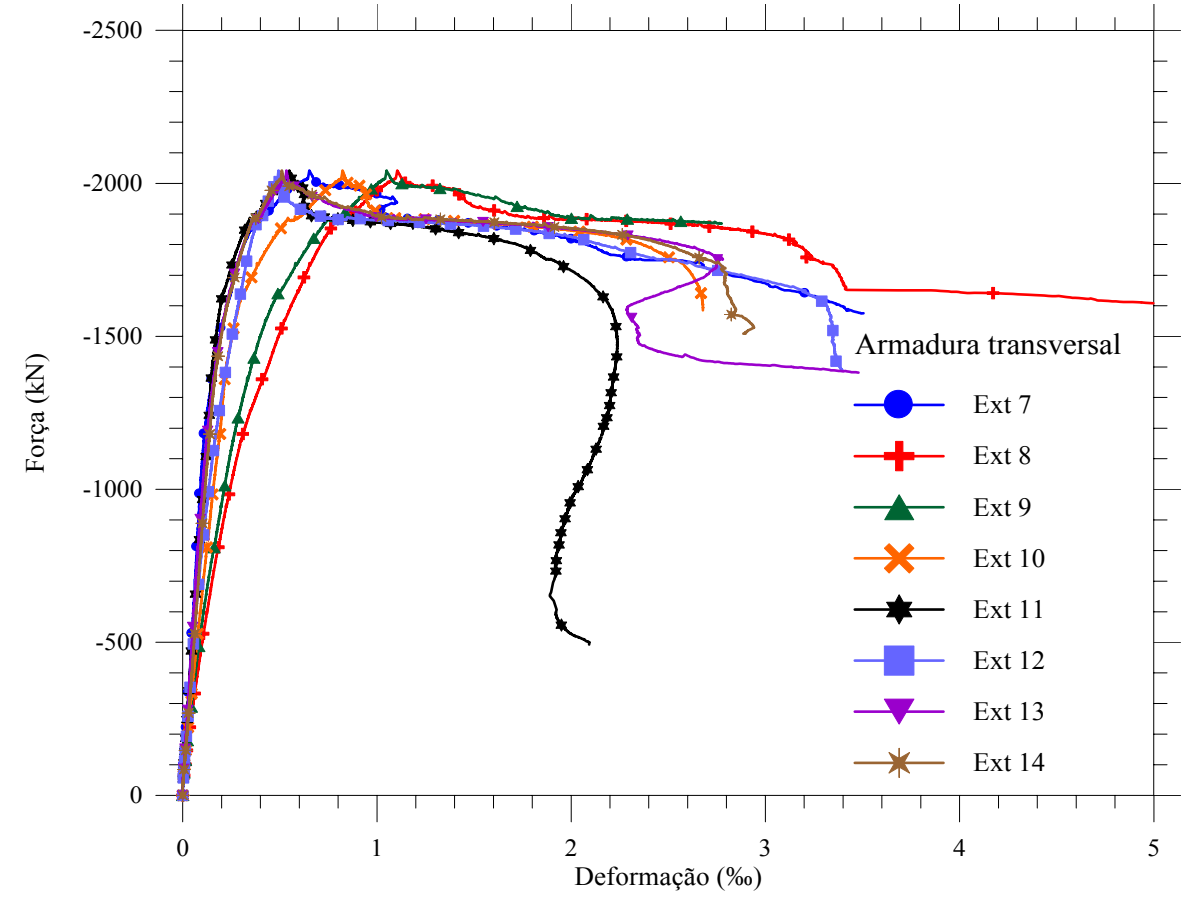

Figura B.33 - Diagrama força aplicada vs. deformação lida pelos extensômetros da armadura transversal. 